UCRL-CR-132364

B339054

\title{
Crustal Structure of China and Adjacent Areas: A Final Report of the Detailed Compilation of Data and Results
}

Walter D. Mooney

June 4, 1998

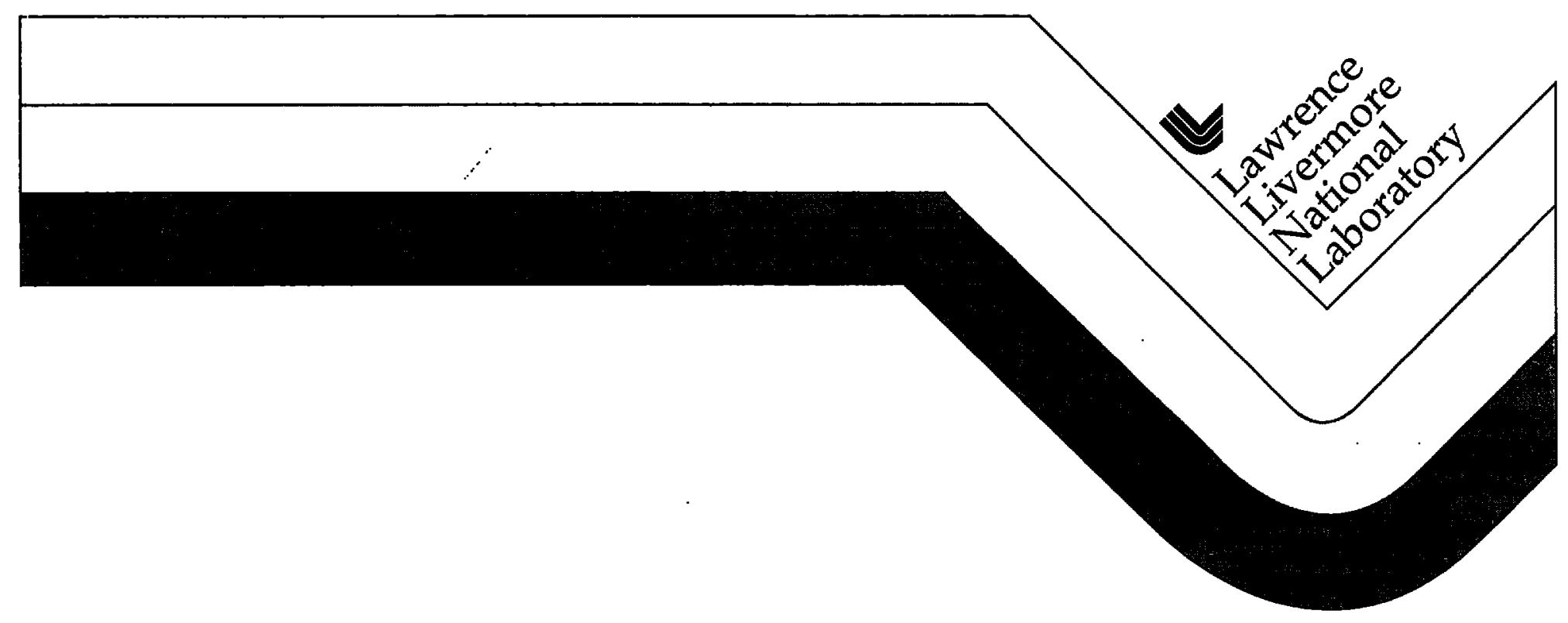




\section{DISCLAIMER}

This document was prepared as an account of work sponsored by an agency of the United States Government. Neither the United States Government nor the University of California nor any of their employees, makes any warranty, express or implied, or assumes any legal liability or responsibility for the accuracy, completeness, or usefulness of any information, apparatus, product, or process disclosed, or represents that its use would not infringe privately owned rights. Reference herein to any specific commercial product, process, or service by trade name, trademark, manufacturer, or otherwise, does not necessarily constitute or imply its endorsement, recommendation, or favoring by the United States Government or the University of California. 'The views and opinions of authors expressed herein do not necessarily state or reflect those of the United States Government or the University of California, and shall not be used for adverlising or product endorsement purposes.

Work performed under the auspices of the U.S. Department of Energy by Lawrence Livermore National Laboratory under Contract W-7405-ENG-48. 


\title{
DOE Memorandum Purchase Order No.:
}

\author{
B339054
}

\section{Crustal Structure of China and Adjacent Areas:}

\section{A Final Report of the Detailed Compilation of Data and Results}

\author{
A Technical Report Submitted to: \\ Keith Nakanishi \\ Lawrence Livermore National Laboratory \\ P.O. Box 808, L-205 \\ Livermore, CA 94551 \\ tel.: 510-423-3923
}

\section{Date:}

June 4, 1998

Submitted by:

Dr. Walter D. Mooney

U.S. Geological Survey

345 Middlefield Road MS 977

Menlo Park, CA 94025

tel.: $650-329-4764$

e-mail: mooney@andreas.wr.usgs.gov 


\section{Table of Contents}

1. Introduction

1.1 Location figure of the studies in this report

1.2 Review of the work accomplished

2. Completed research

2.1 Line 1 - The Crustal Structure in Northwest China

2.2 GTTA - The Seismic Experiments along the Geoscience Transect from Taiwan to Altay in China - A Technical Revicw

2.3 Dabie Shan - Ultrahigh-Pressure Dabie Shan Orogenic Bclt: A Crustal Mode] Derived from Deep Seismic Refraction Profiling

2.4 Earthquake study - Crustal Structure Beneath Xingtai Earthquake Area in North China and its Tectonic Implications

2.5 Golmud-Ejin - Extracts from the Explanatory Notes for the Global Geoscience Transect Golmud-Ejin Transect, China

2.6 Western Yunnan - A Preliminary Study on 3-D Velocity Structure Beneatl Western Yunnan in Southwest China, from Local Earthquake and Deep Seismic Sounding Dala

2.7 China overview - Crustal Structure of China from Decp Seismic Sounding Profiles

3. Supporting Material

3.1 Correspondence with the Chinese as evidence of collaboration in the exchange of visiting scientists

3.2 The protocol for scientific and technical cooperation in earthquake studies between the NSF, USGS and SSB

3.3 The DOE proposal for this cooperative work

3.4 Curriculum Vitac for Dr. Walter D. Mooney 


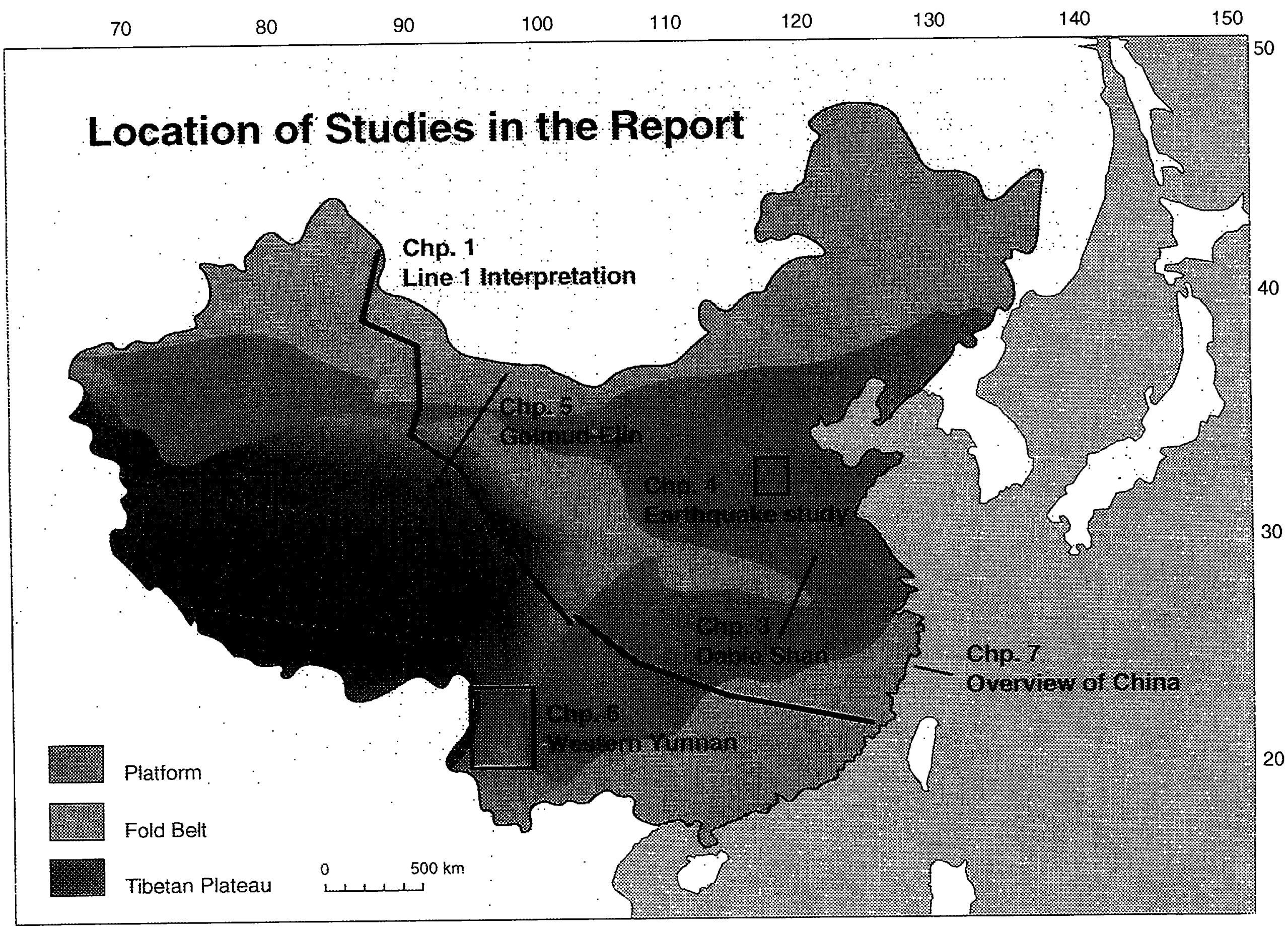




\section{Introduction}

In geophysical terms, China is a "data rich" country. However it is often very difficult for Western scientists to access the available information or identify individuals responsible for program development. The USGS has largely bypassed this bottleneck by virtue of more than two decades of collaborative research based on an official Protocol Agreement.

Geologic and geophysical data are collected by many agencies in China, including the Ministry of Geology and Natural Resources (MGNR), Chinese Academy of Sciences, and the State Seismological Bureau (SSB). The USGS cooperation has primarily been with the SSB, and is based on a formal Protocol established in 1976, which undergoes an annual review. More limited cooperation has taken place with the MGNR. At present the USGS maintains about a dozen cooperative projects with the SSB. One conspicuously successful aspect of the USGS program with the SSB is the operation of the 11-station Chinese Digital Seismographic Network (CDSN), which feeds data to US investigators. The aspect of the USGS program involving seismological studies of the crust and uppermost mantle of China has also long been very active.

The USGS emphasis on cooperation with the SSB is fortuitous in view of the fact that the Central Government decided during the April, 1998, Party Congress to reduce the number of State employees and number of Ministries by more than half. During this shuffle the MGNR will be reduced in size and placed under the administration of the new Ministry of Land and Resources. The Chinese Academy of Sciences will see many changes, including the reduction and merging of the Institute of Geology and Institute of Geophysics into an organization that has not yet been identified. The SSB, which is not administered by any Ministry, will be strengthened and will almost certainly emerge as the leading organization for geophysics within China. The full scope of its responsibilities related to CTBT research is not well known.

This report is focused on the crustal structure of China. Completed research is summarized in seven chapters. The location of the seven study areas is presented in Figure 1. Many of the results reported here have not been published, and are not available elsewhere. No attempt is made in this introduction to summarize these seven chapters; the abstracts serve this purpose. 


\section{Milestones and Deliverables}

\section{Compilation of Geophysical Data and Results:}

New geophysical interpretations and/or seismological data have been provided by the Chinese for the seven study areas in Figure 1. In five of the seven study areas, USGS staff have participated in the analysis of the data and report preparation, most of which was completed in our Menlo Park, California, office. Thus, all results are available in digitial form. Of greatest significance are: (1) the long-range "Geoscience Transect" extending from NW China, across the entire country, to the coast opposite the Island of Taiwan (Chapters 2.1 and 2.2); (2) profile data from East-central China near Wuhan (Chapter 2.3); and (3) network data from SW China (Yunnan and Schezwan Provinces; Chapter 2.6); and (4) a new synthesis of the crustal structure of China (Chapter 2.7).

In addition, Walter $D$. Mooney served as the English language editor of the Atlas of Geophysics in China (Geological Publishing House, 1996), and copies of this book have been provided by the Chinese to $\mathrm{Dr}$. Mooney, who has passed them on to Dr. W. Brunish and Dr. G. Randall, LANL (New Mexico). For reasons that are not clear, it is very difficult to obtain this book (priced at $\$ 200$ US per copy), even in China.

\section{Exchange of High-level Scientists and Administrators:}

High-level Chinese scientists have been sponsored at the USGS-Menlo Park, thereby providing access to data, interpretations, and information regarding future research plans. In 1997/98 we sponsored the Deputy Director of the SSB (Prof. He), the Director of International Cooperation, (Madame Wang Hongzhen), the Director and Vice-Director of the Institute of Geophysics (Prof. Chen Yuntai and Wang Chunyong, respectively), the Bureau Chief of the SSB in Jinjiang Province, and six other important administrators. It is on the basis of such visits that American investigators can reasonably expect access to Chinese interpretations, and to establish personal contacts as the need arises. Because of the size and diversity of Chinese geophysical research institutions, ranging from the centralized SSB offices in Beijing to small, but active Provincial Bureaus, it is difficult to anticipate opportunities to gather data relevant to CTBT monitoring. Openness and visibility within the Chinese scientific community is critical.

\section{Workshop Plans (November, 1998)}

The SSB Director of International Relations has agreed to sponsor a workshop entitled "Geodynamics and Earthquake Hazards in China", to be held in Shanghai in . November (date changed from July). Prof. Francis Wu, Dr. Leonard E. Johnson, and Dr. Mooney will be co-convenors on the American side, and will nominate participants. This workshop was initiated on the American side to broaden bilateral discussions. 


\section{Invitation to participate in a major field program, West-central China, 1998}

American investigators has been invited to participate in a major explosion-seismology field investigation to take place in West-central China in June, 1999. The Project Chief, Prof. Wang Chunyong, visited Menlo Park for three months in 1998 to discuss this and related topics. This project will involve 12 large chemical shots fired in water bodies and borehole. The profile is located at a latitude of $30^{\circ} \mathrm{N}$., from $95^{\circ}$ to $105^{\circ} \mathrm{E}$ (east flank of the Tibetan Plateau. The nature and extent of potential American participation is still under discussion.

\section{Coordination of field programs, $1997 / 1998$}

We have fostered US participation (lead by Prof. Francis Wu) in an SSB project that includes passive seismic recording in NE China, on the border with North Korea. US participation in this project negotiated "on the spot" at the October, 1997, US-SSB Coordinators Meeting in Beijing attended by Mooney and Wu. Dr. Mooney and Dr. L.E. Johnson (NSF) meet on an annual basis for a four day US-PRC Coordinator's meeting to negotiate the list of approved activities between the SSB and America for the coming year. The next coordinator's meeting will be held in September, 1998, at the USGS Seismological Laboratory in Albuquerque, New Mexico. The site was chosen in part to facilitate potential interaction with the staff of the Los Alamos National Laboratory. It is proposed that potential American participation in a large-scale seismic experiment in West-central China (item 4) be negotiated at this important September meeting.

\section{Conclusions}

We achieved all of the goals we set out for this activity, and have also capitalized on some unexpected opportunities. We continue to have a good working relationship with the leading geophysical organization in China, the State Seismological Bureau (SSB), and with the Ministry of Geology and Mineral Resources (MGMR). This relationship has yielded new, unpublished data and interpretations that have allowed us to characterize the properties of the crust and uppermost mantle of China. This relationship has also provided American scientists with access to scientific decision makers, and given us prior knowledge of major scientific initiatives of interest to CTBT monitoring research. 


\title{
The Crustal Structure in Northwest China
}

\author{
Youxue Wang ${ }^{1}$, Xuecheng Yuan', \\ Walter. D. Mooney ${ }^{3}$ and Robert G. Coleman ${ }^{4}$ \\ 1) Second Integrated Geophysical Brigade of CAG, 5 Longshou Beilu, Xi'an 710016, \\ China \\ 2) Chinese Academy of Geoexploration (CAG), 31 Xueyuan Lu, Beijing 100081, China \\ 3) U. S. Geological Survey, 345 Middlefield Rd., Menlo Park, CA 94025, USA \\ 4) Department of Geology and Environmental Sciences Stanford University, Stanford, \\ California 94305
}

\begin{abstract}
We present a new crustal cross-section across northwest China based on a seismic refraction profile and geological mapping. The $1100 \mathrm{~km}$-long seismic refraction profile, locited on the northwesternmost part of the Geoscience Transect from Taiwan to Altai, crosses the southern margin of the Altai block, the Junggar Accretional Belt, the Tianshan Accretional Belt and the Tarim Platform. P-and S-wave seismic data acquired along this profile were used to model both the crustal velocity structure and Poisson's ratio in a section through the crust and upper mantle. The largest difference in crustal thickness is located at the northern end of the profile, where over a distance of $<400 \mathrm{~km}$, it varies from $54 \mathrm{~km}$ thick under the Altai block to $46 \mathrm{~km}$ thick under the Junggar Basin. On the southern side of the basin, the crustal thickness increases to about $49 \mathrm{~km}$, and it remains this thickness over the rest of the southern portion of the profile, with only slight variation. Higher velocity crust with Poisson's ratio of $\sigma=0.25-0.28\left(V_{p} / V_{b}=1.73-1.81\right)$, observed below the Junggar Accretional Belt, may imply either a mafic crystalline Precambrian basement or imbricated Paleozoic accretionary belt, whereas the lower Poisson's ratios $\sigma=0.25-0.26\left(V_{p} / V_{s}=1.73-1.76\right)$, modeled through the crust in the Tianshan province, may imply a more granitic composition. The upper and middle crust of the Tarim Platform has a Poisson's ratio of around $0.25\left(\mathrm{~V}_{\mathrm{p}} / \mathrm{V}_{\mathrm{s}}=1.73\right)$, with lower average $\mathrm{P}$-wave velocities than the Tianshan accretional belt $(6.0-6.3 \mathrm{~km} / \mathrm{s}$ and $6.1-6.5 \mathrm{~km} / \mathrm{s}$, respectively), suggesting
\end{abstract}


highly fractured units in the Tarim Platform. A mid-crustal low-velocity layer $\left(\mathrm{V}_{\mathrm{p}}=5.9\right.$ $\mathrm{km} / \mathrm{s}, \sigma=0.25$ ) straddles the Tianshan-Tarim boundary and is underlain by a lower crust, suggesting that Kushui Fault probably indicates the boundary between Tianshan fold belt and Tarim platform. Observed $P_{n}$ velocities seem to vary with tectonic province as we observed $P_{n}$ velocities of 7.7 7.8 $\mathrm{km} / \mathrm{m}$ between Bogdashan and Tianshan and 7.9 8.0 $\mathrm{km} / \mathrm{s}$ below the Altai fold belt and Tarim Platform.

\section{INTRODUCTION}

In 1988, as part of the Geoscience Transect from Taiwan to Altai (GTTA), the Chinese Ministry of Geology and Mineral Resources (MGMR) collected 3-component seismic data along a $1100 \mathrm{~km}$-long seismic refraction profile across northwest China (Fig. 1). The goal of this project was to gain a better understanding of the deep crustal structure beneath different tectonic provinces in the area, and to provide crustal data for mineral resource development (Xu and Wang 1991; Wang 1992; Yuan, Zuo, and Zhang 1992; Yuan, Zuo, and Zhang 1992 and 1994).

Some information regarding the crustal crustal velocity structure has already been compiled for this area using tomography, including body and surface waves from earthquake data (Futian et al. 1989; Teng et al. 1992,1994; Feng et al. 1980; H. Mahdi and G. L. Pavlis, 1998). In recent years, advances in processing techniques for 3component data have enabled us to model both the P- and S-wave velocity structure from the data collected along the profile, and to infer compositional changes within the crust and uppermost mantle from the modeled Vp/Vs or Poisson's ratios (Gajewski et al. 1990; Kosminskaya 1995; Castagna 1985; Eesley 1989; Carbonell and Smithson 1995; Krilov et al. 1995a; Holbrook et al. 1988; Holbrook, W.D. Mooney, and Christensen 1992) .

\section{GENERAL TECTONICS OF NORTHWEST CHINA}

Like many other continental regions, the geology of northwestern China consists of Precambrian cratons surrounded by accreted terranes that make up fold belts of various ages. Accretion probably commenced at different times around each craton, ranging from the Proterozoic to the Early Paleozoic (Fig. 1). The tectonic evolution of northwest China 
is complex, and includes evidence of Late Paleozoic consolidation that was modified by Mesozoic foreland basin development, followed by Cenozoic uplift produced by compression and strike slip faulting (Berzin, Buslov, and Dobretsov 1991; Sengor, Natalin, and Burtman 1993).

The important cratonic elements of China are the Sino-Korean and Yangtze cratons and, to the west, the Tarim Platform (Fig. 1) (Zhang, Liou, and Coleman 1984). Equally important is the Siberian craton far to the north with its extensive Early to Late Paleozoic accretional belts now outcropping in the Altai Mountains.

The Sino-Korean craton forms a roughly triangular shape which includes Northern China, North Korea, and South Korea (Fig. 1). The nucleus of the craton is considered to have formed $3.0 \mathrm{Ga}$ followed by the Wutai orogeny at $2.0 \mathrm{Ga}$ with final consolidation at $1.7 \mathrm{Ga}$. From Late Proterozoic to Ordovician time, a thick passive margin sedimentary sequence was deposited. Late Ordovician to Early Carboniferous sediments are generally missing. Permian molasse and coal measures mark the final closure between the SinoKorean and Siberian cratono (Zhang, Liou, and Coleman 1984) The Yangtze craton formed in the period between Late Archean and the Late Proterozoic with final consolidation during the Yangtze orogeny ( $825 \mathrm{Ma}$ ) (Zhang 1985; Chang et al. 1994). The Yangtze and Sino Korean cratons were separated by the eastern Paleoasian Ocean (sometimes called Paleo-Tethys) until they collided to form the Qinling accretional belt in the Early Mesozoic (Chang et al. 1994).

The Tarim platform is a relatively small block with many internal basement units characterized by a thick cover of passive margin sediments dating from Late Proterozoic to Cenozoic (Ren et al. 1987). The Yili block forms a very small triangular wedge whose basement is Proterozoic with a similar history to that of the Tarim platform (Zhou, 1997). Present day convergent strike-slip faults have imbedded the Yili Block into the Tianshan (Fig. 1). The consolidation of the Tarim platform, the Yili Block, and the Tianshan accretional zones began in the Carboniferous. The change from marine to lacustrine deposits in the Junggar and Turpan basins was accompanied by collisional and intruding post collisional granites during the Late Carbonifeous and Permian marking the closure of the western Paleoasian Ocean (Carroll et al. 1995). To the east, the Yangzte and Sino- 
Korean cratons with their accreted margins came together in the Early Mesozoic forming the Qinling accretional system (Zhou and Graham,1996). Antecedent to these earlier amalgamations was the Himalayan collision (commencing ca $45 \mathrm{Ma}$ ), that has been marked by $2000 \mathrm{~km}$ of convergence between India and Eurasia, some of which occurs in the previously described consolidation of Central Asia (Northwest China) (Powell and Conaghan, 1973). Basin analyses and fission track studies of the Chinese Tianshan indicates that on set of rapid uplift in the Mid-Tertiary, that continues up to the present, can be related to the Himalayan collision (Carroll et al., 1995; Zhou, 1997). There is good evidence that at least some of the convergence can be accounted for by strike slip motion and compression (folding) across the Altai Mountains to the Kunlun Mountains (Zhou and Graham 1996).

\section{GEOLOGICAL SETTING}

The north-south transect cuts eight distinct blocks at high angles (Fig. 2). Major faults and sutures dividing represent terrane boundaries. Some of these boundaries are still active and have been the locus of major historic earthquakes, while others mark the tectonic zones of Paleozoic and Mesozoic continental growth.

\section{The Altai Block}

North of the Ertysh fault, the Altai block (Fig. 2) includes an Early Paleozoic accretionary wedge nearly $12 \mathrm{~km}$ thick, consisting of metamorphosed sandstone, shales, and minor limestones. Intercalated within these sedimentary sequences are mid-Paleozoic island arc volcanics and calc-alkaline intrusives. Paleozoic low $P$ and high $T$ metamorphism affected all of these rocks with intensity decreasing from north to south (Cunningham et al., 1996a; Cunningham et al., 1996b; Qu and He, 1993; Dong, 1993; Windley et al., 1990) (Fig. 2). The question of the existence of older basement in the Altai is not yet resolved, but the presence of gneissic rocks along the southern border are considered as Precambrian basement (Chang, Ying, and Coleman, 1996). Windley et al. (1994) suggest that these gneisses may represent Precambrian-Early Paleozoic accreted 
fragments. Berzin et al. (1994) show the Altai block as a micro-continent with possible Precambrian basement (Bibkova et al., 1992).

\section{Junggar Accretional Belt}

The Junggar Accretional Belt between the Ertysh and Kelameli faults consists mainly of accreted Devonian and Carboniferous sediments and volcanics with only scattered Ordovician and Silurian rocks. Dismembered ophiolites are concentrated along the Ertysh, Kelimali and Almanti faults (Fig. 2). Associated radiolaria cherts in this zone range from Devonian to Carboniferous. These ophiolites and cherts occur mainly in a serpentinite matrix melange indicating continued subduction and accretion from Early -Middle Devonian to Early Carboniferous. Calc-alkaline intrusions of this time period within the Altai and Junggar accretionary belt are derived from nonh-directed subduction. The final closure along the Junggar accretional belt is marked by abundant post collisional granite intruding both the Junggar belt and extend northward into the Altai block (Coleman, 1989).

\section{Junggar Basin}

The Junggar basin is deposited on a basement similar to the Junggar accretional belt. The basin is triangular in shape, thickening gradually from north to south, and becoming extremely deep along the Bogda island arc mountain front (Fig. 2). The basal upper Permian deposits of the Junggar Basin are non-marine and deposited within a subsiding foreland basin (Carroll et al., 1990). Plate tectonic reconstructions suggest that the basement for the Junggar Basin consists of incompletely subducted mid-Carboniferous ocean crust now imbricated with sedimentary trench volcanic arc deposits.

\section{Bogdashan Volcanic Arc}

The Carboniferous Bogdashan volcanic arc, south of the Junggar Basin, developed by southward subduction and extension within the earlier accreted Paleozoic and Precambrian Tianshan blocks. The core of the arc appears to be centered in the Bogdashan where thick sections of Carboniferous submarine pyroclastics and basal-andesite flows 
extend north and south across the present Junggar and Turpan Basins (Coleman,1989) (Fig. 2).To the west of the Bogdashan in the Borohorashan, the Carboniferous volcanics rest unconformably on Early Paleozoic folded accreticnal complex of trench sediments and dismembered ophiolite. Evidence for a Precambrian basement underlying these Carboniferous volcanics is not seen along the northern front of the Bogdashan (Ren et al., 1987). Permian lacustrine deposits and their overlying granitic-rich clastics are similar in both basins suggesting that an Andean-type arc did not separate the Turpan and Junggar Basin at this time (Greene et al., 1997).

\section{Turpan - Hami Basin}

The Turpan-Hami Basin depositional sequences are similar to those in the Junggar Basin and consist of basal Carboniferous andesitic volcanics overlain by Permian lacustrine mudstones interlayered continental fluvial and volcanic sediments. The Permian sequence is overlain by nearly $3000 \mathrm{~m}$ Triassic and Jurassic foreland-style continental deposits, rich in coals and lacustrine mudstones (Carroll et al., 1995; Greene et al., 1997). The Carboniferous volcanic clastic sequences exposed on the southern margins of the TurpanHami basin are intruded by late Paleozoic calc-alkaline granites related to the Bogdashan arc.

\section{Tianshan}

South of the Kushi Fault ( also called the South Tianshan or Nicolaev Line), the Tianshan zone has been tightly compressed during the Mesozoic and Cenozoic (Fig. 2). The Central Tianshan consists of Proterozoic gneiss and schist intruded by Late Paleozoic calc-alkaline granite. These older rocks are overlain by passive margin carbonate and continental clastics of Middle and Upper Proterozoic age (Ren et al., 1987). The South Tianshan merges with the passive margin of the Tarim Platform. A Late Paleozoic subduction scenerio between the Tarim and Central Tianshan has been suggested by (Allen, Windley, and Zhang, 1992) based on scraps of ophiolite within the South Tianshan fault zone. Pinching and complete wedging-out of the Central Tianshan further eastward, is related to dextral strike slip faulting and crustal subduction of the Central Tianshan 
block under the north facing passive margin of the Tarim Platform (Fig. 2). Finally, the Cenozoic shortening of this area is considered to result from the collision of the Indian Craton to the south (Carroll et al., 1995; Windley et al., 1994). Tha Cenozoic imbrication, and thickening of the crustal section south of the Bogdashan, was accomplished by thrusting and strike-slip faulting at the surface, submerging the Central Tianshan under the Tarim passive margin (Fig. 2). Present day strike slip motion along the Altyn Tagh wedge (Zhou and Graham,1996) has combined to produce an unusually thick continental crust underlying the $\mathrm{GAC}$ transect at this longitude.

\section{Tarim}

The Tarim Platform is covered by a thick foreland sequence of continental deposits. It is nearly $10 \mathrm{~km}$ thick in the central portion, and thins northward to $5 \mathrm{~km}$. The Altyn Tagh fault system has exposed Archean(?) basement on the southern boundary of the craton. These older rocks are cut by early Paleozoic calc-alkaline granite (Fig. 2). Beneath the sediments of the Tarim Basin, Late Proterozoic rocks floor the entire basin and exhibit some extension but the only evidence for older oceanic crust comes from the alkali-rich, rift mafic intrusives, and flows of limited exposure. The Paleozoic sequence overlying these older rocks consists of shallow marine sediments overlain by foreland-type sediments from the Mesozoic to the present (Ren et al.,1990).

\section{Qaidam Depression - Altyn Tagh Fault}

The Qaidam Depresson is a Mesozoic-Cenozoic depression consisting of non-marine strata derived from lacustrine and fluvial fan deposits that contain significant coal measure (Carroll et al.,1990; Ritts, 1995). The basement consists of a late Paleozoic fold belt containing active continental margin sediments and volcanics. The whole sequence is strongly folded and is related to the east-west trending Kunlun suture containing evidence of Paleozoic convergence and development of high P - low T metamorphic rocks. The

Altan Tagh fault zone truncates these deformed E-W trending Qaidam units, juxtaposing them against the mildly deformed Tarim Platform sequnces (Zhou and Graham, 1996). 


\section{SEISMIC DATA}

\section{General considerations}

Seismic energy was provided by twelve shots fired in boreholes. These shots had charge sizes ranging from 1500 to $4000 \mathrm{~kg}$, with a maximum offset of $300 \mathrm{~km}$. The shotpoint interval ranged from 63 to $125 \mathrm{~km}$, and the receiver interval was between 2 and $4 \mathrm{~km}$. The entire profile is not linear, however the layout makes it possible to consider it as three nearly straight segments for purposes of interpretation.

In order to aid in the correlation of phases, reduction velocities of $6.0 \mathrm{~km} / \mathrm{s}$ and 3.46 $\mathrm{km} / \mathrm{s}$ were used for P- and S-waves, respectively. The time scale used for S-waves was multiplied by a factor of 0.58 in the S-wave record section so that they match the P-wave arrival times. Because a slight time shift is introduced by digital filters, the unfiltered Pwave data was used for phase correlation and traveltime picking. In order to improve the signal-to-noise ratio for phase correlation, the S-wave data was filtered with a $0-6 \mathrm{~Hz}$ bandpass.

Commonly used definations of phases, $\mathrm{P}_{\mathrm{g}}\left(\mathrm{S}_{\mathrm{g}}\right)$ actually corresponds to two traveltime segments. The first, near the shotpoint, is a diving wave within the sedimentary layer, whereas the second is the refraction (or diving wave) from the top of basement. $P_{1} P$ $\left(S_{1} S\right), P_{2} P\left(S_{2} S\right)$ and $P_{1} P\left(S_{2} S\right)$ are the reflections from the top of middle crust, lower crust and low velocity layer for $P$-waves (S-waves), respectively. $P_{m} P\left(S_{m} S\right)$ is the reflection from the Moho, and $P_{n}\left(S_{n}\right)$ is the refraction from the Moho. The typical phases mentioned above are shown in some record sections (Fig. 3).

\section{Correlation of phases}

In general, $\mathrm{P}_{\mathrm{B}}\left(\mathrm{S}_{\mathrm{B}}\right)$ is a very clear phase from which we can identify and specify the traveltime very accurately. It contains detailed information about the upper crustal velocity structure, including sediments, or weathered layer, and basement.

The first segment of $\mathrm{P}_{\mathrm{g}}\left(\mathrm{S}_{\mathrm{g}}\right)$, corresponding to the waves propagating in the sediments or weathered layer, is well characterized because it is the first arrival within a distance of $50 \mathrm{~km}$ of the shotpoints. P-wave velocities observed for this segment increase 
from the surface to a greater depth with stronger velocity gradient. The thicker or the lower the near-surface velocity is, the larger the $\mathrm{P}_{\mathrm{g}}\left(\mathrm{S}_{\mathrm{g}}\right)$ time delay. In some places where sediments were thin or absent, this phase has a very small time delay, and an apparent velocity of about $6.0 \mathrm{~km} / \mathrm{s}$ for P-waves (3.46 km/s for S-waves), for example, in the case of record section of SP1 (Fig. 4). However, the traveltimes of $\mathrm{P}_{\mathrm{g}}\left(\mathrm{S}_{\mathrm{g}}\right)$ from shotpoints SP4 and SP7 (Fig. 5 and 6), which are located at the Junggar and Turpan basins respectively, are of a larger time delay. At distances greater than $50 \mathrm{~km}$ about from the shotpoint, $\mathrm{P}_{\mathrm{B}}$ $\left(S_{g}\right)$ becomes a refracted phase along the basement, below the sediments or weathered layer, with an apparent velocity that is usually close to or higher than the reduction velocity.

So far, we have discussed phases that occur as first arrivals near the shotpoint, which are usually easier to identify than later arrivals. The reflection $P_{3} P\left(S_{1} S\right)$ from the top of middle crust, the next phase to arrive after $P_{g}\left(S_{g}\right)$, has a larger amplitude than $P_{B}\left(S_{g}\right)$. At certain distances, this phase seems to be a first arrival because the $P_{g}\left(S_{g}\right)$ energy is too weak to be detected.

The phase $\mathrm{P}_{2} \mathrm{P}\left(\mathrm{S}_{2} \mathrm{~S}\right)$, which corresponds to the reflection from the top of the lower crust, is observed in most of the record sections, and is characterized by its arrival before the $P_{m} P\left(S_{m} S\right)$ phase; $P_{2} P\left(S_{2} S\right)$ intersects $P_{m} P\left(S_{m} S\right)$ between a distance of 200 and 250 $\mathrm{km}$. Despite the very great energy of the $P_{m} P\left(S_{m} S\right)$ phase, some energy from the $P_{2} P$ $\left(\mathrm{S}_{2} \mathrm{~S}\right)$ phase can be seen on the record sections as well.

In the record sections observed southwards from $S P 7$, another phase $P_{L} P\left(S_{L} S\right)$, can be identified in the record sections between the phases $P_{1} P\left(S_{1} S\right)$ and $P_{2} P\left(S_{2} S\right)$. This phase is visible in the trace-normalized record section despite its weak energy when compared to the very strong $P_{m} P\left(S_{m} S\right)$ phase; it nearly parallels $P_{1} P\left(S_{1} S\right)$, but has a lower average velocity. It is the phase that makes the Moho reflection a clear time delay in the related regions (Fig. $3 \&$ Fig.6) . Because no obvious time delay appears for the phases before $P_{2} P\left(S_{2} S\right)$, so the phase $P_{L} P\left(S_{L} S\right)$ is infered as a reflection from the top of a low velocity layer beneath this southern section of the profile.

The Moho reflection $P_{m} P\left(S_{m} S\right)$ represents the arrival with the largest amplitude at distances larger than 100-150 km, which indicates the critical distance range for reflection 
from the Moho. Due to the complex structure, especially low velocity layer within the crust bellow the profile, the phase $\mathrm{P}_{\mathrm{m}} \mathrm{P}\left(\mathrm{S}_{\mathrm{m}} \mathrm{S}\right)$ exists in two segments with a clear time delay at some special location. This cases can be found in the record sections from shotpoint SP7 and SP10 (Fig.6 and Fig.3). In the record section of SP7, the arrivals of $\mathrm{P}_{\mathrm{m}} \mathrm{P}\left(\mathrm{S}_{\mathrm{m}} \mathrm{S}\right)$ becomes later at the distance greater than $170 \mathrm{~km}$ around in the southern branch (about at $780 \mathrm{~km}$ and shotpoint SP7 is located at $602.30 \mathrm{~km}$ along the profile). Meanwhile, in another record section of SP10, the traveltimes of $\mathrm{P}_{\mathrm{m}} \mathrm{P}$ and $\mathrm{S}_{\mathrm{m}} \mathrm{S}$ both delay at the distance shorter than about $200 \mathrm{~km}$ in northern branch (about $700 \mathrm{~km}$ and shotpoint SP10 is $887.70 \mathrm{~km}$ along the profile). These evidences indicate that the northern start point of the low velocity layer must be located at $750 \mathrm{~km}$ around along the profile.

$P_{n}$ was observed for several shots which had receiver offsets $>200 \mathrm{~km}$ where this phase can be seen as a first arrivals in the record sections (Fig.3, 5 and 6). The respective phase, $S_{n}$, is also visible in some $\mathrm{S}$-wave sections respective to $\mathrm{P}$-waves. Forward modeling of $\mathrm{P}_{n}$ observations was used to determine the velocity structure of the uppermost mantle.

\section{MODELING THE DATA}

Based on the phase correlation described above, the first arrivals of the $P_{B}$ phase were used to invert for the upper crustal velocity structure using a finite-difference tomographic method (Hole, 1992). The reflection phases $\mathrm{P}_{1} \mathrm{P}, \mathrm{P}_{2} \mathrm{P}, \mathrm{P}_{2} \mathrm{P}$ and $\mathrm{P}_{\mathrm{n}} \mathrm{P}$ were used to determine the approximate velocity structure of the middle to lower crust with the $\mathrm{X}^{2}-\mathrm{T}^{2}$ method (Giese, Prodehl and Stein, 1976). After establishing an initial crustal P-

wave velocity structure, the final P-wave model was determined using 2-D forward raytracing modeling (Cerveny, Molotkov, and Psencik, 1977; Cerveny and Psencik, 1984) and amplitude modeling using by the reflectivity method (Fuchs and Muller, 1971) and 2D ray methods. By adjusting the velocities and depths of the boundaries with raytracing method, the different phases on the record sections were all appropriately fitted for the traveltimes, and then the $\mathbf{P}$-wave velocity model was established. 
Because the intra-crustal boundaries were kept fixed, the S-wave velocity structure differs from P-wave velocity structure only in its velocity distribution. The upper crust shares similar characteristics to the $\mathrm{P}$-wave structure, and just replacing $\mathrm{P}$-wave velocity with S-wave velocity (assuming Poisson's ratio is 0.25 ) satisfies these data. The Twodimensional forward modeling was used to fit the remaining S-wave phases. Finally, from the respective P- and S-wave velocity models, the distribution of Poisson's ratio can be calculated.

The accuracy of the final model is dependent on a large number of factors, such as shotpoint interval, receiver density, thickness of sediment in shallow and so on, but primarily the correct identification of the various phases and the number of ray paths intersecting a particular volume of the model. Perturbation of the models has shown that resolution of the velocity and depth to interface may be accepted as better than $2 \%$ and $5 \%$, respectively, dependent on the uniformity of structure and the ray-path coverage.

Finally, the final $\mathrm{P}$ and S-wave crustal velocity structures of the profile along the Geoscience Transect from Taiwan to Altai, including the Poisson's ratio structure, are shown in Fig. 9. The models reveal obvious differences between tectonic units.

\section{$P$ and S Velocity Structure}

The crustal velocity model (Fig. 9) shows many significant features. The velocity distribution near surface varies greatly layerally. In Altai block and the Junggar accretional belt, the velocity is very high $(\mathrm{Vp}=5.5 \mathrm{~km} / \mathrm{s}, \mathrm{Vs}=3.1 \mathrm{~km} / \mathrm{s})$. The Bogda shan and Tianshan accretional belt also share similar characteristics. In some Mesozoic and Cenozoic basins, however, such the Junggar, Tourpan-Hami and Dunhuang basins, the velocity is lower $(\mathrm{Vp}=3.7 \sim 5.8 \mathrm{~km} / \mathrm{s}$ and $\mathrm{Vs}=2.3 \sim 3.3 \mathrm{~km} / \mathrm{s})$ than that around the basin, and increases rapidly with depth. In the Junggar Basin, the P-wave velocity near the surface is about $4.3 \mathrm{~km} / \mathrm{s}$ $(\mathrm{Vs}=2.5 \mathrm{~km} / \mathrm{s})$ and increases to $5.8 \mathrm{~km} / \mathrm{s}(\mathrm{Vs}=3.3 \mathrm{~km} / \mathrm{s})$ at about $5 \mathrm{~km}$ below the surface. The Turpan-Hami Basin appears to have the thickest sediments, approximately $10 \mathrm{~km}$, with the low velocity of $3.7 \mathrm{~km} / \mathrm{s}(\mathrm{Vs}=2.3 \mathrm{~km} / \mathrm{s})$ on the surface increasing to $5.9 \mathrm{~km} / \mathrm{s}$ $(\mathrm{Vs}=3.4 \mathrm{~km} / \mathrm{s}$ ) above its basement. For the Dunhuang basin (eastern Tarim), the velocity 
increases similarly from $4.2 \mathrm{~km} / \mathrm{s}(\mathrm{Vs}=2.9 \mathrm{~km} / \mathrm{s})$ to $5.8 \mathrm{~km} / \mathrm{s}(\mathrm{Vs}=3.3 \mathrm{~km} / \mathrm{s})$ over a depth of $6 \mathrm{~km}$.

These data reliable outline the lateral and depth extent of sedimentary basins due to the clear contrast in velocity between basin fill and the top of the crystalline upper crust. Over most of the profile, the velocity of the crystalline upper crust is $6.0-6.1 \mathrm{~km} / \mathrm{s}$ at depths between $8-14 \mathrm{~km}$. However, beneath the Bogda shan, a higher velocity block $(\mathrm{Vp}=6.30 \mathrm{~km} / \mathrm{s}, \mathrm{Vs}=3.7 \mathrm{~km} / \mathrm{s}$ ) exists in the shallow crust.

The velocity in the middle crust is $6.6 \mathrm{~km} / \mathrm{s}$ under the Altai block and Junggar accretional belt, and $6.5 \mathrm{~km} / \mathrm{s}$ between Junggar and Turpan-Hami basins. Towards the southern part of the profile, a lower velocity layer, about $5 \mathrm{~km}$ thick and with a P-wave velocity of $5.9 \mathrm{~km} / \mathrm{s}(\mathrm{Vs}=3.4 \mathrm{~km} / \mathrm{s})$, is overlain by a higher velocity layer of $6.3 \mathrm{~km} / \mathrm{s}$ $(V s=3.6 \mathrm{~km} / \mathrm{s}$ ). Because of the low velocity layer, the time delay of the reflections from Moho become obviously clear, as the phase $\mathrm{P}_{\mathrm{m}} \mathrm{P}$ shown on the record section of shot SP7 and SP10 in which the reflection traveltimes of $P_{m} P\left(S_{m} S\right)$ phase in the south of Kushui ( $\sim 750 \mathrm{~km}$ in the profile) is larger than in the north (see Fig.3, 6,7 and 8).

The thickness of the lower crust varies with tectonic province. especially in the thickness of the layer. The thickness averages $30 \mathrm{~km}$ with a velocity of $7.0 \mathrm{~km} / \mathrm{s}(\mathrm{Vs}=3.9$ $\mathrm{km} / \mathrm{s}$ ) beneath Altai block and Junggar accretional belt, and the Moho is at a depth of about $54 \mathrm{~km}$. The lower crust becomes thin obviously beneath the Junggar basin, where the depth of the Moho is close to $46 \mathrm{~km}$. However towards south, the Moho becomes deeper in a form of two steps with a velocity of $6.9 \sim 7.0 \mathrm{~km} / \mathrm{s}(\mathrm{Vs} \sim 4.0 \mathrm{~km} / \mathrm{s})$, first step in Bogdashan and Turpan-Hami basin with a depth of $47 \mathrm{~km}$ and the second in the southernmost part with a depth of around $50 \mathrm{~km}$.

The velocity distribution derived from $P_{n}$ phases for the uppermost mantle varies from 7.7 to $8.0 \mathrm{~km} / \mathrm{s}$; the most significant characteristic is the lower value of $7.7-7.8 \mathrm{~km} / \mathrm{s}$ under the region between Junggar and Turpan-Hami basin, however higher value of 8.0 $/ \mathrm{km}$ appears beneath Altai block and Junggar accretional belt, Tianshan accretional belt and Tarim platform.

\section{Poisson's ratio}


The Poisson's ratio along the profile is shown in Fig. 9. For the sediments and weathering layer, Poisson's ratio is lower than 0.25 , especially for the sediments in the basins. The Turpan-Hami Basin has a minimum value of $0.18 \sim 0.25$, while the Junggar Basin has a higher value, 0.24-0.25, even when compared with other basins. However, in accretional belts, Poisson's ratio is higher, especially in Altai block and Junggar accretional belt with a value of 0.25 , even in the Junggar basin.

In the upper crystaline and middle crust including lower velocity layer, the Poisson's ratio is around 0.25 except for Altai and Junggar region which is characterized by higher Poisson's ratio of $0.26 \sim 0.27$.

The similar feature to middle crust appears in the lower crust with a value of $0.26 \sim 0.27$ for the most of the profile, however, the value becomes higher beneath the Altai ilock up to 0.28 .

According to the Poisson's ratio section, it seems to be obviously clear that, in a view of whole crust, Poisson's ratio is higher than other areas along the profile beneath the Altai block and Junggar accretional belt, especially the lower crust with the highest value of 0.28 . In the adjacent area, under Junggar basin, Poisson's ratio above the lower crust is higher than any other region along the profile, its sediments aslo shares the same characteristics. In the Junggar basin, a high value of $0.26-0.27$ predominates in the crust, the shallow part also shares the high value of $0.24 \sim 0.25$.

\section{DISCUSSION AND CONCLUSION}

This profile resulted in a high quality data set which was used to derive the crustal structure ( $\mathrm{P}$ and S-wave velocities and Poisson's ratio) beneath the area of the transect. These results reveal the characteristics of the crustal structure (Fig. 9) within the study area. The depth of Moho along the profile has a dramtic variation in the junction of the Junggar accretional belt and the Junggar basin from 54 to $46 \mathrm{~km}$, however, in the south of the junction, the Moho of about $48 \mathrm{~km}$ with a slight variation has good agreement with the results inferred from teleseismic data (Feng et al., 1980; Lui et al., 1989; Teng et al., 1992 and 1994; Hanan Mahdi and Gary L. Pavlis, 1998). 
The Poisson's ratio, an elastic deformation characteristic related to the composition and degree of disturbance of crystalline rocks, typically low for brittle and fractured rocks with high quartz content (Krilov et al., 1995b; Zandt et al., 1994; Zandt and Ammon, 1995; Zandt et al., 1995; Christensen, 1996; Rudnick and Fountain, 1995), becomes more and more important, and has the potential of providing valuable constraints on crustal composition and comprehensively understanding the nature of earth's crust. Now, as laboratory-based compressional and shear wave velocity measurements for common rock types become available, so the Poisson's ratios determined from field measurements are particularly important because the correlation between compresional wave velocity and composition is limited due to the similar compressional wave velocities of many common crustal rock types (e.g., Birch, 1960, 1961; Christensen and Mooney, 1995; Christensen, 1996). By combination of velocity structure with Poisson's ratio, an comprehensive interpretation of the crustal structure is possible (Fig. 1).

The crust in the north of the junction between Altai block and Junggar accretional belt is of highest Poisson's ratio of $\sigma=0.25-0.28$ and the greatest thickness with high velocities along the profile, probably implies that the crust enriches mafic composition and Precambrian basement probably exits there due to the high velocity both $\mathrm{P}$ and S-wave and high Poisson's ratio, which is related to the presence of gneissic rocks along the souther border (Chang, Ying, and Coleman, 1996). Comparing with some seismic results (Fig. 11) in the adjacent area (???????), especially from Russia, we find that, the crust in the northmost part, Altai block, has a very similar feature of velocity structure just with a variation of crustal thickness, this probably reflect the characteristics of the foreland of Siberian craton. However, there is a very distinct difference between Altai block and its south.

In the Junggar basin, there is much discussion concerning the basement, which may be composed of either Precambrian crystalline rocks or Paleozoic accretional rocks (Yang and Yang, 1985; Tao and $\mathrm{Lu}, 1980$ ). The seismic cross section shows a higher Poisson's ratio of 0.26-0.27 than that of 0.25-0.26 in its northern side, especially in the upper and middle crust. This may imply a mafic-rich basement, probably Precambrian basement. With a consideration of the obvious variation in crustal thickness against both sides and other 
geophysical evidences (L. Zhang, 1991) combined with the outcrops of Precambrian rocks around the Junggar Basin in the accretionary belts peripheral to the basin (C. Zhang, 1997), we prafer to infer the crust a Precambrian Massif or Precambrian crust other than oceanic crust imbricated with accretionary sediments.

The crust evolution of Bogdashan and Turpan-Hami basin is relatively complicated, and there are some controversies about the nature of the crust. Along the wide-angle reflection/refraction profile, a lower Poisson's ratio of $0.25-0.26$ in this region was observed. Lead systematics on the Tianshan post collisional granites south of the Nicolaev Line reveal isotopic ratios characteristic of Precambrian crustal rocks distinctly different than post collisional granites in the Junggaar accretional belt. The young age of the postcollisional thermal event has prevented fractionation and underplating typical for much older cratons (Rudnick and Fountain, 1995). The oldest exposed rocks in this region are Paleozoic ophiolitic, accretionary and arc rocks of oceanic affinity. The latest results from the isotopic variation of $\mathrm{Nd}, \mathrm{Sr}$, and $\mathrm{Pb}$ in Paleozoic granitoid Plutons along an east Junggar-Bogdashan-Tianshan transect show that the distinctive differences exist between this region and the adjacent area, and that the primary magamas chiefly from depleted mantle sources were probably MORB-like basalt, extracted from upwelling asthenosphere behind downgoing subduction slabs and ponded at the base of the oceanic arc crust (Wen et al., 1998). According to Russian deep seismic sounding results (Krilov et al., 1995b), the low Poisson's ratio may imply that the block may consist of migmatized accretional crust produced by the thermal event related to the passive collision between the Junngar and Tienshan accretional belts and the crust has undergone homogenization and melting during the late Paleozoic thermal event marked by post collisional granites which are quart-rich with much calc-alkaline intrusives. In other hand, because of the strong and frequent geological and tectonic activity, the crust become very fractured so that the Poisson's ratio within the crust becomes lower.

In the south of Turpan-Hami basin along the profile, Poisson's ratio for the basement and middle crust is also lower, probably due to the presence of granites formed in the same thermal event. The lower crust has a higher Poisson's ratio of $0.26-0.27$ than above 
due to fractionation of the older crust and perhaps development of granulite facies rocks in the lower crust. Because the fault Altyn Tagh is a strike-slip fault at the boundary between the Tarim Platform and the Kunlun-Qilian-Qinling fold system, the low velocity layer within the middle crust with a low Poisson's ratio of 0.25 can be considered to be composed of calc-alkaline intrusives in the middle crust near the fault zone. However, the Poisson's ratio becomes higher in the lower crust beneath the Dunhuang (Western Tarim) basin than that beneath Tianshan region, so it can be deduced that the crust, specially the lower crust, is not very mafic, in other words, the older crust in the southern part of profile may be Tarim Platform that was invaded by granitic materials formed during the thermal event that formed in the Late Palaeozoic collision and delamination and Kushui fault near shotpoint SP9 probably is the boundary between Paleozoic acretional belt and Tarim platform.

We have modeled the crustal velocity structure both $\mathrm{P}$ and S-wave and Poisson's ratio along the wide angle reflection profile in northwest China to invesitigate the crustal characteristics and possible crustal compositon. In summary, we have infered following conclussion according to the crustal model:

1. Beneath Altai and Junggar regions, a Precambrian basement probably exists by the evidence of high velocity both $\mathrm{P}$ and S-wave, high Poisson's ratio and some presences of Precambrian rocks within or aroud these regions.

2. A grand accretionel belt maybe exists between the southern margin ofJunggar basin and northern margin of Tarim platform and is composed of Bogda Shan, TurpanHami basin and Tianshan, being produced by the thermal event related to the passive collision between the Junngar and Tienshan accretional belts and the crust has undergone homogenization and melting during the late Paleozoic thermal event marked by post collisional granites which are quart-rich with much calc-alkaline intrusives. The lower Poisson's ratio is mainly caused by the vast of post collisional qurtz-riched granites. In other hand, the low Poisson's ratio also has the contribution of fractured crust which is characterized in this region. 
3. The low velocity layer in the southern part of the profile probably is due to the calc-alkaline intrusives in the middle crust near the fault zone between Tianshan and Tarim.

\section{ACKNOWLEDGEMENTS}

We would like to express a special thanks for the support from the U.S. Geological Survey for the scientific exchange program. We thank those who provided advice on the data processing and interpretation during this research, including George A. Thompson from Stanford University, USA, C. Prodehl and F. Wenzel from the Geophysical Institute at Karlsruhe, Germany, G. Fuis, J.J.Luetgert and J. Hole from the U.S. Geological Survey, Takao Ohinato from the Japan Geological Survey, E.Gurria from Intituto Geografico Nacional, Spain. We also thank Dr. J. Hole for providing the data analysis code of the finite difference travel-time inversion and Takao for using his finite difference algorithm for 2-D heterogeneous media with transparent boundary conditions and nature topography to calculate the synthetic seismograms in this research. The Stanford China Industrial Group provided much new data concerning basin development and C.A. Hopson has shared new isotopic data on granites closely related to the transect. 


\section{REFERENCES}

Allen, M.B, M.C. Sengor, and B.A. Natalin. 1995. Junggar, Turfan and Alakol basins as Late Permian to ?Early Triassic extensional structures in a sinistral shear zone in the Altaid orogenic collage, Central Asia. Journal of the Geological Society, London 152:327-338.

Allen, M.B., B.F. Windley, and Chi Zhang. 1992. Paleozoic collisional tectonics and magmatism of the Chinese Tien Shan, central Asia. Tectonphysics 220:89-115.

Berzin, N.A., M.M. Buslov, and N.L. Dobretsov. 1991. Geology and tectonics of Gorny Altai (Guide Book): Acad. Sci. Novosibrsk.

Berzin, N.A., Coleman. R.G., N.L. Dobretsov, L.P. Zonenshain, X. Xiao, and E.Z. Chang. 1994. Geodynamic map of the western part of the Paleoasian Ocean. Russian Geology and Geophysics 35 (7-8):5-22.

Bibkova, Y.V., T.I. Kimozova, I.K. Kozakov, A.B. Kotav, L.A. Neymark, B.M. Gorokhovskiy, and I.K. Shuleshko. 1992. U-Pb ages for polymetamorphic complexes on the southern flank of the Mongolian and Gobi Altai. Geotectonics 26:166-172.

Carbonell, R. , and S.B. Smithson. 1995. P- and S-wave velocity determination: Implications for anisotropy and Poisson's ratio. .

Carroll, A.R., S.A Graham, M.S. Hendrix, D. Ying, and D. Zhou. 1995. Late Paleozoic tectonic almagamation of northwestern China: sedimentary record of the northern Tarim, northwestern Turpan and southern Junggar basins. Geological Society of america Bulletin 107:571-594.

Carroll, A.R., S.A. Graham, S.A. Hendrix, J. Chu, C.L. McKnight, X. Xiao, and Y. Liang. 1990. Junggar basin, northwest China: Trapped late Paleozoic ocean. Tectonophysics 181:1-14.

Castagna, J.P. 1985. Relationships between compressional wave and shear wave velocity in clastic silicate rocks. Geophysics 50 (4):571-581. 
Cerveny, V. , I.A. Molotkov, and I. Psencik. 1977. Ray method in seismology. Prague.: Univerzita Karlova.

Cerveny, V., and I. Psencik, eds. 1984. SEIS83-numerical modeling of seismic wavefield in 2-D laterally varying layered structures by the ray method, in: E. R. Engdah] (editor), Documentation of earthquake algorithms. World data center ( A ) for solid earth geophysics, Boulder, Colo., Rep. SE-35, 36-40. Edited by E. R. Engdahl. Vol. Rep. SE-35, Documentation of earthquake algorithms. World data center ( A ) for solid earth geophysics, Boulder, Colo., Rep. SE-35, 36-40. Boulder, Colo.: World Data Center.

Chang, E.Z., X. Ying, and R.G. Coleman. 1996. Tectonic transect map across RussiaMongolia-China (Western Part). Oklahoma City: American Association of Petroleum Geologists.

Chang, E.Z, X. Ying, D. Zhou, and L. Wang. 1994. Geodynamic evolution of continental margins in Eastern Asia and tectonic setting of East China. In Proc. of the 29th Int. Geol. Conf., Part B, edited by R. G. Coleman. Kyoto, Japan: VSP, Utrecht.

Christensen, N. I. 1996. Poisson's ratio and crustal seismology. Journal Of Geophysical Research 101 (b2):3139-3156.

Christensen, N. I. and W. D. Mooney, Seismic velocity structure and composition of the continental crust: A global view, J. Geophys. Res., 100,9761-9788, 1995.

Coleman, RG. 1989. Continental growth of northwest China. Tectonics 8:621-635.

Cunningham, W.D., B.F. Windley, D. Dorjnamjaa, J. Badamgarov, and M. Saandar. 1996a. Late Cenozoic transpression in southwestern Mongolia and the Gobi AltaiTien Shan connection. Earth and Planetary Science Letters 140:67-81.

Cunningham, W.D., B.F. Windley, D. Dorjnamjna, G. Badamgarov, and M. Saandar. 1996b. A structural transect across the Mongolian Western Altai; Active transpressional mountain building in central Asia. Tectonics 15 (1):142-156.

Dong, S. 1993. Metamorphic and tectonic domains of China. J. metamorphic Geol. $11: 465-481$.

Eesley, R.A. 1989. Analysis of compressional and shear-wave seismic data from the Prudhoe Bay Field. Leading Edge No. 11:10-13. 
Feng, Rui, Jieshu Zhu, Yunyu Ding, Guoying Chen, Zhengqin He, Shubin Xiang, Hainan Zhou, and Kezhong Shun. 1980. Using surface wave to study the crust structure of China. Acta Seismologica Sinica, 3:335-350.

Feng, Y., R.G. Coleman, G. Tilton, and X. Xiao. 1989. Tectonic evolution of the W. Junggar Region, Xinjiang, China. Tectonics 8:729-752.

Fuchs, K, and G. MŸller. 1971. Computation of synthetic seismograms with the reflectivity method and comparison with observations, Geophys. J. R. Astr. Soc. 23:417-433.

Futian, Liu, Qu Kexin, Wu Hua, Li Qiang, Hua Jian, and $\mathrm{Hu} G$. 1989. The Tomography of Chinese Continent and its adjacent are. Acta Geophysica Sinica 32:281-291.

Gajewski, D., R. Stangle, K. Fuchs, and k.J. Sandmeier. 1990. A new constraint on the composition of the topmost continental mantle -- anomalously different deoth increases of P- and S-wave velocity. Geohysical Journal International 103:497507.

Giese, P., C. Prodehl, and A. Stein. 1976. Explosion Seismology in Central Europe. Berlin Heidelberg, New York.: Springer-Verlag.

Greene, T.J., A.R. Carroll, M.S. Hendrix, J. Chu, and C.L. McKnight. 1997. PermianTriassic basin evolution and petroleum system of the Turpan-Hami basin, injiang Province, northwest China. AAPG Abstracts with Programs.

Hanan Mahdi and Gary L. Pavlis, 1998. Velocity variations in the crust and upper mantle beneath the Tien Shan inferred from Rayleigh Wave dispersion, Journal of Geophysical Research, 103 (b2):2693-2704.

Holbrook, W.S., D. Gajewski, A. Krammer, and C Prodehl. 1988. An interpretation of wide-angle compressional and shear wave data in Southwest Germany: Poisson's Ratio and petrological implication. Journal of Geophysical Research 33:12,081 12,106 . 
Holbrook, W.S., W.D. W.D. Mooney, and N.I. Christensen. 1992. The Seismic velocity structure of the deep continental crust. In Continental Lower Crust, Elsevier. Developments in Geotectonics, edited by D. M. Fountain, R. Arculus and R. W. Kay: Elsevier.

Hole, J. A, 1992. Nonlinear high-resolution three-dimensional seismic travel time tomography. Journal Of Geophysical Research, B, 97 (B5):6553-6562.

Kelly, K.R., R.W. Ward, S. Treitel, and R.M. Alford. 1976. Synthetic seismograms: A finite-difference approach. Geophysics 41:2-27.

Kosminskaya, I.P. 1995. Progress in deep seismic sounding studies of the earthÔs crust and upper mantle. In: Walter D. Mooney ( editor ), 1993, CCSS Workshop Proceedings volume, U. S. Geological Survey, 165-194.J. Hole, 1992. Nonlinear high-resolution three-dimensional seismic travel time tomography. Journal Geophysical Research 97:6553-6562.

Krilov, S.V., V.S. Mishenkina, V.S. Seleznjov, and I.F. Sheludko. 1995a. Methods and results of detailed seismic investigations of the earth's crust in the Baikal rift zone. In CCSS Workshop Proceedings, edited by W. D. Mooney: U.S. Geological Survey 9-33.

Krilov, S.V., Z.R Mishenkina, V.S. Seleznjov, and I.F. Sheludko. 1995b. Methods and results of detailed seismic investigations of the earthõs crust in the Baikal rift zone. In: Walter D. Mooney (editor), 1993, CCSS Workshop Proceedings volume, U. S. Geological Survey, 9-33. In CCSS Workshop Proceedings volume, U. S. Geological Survey, 9-33, edited by W. D. Mooney: US Geological Survey.

Kwon, S.T., G.R. Tilton, R.G. Coleman, and Y. Feng. 1989. Isotopic studies bearing on the tectonics of the west Junggar region, Xiangiang, China. Tectonics 8:753-757.

Ohinato, Takao, and Bernard Chouet. 1996. A free-surface boundary condition for including $3 \mathrm{D}$ topography in the finite difference method. To be submitted to BSSA.

Powell, C.M., and P.J. Conaghan. 1973. Plate tectonics and the Himalayas. Earth \& Planetary Science Letters 20:1-12.

Qu, G., and G. He. 1993. The orogeny in the Altaides. Acta Geologica Sinica 6 (1):1-5. 
Ren, J., C Jiang, Z Zhang, Qin. D., and T.K. Huang. 1987. Geotectonic evolution of China. Beijing: Science Press.

Ren, J.S., T.Y. Chen, B.G. Niu, Z.G. Liu, and F.R. Liu. 1990. Tectonic evolution of the continental lithosphere and metallogeny in Eastern China and adjacent areas. Beijing: Science Press.

Ritts, B.D. 1995. Mesozoic tectonics of the Qaidam regino, NW China, and the relationship between Mesozoic Qaidam and Tarim basins. Geological Society of america Abs. with Programs 1995 Annual Meeting 27 (6):456.

Rudnick, R.L., and D.M. Fountain. 1995. Nature and composition of the continental crust: a lower crustal perspective. Reviews of Geopyhsics 33 (3):267-309.

Sengor, A, M.C., B.A. Natalin, and V.S. Burtman. 1993. Evolution of the Altaid tectonic collage and Palaeozoic crustal growth in Eurasia. Nature 364:299-307.

Tao,Junzheng and $\mathrm{Zheng} \mathrm{Lu}, 1981$. The preliminary research on plate tectonics in Xingjiang area, Xingjiang Geology, No.1, p10-17.

Teng, Jiwen, H. Wu, A.W. Wang, and X.L. Sun. 1992. The lithosphere structure and dynamics of south China and its continental margin (abstracts). 29th IGC Kyoto, Japan 2:427.

Teng, Jiwen, Liu Futian, Quan Youli, Liu Jianhua, Yike Liu, Jichun Wei, Ji Lianxiang, and Yang Zhanshou. 1994. Seismic Tomography of The Crust and Mantle under The Orogenic Belts and Sedimentary Basins of Northwestern China. Advances in Sold Earth Geophysics in China 6-80.

Wang, Youxue. 1992. Discussion on division problem of tectonic units in Xinjiang area from seismic refraction results. Abstracts of 29th International Geol. Congress. Abstracts of 29th International Geol. Congress 2:463.

Wen, Jianping, C.A. Hopson, Yaoquig Tang, and G.R. Tilton. 1997. Geology and isotopic variation of $\mathrm{Nd}, \mathrm{Sr}$, and $\mathrm{Pb}$ in Paleozoic granitoid plutons along an East JunggarBogdashan-Tianshan transect, NW China, with tectonic implications. International Geology Review (In Press). 
Windley, B.F., M.B. Allen, C. Zhang, Z-Y. Zhao, , and G-R. Wang. 1990. Paleozoic accretion and Cenozoic redeformation of the Chineses Tien Shan Range, central Asia. Geology 18:128-131.

Windley, B.F., J-H. Guo, J-Y. Li, and C. Zhang. 1994. Subdivisions and tectonic evolution of the Chineses Altai. Russian Geology and Geophysics 35 (7-8):98-99.

$\mathrm{Xu}$, Xinzhong, and Youxue Wang. 1991. The Velocity Characteristics of Geoscience Transect from Keketuohai to Aksai. Paper read at PROJECT 283: Geodynamic Evolution and Main Sutures of paleoasian Ocean, at Beijing.

Yang, Shennan and Weiran Yang, 1981. Regional tectonics of China. Geological publishing house.

Yuan, Xuecheng, Yu Zuo, and Chaowen Zhang. 1994. Evidences for the West China Craton and its evolution. In Reconstruction of the Paleo-Asian Ocean, edited by $R$. G. Coleman. Utrecht: VSP.

Yuan, X., Y. Zuo, and C. Zhnag. 1992. Evidences for the West China Craton and its evolution. In Proc. of the 29th Int. Geol. Conf., edited by R. G. Coleman. Kyoto, Japan: VSP, Utrecht.

Zandt, G., Aaron A. Velasco and Susan L. Beck, 1994. Composition and thickness of the southern Altiplano crust, Bolivia. Geology, Vol. 22, p.1003-1006.

Zandt, G., and C. J. Ammon. 1995. Continental crust composition constrained by measurements of crustal Poisson's ratio. Nature 374:152-154.

Zandt, G., Stephen C. Myers and Terry C. Wallace, 1995. Crust and mantle structure across the masin and Range-Colorado Plateau boundary at $37^{\circ} \mathrm{N}$ latitude and implications for Cenozoic extensional mechanism, J. Geophys. Res., Vol. 100, No. B6, p10,529-10,548.

Zhang, Zh. M. 1985. Tectonostratigraphic terranesd of Japan that bera on the tectonics of mainland Asia. In Tectonstratigraphic terranes of the Circum-Pacific region, edited by D. G. Howell. Houston: Circum-Pacific Council for Energy and Mineral Resources.

Zhang, Zh. M., J.G. Liou, and R.G. Coleman. 1984. An outline of plate tectonics of China. Geol. Soc. Amer. Bull. 95 (3):295-312. 
Zhang, L., 1991. The tectonic framwork of Xinjiang plate and its crustal evolution. The proceeding of the second symposium on the geological resources in Tianshan area.

Zhang, C., 1997. Basic tectonic framwork and evolution of Altai-Altun region. In: Memoirs of the geoscience transection for the continental lithosphere beneath Altai-Taiwan, China, edited by Yuan Xuecheng, China university of geosciences press.

Zhou, Da. 1997. Amalgamation and uplift of the Chinese Tian Shan. Paper read at Stanford-China Geosciences Industrial Affiliates, 1997 Annual Review, at Stanford University.

Zhou, Da, and S.A. Graham. 1996. Extrusion of the Altyn Tagh wedge: A kinematic model for the Altyn Tagh fault and palinspastic reconstruction of northern China. Geology 24 (5):427-430. 


\section{Figures}

Figure 1 Tectonic setting of China indicating location of Geoscience transect line.

Figure 2. Tectonic Map of the Northwest China CAG Geoscience Transect Line Shotpoint layout used in the experiments are shown as numbered dots. Mapping modified from Wang et al, (1996)

Figure 3. Record sections of shotpoint SP1. ( upper: trace-normalized band-pass filtered $(0-8 \mathrm{~Hz}) \mathrm{S}$-wave record section with a reduction velocity of $3.46 \mathrm{~km} / \mathrm{s}$ and a factor of 0.58 in time scale with respect to P-wave record section; lower: tracenormalized P-wave record section with a reduction velocity of $6.00 \mathrm{~km} / \mathrm{s}$.)

Figure 4. Record sections of shotpoint SP4. ( upper: trace-normalized band-pass filtered (0-8 Hz) S-wave record section with a reduction velocity of $3.46 \mathrm{~km} / \mathrm{s}$ and a factor of 0.58 in time scale with respect to P-wave record section; lower: tracenormalized $P$-wave record section with a reduction velocity of $6.00 \mathrm{~km} / \mathrm{s}$.)

Figure 5. Record sections of shotpoint SP7. ( upper: trace-normalized band-pass filtered $(0-8 \mathrm{~Hz}) \mathrm{S}$-wave record section with a reduction velocity of $3.46 \mathrm{~km} / \mathrm{s}$ and a factor of 0.58 in time scale with respect to P-wave record section; lower: tracenormalized $P$-wave record section with a reduction velocity of $6.00 \mathrm{~km} / \mathrm{s}$.)

Figure 6. Record sections of shotpoint SP10. ( upper: trace-normalized band-pass filtered $(0-8 \mathrm{~Hz}) \mathrm{S}$-wave record section with a reduction velocity of $3.46 \mathrm{~km} / \mathrm{s}$ and a factor of 0.58 in time scale with respect to P-wave record section; lower: tracenormalized $P$-wave record section with a reduction velocity of $6.00 \mathrm{~km} / \mathrm{s}$.)

Figure 7. Raypath and sythetic seismogram for shotpoint SP7

Figure 8. Raypath and sythetic seismogram for shotpoint SP10

Figure 9. The crustal structure of the profile along the GTTA. (upper: P-wave velocity structure; lower: S-wave velocity structure and Poisson's ratio, where the dashed lines indicate the top of basement.)

Figure10. Geological cross-section of the transect with P-wave velocity structure superimposed (Section follows shotline and therefore has some distortion crossing Bogdashan). 


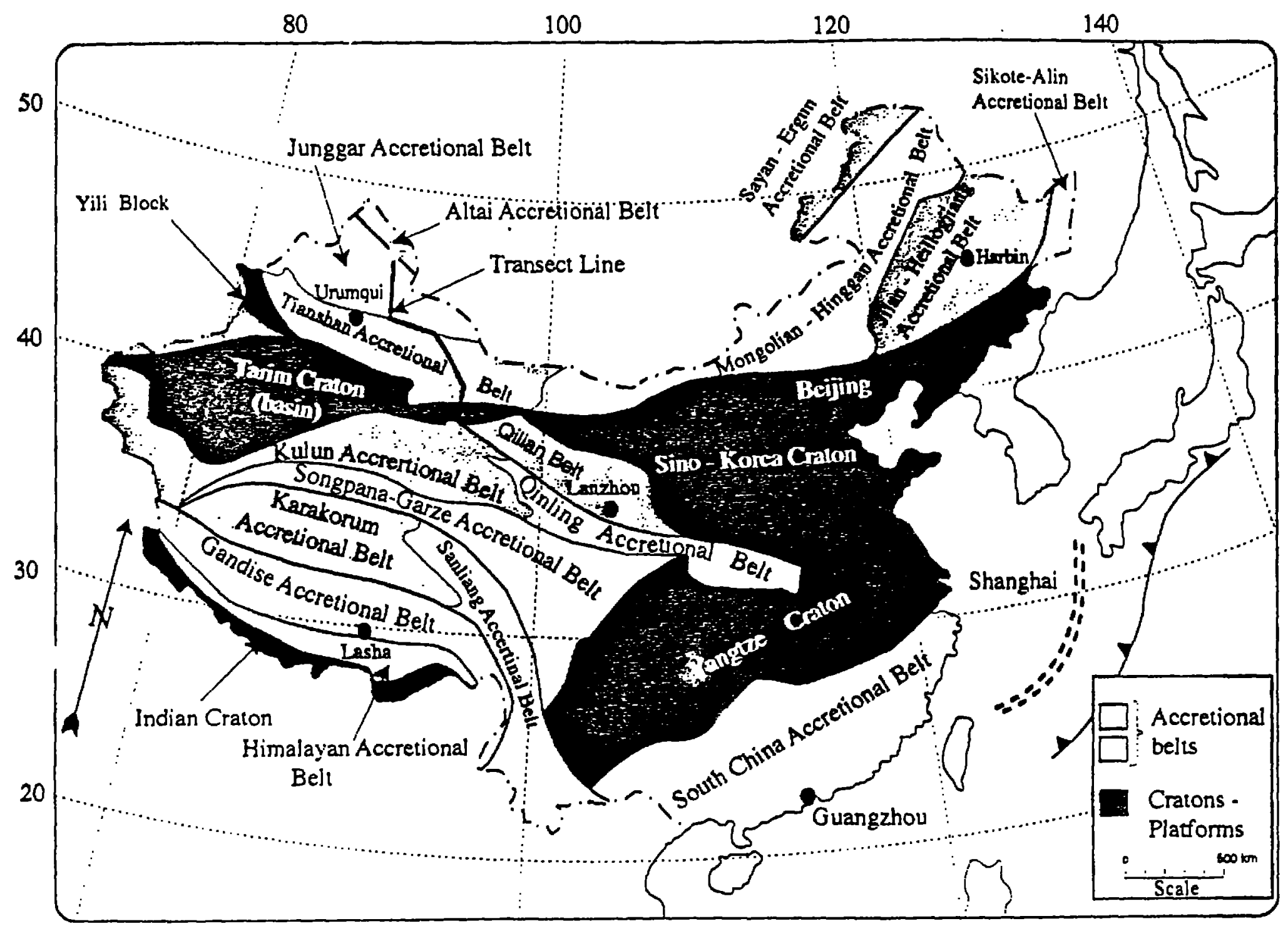




\section{Geodynamic Map of the Northwest China}

\section{CAG Geoscience Transect Line 1}





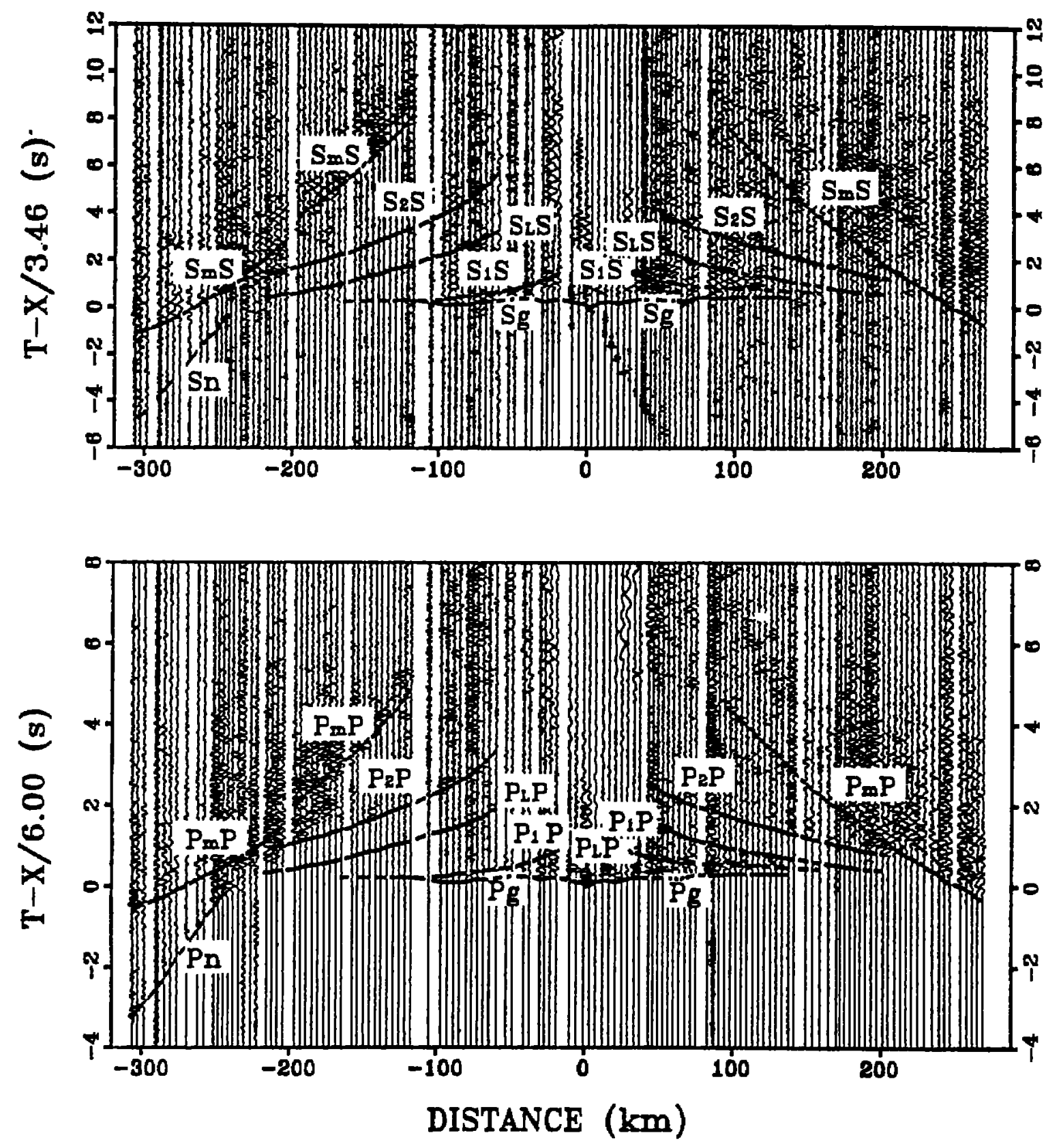

Fig. 3 RECORD SECTIONS OF SHOTPOINT SP10 

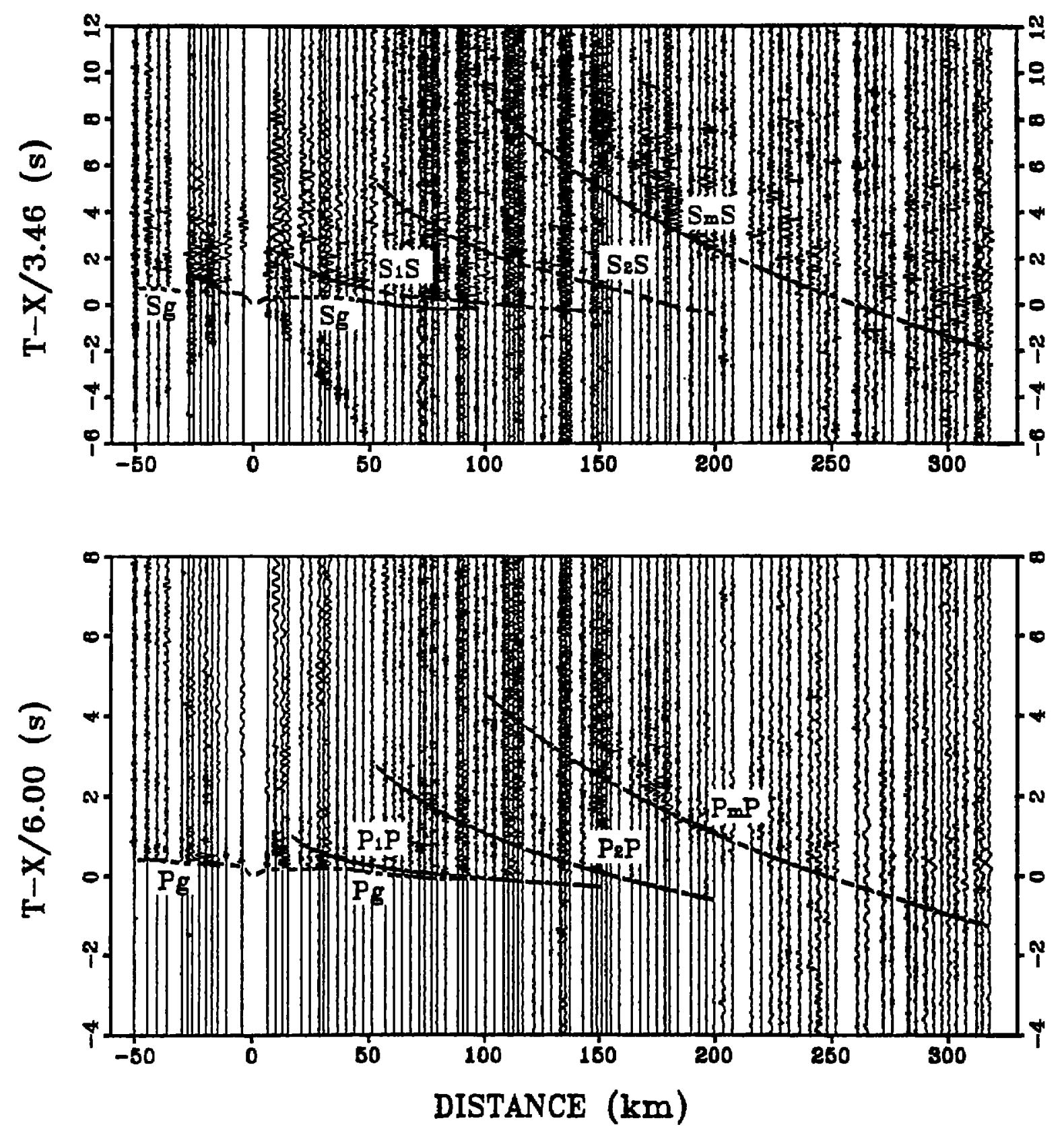

Fig. 4 RECORD SECTIONS OF SHOTPOINT SP1 

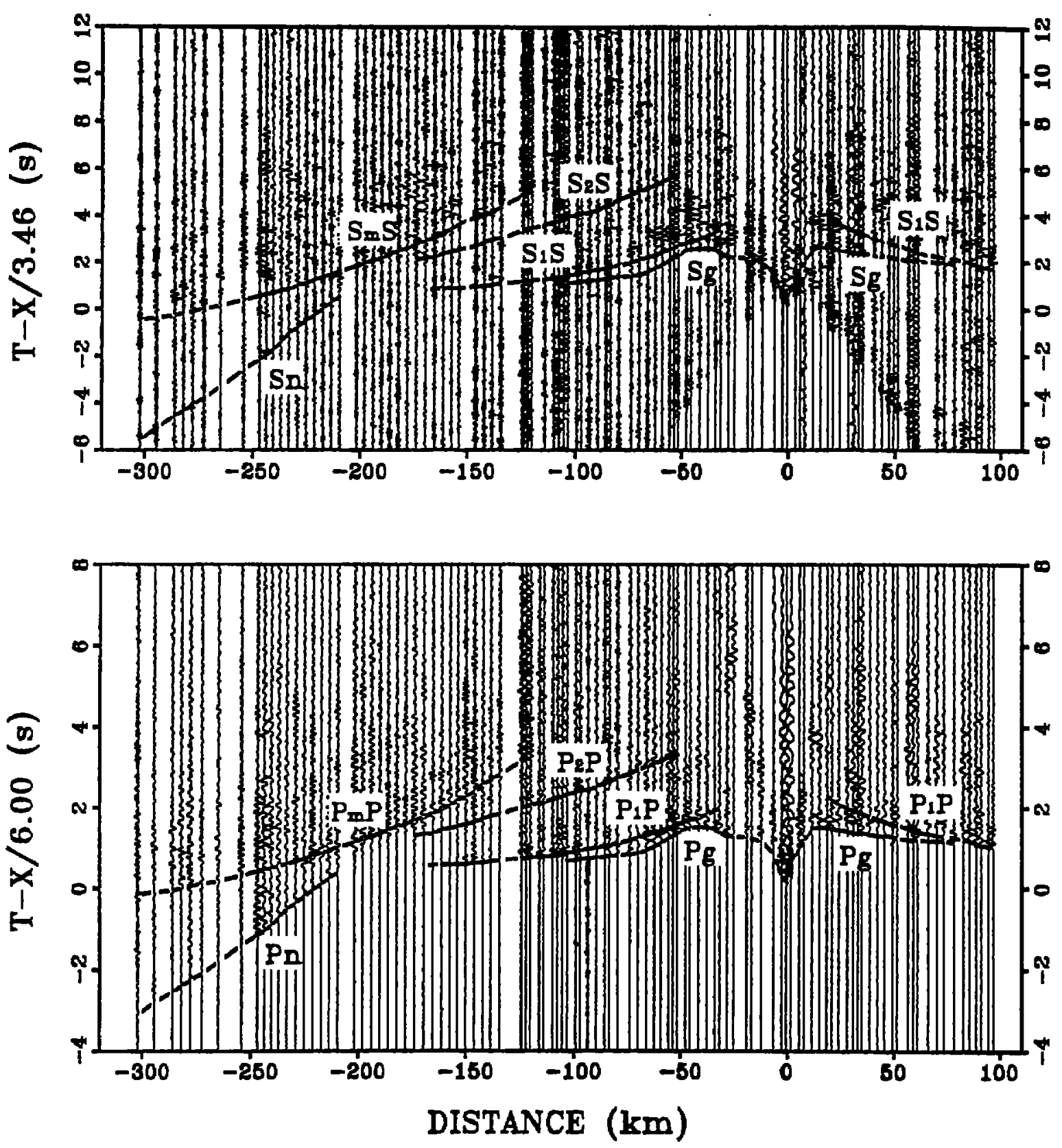

Fig. 5 RECORD SECTIONS OF SHOTPOINT SP4 

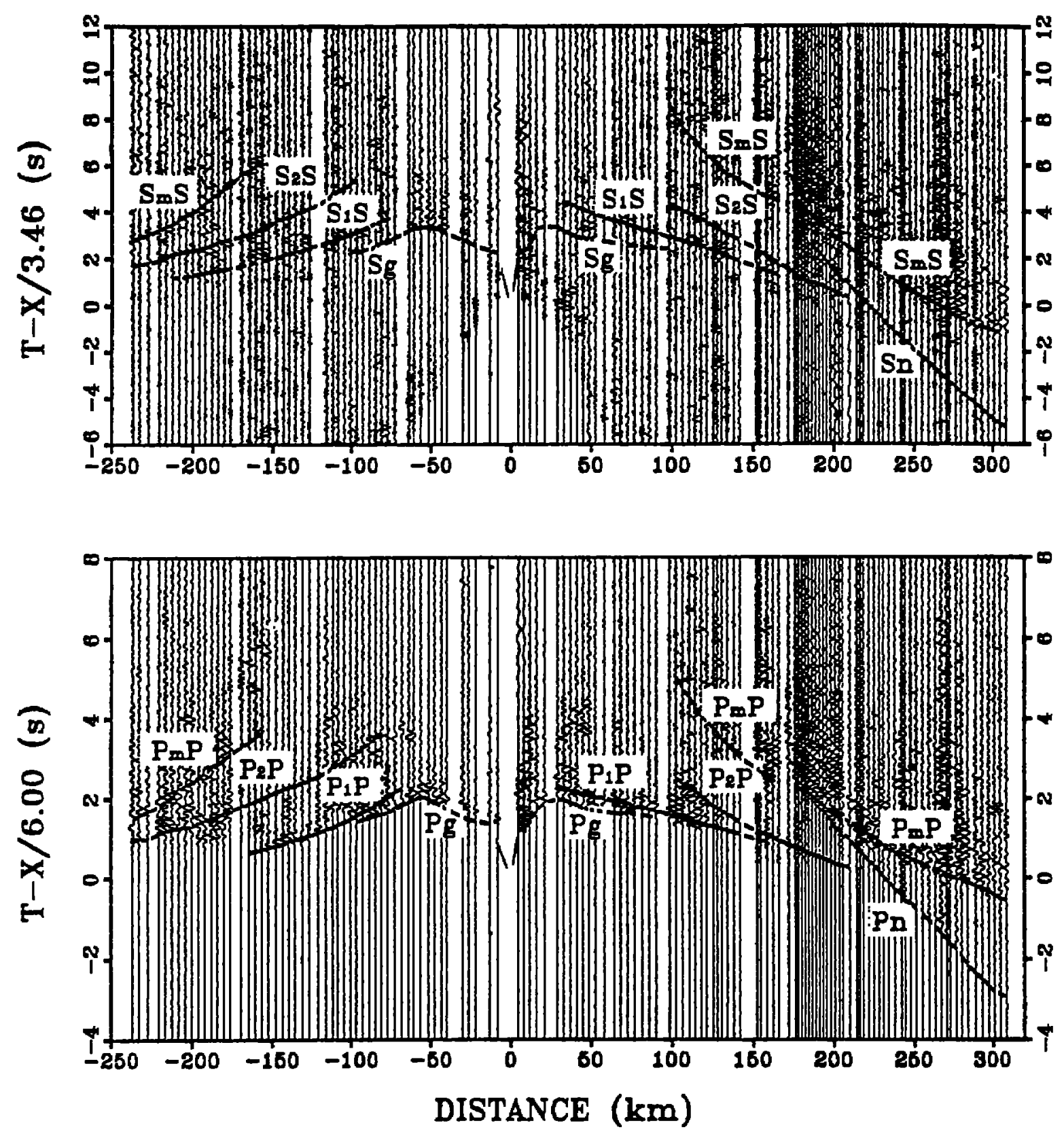

Fig. 6 RECORD SECTIONS OF SHOTPOINT SP7 

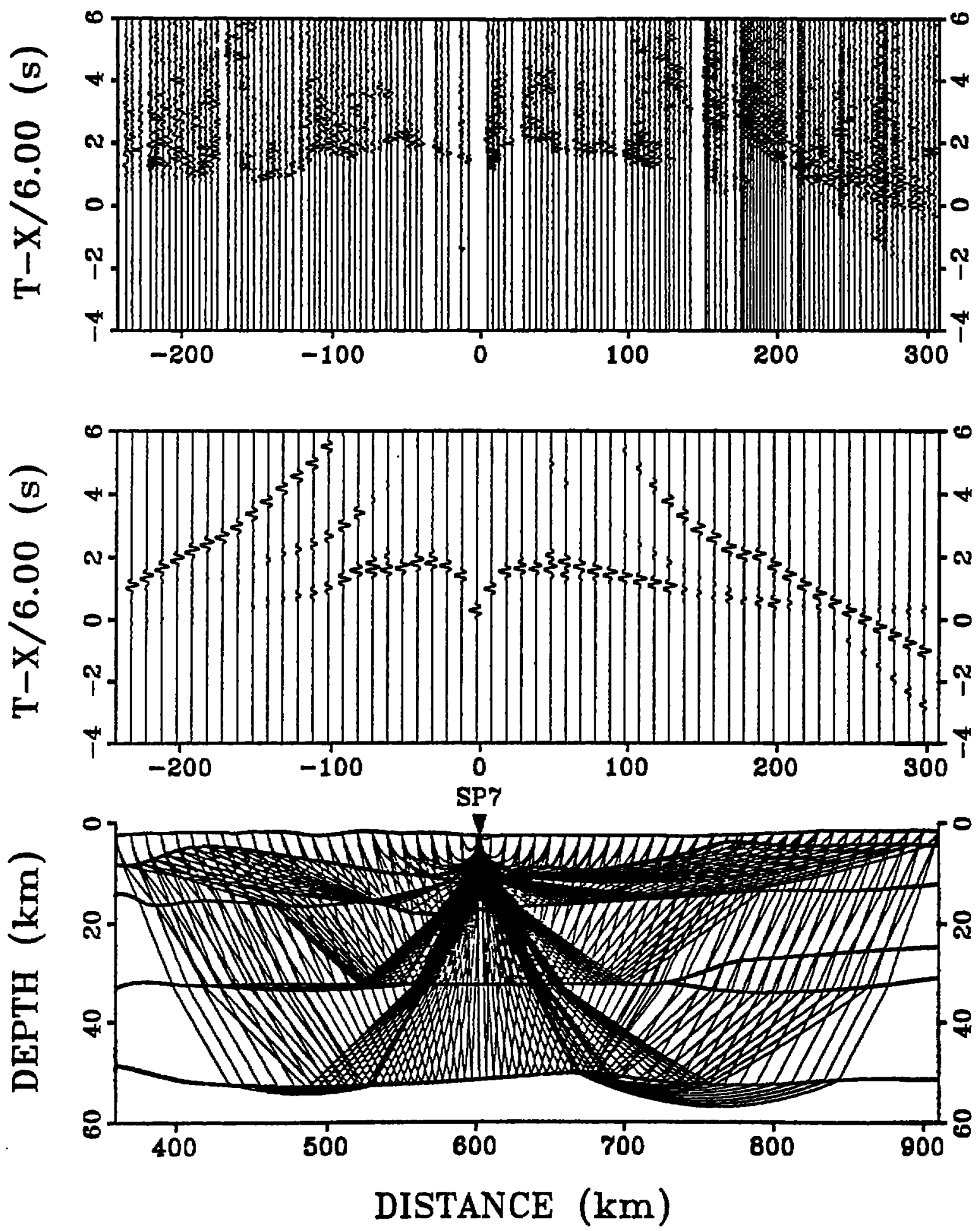

Fig. 7 RAYPATH AND SYTHETIC SEISMOGRAM FOR SHOTPOINT SP7 

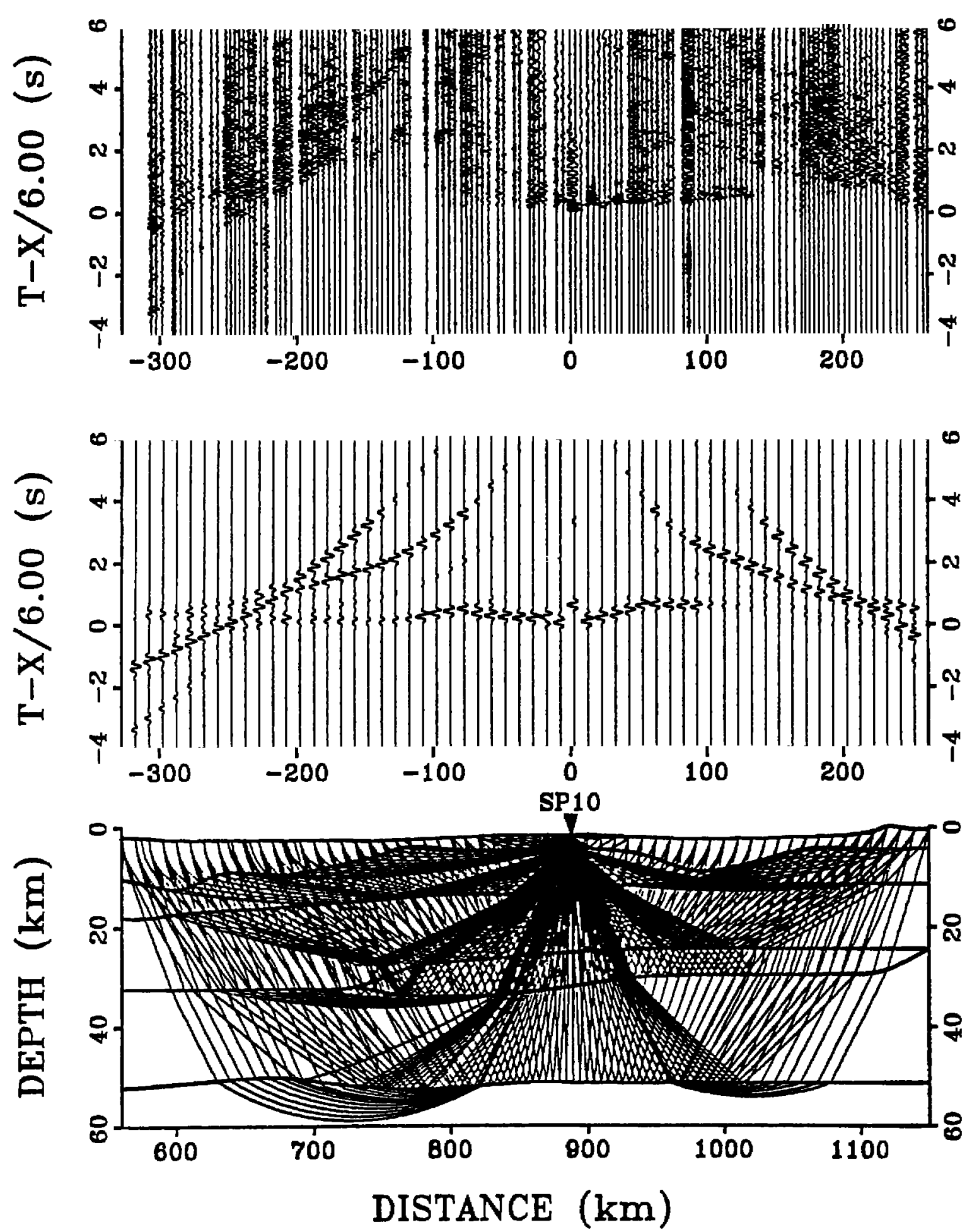

Fig. 8 RAYPATH AND SYTHETIC SEISMOGRAM FOR SHOTPOINT SP10 
Fig. 9
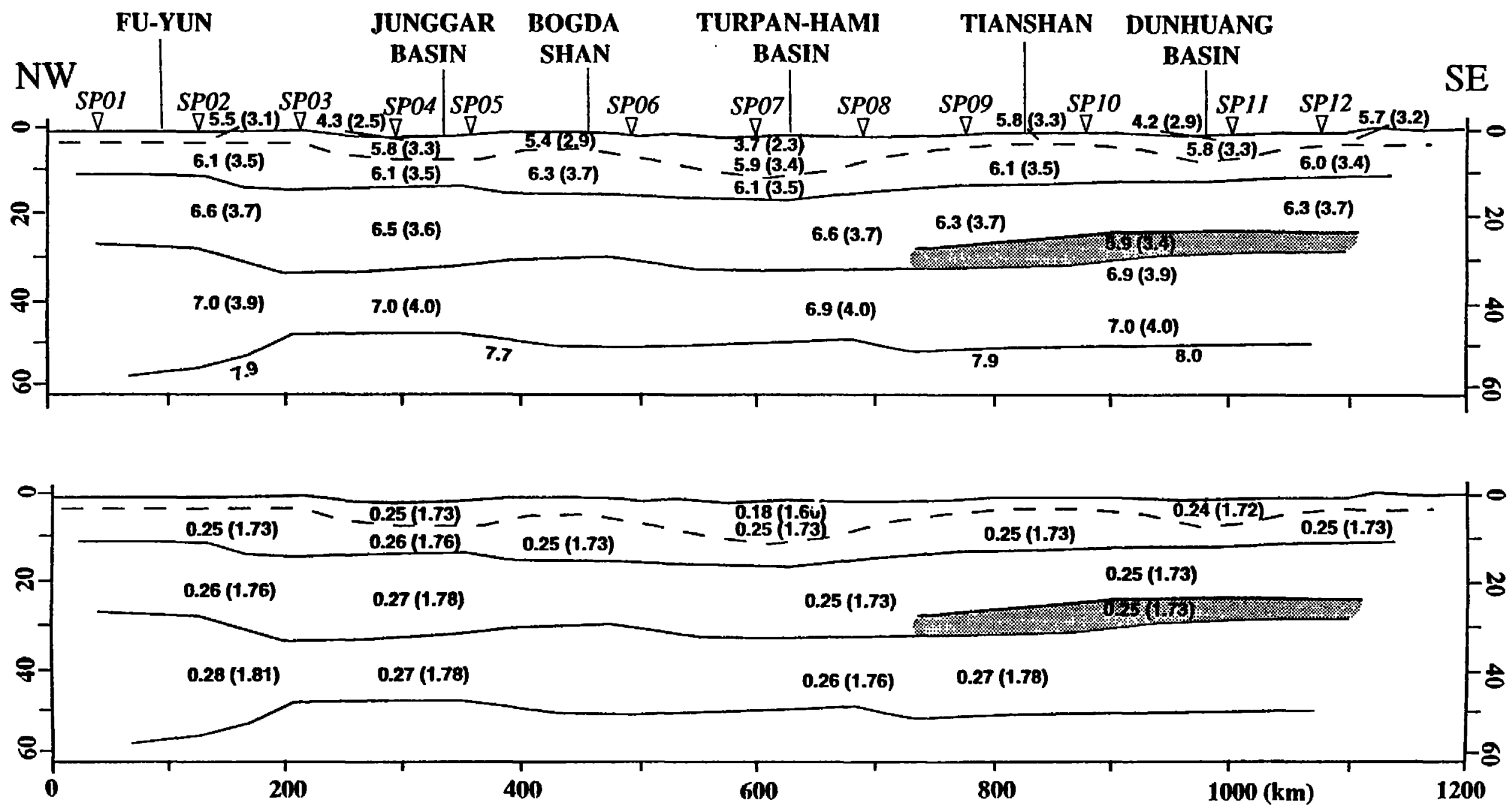


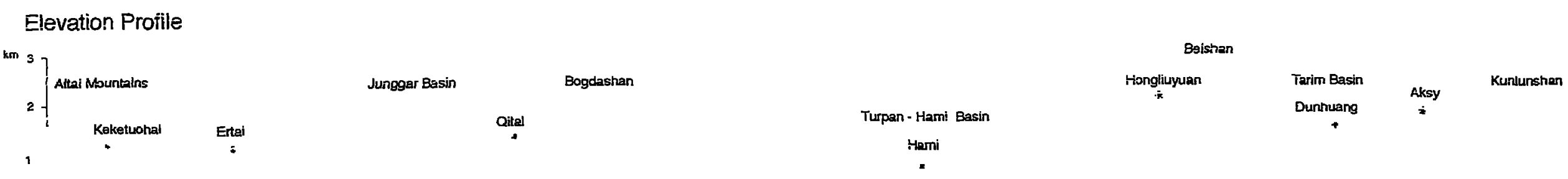

a
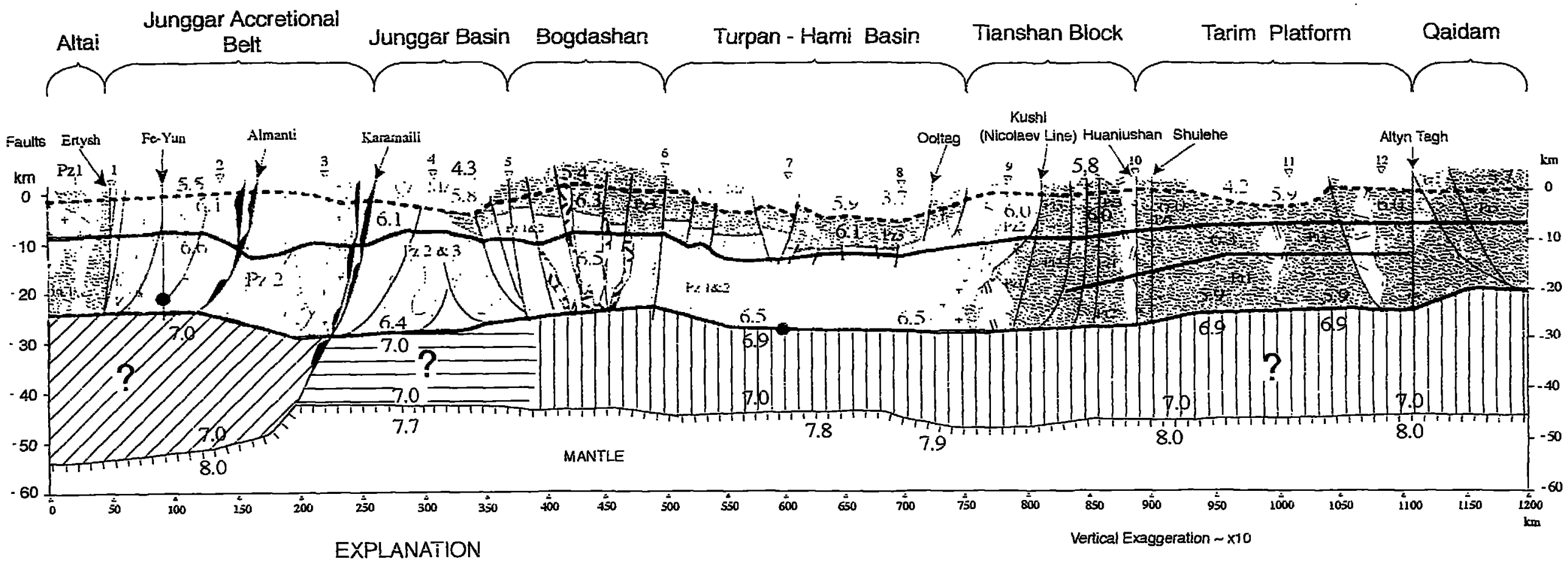

Cz - Mz Continentel sediments
PZ 3 accretion
PZ 1 accretion 1 accretion
Precambrian

TIy island arc magma

+4 A-typegranite $\quad$ Ophiolite

TTT Top of the mantle velocities

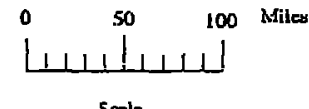




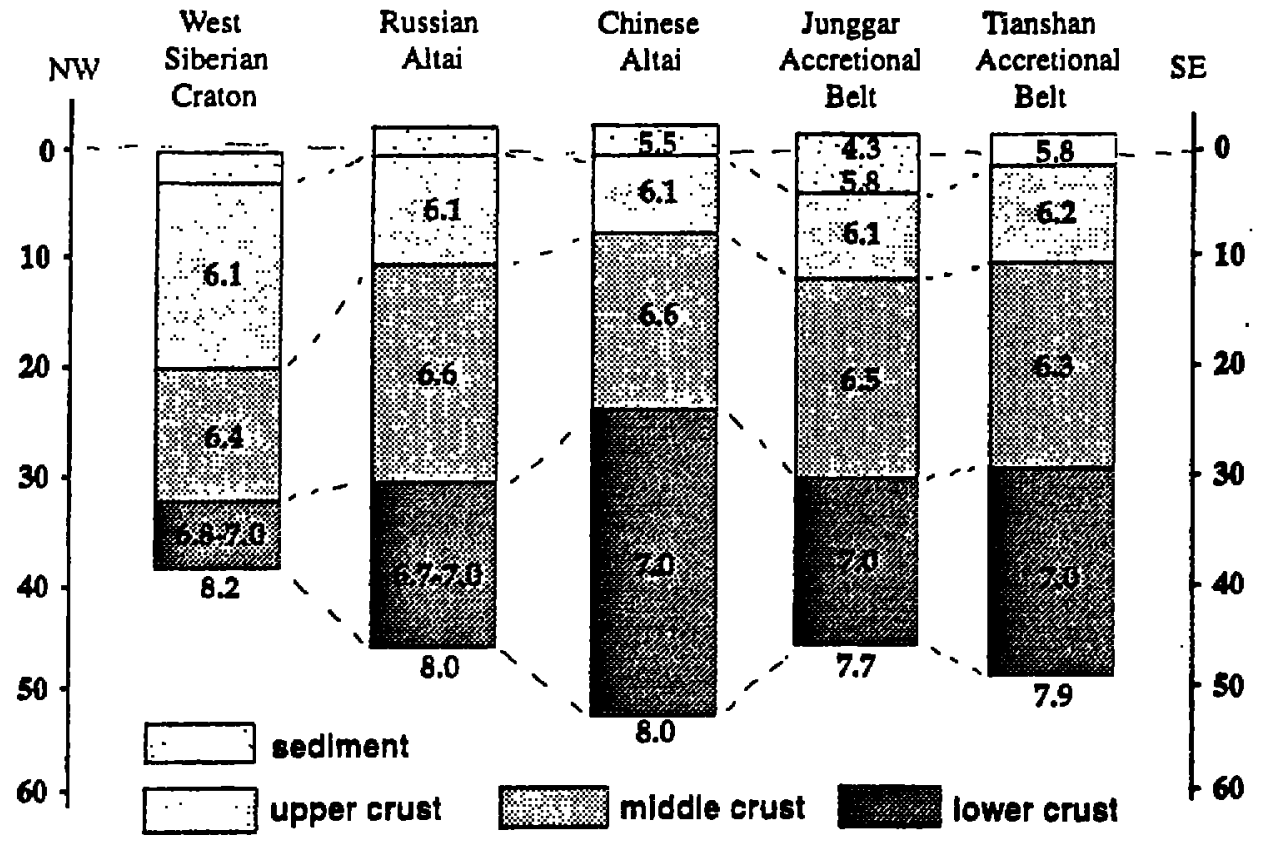

Fig. 11 Primary crustal structure along the profile and its adjacent area 


\title{
The Seismic Experiments along the Geoscience Transect from Taiwan to Altay in China - A Technical Review
}

Youxue Wang ${ }^{1}$, Xuecheng Yuan ${ }^{2}$ and Walter D. Mooney ${ }^{3}$

1) Second Integreted Geophysical brigade of CAG, 5 Longshou Beilu, Xi'an 710016, China

2) Chinese Academy of Geoexploration (CAG), 64 Funei Dajie, Beijing 100812, China

3) U. S. Geological Survey, 345 Middlefield Rd., Menlo Park, CA 94025, USA

\begin{abstract}
During the seventh Five Year Plan of the People's Republic of China, the Ministry of Geology and Mineral Resources designed an ambitious geological and geophysical survey, the Geoscience Transect from Taiwan to Altay, as part of the International Lithosphere program in China. This project was carried out with integrated geological and geophysical methods. Among the geophysical methods, seismic refraction/wide-angle reflection techniques played an important role, and the 4300-km-long transect was covered by several end-toend seismic profiles. The shotspacing along these profiles ranged from $28 \mathrm{~km}$ to $209 \mathrm{~km}$, with an average shotspacing of $90 \mathrm{~km}$. The charge size was 0.8-3.926 tons, depending upon the requirements of the arca. Fifty-one shots were fired at 46 shot points. The spacing of stations was about $2 \mathrm{~km}$ near each shotpoint, $4 \mathrm{~km}$ for distances less than $300 \mathrm{~km}$ and $8 \mathrm{~km}$ beyond $300 \mathrm{~km}$.

The major scientific goals of the project were: (1) to reveal the crustal and upper mantle structure and the tectonic features along the transect in detail, (2) to study the relationship between deep crustal and mantle structure, (3) to study the evolution of the Chinese landmass, and (4) to answer other fundamental geological questions.
\end{abstract}

\section{INTRODUCTION}

China's seventh Five Year Plan (1986-1990), a geological and geophysical project called the Geoscience Transect from Taiwan to Altay (GTTA), was carried out, which included several seismic refraction/wide angle reflection profiles (Fig.1). From the northwest towards the southeast of China, the transect crossed the Tianshan Fold System, the Tarim Platforn, the eastern margin of the Tibetan Plateau, including the Qinling-Kunlun-Qilian Fold System and the Qinghai-Tibet Fold System, the Yangtze Platform and the southeast China Fold System (Shennan Yang and Weiran Yang, 1981). The geological and tectonic setting along the transect are complicated, and significant topographical relief defines the area. 
The structure of the crust and the upper mantle along much of the transect has in the past only been studied with tomography using earthquake data (Rui Feng et al., 1980, Futian Liu et al., 1989, Jiwen Teng et al., 1992, Jiwen Teng et al., 1994 ). There are some controversial geological uncertainties along the transect, mainly concerning the geometry of the boundaries between different tectonic units at given depths. The purpose of the GTTA was to study the relationship between the crustal and upper mantle structure and the known tectonic features of China. The ultimate goal was to gain an understanding of the evolution of the Chinese landmass (Xuecheng Yuan, 1992, Youxue Wang,1992, Xinzhong Xu and Youxue Wang, 1991). Because the transect is very long, $4,300 \mathrm{~km}$, it was divided into five segments for simplification, by dealing with only a small portion at a time.

The project was coordinated by the Chinese Academy of Geoexploration, and involved numerous institutions and scientists, including the Chinese Academy of Geoexploration, the Chinese Academy of Geology, The Second Integrated Geophysical Brigade of the MGMR (the Ministry of Geology and Mineral Resources), Chengdu College of Geology, Changchun College of Geology, Xi'an College of Geology, and the Sichuan Seismological and Geological Brigade.

\section{FIELD WORK AND DATA ACQUISITION}

\subsection{Environment}

The local environment changes greatly from one end of the transect to the other. Line 1, for example, located in northwest China, crosses an arid landscape with a deep water table and high topographical relief. Lines 2 and 3 are located at the eastern margin of the Tibetan Plateau and contain extreme topographical relief; the maximum difference in elevation is more than 3000 meters. The conditions for transportation here are very poor, with some lakes and rivers near or across the profile lines. The water table is deep in most of the area throughout Lines 1, 2 and 3. For Lines 4 and 5, most of the area traversed is mountainous or hilly terrain with a shallow water table. In the northwestern areas, including Lines 1 and 2 , the cultural noise is low due to low population density and few industries near the profiles. However, Line 3 has a high noise level due to a river which runs parallel to the profile. In the southeastern parts, the cultural noise is high as well.

\subsection{Pre-site survey}

The locations of the shotpoints and of all recording sites in the seismic survey were determined several months before the expcrimental expedition began. According to the designed profile, the sites were determined on a 1:50,000 topographical map with an accuracy of $25 \mathrm{~m}$. Each was marked with a colored tag in order to find it quickly and without complication during the experiment. The sites were generally located far from any source of cultural noise so the seismic signals would not be contaminated, and the shots were usually fired at midnight in order to avoid this contamination and to collect higher quality data.

2.3 Communication 
Because the transect is very long, groups working on drilling, shooting and recording were not gathered in the same place, but were instead spread out along the profile according to the seismic experimental design. To ensure that the experiment would run smoothly, a communication system was required for the whole seismic refraction/wide angle reflection operation. For this purpose, a radio network was set up using a fixed frequency channel made available by the government. The system had several parts, a general station to issuc, inform, or change the experiment plan, and several sub-stations for drilling, shooting and recording seismic data.

\subsection{Drilling and shooting}

A majority of the shots were fired in drill holes, but some were fired in lakes or rivers located along the profile. We learned that shooting in drill holes is more effective in producing seismic energy than is shooting in water, so we fired shots in drill holes as often as possible. Shooting in drill holes is more effective when the explosives in the drill holc are under or within the water table, so the holes were drilled deeper in areas where the environment was arid or the water table was deep. For large charges of up to 4 tons, a multi-hole array was required to hold the explosive and enhance the explosion energy. The explosive used in the seismic experiments was TNT.

Tablc 1 lists all shots fired along the transect during the experiments with their respective parameters.

Table 1. Shotpoint parameters in the experiments

\begin{tabular}{ccccccc}
$\begin{array}{c}\text { shot } \\
\text { number }\end{array}$ & date & longitude & latitude & $\begin{array}{c}\text { elevation } \\
\text { (m) }\end{array}$ & $\begin{array}{c}\text { charge } \\
\text { (tons) }\end{array}$ & type \\
\hline 01 & $08 / 07 / 88$ & 464403.00 & 894123.00 & 997 & 3.419 & hole \\
02 & $08 / 07 / 88$ & 460127.00 & 900837.00 & 940 & 2.000 & hole \\
03 & $07 / 31 / 88$ & 451421.00 & 900800.00 & 1177 & 1.572 & hole \\
04 & $07 / 31 / 88$ & 442722.00 & 900600.00 & 658 & 2.547 & hole \\
05 & $07 / 27 / 88$ & 435337.00 & 901045.00 & 1125 & 3.926 & hole \\
06 & $07 / 22 / 88$ & 432908.00 & 913758.00 & 862 & 1.554 & hole \\
07 & $07 / 17 / 88$ & 430210.00 & 924949.00 & 780 & 3.000 & hole \\
08 & $07 / 17 / 88$ & 424244.00 & 935204.00 & 800 & 3.000 & hole \\
09 & $07 / 11 / 88$ & 420240.00 & 943030.00 & 1070 & 1.500 & hole \\
10 & $07 / 11 / 88$ & 411829.00 & 951430.00 & 1755 & 3.007 & hole \\
11 & $07 / 02 / 88$ & 401418.00 & 944655.00 & 1093 & 1.500 & hole \\
11 & $08 / 05 / 89$ & 401417.81 & 944655.19 & 1093 & 1.450 & hole \\
12 & $07 / 02 / 88$ & 393917.00 & 942215.00 & 1642 & 3.300 & hole \\
13 & $08 / 05 / 89$ & 385137.00 & 941831.00 & 2862 & 3.000 & hole \\
14 & $07 / 31 / 89$ & 370820.00 & 973251.00 & 2849 & 3.000 & hole
\end{tabular}




\begin{tabular}{|c|c|c|c|c|c|c|}
\hline 15 & $07 / 31 / 89$ & 374856.00 & 952020.00 & 3158 & 3.000 & water \\
\hline 16 & $07 / 23 / 89$ & 360427.00 & 981012.00 & 3505 & 3.100 & hole \\
\hline 17 & $07 / 23 / 89$ & 351958.00 & 990945.00 & 4131 & 3.295 & water \\
\hline 18 & $08 / 28 / 87$ & 332158.69 & 1003032.63 & 3880 & 3.830 & hole \\
\hline 19 & $08 / 28 / 87$ & 325416.91 & 1014529.69 & 3380 & 2.920 & hole \\
\hline 20 & $09 / 20 / 87$ & 322059.31 & 1023947.38 & 4000 & 2.156 & water \\
\hline 21 & $09 / 10 / 87$ & 312754.31 & 1031836.19 & 2370 & 2.700 & water \\
\hline 22 & $09 / 24 / 87$ & 302406.59 & 1040714.13 & 470 & 3.160 & hole \\
\hline 23 & $09 / 12 / 86$ & 314312.00 & 1035024.00 & 350 & 1.000 & water \\
\hline 23 & $09 / 16 / 86$ & 314312.00 & 1035024.00 & 350 & 3.000 & water \\
\hline 24 & $09 / 20 / 86$ & 311200.00 & 1045812.00 & 350 & 3.000 & water \\
\hline 25 & $09 / 28 / 86$ & 300936.00 & 1055248.00 & 350 & 2.000 & water \\
\hline 26 & $10 / 09 / 86$ & 294312.00 & 1063300.00 & 350 & 1.500 & water \\
\hline 26 & $10 / 13 / 86$ & 294312.00 & 1063300.00 & 350 & 3.000 & water \\
\hline 27 & $10 / 17 / 86$ & 291948.00 & 1074312.00 & 350 & 1.000 & water \\
\hline 28 & $10 / 21 / 86$ & 285324.00 & 1082024.00 & 350 & 3.000 & water \\
\hline 29 & $11 / 01 / 86$ & 275700.00 & 1094048.00 & 350 & 1.000 & hole \\
\hline 30 & $11 / 03 / 86$ & 271858.59 & 1112456.63 & 200 & 2.000 & water \\
\hline 30 & $11 / 10 / 86$ & 271858.59 & 1112456.63 & 200 & 2.050 & water \\
\hline 31 & $11 / 10 / 86$ & 270652.09 & 1120619.88 & 150 & 0.994 & hole \\
\hline 32 & $11 / 12 / 86$ & 265606.19 & 1122852.25 & 92 & 0.948 & hole \\
\hline 33 & $11 / 16 / 86$ & 270420.00 & 1125826.00 & 110 & 1.000 & hole \\
\hline 34 & $11 / 20 / 86$ & 264535.31 & 1133235.00 & 120 & 1.500 & hole \\
\hline 35 & $11 / 20 / 86$ & 270043.41 & 1140020.63 & 160 & 1.010 & hole \\
\hline 36 & $11 / 27 / 86$ & 265818.19 & 1143804.88 & 94 & 1.000 & hole \\
\hline 37 & $12 / 02 / 86$ & 264610.91 & 1145636.63 & 70 & 1.000 & hole \\
\hline 38 & $12 / 02 / 86$ & 262233.00 & 1152007.38 & 155 & 1.542 & hole \\
\hline 39 & $12 / 06 / 86$ & 262323.09 & 1160025.63 & 200 & 1.542 & hole \\
\hline 40 & $12 / 12 / 86$ & 261345.41 & 1162118.00 & 280 & 1.000 & hole \\
\hline 41 & $12 / 12 / 86$ & 261634.41 & 1163815.25 & 335 & 1.000 & ole \\
\hline 42 & $12 / 17 / 86$ & 260352.70 & 1171934.63 & 255 & 1.000 & hole \\
\hline 43 & $12 / 17 / 86$ & 254623.30 & 1174259.38 & 670 & 1.000 & ole \\
\hline
\end{tabular}




$\begin{array}{rrrrrrr}44 & 12 / 26 / 86 & 252056.20 & 1181510.75 & 145 & 0.990 & \text { hole } \\ 45 & 12 / 29 / 86 & 250421.91 & 1182943.88 & 40 & 1.300 & \text { hole } \\ 46 & 12 / 30 / 86 & 245219.50 & 1185706.75 & -10 & 2.500 & \text { water }\end{array}$

\subsection{Recording and Equipment}

Analog seismographs were used during the experiments, two of which were 1-component and 3component seismometers. Before 1988, both kinds of seismometers were used in the experiments, so Lines 3 and 5 have measurements of both types. One-component equipment was not used in the experiments after 1987.

Table 2. Equipment list used in the seismic experiments

\begin{tabular}{|c|c|c|c|c|}
\cline { 3 - 5 } \multicolumn{2}{c|}{} & \multicolumn{3}{c|}{ Number of Sensors } \\
\hline Profile & Year & 1-component & 3-component & Total \\
\hline Linc 1 & 1988 & 0 & 168 & 168 \\
\hline Line 2 & 1989 & 0 & 168 & 168 \\
\hline Line 3 & 1987 & 60 & 168 & 228 \\
\hline Line 4 & 1986 & 0 & 60 & 60 \\
\hline Line 5 & 1986 & 70 & 130 & 130 \\
\hline
\end{tabular}

For each profile, a consistency test for the seismometers was conducted at the beginning of the experiments. The time service system was the BPM time signal.

\subsection{Design of the experimental layout}

The layout for the seismic survey was designed in accordance with the main goals and environmental conditions prior to experimentation. Usually, reversed observation systems were used in the experiments. The receiver stations were tightly spaced near the shotpoints to study the detailed structure of the shallow crust. The spacing was increased at large distances from the receivers to record the Pn phase from the uppermost mantle.

In order to study the velocity structure of the crust and the uppermost mantle in detail, the shotpoints were spaced as close together as possible. On Line 1, and for the profiles in southeastern China, the shotpoint spacing was generally less than $100 \mathrm{~km}$. On the Qinghai-Tibet Plateau, because of the poor transportation and drilling conditions, the shotpoint spacing was very large. The greatest shotpoint spacing in this area was more than $200 \mathrm{~km}$ (Fig. 2). 


\section{DATA EVALUATION}

With 51 shots, 48 record sections were obtained during the seismic experiments. Most of these sections display high quality P-wave and S-wave data from 3-component seismometers (Fig.3). In some cases, shear wave data was also acquired with the 1-component seismometers (Fig.4).

In the scismic wave field, the $\mathrm{Pg}, \mathrm{Sg}, \mathrm{PmP}$ and $\mathrm{SmS}$ phases have a strong amplitude and are easily identified. The refraction phase from the uppermost mantle, $\mathrm{Pn}$, can be identified because it is the first arrival at distances greater than $200 \mathrm{~km}$ in some sections along the transect. The Sn phase is more difficult to identify, as it is a secondary wave.

From the 3-component record sections, it can be found that shear wave phases are easier to identify in the horizontal components ( $\mathrm{L}$ - and $\mathrm{T}$ - components) than in the vertical component (Z-component).

\section{DATA PROCESSING AND INTERPRETATION}

The data from the seismic profiles along the Geoscience Transect were recorded on analog tapes. The analog seismic records (100 samples/s with a 60 second sampling length each) were digitized by A/D transformation on an IBM-compatible PC/386, so that the data included both P- and S-wave information. Digital processing of the data included clock drift corrections and frequency filtering before plotting the data in the form of reduced time-distance record sections. The record sections were plotted with a reduction velocity of $6.00 \mathrm{~km} / \mathrm{s}$ for P-waves and $3.46 \mathrm{~km} / \mathrm{s}$ for S-waves. In order to perform phase identification and correlation, the time scalc for S-waves used in plotting the record section is equal to that of the P-wave divided by 1.73 (J.P. Castagna, 1985, W.S. Holbrook ct al., 1988, R.A. Eesley, 1989).

Following the phase correlation and identification, an initial interpretation was made. First, a 1-D crustal and upper mantle velocity model was obtained by 1-D inversion methods (K. Fuchs and G. Muller, 1971). Then a 2-D crustal and upper mantle model was established with 2-D ray-tracing methods (P.Giese et al., 1976, V.Cerveny et al., 1977). The P-wave velocity structure for the crust and upper mantle along the GTTA is shown in Fig.5.

\section{CONCLUSION}

The seismic experiment along the Geoscience Transect from Taiwan to Altay is the longest transect in the world. It was a great success which provided excellent data for the in depth study of the structure of the crust and upper mantle under China.

From these seismic experiments, much information was gained about field work, data processing and interpretation and the crustal and upper mantle structure along the profile. Many detailed studies were completed using information gained from the field work. The P-wave velocity structure of the crust and upper 
mantle was also established for the Geoscience Transect, and will be published soon. During the experiments, high quality $\mathrm{P}$ - and S-wave data were acquired. It is this combination of $\mathrm{P}$ - and S-wave data which makes it possible to study the crustal and upper mantle structure in detail, especially in regards to the composition of these units (D. Gajewski et al., 1990, W.S. Holbrook et al., 1992). The study of the S-wave velocity structure will be continued further.

\section{ACKNOWLEDGEMENTS}

Wc would like to thank all those who took part in the seismic experiments along the Geoscience Transect from Taiwan to Altay. During its execution, some scientists, such as George A. Thompson from Stanford University, USA, C. Prodehl and F. Wenzel from Gcophysical Institute at Karlsruhe, Germany, provided advice on the data processing and interpretation. Also some academic exchanges were held with the Geophysical Institute at Karlsruhe and the US Geological Survey. 


\section{REFERENCES}

Compiling Group of SSB, 1988. Results on Geophysical Exploration of Crust and Upper Mantle in China. Seismological Press, Beijing.

D. Gajewski, R. Stangle, K. Fuchs and K.J. Sandmeier, 1990. A new constraint on the composition of the topmost continental mantle - anomalously different depth increases of P- an S-wave velocity. Geophys. J. Int., 103: 497-507.

Futian Liu, Kexin Qu, Hua Wu, Qiang Li, JianHua and Ge Hu, 1989. The Tomography of Chinese Continent and its adjiacent area. Acta Geophysiica Sinica, 32, 281-291.

Jiwen Teng, Wu H., A.W. Wang and X.L. Sun, 1992. The lithosphere structure and dynamics of south China and its continental margin (abstracts). 2, 29th IGC Kyoto Japan, 427.

Jiwen Teng, Futian Liu, Youli Quan, Jianhua Liu, Yike Liu, Jichun Wei, Lianxiang Ji and Zhanshou Yang, 1994. Seismic Tomography of The Crust an Mantle under The Orogenic Belts and Sedimentary Basins of Northwestcrn China. Advances in Sold Earth Geophysics in China, 66-80.

J.P. Castagna, 1985. Relationships between compressional wave and shear wave velocity in clastic silicate rocks. Geophysics, 50(4), 571-581.

P. Giese, C. Prodehl and A. Stein, 1976. Explosion Seismology in Central Eurape. Springer-Verlag, Berlin Heidelberg, New York.

R.A. Eesley, 1989. Analysis of compressional and shear-wave seismic data from the Prudhoe Bay Field. Leading Edge, No. 11, 10-13.

Rui Feng, Jieshou Zhu, Yunyu Ding, Guoying Chen, Zhengqin He, Shubin Xiang, Hainan Zhou and Kezhong Shun, 1980. Using surface wave to study the crust structure of China. Acta Seismologica Sinica, 3, 335-350.

Shennan Yang and Weiran Yang, 1981. Regional Tectonics of China. Geological publishing house.

V. Cerveny, I.A. Molotkov and I. Psencik, 1977. Ray Method in Seismology. Uni. Karlova, Praha, 214 pp.

W.S. Holbrook, D. Gajewski, A. Krammer and C. Prodehl, 1988. An interpretation of wide-angle compressional ans shear wave data in Southwest Germany: Poisson's Ratio and petrological implication. J. Geophy. Res., 33: 12,081-12,106.

W.S. Holbrook, W.D. Mooney and N.I. Christensen, 1992. The Seismic velocity structure of the deep continental crust. In: D.M. Fountain, R. Arculus and R.W. Kay (Editors), Continental Lower Crust, Elsevier. Developments in Geotectonics 23, 1-43.

Xinzhong Xu and Youxue Wang, 1991. The Velocity Characteristics of Geoscience Transect from Keketuohai to Aksai. Report No. 2 of The IGCP PROJCT 283: Geodynamic Evolution and Main Sutures of Paleoasian Ocean, Beijing, 126.

Xuccheng Yuan,1992. Mid-Asia Geoscience Transect. Abstracts of 29th International Geological Congress, Vol. 2 of 3,478 . 
Youxue Wang, 1992. Discussion on Division Problem of Tectonic Units in Xinjiang Area from Seismic

Refraction Survey Results. Abstracts of 29th International Geological Congress, Vol. 2 of 3, 463. 


\section{FIGURE CAPTIONS}

Fig. 1 The regional tectonic map of China and the location of the geoscience transect from Taiwan to Altay (after Shennan Yang et al.,1985)

Fig. 2 Layouts used in the experiments along the transect

Fig. 3 Typical 3-component seismic record sections (upper is the vertical, middle and lower both are horizontal, the sections were recorded from shotpoint 7 in Line 1)

Fig. 4 Typical 1-component seismic record section (recorded from shotpoint 38 in Line 5)

Fig. 5 The crustal P-wave velocity structure along the geoscience transect from Taiwan to Altay (upper is the northwest part and lower is the southeast part) 


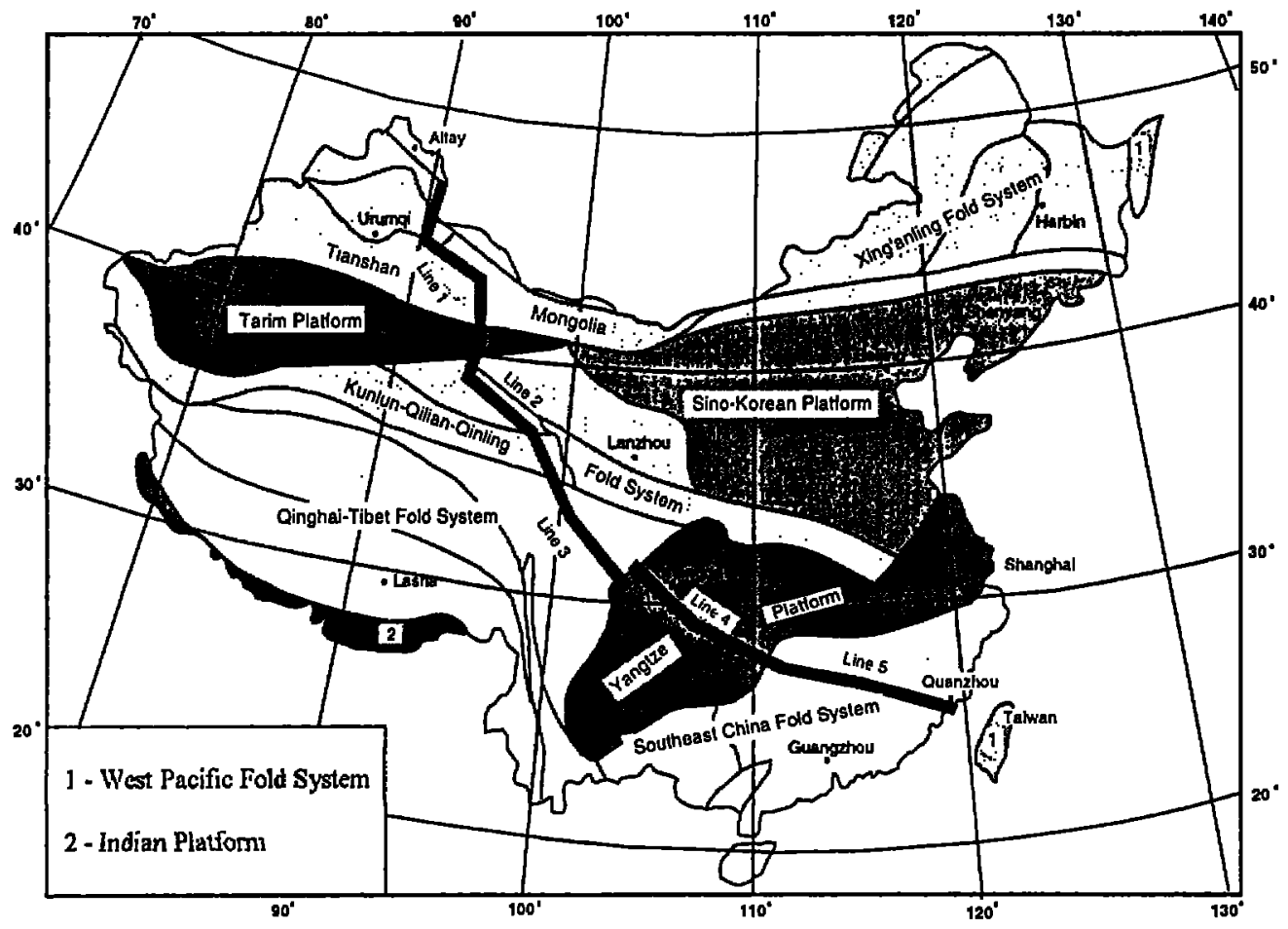

Fig. I 

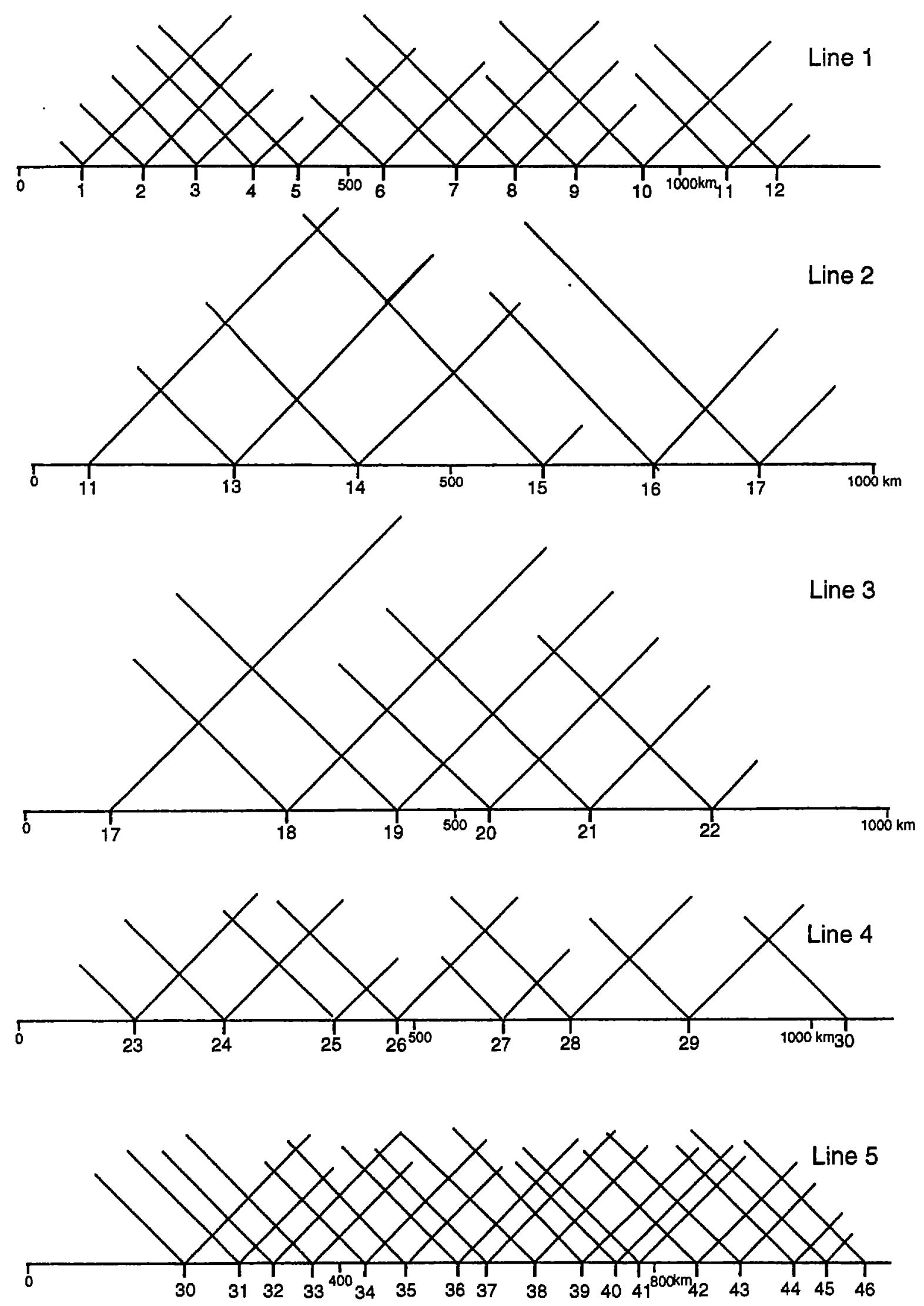

Fig. 2 

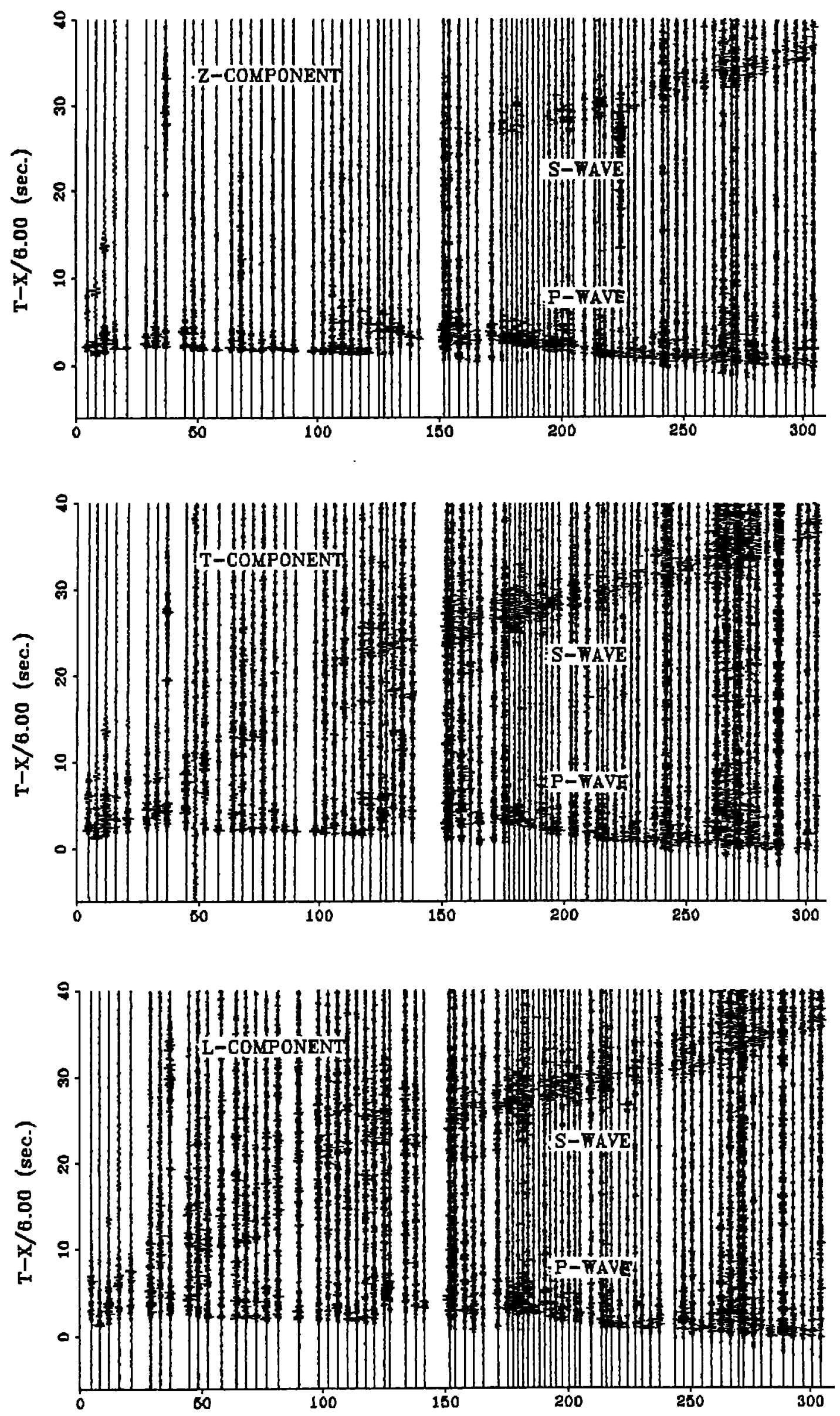


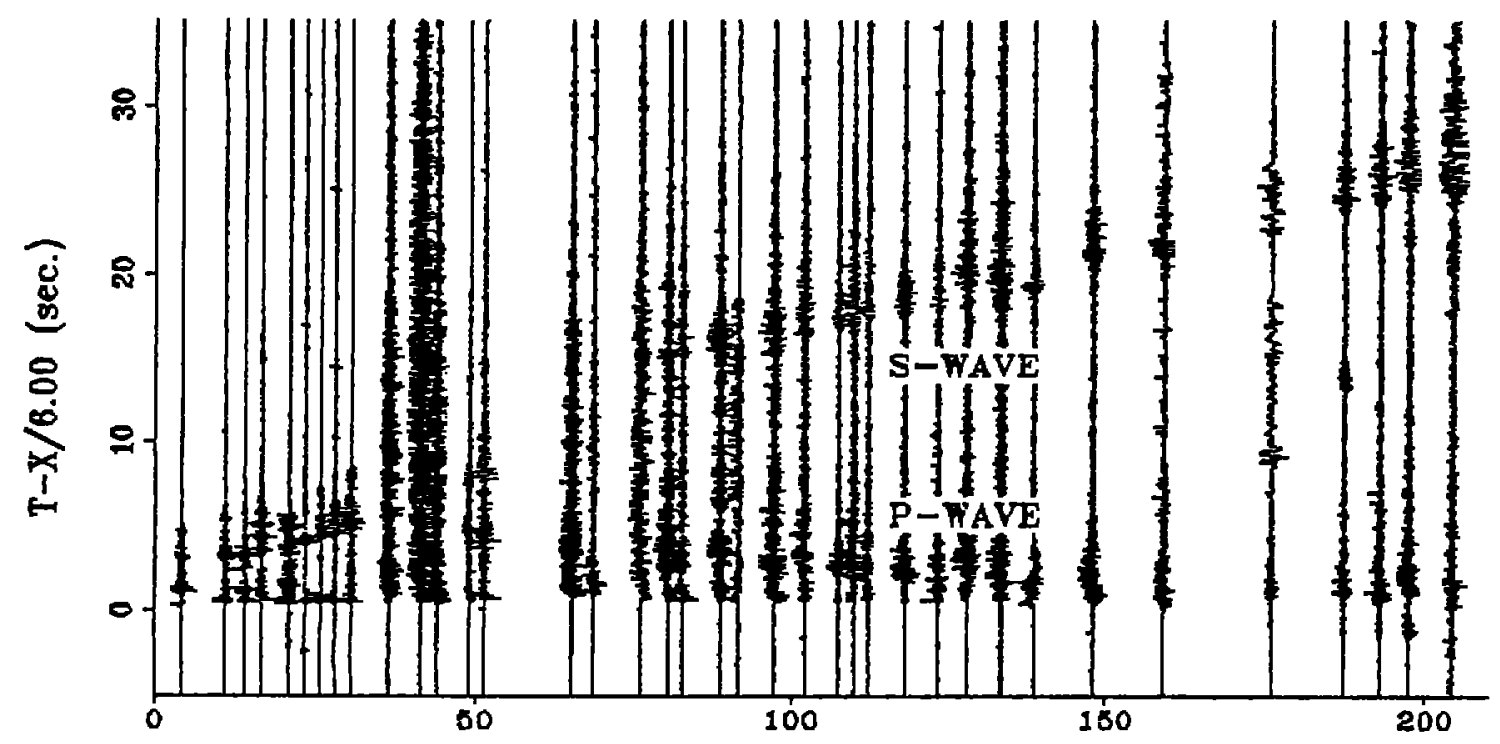

Fig. 4 

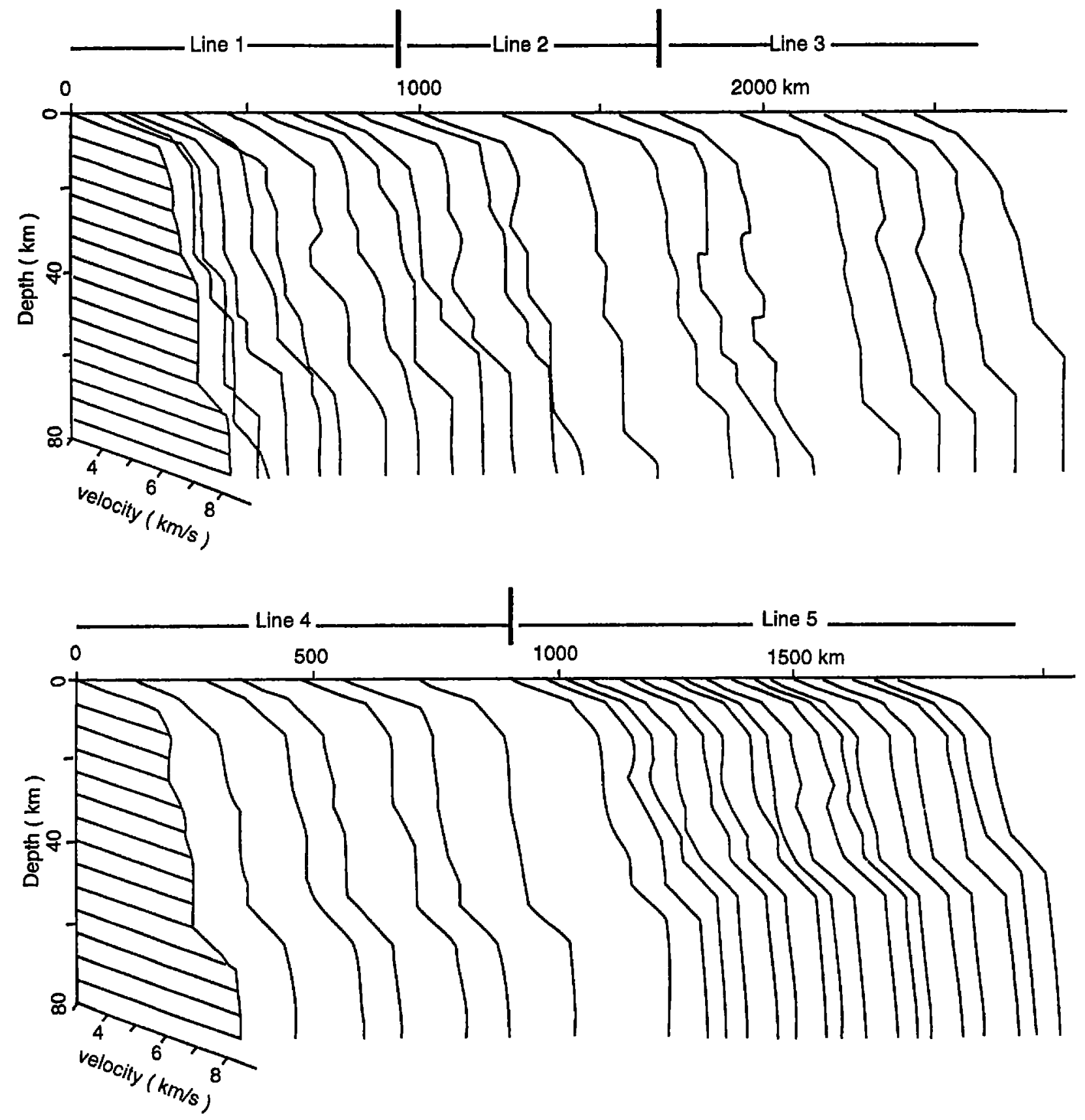

Fig. 5 


\title{
A crustal model of the ultrahigh-pressure Dabie Shan orogenic belt, China, derived from deep seismic refraction profiling
}

\author{
Chun-Yong Wang and Rong-Sheng Zeng \\ U.S. Gcological Survey, Menlo Park, California \\ Institute of Geophysies, China Scismological Bureau, Beijing \\ W. D. Mooney \\ U.S. Gcological Survey, Menlo Park, California \\ B. R. Hacker
Gcological Sciences, University of California, Santa Barbara
}

\begin{abstract}
We present a now crustal cross section through the enst-west trending ultrahigh-pressure (UHP) Dabie Shan orogenic belt, enst central China, based on a 400km-long seismic refraction profilc. Data from our profilc reveal that the cratonal blocks north and south of the orogen are composed of 35-km-thick crust consisting of three layers (upper, middle, and lower crust) with avcrage scismic velocitics of $6.0 \pm 0.2 \mathrm{~km} / \mathrm{s}$, $6.5 \pm 0.1 \mathrm{~km} / \mathrm{s}$, and $6.8 \pm 0.1 \mathrm{~km} / \mathrm{s}$. The crust reaches a maximun thickness of $41.5 \mathrm{~km}$ beneath the northern margin of the orogen, and thus the present-day root bencath the orogen is only $6.5 \mathrm{~km}$ thick. The upper mantle velocity is $8.0 \pm 0.1 \mathrm{~km} / \mathrm{s}$. Modeling of shear wave data indicate that Poisson's ratio increases from $0.24 \pm 0.02$ in the upper crust to $0.27 \pm 0.03$ in the lower crust. This result is consistent with a doninantly felsic upper crustal composition and a mafic lower crustal composition within the amphibolite or granulite metamorphic facies. Our scismic model indicates that eclogitc, which is abundant in surface exposures within the orogen, is not a volumetrically significant component in the middlc or lower crust. Much of the Triassic structure associated with the formation of the UHP rocks of the Dabic Shan has been obscurcd by post-Triassic igneous activity, cxtcnsion and large-offset strike-slip faulting. Nevertheless, we can identify a high-vclocity $(6.3 \mathrm{~km} / \mathrm{s})$ zone in the upper ( $<5 \mathrm{~km}$ depth) crustal core of the orogen which we interpret as a zonc of ultrahigh-pressure rocks, a north dipping suturc, and an apparent Moho offsct that marks a likely active strikc-slip fault.
\end{abstract}

\section{Introduction}

The Qinling-Dabie Shan orogenic belt was created by the Triassic subduction of the northern edge of the Yangtze craton and subscquent collision with the Sino-Korean craton (Figure 1). Widespread ultrahigh-pressure (UHP) coesitc-bearing ccologite facies rocks in the custern Dabic Shan indicate that during this collision, crustal rocks were subducted to depths $>120 \mathrm{~km}$ and then exhumed [Hacker et al., 1995a]. This Mcsozoic orogen, however, is characterized by neither the prominent lopography nor thick crust [Zeng et al., 1995; li and Mooney, 1998] that is expected in collisional orogens involving subduction of continental crust. To determine the deep crustal structure of the Dabic Shan, a 400-km-long deep seismic refraction profile was recorded in 1994. In this paper we present a two-dinensional (2-D) model of the crustal structure across the Dabic Shan and relate this structure to the processes that created and later modificd the orogen. This model supersedes that of Dong $\mathrm{cl}$ al. [1996], who presented a preliminaty model based on only a portion of the scismic refraction available data.

Copyright 2000 by the American Geophysical Union.

Puper number $1999 \mathrm{JB} 900415$.

()1 48-0227/00/1999JB900415\$09.00

\section{Regional Geologic Setting}

The Oinling-Dabie Shan orogenic belt extends WNW-ESK for more than $2000 \mathrm{~km}$ and contains abundant high-pressure metamorphic rocks including abundant coesitc-bearing eclogitc and blueschist facies rocks [Liou et al., 1989)]. UHP rocks crop out in the threc easternmost ranges of the Qinling-Dabic orogen, in the Hong'an, Dabie, and Su-I,u arcas (Figure 1). These rocks are believed to have been formed by north direcled subduction of the Yanglec craton or of a microcontinent bencath the Sino-Korcan craton. Structural [Hacker et al., 1995a], metamorplic [Lion of al., 1995], and geochronologic [Hacker and Wang, 1995; Hacker et al., 1998] data from the Dabie Shan have becn interpreted to indicatc that exhumation of UHP rocks occurred in two stages. In the Triassic-Jurassic, large-scalc normal faults brought the UHP rocks from cclugite facies to amphibolito facies depths [Hacker et al., 1998]. From 133 to $122 \mathrm{Ma}$, northwest-southeast cxlension coincident with voluminous nagmatism brought the UIHP rocks to within 10-15 km of the surface [Hacker et al., 1995a, 1998].

In the Dabic Shan area, there are threc cast-southeast trending belts separated by faults (Figure 2). (1) The Foziling Group consists of flysch that has been overlain by Cretaccous volcanic rocks. (2) The Dabic Shan contains a prograde highto ultrahigh-pressure metamorphic sequence in its southern 


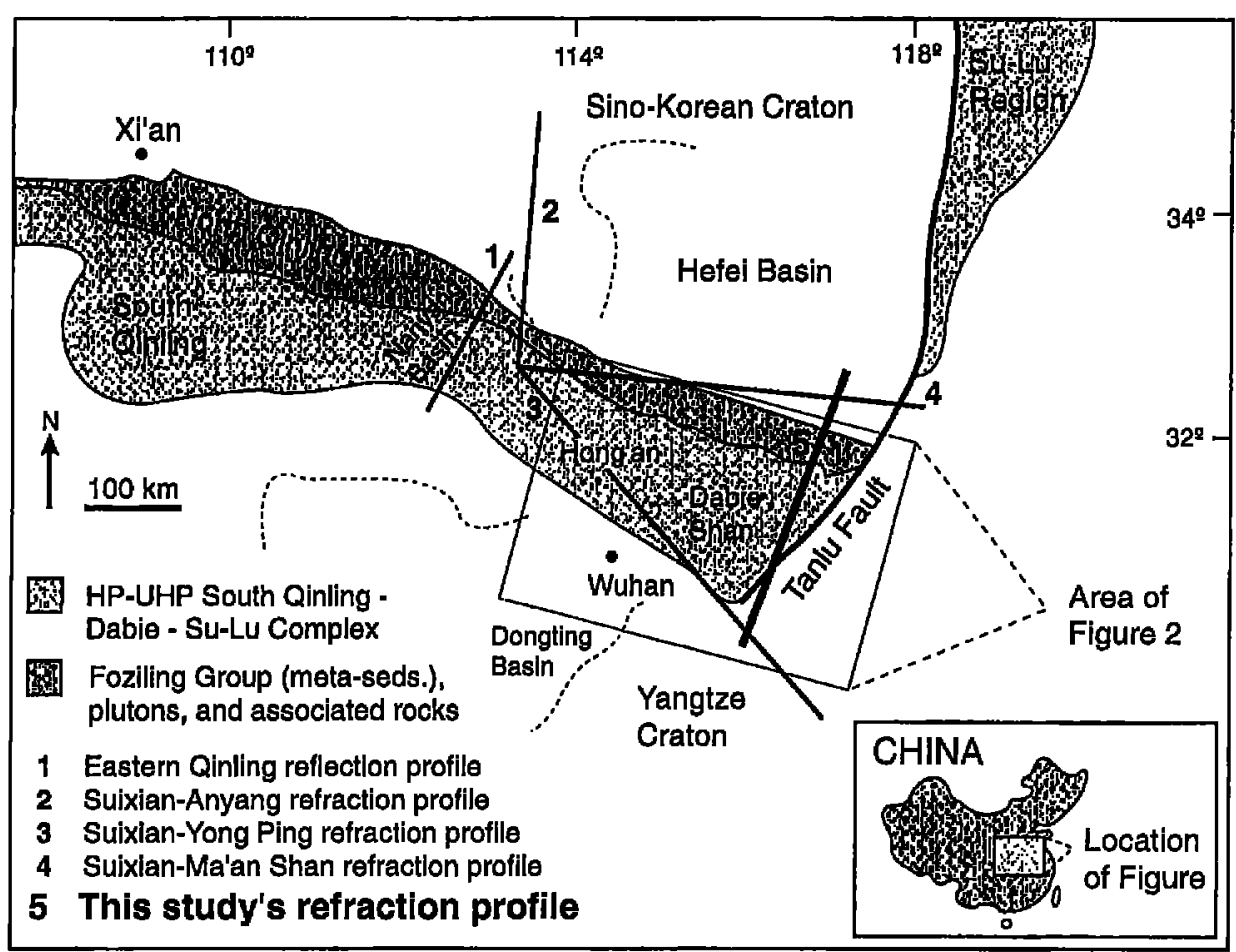

Figure 1. Gcologic map of the Qinling-Dabic Shan orogenic belt in the central castern China. The region is exceptional for the widespread occurrence of ultrahigh-pressure rocks, including coesite-bearing cclogite and rare diamonds. The Su-Lu region is displaced to the northeast of Dabic Shan by the Tan-Lu fault. Previously published scismic reflection and refraction profiles are indicated (citations in text).

half and Cretaceous plutons and orthogneiss in its northern half [Hacker at al, 1995n]. (3) The Foreland fold belt comprises a thick series of late Proterozoic felsic volcanic rocks and line-grained sedimentary rocks overlain by Late Proterozoic to Middle Triassic sandstone, limestonc, and shalc. South of the Foreland fold belt, there arc cast-west trending folds with scveral kilometer long wavelengths that continue across the southward projection of the Tan-Lu fault.

The Dabic Slian complex and the Foziling Group are abruptly truncated to the east by the Tan-Lu fault (Figures 1 and 2). This apparently sinistral fault may have formed in the Triassic during the continental collision between the SinoKurcan and Yanglze cratons [e.g., Yin and Nie, 1993], and dextral displacement is thought to have continued through the Jurassic and Furly Cretaccous [Xu et al., 1987; Chen et al,, 1988]. Today this fault is expressed as a post-Late Cretaccous normal fault between the Dabic Shan complex and the Foreland fold belt.

\section{Previous Geophysical Results}

Although this study is the first seismic profile across the Dabie Shan itsclf, there are several nearby seismic reflection and refraction profiles (Figure 1). The Eastern Qinling reflection profilc [Yuan et al., 1994] is $\sim 300 \mathrm{~km}$ west of the Dabic Shan. This profile images the Qinling orogen that separates the Sino-Korcan and Yangtze cratons. According to Yuan et al. [1994] the reflection data provide evidence that late in the collision process the lower crust of the Qinling orogen was subducted southward beneath the Yangtze craton, whereas the upper crust, was overthrust on a large scalc to the soutll.

Threc seismic refraction profiles are located west, south, and nortl of the orogen (Figure 1). These are the Suixian- $A$ nyang profile [Hu et al., 1986], the Suixian-Yongping profile [Group of Industrial Lxplosion Observation, 1988] for which a geoscicnce transcct was compiled [Wang et al., 1995], and the SuixianMa'an Shan profilc [Zheng and Teng, 1989]. All threc profiles recorded inclustrial explosions near the cily of Suixian. South of the Dabie Shan, the crustal thickness is $34 \mathrm{~km}$, and the average crustal velocity is $6.35 \mathrm{~km} / \mathrm{s}$ [Group of Industrial I $\mathrm{i}$ plosion Observation, 1988]. North of the Dabie Shan, the Hefei basin has a $32-\mathrm{km}-[$ (]ick crust with an average yclocily of 6.25 $\mathrm{km} / \mathrm{s}$ [Zheng and Teng, 1989]. The Suixian-Anyang profile passes through the southern portion of the Sino-Korean cra-

Table 1. Locations of Shot Points

\begin{tabular}{llcr}
\hline Shot Point & \multicolumn{1}{c}{ Nannc } & Latitude N & Longitude 'ं \\
\hline ZhM & Zhuangmu & $32^{\circ} 23.6^{\prime}$ & $117^{\circ} 07.7^{\prime}$ \\
Gu't' & Guantin & $31^{\circ} 50.1^{\prime}$ & $116^{\circ} 52.3^{\prime}$ \\
Bu'T & Butasi & $31^{\circ} 28.9^{\prime}$ & $116^{\circ} 44.5^{\prime}$ \\
ZhZ & Zhuangzhong & $30^{\circ} 43.3^{\prime}$ & $116^{\circ} 17.2^{\prime}$ \\
JnG & Jinggung & $30^{\circ} 46.6^{\prime}$ & $116^{\circ} 52.3^{\prime}$ \\
ErL & Erlanghe & $30^{\circ} 15.3^{\prime}$ & $116^{\circ} 03.1^{\prime}$ \\
CaS & Caishan & $29^{\circ} 51.6^{\prime}$ & $115^{\circ} 48.9^{\prime}$ \\
ZhG & Zhuanggongdu & $29^{\circ} 09.1^{\prime}$ & $115^{\circ} 39.1^{\prime}$ \\
\hline
\end{tabular}




\section{Explanation}

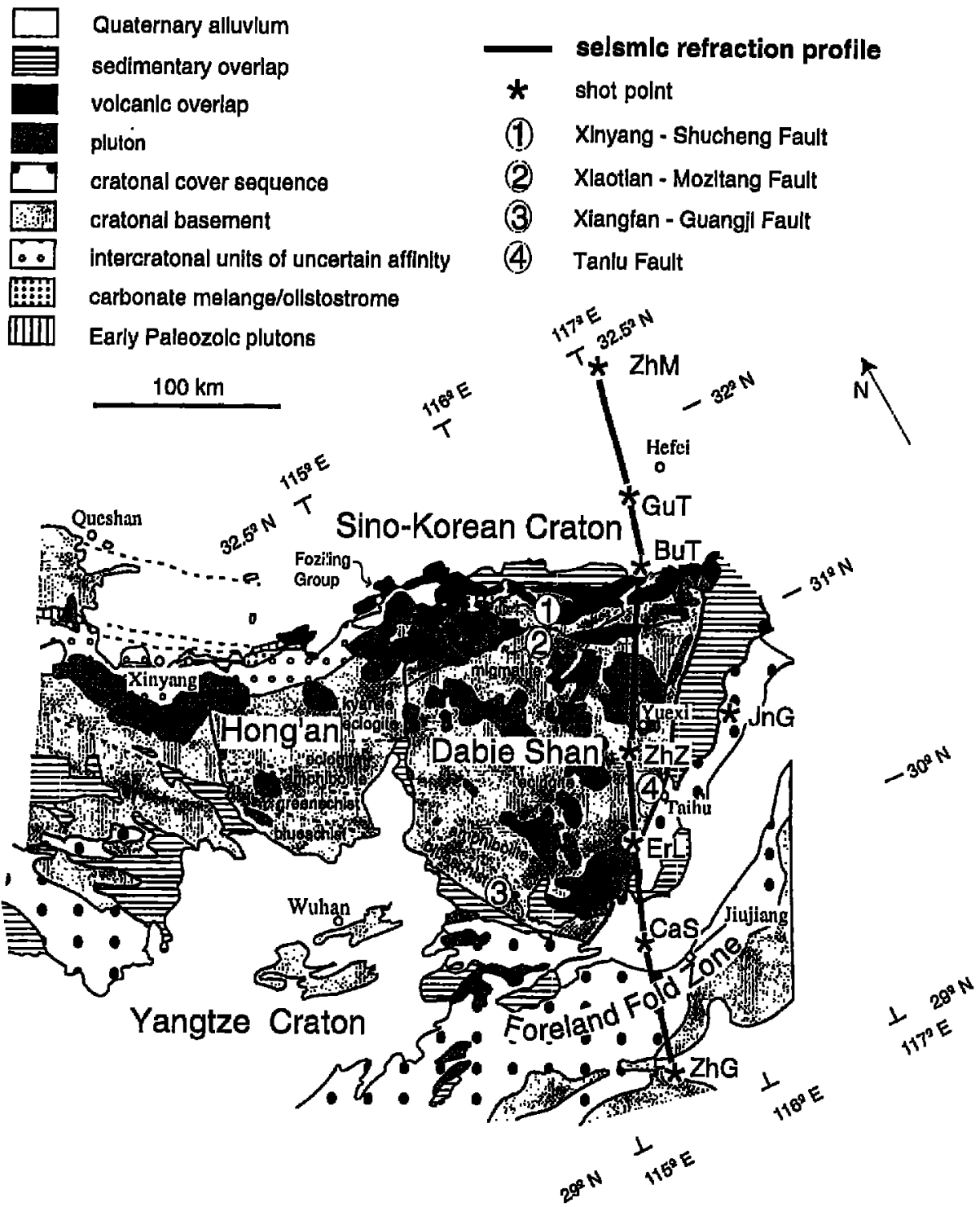

Figure 2. Geologic setting of the Dabic Shan and location of the sejsmic refraction profile [after Hacker ef al. [1995b]. Shot points are ZhM (Zhuangmu), GuT (Guantin), BuT (Butasi), ZliZ (Zhuangzhong), JnG (Jinggong), ErL (Erlanghe), CaS (Caishan), and ZhG (Zhanggongdu).

ton, which has a 34-km-thick crust with an average velocity of $6.30 \mathrm{~km} / \mathrm{s}$ [Hu et al., 1986].

The Bouguer gravity data in the study area delineate an ellipsoidal negative anomaly with a $-50 \mathrm{mGal}$ average and $-75 \mathrm{mGal}$ low centered on the Dabie Shan (i.e., $50 \mathrm{kn}$ west of shot point ZhZ, Figure 1) [Qiu and Guo, 1989]. The negative anomaly correlates with higher topography $(\sim 1200 \mathrm{~m})$ and a small $(6.5 \mathrm{~km})$ crustal root, as described below. The gravily data have not been modeled in this study.

\section{Layout of the Profile}

Our scismic refraction profile trends $\mathrm{N} 25^{\circ} \mathrm{E}$ and begins in the north within the Hefei basin of the Sino-Korean craton, passes through the Dabie Shan, and cnds in the Yangtze craton. The profile crosses four significant strike-slip faults from north to south: the Xinyang-Shucheng, Xiaotian-Mozitang, Xiangfan-Guangji, and Tan-Lu faults (Figure 2).

Eight shots (Table 1) were recorded by a total of 150 analog recorders. Seismic encrgy was generated by borchole explosions, with the exception of the shot at ZhZ (Figure 2), which was an underwater explosion. Sholpoints were spaced $\sim 50 \mathrm{~km}$ apart, with the exception of shol points BuT and Zh' 2 which were $\sim 90 \mathrm{~km}$ apart. The explosive charge of each shot varied from 1000 to $2000 \mathrm{~kg}$, based on the site conditions and the maximum shot-recorder distance. Seismic recorders were spaced 3-4 km outside the orogen and were $1 \mathrm{~km}$ apart within the orogen to obtain higher resolution. Most recorders were 
three-component scismographs with 1-Hz geophones. The analog records werc digitized with a $10-\mathrm{ms}$ sampling interval.

\section{Data Interpretation}

\subsection{General Analysis of Seismic Phases}

A complete set of all record sections are presented herc. Details of the indiviclual sections will be discussed below. Methods of interpretation of seismic refraction data and model uncertaintics arc discussed by Mooney [1989], who estimates that seismic velocities are accuratc to better than $3 \%$ and boundaty deptlss (e.g., Moho) are accurate to betler than $10 \%$ of the calculated depth. The phases $P g$ and $P n$ arc recognizable as the first arrivals on all record sections. $P g$, the refracted wave propagating within the upper crust, is observed at distances of $<100 \mathrm{~km} . P^{n} n$, the refraction within the uppermost mantlc, is a first arrival at distances beyond $160 \mathrm{~km}$.

Besides the $P g$ and $P n$ phases, four other phases can be recognized as secondary arrivals with highly variable clarily. The most prominent secondary phase, $P m P$, is a wide-angle reflection from the crust-mantle boundary. This phase is visible for all shots. Additional wide-angle reflections, labeled $P_{1}, P_{2}$, and $P_{3}$, arc variably observed from intracrustal interfaces. These reflections are gencrally weakcr than $P m P$. One reason for this may be seismic scattering caused by finc-scale structure [Levander et al, 1994]. While it is generally accepted that the crust is grossly layered and that velocity generally increases with depth [Meissner, 1986; Mooney and Brocher, 1987; Christensen and Mooney, 1995], finc-scale struclure can also effect the seismic response of the crust. Numcrical modeling demonstrated that such fine-scale structure can be inisinterpreled to indicate crustal layering [Mereu and Ojo, 198]; Ojo and Meren, 1986; I.evander and Holliger, 1992; Levander et al., 1994]. Our interpretation is based on the assumption that the phases $P_{1}, P_{2}$, and $P_{3}$ are ray geometric (i.c., specular) reflections. However, we acknowledge that fine-scale structure probably is also significant. It is unlikely, based on the evidence from global seismic reflection profiles, that the crust contains continuous, smooth specular reflectors at the scale of this study [Levander and Holliger, 1992]. Thus our model is an internally consistent (i.e., satisfying obscrvations from multiple sources and receivers), layered approximalion to a hetcrogeneous crust. Only significantly more dense seismic data will reveal how close this model is to the fine-scalc structure.

\subsection{Shot Point ZhM (Zhuangmu)}

Shot point $\mathrm{ZhM}$ (Figure 3) is located in the Ilefei basin of the Sino-Korean craton. $\mathrm{Pg}$ has an apparent velocity of 6.15$6.25 \mathrm{~km} / \mathrm{s}$ al clistances from 40 to $75 \mathrm{~km} . P_{1}$ is a reflection with an apparent velocity of $6.2 \mathrm{~km} / \mathrm{s}$ between 55 and $90 \mathrm{~km}$. Rellection $P_{2}$ is observed between 100 and $140 \mathrm{~km}$ with an apparent velocity of $6.2-6.3 \mathrm{~km} / \mathrm{s}$. However, the precritical reflection for the phase $P_{2}$ is not clear at distances of $<100 \mathrm{~km}$, perhaps due to crustal scattering, as mentioned above. $P m P$ is a very clear, high-amplitude phase from 70 to $270 \mathrm{~km}$. The $P m P$ waveform near the critical angle is remarkably simple, with an abrupt onset that we have modeled using synthetic scismograms with a first-order transition and a significant $(\sim 1.0 \mathrm{~km} / \mathrm{s})$ jump in vclocity. Such crisp $P m P$ waveforms arc common in regions that have experienced crustal extension, such as much of western Europe and the Basin and Range [Catchings and Mooney, 1991; Jarchow et al., 1993]. The average crustal velocity, calculated from $P m P$ travel times between
70 and $200 \mathrm{~km}$ on the section $\mathrm{ZhM}$, is $6.25 \mathrm{~km} / \mathrm{s}$. A strong sccondary phase with a low apparent velocity of $\sim 6.1 \mathrm{~km} / \mathrm{s}$ that appears to be a continuation of $P_{m} P$ is observed from 200 lo $270 \mathrm{~km}$ following $P_{n}$. This phase $\left(P_{x}\right)$ cannot simply be the asympotic wide-angle $P m P$ rellection becausc, in this case, the apparent velocity would bo equal to the velocity of the lower crust $(6.6-6.9 \mathrm{~km} / \mathrm{s}$ in this region). The travel time and amplitude of this phase are similar' to a prominent phase observed on the Suixian-Ma'an Shan profile [Zheng and Teng, 1989] arc several possible interpretations of it. Zheng and Teng [1989] considered it to be a diffracted wave from the Moho. However, we are able to obtain an excellent travel time fit to the phase $P_{x}$ with a reflection from the boltom of a modest low-velocity zone at a depth of $17 \mathrm{~km}$. This interpretation is csscntially the same as that of Ye et al. [1995], who obscrved a similar promincnt phase in data from the Swiss Alps. $\Gamma^{\prime} n$ is a clear first arrival beyond the distance of $160 \mathrm{~km}$ and has an apparent velocity of about $8.0 \mathrm{~km} / \mathrm{s}$.

\subsection{Shot Point Gu'T (Guantin)}

Shotpoint GuT (Figure 3) is also in the Hefci basin, $\sim 66 \mathrm{~km}$ south of shot point ZhM. In record section GuT-north the apparent velocity of $P g$ is about $6.15 \mathrm{~km} / \mathrm{s}$, in agreement with the reversing data from shot point $\mathrm{ZhM}$. On section GuTsouth the apparent velocity of the $P y$ phase is $6.2 \mathrm{~km} / \mathrm{s}$. Phasc $P_{1}$ has an apparent velocity of $6.25 \mathrm{~km} / \mathrm{s}$ between 70 and 110 km. $P_{2}$ is a clear reflection at distance between 120 and 160 $\mathrm{km}$, but is very weak at pre-critical distances. P $m P$ is the highest amplitudc arrival at distance between 80 and $140 \mathrm{~km}$, but it is not clear beyond $140 \mathrm{~km}$. $P_{n}$, with an apparent velocity of $8.1 \mathrm{~km} / \mathrm{s}$, is observed as a clour first arrival beyond $170 \mathrm{kn}$.

\subsection{Shot Point BuT (Butasi)}

Shot point BuT (Figure 4) is located in the Foziling schist, $\sim 10 \mathrm{~km}$ north of the active strikc-slip Xinyang-Shucheng fault, and $\sim 40 \mathrm{~km}$ north of the Cretaccous left-lateral, normal Xiaotian-Mozitang fault. On section BuT-north the apparent velocity of $P g$ is $6.0 \mathrm{~km} / \mathrm{s}, 0.2 \mathrm{~km} / \mathrm{s}$ less than the reversed observation (scction GuT-south). A decpening of the basement to the north is likely to cause this difference. The phase $P_{1}$ can be traced between 30 and $70 \mathrm{~km}$. The phases $P_{2}$ and $P_{3}$ cannot be recognized on the north section duc to the sparse station spacing. $P m P$ is clearly obscrved at distances of $70-110 \mathrm{~km}$.

On record section BuT-south, $P g$ arrival times are about $0.5 \mathrm{~s}$ earlier than on the section to the north. This confirms a northward dipping basement. In addition to $P_{1}$, there are two intracrustal reflection phases $\left(P_{2}\right.$ and $\left.P_{3}\right)$ that arc variably visible on the section. Phase $P m P$ is once again very clear and is doninant at distances between 90 and $160 \mathrm{~km} . P m P$ travel times al distances of 90-140 km on record section BuT'-south ate $\sim 1.0$ s later than the travel time on scction BuT-north. This indicates that the Moho deepens to the south of BuT. The $P m P$ travel times for BuT-south are also about $1.0 \mathrm{~s}$ later than for GuT-south (Figure 3), also indicating that the Moho decpens soulh of shot point Bu'T.

\subsection{Shot Point ZhZ (Zhuangzhong)}

Shot point $\mathrm{ZhZ}$ (Figure 4) is located within the cocsitebearing cclogite unit, with the receivers to the south passing through the UHP zonc. The Cretaccous symmagmatic normal fault that dropped the coesite-eclogite unit down relative to the northern orthogneiss in the footwall is cxposed a fow kilometers north of the shot point. Unlike the other shots, the explo- 

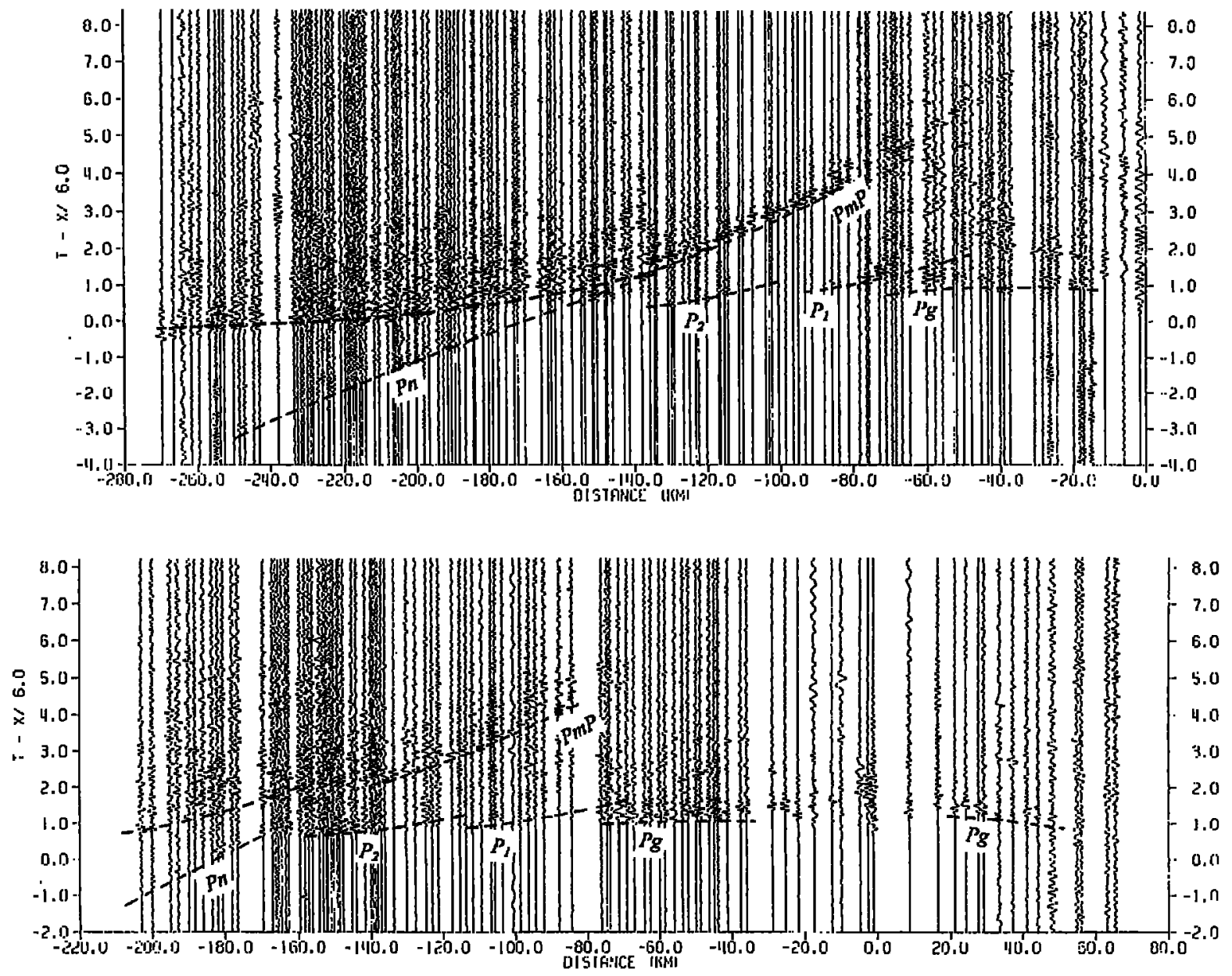

Figure 3. (top) Trace-normalized low-pass filter $(10 \mathrm{~Hz})$ record section of shot point ZhM. For this and all other record section the travel time curves are theoretical curves calculated from the final velocily model. Shot point locations are shown in Figure 2 . The dominant phases on the section are (1) $P, n P$ (rellection from Moho), which has a very simple waveform near the critical distance $(\sim 120 \mathrm{~km})$, and (2) $P_{x}$, which has a low $(6.1 \mathrm{~km} / \mathrm{s})$ apparent velocity and is interpreted as a wide-angle reflection from the bottom of midcrustal jow-velocity zone (see text for additional discussion). The phase refracted just below the Moho $(P n)$ is clearly recorded as a first arrival. The corresponding shear wave phase $S n$ was nol observed. (bottom) Record scction of shot point GuT. The dominant phase $P m P$ stops at about $145 \mathrm{~km}$. The intracrustal phases $P_{1}$ and $P_{2}$ arc weakly recorded at precritical distances (less than $\sim 80 \mathrm{~km}$ ), possibly due to scattering in the crust.

sion was detonated under water, and reverberalions with higher-frequency content are observed on the records.

On record section $\mathrm{ZhZ}$-liorth, $\mathrm{Pg}$ has an apparent velocity of $6.0 \mathrm{~km} / \mathrm{s}$. The upper crustal reflection $P_{1}$ is weaker than that in the section to the south. Phase $P_{2}$ can be traced from 50 to $120 \mathrm{~km} . P_{3}$ is not at all clcar. $P m P$ is the strongest phase on the section beyond $80 \mathrm{~km}$.

On record section ZliZ-south, $P g$ has an apparent vclocity of $5.95 \mathrm{~km} / \mathrm{s}$. A distinct phase $P_{1}$ with larger amplitude than that of the $P g$ phase can be traced from 20 to $70 \mathrm{~km}$. This phase is also strong on the section JnG-south (sec below). The phases $P_{2}$ and $P_{3}$ are not clearly observed. The shot pointrecorder distances are too short to record either $P m P$ or $P n$.

\subsection{Shot Point JnG (Jinggong)}

Shot point JnG (Figure 5) is located on the Yangtze craton, cast of the Tan-Lu fault. It is offsct $\sim 50 \mathrm{~km}$ east of the main line. Because the main line is not perfectly straight, the records beyond $70 \mathrm{~km}$ can be approximated as in-line obscrvations (Figure 2). The travel time of the phase $P m P$ for propagation to the north is similar to ZhZ-north. The phase $P m P$ is also clearly observed on section $\mathrm{Jn}_{12}$-south, and this observation is important in vicw of the lack of $P m P$ from section ZliZ-soutl.

\subsection{Slot Point ErL (Erlanghe)}

Shot point ErL (Figure 5) is located in the southern half of the high-pressure metamorphic belt, just west of the Tan-Lu fault. The apparent velocity of $P g$ is $5.95 \mathrm{~km} / \mathrm{s}$, in agreement with section ZhZ-south. Although the phase $P_{1}$ behind $P g$ can be traced to $120 \mathrm{~km}$, its energy is weaker than the $P_{1}$ on section ZhZ-south. Similar to scction BuT-south, phasc $P_{2}$ is strongest at distances of $120-150 \mathrm{~km} . P m P$ is dominant beyond $80 \mathrm{~km}$ and consists of a simple waveform with an abrupt onset. The arrival time at $100 \mathrm{~km}$ is $0.5 \mathrm{~s}$ carlicr than on sections $7 \mathrm{hZZ}$ - 

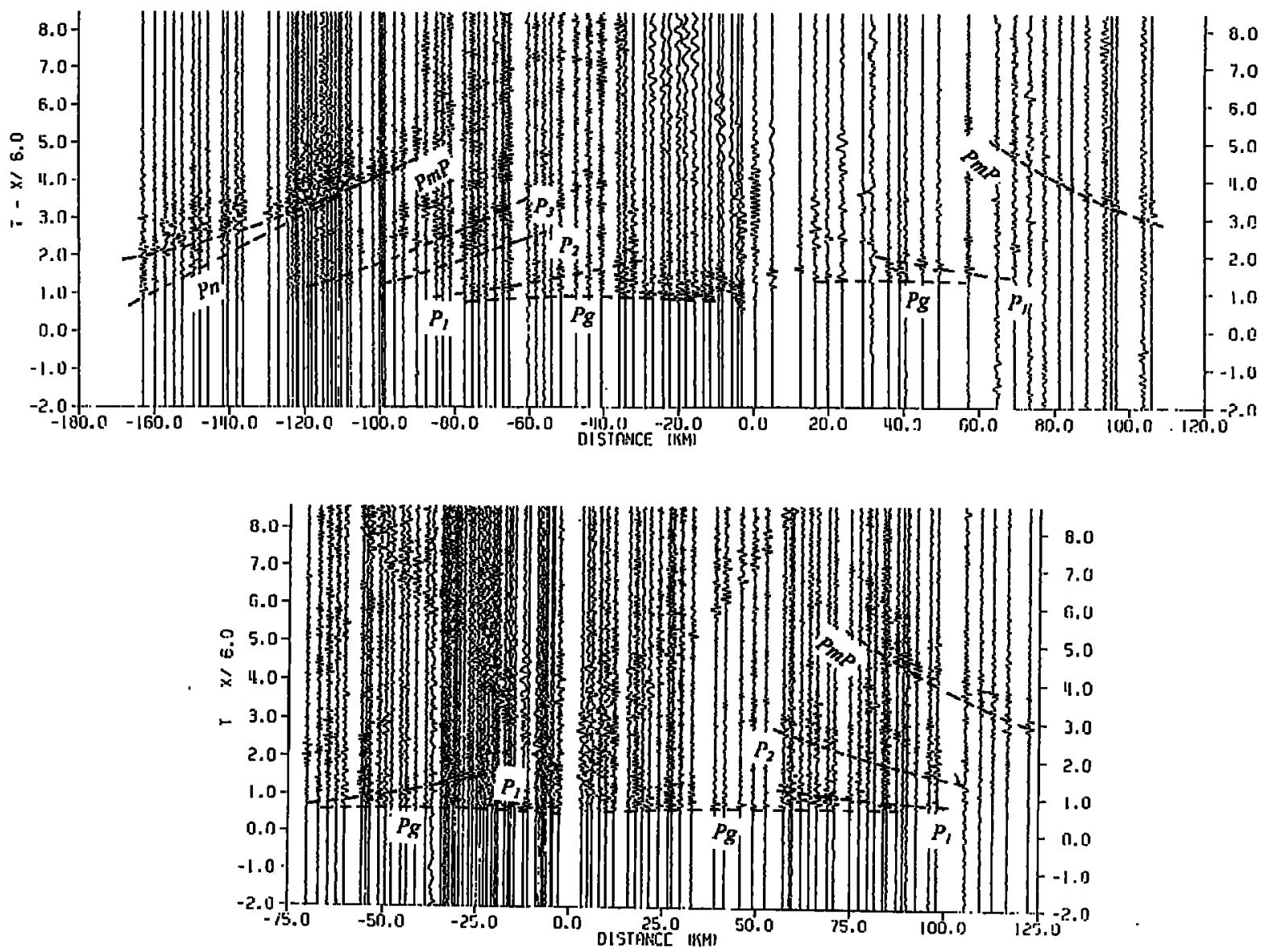

Figure 4. (top) Trace-normalized low-pass filter $(10 \mathrm{~Hz})$ record section of shot point Bu'T'. 'The Moho reflection, $P m P$, is a strong phase in the data recorded to the south. Two intracrustal reflection phases, $P_{2}$ and $P_{3}$, are cvident with variable amplitude before the phase $P m P$. Station spacing averaged $4 \mathrm{~km}$ to the north of the shot point. (bottom) Record section of shot point ZhZ. A distinct reflection phase $\left(P_{1}\right)$ is cvident 0.3 to $0.7 \mathrm{~s}$ behind the $P g$ phase on the record section to the south. The Moho reflection, $P m P$, is clearly recorded to the north, and there is abundant seismic energy following the first arrival, $P g$, and before $P m P$. We identify three intracrustal reflected phases, $P_{1}, P_{2}$, and $P_{3}$, but scattering may also contribute to this seismic energy.

north and BuT-south. $P n$ is weakcr than on sections of $\mathrm{ZhM}$ and GuT-south. Except for $P g$ and $P m P$, all of the pliases on the section are weaker than on the section BuT-south.

\subsection{Shot Point CaS (Caishan)}

Shot point CaS (Figure 6) is located in the fold-thrust belt south of the Dabic Shan, close to the Yangtze River. On scction CaS-north, $P g$ is gencrally obscured near the shot point duc to the high background noisc. $P_{1}$ and $P_{2}$ are observed variably. 'The arrival time of $P m P$ is basically the same as that of ErL-nortly. The profile is not long enough for $P n$ to be rccognized as the first arrival. Although there is only a short obscrvation distance $(\sim 10 \mathrm{~km})$ south of the shot point, we can casily see from the late $P g$ arrival time that the basement deepens bencath the Yanglze River valley.

\subsection{Shot Point ZhG (Zhanggongdu)}

Shot point ZhG (Figurc 6) is locatcd in the Yanglze craton. $P g$ can be traced from 10 to $60 \mathrm{~km}$ with an apparent velocity of $5.9 \mathrm{~km} / \mathrm{s}$. Between $P g$ and $P m P$, intracrustal reflection $P_{2}$ is evident from 70 to $110 \mathrm{~km}$. The $P m P$ travel time at it distance of $100 \mathrm{~km}$ is similar to that on sections CaS and ZhM. $P_{n}$ appears beyond $\sim 160 \mathrm{~km}$ as the first arrival and has an apparent velocity of $\sim 7.9 \mathrm{~km} / \mathrm{s}$.

\section{Two-Dimensional Modeling}

A finite difference tomographic inversion method [Vidale, 1988,1990 ] was used to model the upper crustal velocity structure based on the $\mathrm{Pg}$ arrivals. Modcling of the micldle and lower crust and uppermost mantle was then carricd out using 2-D forward ray tracing. The travel times and amplitudes of all of these seismic phases have been calculated using the programs "MacRay" [Luetgert, 1992] and "SEIS-83" [Cerveny al al., 1977; Cenveny and Psencik, 1984]. Synthetic scismograms have becn calculated using the asymptotic ray theory [Ceneny and Psencik, 1984].

In the finite difference travel time method, travel times are extrapolated outward from the source region to each point in the model [Vidale, 1988, 1990]. We used an inversion method 

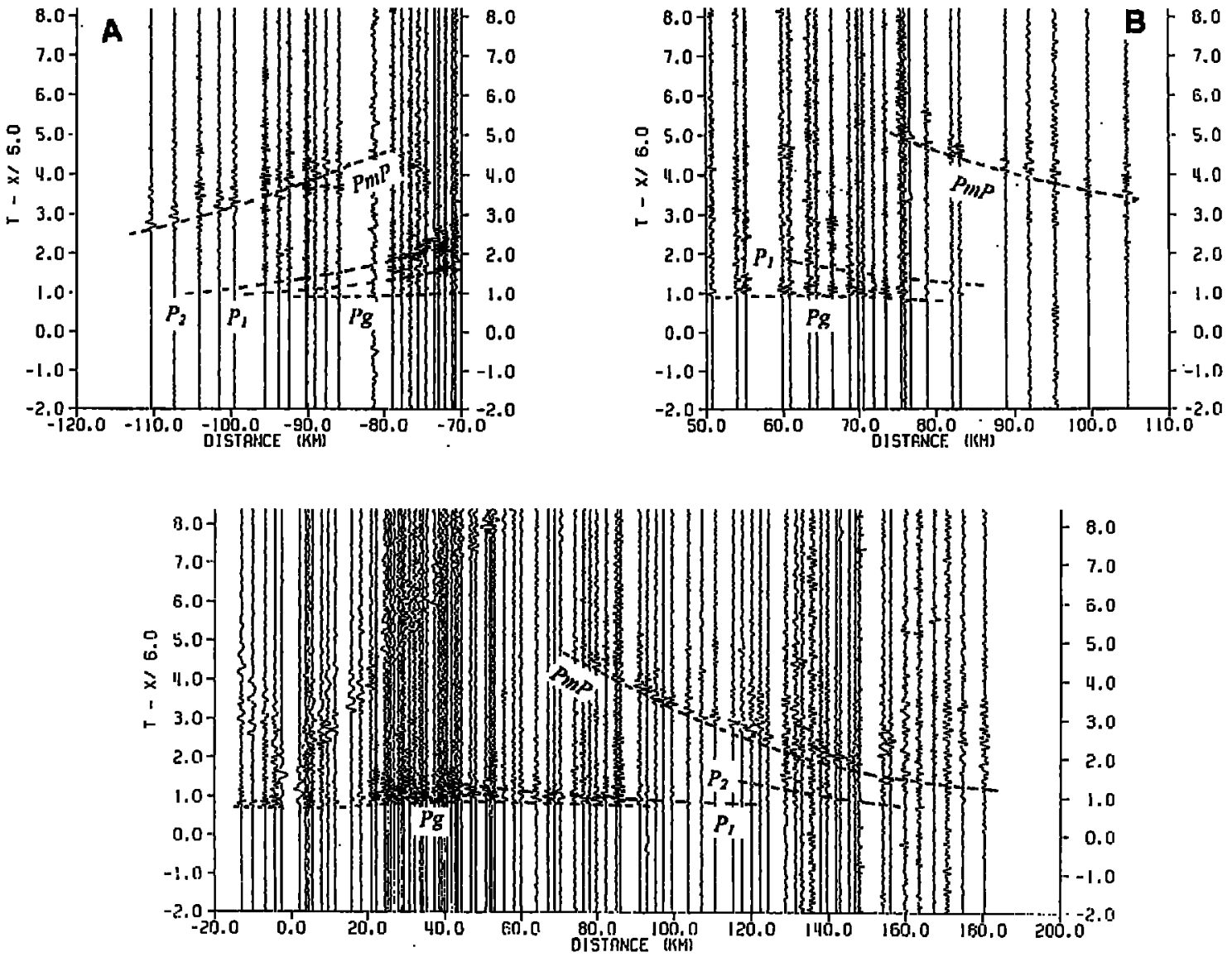

Figure 5. (top) 'Irace-normalized low-pass filter (10 IL $\mathrm{Hz}$ record section of shot point JnG, which was localed off-line. The reflection from Moho, $P m P$, is clcarly recorded and is delayed on the section to the north relative to the section to the south. Intracrustal reflections, labeled $P_{1}$ and $P_{2}$, are clear only on the data to south where the station spacing is $1-2 \mathrm{~km}$ (70-80 km distance range). (bottom) Record section of shot point ErL. 'The $P m P$ reflection is very clear, and the travel tine curvature constrains the average crustal velocily to $\sim 6.3$ $\mathrm{km} / \mathrm{s}$. The intracrustal reflection $P_{2}$ is well recorded at distances around $140 \mathrm{~km}$. The refraction from 10 uppermost mantle, $P_{n}$, is not visible in these data.

capable of imaging media containing strong velocily variations [Ammon and Vidale, 1993; Hole, 1992]. The inversion mode] was parameterized using $4-\mathrm{km}$ cells. To maintain accuracy, a uniform $1 \mathrm{~km}$ squarc grid was used for the travel time calculation. A total of $479 P g$ arrival times were used in the inversion. The final velocity model (ligure 7a) was oblained after 5 iterations. The RMS travel time residual decreased from 0.35 to $0.10 \mathrm{~s}$ for the modcl. There is no significant difference between the models obtained after 5 and 10 iterations. The resolution of the inversion was assessed by summing the number of rays traveling through cach ccll (Figure $7 \mathrm{~b}$ ). 'The central part of the profile (between 90 and $270 \mathrm{~km}$ ) was covered by more than 25 rays. The rays in the area between 100 and 200 $\mathrm{km}$ on Figure $7 \mathrm{~b}$ do not penetrate below a depth of $\sim 5 \mathrm{~km}$ duc to the presence of a high-velocity zone. Velocities at depths $<5$ $\mathrm{km}$ are well resolved, especially in the central part of the profile. The most prominent feature is a high-velocity (6.3 $\mathrm{knz} / \mathrm{s}$ ) zone beneath shotpoint $\mathrm{ZhZ}$, in the middle of the UHP zone. We discuss this feature below.

The crustal structure below $\sim 10 \mathrm{~km}$ was determined from the wide-angle reflections. As discussed carlier, phase $P_{1}$ has a high amplitude on the record section of ZhZ-south. The diflerence of travel time between $P_{1}$ and $P g$ at distances of 20 and $70 \mathrm{~km}$ are 0.75 and $0.3 \mathrm{~s}$, respectively. The calculation of synthetic scismograms indicates that a higher velocity layer $(6.4$ $\mathrm{km} / \mathrm{s}$ ) bencath an interface at a depth of $\sim 7 \mathrm{~km}$ provides a good match to the $P g / P_{1}$ amplitude ratio. The high-velocily $(6.4 \mathrm{~km} / \mathrm{s})$ layer is modeled as a thin layer in order to fit the travel times of later arriving phase, (i.e., $P_{2}, P_{3}, P_{m} P$ ) and because a thicker layer at shallow depth would causc an unreasonably large gravity anomaly.

Figure 8 shows the comparison between observed and calculated travel time data and between observed and synthetic scismograns from shot point BuT. The observed and culculated travel times and amplitudes are in reasonable agreement. The greater complexity of the observed wave field compared with the synthetic wave field indicates that the crust does not contain continuous, smooth specular reflectors, as was mentioned carlicr. Scattering in the crust may also contribute to the amplitude misfits between the calculated and observed intracrustal pleases.

The 2-D crustal velocity structure across the Dabic Shan is shown in Figure 9a. The contoured velocity values are the 

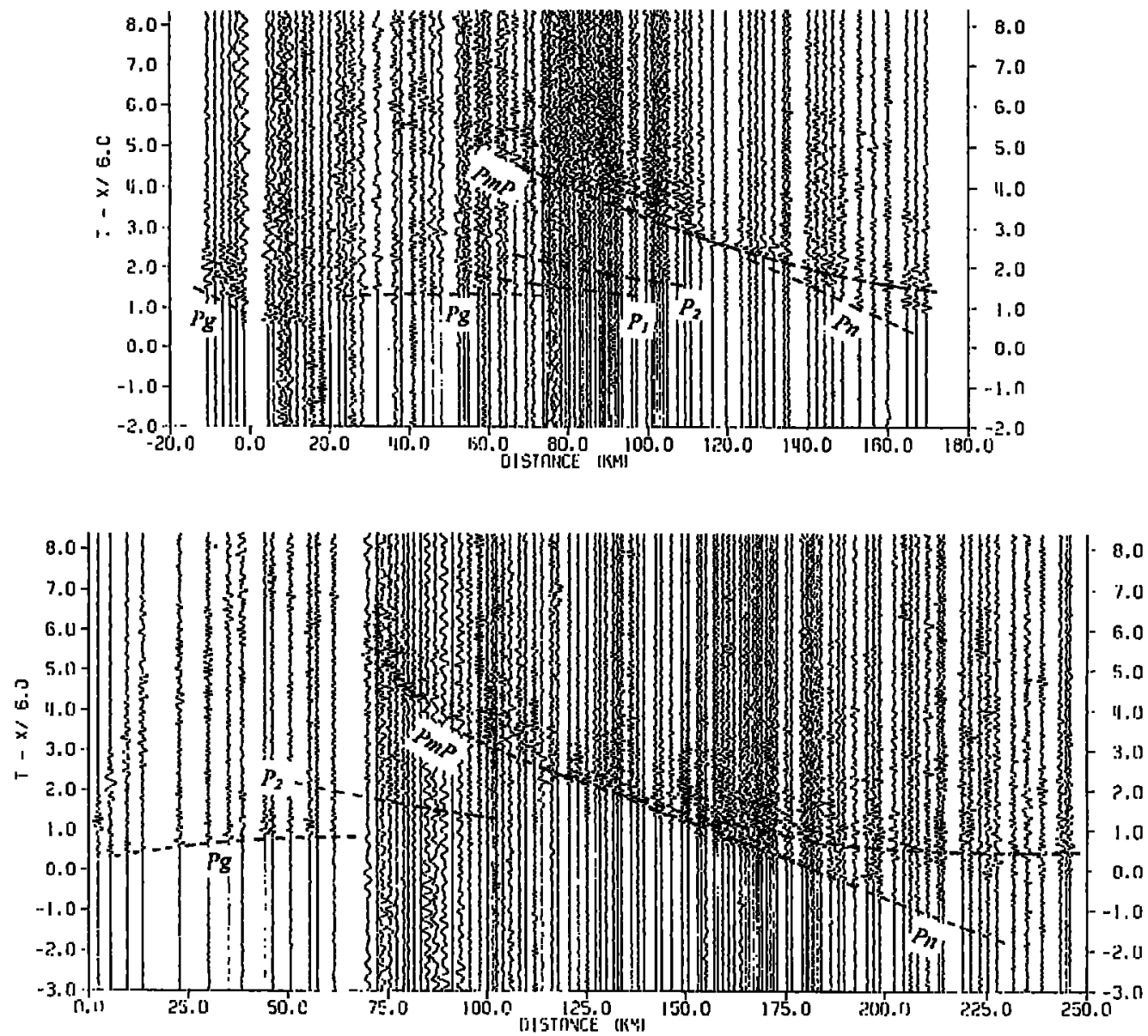

Figure 6. (top) Trace-normalized low-pass filter $(10 \mathrm{~Hz})$ record scction of shot point CaS. $P m P$ is clearly observed, but the inlracrustal reflections $P_{1}$ and $P_{2}$ are not highly coherent phases, even in the most densely recorded portions of the profile. Seismic scattcring may play a rolc in the generation of the $P_{1}$ and $P_{2}$ phases. (bottom) Record section of shot point ZhG. $P m P$ and $P n$ arrival phases are clearly obscrved. These observations, logetler with the reversing profile from shotpoint ZhM-south, and provide strong constraints on the averagc crustal velocity, crustal thickness and uppermost mantle velocily.

result of interative forward modeling of scismic travel times of phases arriving after $P g$. The location of seismic control on the depth of the crustal boundarics is indicated by heavy solid lines. The Moho discontinuily is $\sim 6 \mathrm{~km}$ deeper beneath the Xiaotian fault than bencath the Sino-Korcan and Yangtze cratons, where an offset of $\sim 3.5 \mathrm{~km}$ appears to exist. The Moho offset was inferred from (1) a travel time difference of $1.0 \mathrm{~s}$ for the $P m P$ reflection as recorded from shot points GuT and $B u T$, even though the distance between the two shot points is only $40 \mathrm{~km}$ (Figurcs 3 and 4); (2) $P m P$ arrivals from shot point GuT-south, which are very clear from 90 to $145 \mathrm{~km}$ and are abruptly interrupted at the distance of $\sim 145 \mathrm{~km}$ (Figure 3); and (3) the clear travel time difference of $1.0 \mathrm{~s}$ for $P^{2} m P$ from Bu'l--north versus BuT-south (Figurc 4).

\section{7. $S$ Wave Velocity and Poisson's Ratio}

The horizontal components of the seismic records were used to deternine the shear wave velocity structure beneath the Daluic Shan. The phases $S g$ and $S m S$ appear clearly on the record sections of most shot points (c.g., ErL in Figure 10).
However, the uppernost mantle phase $S n$ can not be identified on the record sections. In addition, the converted wave $P m S$ reflected from the Moho can be recognized on the records of BuT and JnG. The $S$ wave velocity model was obtained using two-dimensional ray tracing, as for the $P$ wave model. $S$ wave velocities and Poisson's latio within the crust are shown in Figure 9b. Fourteen out of fifteen values of Poisson's ratio are in the range $0.23-0.27$ (one valuc is 0.29 ). Because the $S$ wave phases reflected on the intracrustal interfaces are generally more difficult to identify than $P$ wave reflections, the $S$ wave velocities in the midcrust have larger uncertaintics. However, the very clear $P m P$ and $S m S$ reflections provide very good constraints on the average whole crustal Poisson's ratio (0.25-0.26; Figurc 9b). The fact that the many record sections contain both clcar $P_{n}$ and $S m S$ phases, but lack the phase $S n$, may indicate a negative $S$ wave velocity gradient in the uppermost mantle.

Our seismic model indicates that Poisson's ratio, which is an indicator of crustal composition [c.g., Holbrook et al., 1992; Christensen, 1996] varies with depth from 0.23-0.26 in the 

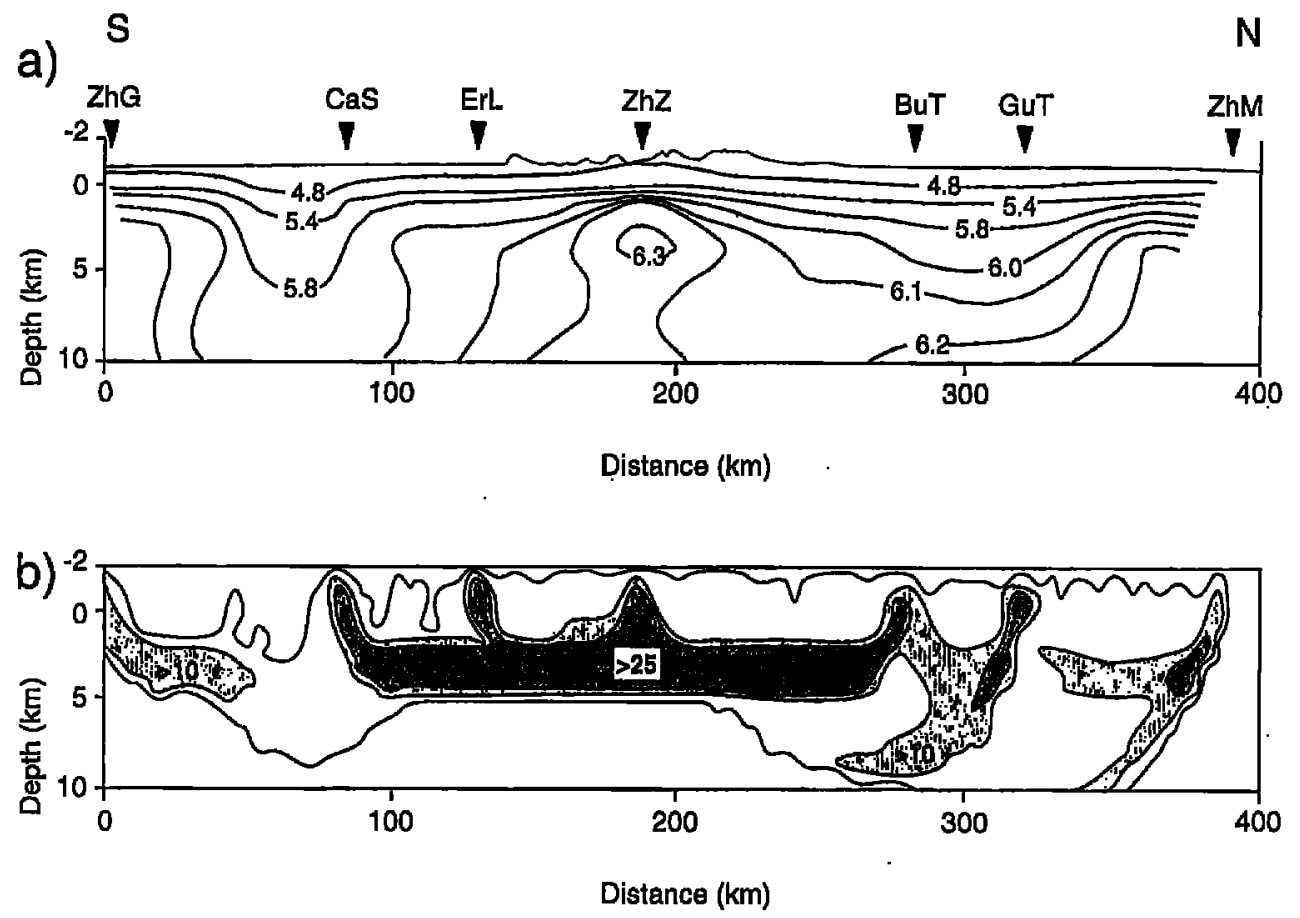

Ijigure 7. Upper crustal velocity structure (a) Model with velocity isolines $(\mathrm{km} / \mathrm{s})$ derived from finite difference travel time inversion. The high-velocity zone $(6.3 \mathrm{~km} / \mathrm{s})$ correlates with the antiformul corc of the uppermost crust of the orogen where ultrabigh-pressure rocks nccur. (b) Nunber of rays traveling through each cell. The central part of the profile (between 80 and $280 \mathrm{~km}$ ) was covered by sufficient rays and the inverted velocities at depths are reliable. The rays in the interval between 100 and $200 \mathrm{~km}$ do not penetrate below the depth of $\sim 5 \mathrm{~km}$ due to the high velocity zone $(6.3 \mathrm{~km} / \mathrm{s})$.

upper crust to $0.26-0.29$ in the lower crust. Estimated uncertaintics are 0.02-0.03. The composition of the crust of castcro China, including the arca of the Dabie Shan orogen, has proviously been discussed by Gao et al. [1998], Ji and Mooney [1998], and Kern et al. [1998]. The combined compressional and shear wave model (Figure 9) is consistent with these previous models for an upper crustal composition of felsic metasedimentary and granitic rocks, a middle crust of intermediatc (dioritic) composition, and a lower crustal composition of intermediateto-mafic rocks in the amphibolite to granulite metamorphic facies. There is no scismic evidence for a volumetrically significant amount of high-velocity eclogite within the deeper crust, despite the fact that eclogite is locally cxposed within the Dabic Shan [Kern et al., 1998].

\section{Discussion}

Despite significant collisional convergence in the Mesozoic and the presence of surficjal ultrahigh-pressurc rocks, only il modest crustal root presently exists beneath the Dabie Shan. The crust thickens from $35 \mathrm{~km}$ bencath the Yangtze craton to $41.5 \mathrm{~km}$ at the northern margin of the Dabic Shan and thins to $34 \mathrm{~km}$ beneath the Sino-Korcan craton. The average velocities of the crust bencath the Yangtzc craton, the Dabie Shan, ancl the Sino-Korean craton are $6.35,6.30$, and $6.25 \mathrm{~km} / \mathrm{s}$, respectively. Both the Yangt\%c craton and the Sino-Korcan craton have a three-layer crustal structure with velocities of $6.0-6.2$, 6.5 , and $6.8 \mathrm{~km} / \mathrm{s}$. A high-velocity $(7.0-7.4 \mathrm{~km} / \mathrm{s})$ lower crust, which is common beneath plattorms and shiclds [Holbrook et al., 1992; Rudnick and Fountain, 1995; Chrislensen and Mooney, 1995], is not present. The scismic velocity bencath the Moho is a typical continental value of $8.0 \pm 0.1 \mathrm{~km} / \mathrm{s}$. Dong ef al. [1996] used a portion of thesc same scismic refraction data to get a preliminary crustal model that differs in several important detaijls from our paper. For example, their model has no upper crustal high-velocity $(6.3 \mathrm{~km} / \mathrm{s})$ zone bencath the UHP belt (Figure 7), and no Moho offset beneath the Xinyang-Sliuclieng fault (Figure 9). Our model contains more details than that of Dong et al. [1996] because we have modeled the complete data set with a combination of finite difference travel time and 2-D ray trace methods.

The structure of eastern China, including the Dabie Shan, is comparable to highly extended crust, which has an average thickness of $30.5 \pm 5.3 \mathrm{~km}$ and avcrage crustal velocity of $6.21 \pm 0.22 \mathrm{~km} / \mathrm{s}$ [Li and Mooney, 1998; Christensen and Mooney, 1995; Rudnick and Fountain, 1995]. Recent global scismic tomographic inversions indicate that the lithosphere is significantly thinner beneath eastern China than bencath the Sibcrian craton, Canadian shicld, or Baltic shicld [Ekström et al., 1997]. These observations indicate that the lithosphere has been thinned in eastern China, including benenth the Dabic Shan, and that the crust has undergone moderate exlension. This interpretation is supported by high heat flow $(58-87 \mathrm{~mW} /$ $\mathrm{m}^{2}$ ) and quantitative modeling that suggests a lithospheric thermal thickncss of $<100 \mathrm{~km}$ [Yuan, 1996]. Taking these observations further, Gao et al. [1998] and Kern el al. [1998] speculate that a mafic (eclogitic) lower crust in eastern China, 



Figure 8. Calculation of ray tracing and 2-D synthetic seismogram and comparison with the observed data of shot point BuT. (a) Record scction with normalized trace. (b) Tracc-normalized synthetic record section. Amplitudes are generally stronger than observed data because seismic scattering and attenuation have been neglected. (c) Observed and calculated travel times, where crosses and pluses denote the observed and calculated travel times (s), respectively, with a reduced velocity of $6.0 \mathrm{~km} / \mathrm{s}$. (d) Ray paths, where asterisk denote shot point. 
a)

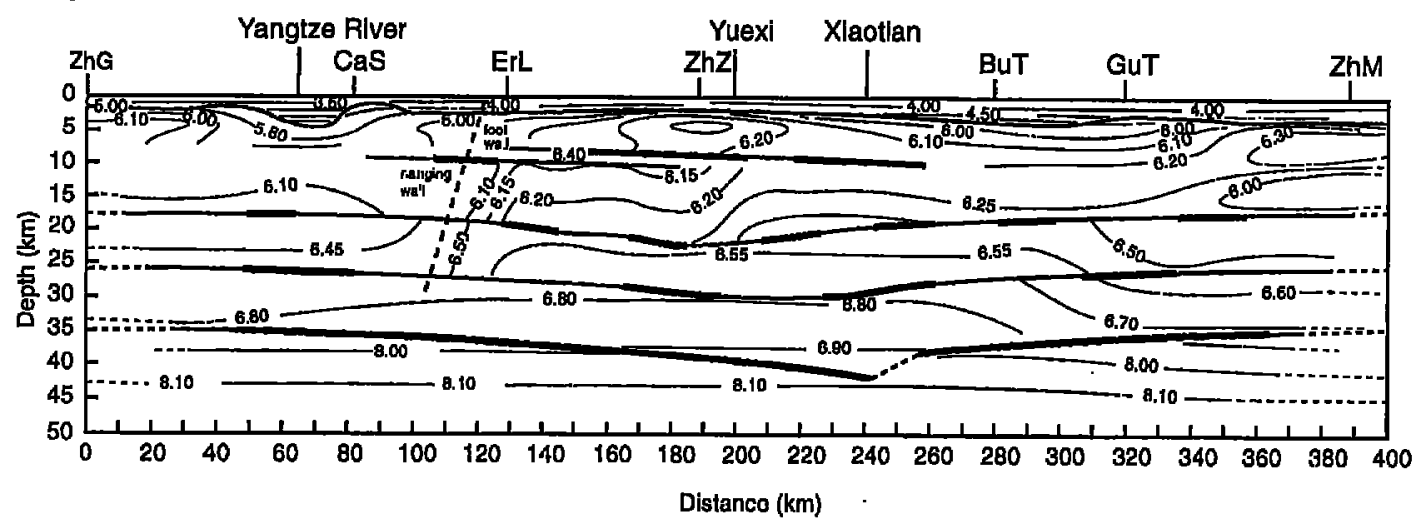

b)

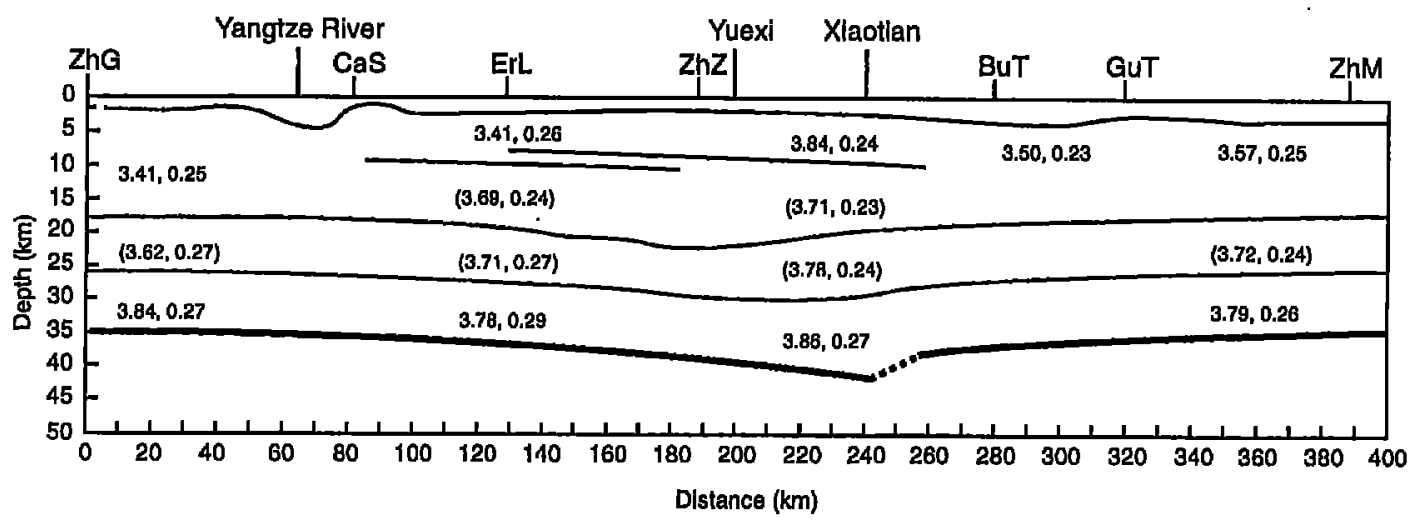

c)

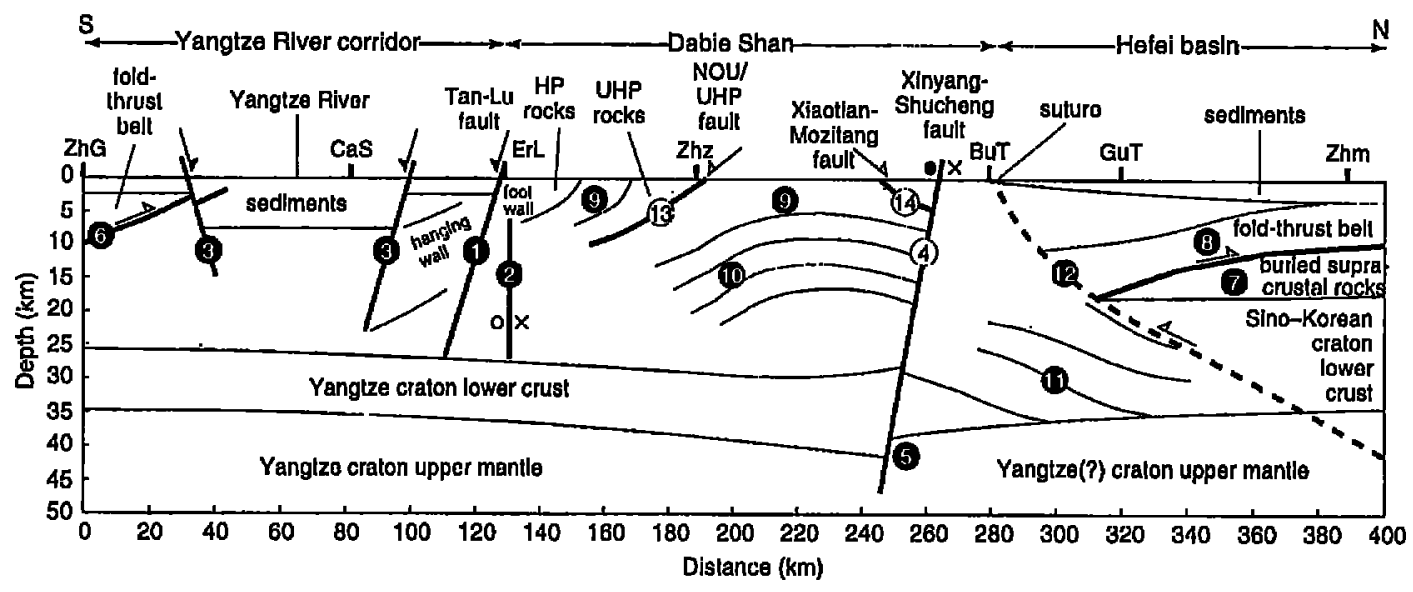

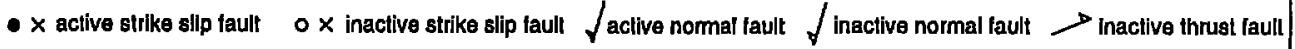

ligure 9. Final 2-D crustal model of the Dabic Shan. (a) $l$ wave crustal structure. The velocity of upper crust $(0-7 \mathrm{~km})$ is determined from $P y$ using the finite difference inversion. The interfaces were determined by the arrival times of the wide-angle reflection and $P n$ waves from the all cight shots. Dashed line indicates the Moho offset. Velocities are accurate to better than $3 \%$; depth of boundaries is accurate to better than $10 \%$ of the total depth [Mooney, 1989]. (b) $S$ wave velocity and Poisson's ratio in the crustal structure, which has the same interfaces as the $P$ wave modul. Velocitics and Poisson's ratios denoted with brackets indicate larger uncertaintics ( $\sim 5 \%$ in shear wave velocity; $\sim 15 \%$ in Poisson's ratio). (c) Geological interpretalion of Dabic Shan orogenic structure. Sec discussion, including key to numbers, in text. 


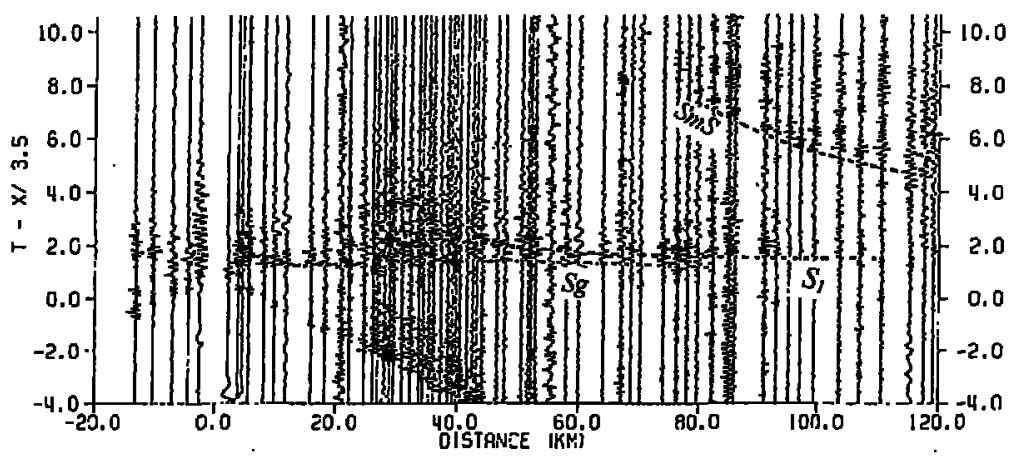

Figure 10. Record section with $S$ wave arrivals (radial component), plotted with reduced velocity $3.50 \mathrm{~km} / \mathrm{s}$ of shot point ErL. The direct arrival $S g$, intracrustal reflection $S_{1}$, and Moho reflection $S m S$ are clearly observed. Additional intracrustal reflections are gencrally weak and are variably recorded from other shot points. The quality of the $S$ wave data in this record section is typical of the olher shots recorded in this study.

including the Dabie Shan, was delaminated and recycled into the upper mantle during Cenozoic crustal extension.

We have combined our seismic model and the geological interpretation of Hacker ef al. [1998] in at speculative crustal cross scction of the Dabic Shan (Figure 9c). Referring to the numbered struclural elements in Figure 9c, the active Tan-Lu fault (1) is an east dipping normal fault with a clcar seismic signature defined by higher velocities in its footwall. As noted earlicr, the conventional interpretation of the Tan-Lu fault is that it began as a Triassic sinistral strikc-slip fault [e.g., Yin and Nie, 1993]; stcep velocity gradients (2) cast of the interpreted position of the modern Tan-I.u fault may rellect this older structure. Oblique normal faults that bound the Yangtze River SE of the Dabic Shan (3) can also be correlated with velocity gradients. $\Lambda \mathrm{n}$ active sinistral strikc-slip fault near the northern topographic limit of the Dabic Shan, the Xinyang-Shucheng fault (4), has no clear scisnic signature within the crust; however, we speculate that it is responsible for the obscrved Moho offset (5). The scismic velocity structure south of the Dabic Shan may reflect contractional deformation associated with the fold-1hrust belt (6). Likcwise, we interpret the scismic velocity structure beneath the northern I-Jefei basin as reflecting thrusting in the hanging wall of the Sino-Korcan crust, with middle crustal rocks (8) over supracrustal rocks (7). Morc spcculatively, we tic the homoclinal south dipping foliation and south plunging lineation within the high- to ultrahigh-pressure section cxposed in the southern Dabic Shan [Hacker ct al., 1995b] to the northward increasing velocity gradient at (9). Hacker et al. [1998] described the pre-Cretaceous structure of the Dabic Shan as a crustal-scale antiform formed by warping of the higl1to ultrahigh-pressure slals drawn southward out from beneath the Sino-Korcan craton. We postulate that northward increasing velocity gradicnts at $(10)$ and southward increasing velocity gradients at (11) arc part of this antiform, which uplifts rocks will miderustal velocitics into the upper crust. This leads further to the implication that the suture between the two cratons is north of this antiform (not at the Moho offset), and we speculatively show it at location (12), dipping north bencath the trace of the isotopically defined crustal suture [Hacker et al., 1998]. Cretaceous normal faults that bound the southern (13) and northern (14) edges of the northern Dabic Shan magmatic-extensional complex have no clear scismic signature.

\section{Conclusions}

The crustal structure of the Dabic Shan has been delermined from a new deep seismic refraction profile. In the shallow crust beneath the cxposed ultrahigh pressurc (UHP) rocks, there is a broad (50 km wide) high-velocity $(6.2-6.3 \mathrm{~km} / \mathrm{s})$ zonc centcred at a depth of 4-5 kn and a thin (1 km thick) highvelocity $(6.4 \mathrm{~km} / \mathrm{s})$ layer at a depth of $8 \mathrm{~km}$. Below $9 \mathrm{~km}$, the middle and lower crust bencath the UHP zone are very similar to the crust to the north and south (i.c., bencath the SinoKorean and Yangtze cratons, respectively). This suggests that UHP rocks are primarily concentrated in the upper crust (above $9 \mathrm{kn}$ depth) of the orogen. Our seismic model indicates that ccolgite is not volumetrically significant within the middle or lower crust.

There is only a modest ( $6.5 \mathrm{~km}$ deep) crustal root bencath the Dabic Shan. The thickness of the crust ranges from $\sim 35$ $\mathrm{km}$ bencath the Yanglze and Sino-Korean cratons to a maximum of $41.5 \mathrm{~km}$ at the northern margin of the Dabie Shan. The small variation in depth to the Moho along this $400-\mathrm{km}$ long profile indicates that the crust involved in the l'riassic collision has undergone postcollisional thiuning. This has becn accomplished by a combinalion of isostatic uplift, erosion, and moderate crustal extension. An olsserved Moho offset is likely duc to an active strike-slip fault. Much of the Triassic structure associated with the formation of the orogen and UHP rocks has been obscured by post-Triassic cvents. However, the crustal velocily struclure deternined for this profile is compalible with a north dipping suture located north of the Jabic Shan (Figure 9c) and an antiformal culmination of UHP rocks in the center of the Dabic Shan (Figure 7).

Acknowledgments. This research was jointly supported by the Natural Sciences Foundation of Chinat and the Chinese Joint liarthquake Sciences lioundittion under grants NSFC49374208 and JESF9:-031. The fieldwork wis conducted with the assistance of X. K. Zhang, B. Y. Chen, X. B. Chen, and the Geophysical Prospecting Center of the China Seismological Buretu. The authors wish to express their sincero thanks to those who helped. Copies of these data may be requested from the lirst author. We thank $J$. $\wedge$. Holc for providing the finite difference travel time inversion code used in this study. R. C. Culeman, K. Favret, R. W. Girdler, and R. Meissner provided constructive comments on a carly version of this paper. Reviews by $A$. R. Levander, D. M. Fountain, and an anonymous reviewer led to significant revi- 
sions of the subnitted minuscript. 'The uthors are grateful to all of these reviewers. The first two authors were supported by the US $\Lambda$ PRC Protocol Agreement for Scientilic and Technical Cooperation in Tarthquake Studics as visiting scholars at the U.S. Geologic Survey in Menlo Park, California. B. R. Hacker was supported by NSF grants EAR-9417958 and EAR-9796119.

\section{References}

Ammon, C. J., and J. E. Vidale, Tomography without rays, Bull. S'cismol. Soc: Am., 83, 509-528, 1993.

Catchings, R. C., and W. D. Mooncy, Basin and Range crustal and upper mantle struclure along the $40^{\circ} \mathrm{N}$ parillel, nortliwest Nevada, $J$. Geophys. Ress, 96, 6247-6267, 1991.

Cerveny, V., and I. Psencik, SLiIS83-numerical modeling of seismic waveficld in 2-D laterally varying layered structures by the ray method, in Documentation of Earthquake Algorithms, edited by L. R. Lingdahl, Rep. SE-35, pp. 36-40, World Data Center (A) for Solid Earth Gcophysics, Bouldur, Colo., 1984.

Cerveny, V., I. A. Molotkov, and I. I'sencik, I, Ray Method in Seismology, Univerzita Karlova, Prague, 1977.

Chen, W. J., Q. Li, D. Li, X. Wang, Geochronological implications of $\mathrm{K} / \mathrm{Ar}$ isotope system of fault gouge-at preliminary study, Phys. Chem. Earth's Imer, 17, 17-23, 1988.

Christensen, N. J., Poisson's ratio and crustal scismology, J. Geophys. Res., 101, 3130-3156, 1996.

Christensen, N. I., and W. D. Mooney, Seismic structure and composition of the continental crust: $\Lambda$ global review, J. Gcophys. Res., 100 , $9761-9788,1995$.

Dong, S., X. Wu, R. Gao, D. Lu, Y. Li, Y. Ile, J, 'Jang, I'. Gao, M. I lou, and D. I Luing, Preliminatry study on deep geology of Dabic orogenic belt, in Continental Djnumies, vol. 1, pp. 103-108, Chin. Acad. of Geol. Sci., Beijing, 1996.

Lekström, G., J. 'Trump, and L. W. Larson, Mcusurements and global models of surface wave propalgation, J. Geophys. Res., 102, 8137$8158,1997$.

Gao, S., B. R. Zhung, Z. M. Jin, H. Kern, Z. D. Zhao, 7'. C. Luo, How matic is the lower continental crust?, Earth Planet. Sci. Lett., 16I, 101-117, 1998.

Group of Industrial Explosion Observation, Differences of the crustal structures among the areas of Ilenan, Ilubei and Shatuni provinces (in Chincsc), in Progresses on the resucarch of Deep Structure in Chinese Continent, pp. 192-204, Geol. Publ. Housc, Beijing, 1988.

J lacker, B. R., and $Q$. C. Wang, Ar/Ar geochronology of ulltuhighpressure metamorphism in central Clina, Tectonics, 14, 994-1006, 1995.

Hacker, B. R., L. Ratschbacher, L. Webb, and S. Dong. What brought then up? Exhumation of the Dabie Shan ultrahigh-pressure rocks, Geology, 23, 743-746, 1995a.

Hacker, B. R., X. Wang, L. A. Eide, and L. Rutschbacher, Oinling-Dabic ultrahigh-pressure collisional orogen, in Tectonic Fvolution of Asia, edited by A. Yin and T. M. Harrison, Cambridge Univ. Press, 1995b.

Hacker, B. R., L. Ratschbacher, L. Wcbb, T. Ireland, D. Walker, and S. Dong, U/Pb zircon ages constrain the architecture of the ultrahigh-pressure Qinling-Dabic Orogen, China, Fanh Planet. Sci. Lett., $161,215-230,1998$

Holbrook, W. S., W. D. Mooncy, and N. I. Christensen, The scismic velocity of the deep continental crust, in Comtinental l.ower Crust, edited by D. M. Fountain, R. Arculus, and R. W. Kay, pp. 1-34, EIsevier, New York, 1992.

Hole, J., Nonlinear high-resolution three-dimensional seismic travel time tomography, J. Geophy. Res., 97, 6553-6562, 1992.

$H u, H . X ., X$. B. Chen, and B. X. Zhang, Interpretation of deep seismic sounding data from the Suixian-Anyang profile in central China (in Chinesc), Acta Seismol. Sin., 8, 37-49, 1986.

Jarchow, C., G. A. Thompson, R. Catchings, and W. D. Mooney, Seismic detection of active magmatic underplating bencath l/10 Basin and Range Province, westcrn United States, J. Geophys. Res, $98,22,095-22,108,1993$.

Kern, II., S. Gao, Z. M. Jin, T. Pill, and S. Y. Jin, Petrophysical studies on rocks from the Dabie ultrahigh-pressure (UIIP) metamorphic belt, Central China: implications for the composition and delamination of the lower crust, 7ectonophysics, in press, 1998.

Levander, A. R., and K. Holliger, Small scalc hetcrogencily and largescale velocity structurc of the continental crust, $J$. Geophys, Res., 97 8797-8804, 1992 .
Levander, $\Lambda$, R. W. England, S. K. Smith, R. W. Hobbs, J. A. Goff, and $\mathrm{K}$. Holliger, Stocastic characterization and the seismic responsc of upper and middle crustal rocks based on the Lewisian gneiss complex, Scotland, Geophys. J. Int., 179, 243-259, 1994.

$\mathrm{Li}$, S., and W. D. Mooncy, Crustal structure of China from deep seismic sounding profiles, Tectonophysics, 288, 105-113, 1998.

Liou, J. G., X. Wang, R. G. Coleman, Z. M. Zhang, and S. Maruyama, Blueschists in major sulure zones of China tectonics, Fectonics, 8 , 609-619, 1989 .

Liou, J. G., R. Y. Zhang, L. A. Lide, S. Maruyana, X. Wang, and W. G. Lirnst, Metamorphism and tectonics of high-P and ultrahigh-P belts in Dabie-Sulu Regions, eastern central China, in Tectonic Evolution of Asia, edited by $\mathrm{A}$. Yin and T. M. Harrison, Cambridge Univ. P'ress, New York, 1995.

Luetgert, J, H., MacRay: Interactive two-dimensional seismic raytracing for the Macintosh, U.S. Geol. Sun. Open File Rep., 92-356, 1992.

Meissner, R., The Continentul Crust: $A$ Geophysical Approach, 426 pp., Acadenic, San Diego, Cálif., 1986.

Mereu, R. F, and S. B. Ojo, The scattering of seismic waves through a crust and upper mantle with randon lateral ind vertical velocity inhomogencities: Phys. Earth Planet. Inter, 26, 233-240, 1981.

Mooney, W. D., Seismic methods for determining earthquake source parameters and lithospheric structure, in Geophysicul Frameswork of the Continental Unitred States, edited by L. C. Pakiser and W. D. Mooncy, Mem. Geol. Soc. Am., 172, 11-34, 1989.

Mooncy, W. D., and T. M. Brocher, 1987, Coineident seismic rellection/rcfraction studies of the continental lithosphere: A global review, Rev. Geophys., 25, 723-742.

Ojo, S. B., and R. F. Mereu, The effect of random velocity fluctuattions on the travel times and amplitudes of seismic waves, $R$. Astron. Soc. Geophys. J., 84, 607-618, 1986.

Qiu, G. H., and Q. B. Guo, 1:500,000 gravity anomaly mapping of the Dibie shan aren in Hubci, Hentun, and Anhui provinces and discussion on the tectonics (in Chinese), Anhui Gcosci. 'Techol, 2, 53-66, 1989.

Rudnick, R. L., and D. M. lountain, Nature and composition of the continental crust: A lower crustal perspective, Rev. Geophys., 33, 267-309, 1995

Vidale, J. E., Finite-difference calculation of travel-times, Bull. Scismol. Soc. Am., 78, 2062-2076, 1988.

Vidals, J. E., Finite-difference calculation of travel-times in threc dimensions, Geophysics, 55, 521-526, 1990.

Wing, C. Y., Z. Y. Lin, and X. B. Chen, Comprehensive study of geophysical data on geoscience transect from Menyuan, Oinghai Province, to Ningde, Fujian Province, China, Acta Geophys. Sin., 39, $590-598,1995$.

$X u, J$. W., G. Zhu, W. X. Tong, X. R. Cui, and Q. Liu, Formation and cvolution of the Tancheng-Lujiang wrench fault system: a major shear systcm to the northwest of the Pacific Ocean, Tectonophysics, 134, 273-310, 1987.

Yc, S., J. Ansorge, Li. Kissling, and St. Mucller, Crustal structure beneath the enstern Swiss $\mathrm{Alps}$ derived from scismic refraction data, Tectonophysics, 242, 199-221, 1995.

Yin, $\boldsymbol{A}$. and S. Nic, An indentation model for the North and South China collision and the development of the Tanlu and Honam fault systcmis, custcrn Asia, Tectonics, 12, 801-813, 1993.

Yuan, X. C., Atlas of Geophysics of China, 216 pp., Geol. Publ. Housc, Beijing, 1996.

Yuin, X. C., M. C. Xu, W. B. 'T'ang, and Q. H. Wang, Scismic reflection profile on castern Qinling continental crust (in ('hinesc), Aeta Geophys. Sin., 37, 749-758, 1994.

Zeng, R., W. Sun, 'I' Mao, Z. Lin, H. Hu, and G. Chen, The nup for the depth of Moho discontinuity in Chinese continent, Acra Seismol. Sin., 17, 322-327, 1995.

Zheng, Y., and J. W. 'Teng, Crustal and upper mantle's structure in Suixian-Ma'an Shan area and some clutracteristics on the Tan-Lu tcctonic zone (in Chinese), Acta Geophys. Sin., 32, 648-652, 1989.

B. R. Ilacker, Geological Scicnces, Univursily of Califurnia, Santa Barbara, C^ 93160-9630.

W. D. Monncy, U.S. Gcological Survcy, MS 977, 345 Middlefield Road, Menlo Park, CA 94025. (mooney@usgs.gov)

C.-Y. Wang and R.-S. Zcng, Instilult of Geophysics, Stite Seismological Bureau, Beijing, 100081, Chinu.

(Received June 9, 1998; revised November 3, 1999; accepted November 15, 1999.) 


\title{
Crustal Structure Beneath Xingtai Earthquake Area in the North China and its tectonic implication
}

\author{
Chun-Yong Wang Xian-Kang Zhang*, Zhong-Yang Lin Qing Ju Wu \\ Institute of Geophysics, Stale Seismological Bureau, Beijing 100081, CHINA \\ "Geophysical Prospecting Center, State Seismological Bureau, Zhengzhou 450003, CHINA
}

Abstract Xingtai earthquakes of 1966 occurred in the central region of North China basin. To obtain detail crustal structure and then understand the seismotectonics of Xingtai earthquakes, three decp seismic reflection profiles were conducted in Xingtai earthquakes area in recent years. The CDP stacking sections show the basin and range structure in the shallow crust, a large-scale detachment in middle crust. In addition, a high-angle fault in mid-lower crust is inferred according to the discontinuity and inclination of the reflection events on the sections. The moderate-low angle normal fault in shallow crust, the highangle fault in mid-lower crust, and the detachment in middle crust have formed a spatial distribution of the faults in Xingtai earthquake area. The junction of the three faults is beneficial to the stress concentration and energy accumulation. The Xingtai earthquakes occurred on this kind of the background in crust. The high-angle fault in mid-lower crust may be the seismogenic fault of the Xingtai earthquakes. The regional compressive tectonic stress in near EW direction and the additional stress produced by the upwelling of magma had jointly acted on the fault to cause the occurrence of the Xingtai earthquakes.

\section{Introduction}

In March of 1966, five strong earthquakes (Xingtai earthquakes) with magnitude $M>6.0$ occurred in the Shulu graben, a small narrow basin with a length of $100 \mathrm{~km}$ and a width of $50 \mathrm{~km}$ in the west-central region of the North China basin (Figs. 1,2). And during the period of 1966-1984, there are over 68,800 earthquakes in this and surrounding regions. Fig. 3 indicates the locations of the earthquakes with $M>2.8$. Many' seismological studies have been conducted since 1966 in the Xingtai earthquake area attcmpting to understand the seismicity, earthquake source, ground deformation, geologic setting, crustal structure, earthquake hazards and prediction of earthquake in this area.

The scismotectonics of the Xingtai earthquakes, however, is still not clear. For example, the focal mechanisms of the first shock $(\mathrm{Ms}=6.8)$ and the main shock $(\mathrm{Ms}=7.2)$ are nearly vertical dextral strikeslip (Seismological Bureau of Hebei province, China, 1986), while the epicenters of the earthquakes are 
close to a major normal fault in the Shulu graben. After the Xingtai earthquakes, there are the Hejian earthquake $(M s=6.3)$ in 1968, the Bohai earthquake $(M s=7.4)$ in 1970 , the Haicheng earthquake $(M s=7.3)$ in 1975, and the Tangshan earthquake $(M s=7.8)$ in 1976 sequentially in the North China basin. It is necessary to obtain a detail crustal structure in order to understand the seismotectonics in these areas.

Several deep seismic sounding (DSS) profiles were carried out in North China basin from late of 1960 's to 1980 's (see Sun et al., 1986) for the sake of understanding the relation of the crustal structure to the strong earthquakes. The basic outline and some parameters (thickness and average velocity) of the crust were obtained. However, the lower resolution of the DSS profiles to crust prevents the further investigation. Three deep seismic reflection profiles with a total length of about $150 \mathrm{~km}$ were conducted in Xingtai earthquakes area in recent years. The interpretation of the reflection profiles is based upon the common depth point (CDP) stack technique. The standard data processing procedure of seismic reflection profile is used. A detail imaging of the crustal structure in the Xingtai earthquake area is obtained.

\section{Geologic setting and previous geophysical survey}

North China basin, a large-scale Cenozoic rifted basin, is situated in the east of the Sino-Korean platform, and is adjacent to the Taihangshan uplift westerly, to the Yanshan uplift northerly, to the Luxi uplift southeasterly', and to the Bohai sea easterly. It was a stable continental block before Mesozoic and underwent several significant phases of faulting and subsiding in Mesozoic and Cenozoic (Ye et al., 1985; Hellinger et al., 1985). A series of NNE-NEE faults and some of NWW faults interweave and cut the basin into block structure. The Jizhong depression, the Canxian uplift, the Huanghua depression, the Chenning uplift and the Jiyang depression are consecutively distributed from the west to east in the central North China basin (Fig.1). Each large-scale depression is generally composed of grabens and horsts. The Southern part of the Jizhong depression, where most of earthquakes are located in, consists of the Jinxian graben, the Ningiin horst, the Shulu graben, the Xinhe horst and the Nangong graben (Fig. 2).

The first DSS profile in North China basin was conducted in the late of 1960's (Fig.1, Profile a), which extends from the Yuanshi (close to the Taihangshan uplift) to Jinan (close to the Luxi uplift) and passes through the epicenter of the main shock of Xingtai earthquakes. Teng et al. (1974) suggested that the structure along the profile is divided into five blocks by several deep faults extending to Moho, the lower crust is more complicated according to the several seismic phases of the lower crust, and a thin high velocity layer is possibly in the middle crust. After that, several DSS profiles were carried out in North China basin. The basic features of the crustal structure in Xingtai earthquake area and its surrounding (Sun et al., 1986; Zhu et al., 1995) are the three-lay'er crustal model, the lower average crustal velocity 
$(6.2-6.3 \mathrm{~km} / \mathrm{s})$, the thinned crust $(30-33 \mathrm{~km})$ and the uplifted Moho. Due to the sparse shot points and few number of fold coverages along the seismic profile, the collected data are not sufficient to image the detail crustal structure beneath the Xingtai earthquake area, however.

\section{Profile framework}

To understand the seismotectonics, obtaining a detail crustal structure beneath the Xingtai carthquake areas is needed. Three deep seismic reflection profiles were successively conducted in Xingtaj earthquake area in 1991 and 1992. The locations of these profiles are in Fig. 2. Where profile A, the Ningin-Xinhe profile, is with a length of $40 \mathrm{~km}$; profile $B$, the Lincheng-Julu profile, is $55 \mathrm{~km}$ long; and profile $C$, the Renxian-Ningin profile, is also $55 \mathrm{~km}$. Profiles $A$ and $B$ pass through the epicenters of the first and main shocks respectively, and Profile $C$ intersects the other two profiles at the first and main carthquake epicenters. These reflection profiles are coincident with three previous DSS profiles, the Yuanshi-Jinan profile (Teng et al. 1974), the Tai'an-Longyao-Xinzhou profile (Zhu et al., 1995, Fig. 1, profile b), and the Renxian-Hejian-Wuqing profile (Sun et al., 1986, Fig. 1, profile c). The coincident scheme can obtain more reliable crustal model beneficial from both reflection and DSS profiles (Mooney and Brocher, 1987).

The observation scheme is an one-side spread and 24-fold coverage using a 96-channel MDS-10 digital seismograph. The gcophone group interval is $100 \mathrm{~m}$ with a minimum offset of $1000 \mathrm{~m}$. The record time is $20 \mathrm{~s}$ with a sample interval $4 \mathrm{~ms}$. The seismic sources are explosive shots below a depth of $25 \mathrm{~m}$ in holes, which makes explosion under the ground water level and keeps good excitation condition on the field sitc.

Wc havc used the standard data processing procedure of seismic reflection profile, which includes the demultiplex, field static correction, pre-processing, deconvolution, velocity analysis, residual static correction, normal (or dip) moveout and migration. The optimal velocity-depth function is generally chosen from a series of stacking velocity in the module of velocity analysis. However, the rcliable velocity estimate is only for upper crust (i.e. the two-way travel time (TWT) $<4.0 \mathrm{~s}$ ). The deep velocity estimate is provided by the crustal velocity structures from the threc DSS profiles. The interpretation was based on the CDP stacking sections and was partly referred to the migrated sections.

\section{Crustal Structure}

Figs. 4,5, and 6 are the CDP stacking sections of profiles $A, B$, and $C$, respectively. These sections indicate that the shallow crust is a typical extension, a result consistent with the seismic reflection 
studies of the oil exploration in this area (Xu et al. 1985). The graben and horst structure, asymmetric faulted basin, and listric normal fault are developed in the shallow crust, and laminas in crust-mantle transition(Figs. 4 and 5). The Xinhe fault, the main fault of the Shulu graben, extends in listric shape to below 4.0 s TWT (Fig. 6), where the metamorphic rocks are developed in Paleozoic, and also in early and middle Proterozoic. It controls the stratum distribution in Mesozoic and Eogene, and extends upward to Neogene and Quaternary.

The Moho reflection events clearly appear from 10-11.5 s TWT on these three profiles suggesting a feature of high-energy, well-continuitv, multi-cycle and long-duration. These reflections are related to the crust-mantle transition. The differen duration time among these three profiles (Figs. 4,5 and 6) suggests that the transition is lateral inhomogeneous. Some of reflection events are even too weak to be continuous on the profile $B$. The depth at the bottom of the transition is $30-32.5 \mathrm{~km}$ from the time-depth conversion, which is consistent with the depth of Moho from the DSS profiles. In addition, the reflection events in the section of 13.5-14s TWT may indicate that local discontinuity exists in the uppermost mantle beneath the Shulu graben.

A set of low-angle reflection events with long continuity and strong energy are illustrated from 2.5-4.5s TWT in the profiles A and B. The stretch length is about $40 \mathrm{~km}$ and it cannot be caused by sedimentary bedding because the sedimentation reflection is shorter. We interpret them as a detachment, which was developed in the crystalline basement and was inclined eastwards from a depth of $5 \mathrm{~km}$ at the west to $10 \mathrm{~km}$ deep at the eastern part along the profile. The strong reflection events may be due to a mylonite zone in mid-crust. There is no strong acoustic impedance at the depth (Zhu et al., 1995). In general, the strong reflection is difficult to be generated. Based on the laboratory results (Jones and Nur, 1983), the reflection can be observed on the mylonite zone due to its strong anisotropy even though there are no large contrasts in velocity and density. According to the stretching tendency, we suggest that the detachment outcrop 10-15 km to the western end of the profile $B$, which is confirmed recently by the field geological survey (Ma et al., 1995). This detachment is connected to a shear zone in the Taihangshan piedmont fault belt. Several major boundary faults in shallow part of the Jizhong depression converge to the detachment in listric shape (Ma et al., 1995).

Based on the continuity, energy duration, and inclination of reflection events in mid-lower crust and Moho transition along profiles $\mathrm{A}$ and $\mathrm{B}$, and referring the amplitude variation of the wide-anglc reflection on Moho (Zhu et al., 1995), we infer that a vertical boundary from the depth of the detachment down to Moho transition exists on the sections (Figs. 4,5), which respectively passes through the epicenters of the first and main shocks, and it may be related to a high-angle fault. Fig. 7a shows a projection of the earthquake hypocenters $(M>2.8)$ on the profile A with a width of $25 \mathrm{~km}$. Most of the hypocenters with $M>5.0$ are lain in a vertical belt of about $10 \mathrm{~km}$ wide (around Dongwang in Fig. 7a). It scems to be a high-angle earthquake fault in the crust. The existence of the high-angle fault is consistent 
with the focal mechanism of the first and main shocks (Seismological Burcau of Hebei province, China, 1986). Consequently, it may be related to the sequential occurrence of the Xingtai earthquakes.

Figs. 4,5 and 6 indicate that many reflection events in the mid-lower crust are characterized as lamination along profiles, and are strongly deformed. This may imply a possible upwelling of mantle material. The intrusion of magma will generate additional extension stress in the upper crust and heats up the lower crust simultaneously. This will decrease the viscosity and results in dehydration in the lower crust. Then, the dehydrated water goes upward and deposits in the middle crust. The extension stress, the compound effects of heat and water will impel a detachment formation. This feature is similar to the two-layer rheologic model (Sibson, 1982). In fact, the detachment is a transition with certain range. The strong carthquakes generally occur in this zone. Fig. $7 \mathrm{~b}$ is similar to Fig. 7a, except that the projection is on the Profile C. The standard error of the earthquake locations is less than $5 \mathrm{~km}$. Note that $85 \%$ of earthquakes with $M>5.0$ are at depths of $10 \mathrm{~km}$ and $20 \mathrm{~km}$, and few of earthquakes are below $25 \mathrm{~km}$ in depth. Conservatively speaking, the transition zone is between depths of 10 and $25 \mathrm{~km}$.

Profile $\mathrm{C}$ lies in the Shulu graben and parallels almostly to Xinhe fault. The section within $0-4 \mathrm{~s}$ TWT (Fig. 6) shows that the Shulu graben may be divided into three parts by' a set of NW-trending faults. These shallow faults extend to the top of crystalline basement with a lower angle. Many reflection events with lamination and deformation appear on the scetion of 4-10s TWT, which extend upward from the bottom of the crust, The arched events at about $4.0 \mathrm{~s}$ TWT are related to the detachment on profiles $A$ and B.

The reflections below the arcuate events crossing each other (Fig. 6, 4-7 s TWT) are called as crocodiles (Meissner et al. 1992). After doing the migration process on the data processing procedure, the arcuate and crocodiles events still exist on profiles $C$. It infers that there is really a special structure in the middle crust. The crocodiles indicate the shorten process of the crust in compressed zone. This feature exists in the Basin and Range province in the western United States, and is interpreted as a product of the compression before the extension (Klemperer et al.,1986). If it was the way for the Xingtai earthquakes area, there would be a compression before the formation of the North China basin.

Based on the imagings of three reflection profiles and referring the velocity structure from Teng et al. (1974), Zhu et al. (1995), and Sun et al. (1986), the three-dimensional sketch of the crustal structure in the Xingtai earthquake area is presented in Fig. 8. There are two grabens with moderate-low angle normal faults and dense reflection events and a horst with few reflection events in upper crust and a high-angle fault in mid-lower crust. A long stretch of detachment is in the middle crust, and a low velocity zone is beneath the detachment. The junction of the three faults is beneficial to the stress concentration and energy accumulation (Song et al., 1993). There are laminations in the mid-lower crust, which indicate the upwelling from the mantle. The upper plate above the detachment slipped eastwards due to the effect of extension and gravity in Cenozoic. 


\section{Discussion and Conclusion}

The deep seismic reflection profiles conducted in Xingtai earthquake area show more clear crustal images than that produced before. This is attributed to the data with high signal-noise rate (due to the field conduction in winter) and the multi-stack scheme, although the number of fold coverage on the profiles is not very high. The site conditions are ideal and keep good ground coupling for the geophones. The crustal structure from the reflection profiles is basically consistent with that from the coincident the DSS profiles, in which the complicated lower crust, the lower average crustal velocity $(6.2-6.3 \mathrm{~km} / \mathrm{s})$, the thinned crust (30-33km) and the uplifted Moho characterize the Xingtai earthquake area.

The inconsistency of the seismotectonics between the focal mechanism and the field geological survey may attribute to the discrepancy of the different geological events in the time and space domains. The discrepancy in the space domain is mentioned in this paper. As for the discrepancy in the time domain, since the neotectonic movement of North China plain, the sedimentary tectonics and the stress pattern has been changed considerably. A trending-EW seismic reflection profile of oil exploration, which passes through the Xingtai earthquake area and reaches the Taihangshan piedmont, indicates that a thrust fault inclines eastwards and cuts in the Quaternary stratum and its frontier has been strongly deformed. (G.D. Liu, 1995, private communication). The average $P$ and $T$ axes of tectonic stress field in North China is nearly horizontal, trending NEE-SWW and NNW-SSE, respectively (Xu et al., 1992). These implicate that the Xinglai earthquake area has undergone regional compression trending near $\mathrm{EW}$ at the present time. Consequently, the Xingtai earthquakes occurred under the environment of the crustal structure beneficial to the stress concentration and energy accumulation.

Based on these deep seismic reflection profiles, and combining with results of other geophysical survey, we got the following points about the seismotectonics of Xingtai earthquake area:

1. The moderate-low angle normal fault in upper crust, the high-angle fault in mid-lower crust, and the detachment in middle crust had formed a spatial distribution of the faults in Xingtai earthquake area. The detachment may play an important role in the tectonics of Cenozoic extension in North China basin. The junction of the three faults is beneficial to the stress concentration and energy accumulation.

2. The high-angle fault in mid-lower crust can be thought as a seismogenic fault of the Xingtai earthquakes. This fault may exist before the Cenozoic extension, and is reactivated recently. The shear stress acts on the fault to cause dextral slip.

3. The modern regional tectonic stress field and the additional stress field produced by the intrusion of magma had jointly acted on the fault to cause the occurrence of the Xingtai earthquakes. The major action is the regional tectonic stress. 
Acknowledgments This research was jointly supported by the National Scientific and Technological Committee and the State Seismological Bureau (SSB), China, under the grants NSTC85-907-02-01 and SSB85-02-01. The authors greatly appreciate the valuable suggestions about the field work and data interpretation by R.S. Zeng, G.Y. Ding, Y.T. Chen, J.W. Teng, G.D. Liu and Y.S. Zhang. The field work of this project was conducted by the group in SSB of China. Data collection and processing were assisted by the Geophysical Prospecting Bureau of the General Corporation for Oil and Natural Gas, China. We also wish to express our sincere thanks to them.

References

Jones, T. and Nur, A., 1983, Velocity and attenuation in sandstone at elevated temperatures and pressures, Gcophys. Res. Lett., 10, 140-143.

Klemperer, S., Hange, T., Hauser, E., Oliver, J. and Potter, C., 1986, The Moho in the northern Basin and Range Province, Nevada, along the COCORP $40 \mathrm{~N}$ seismic reflection transect, Bull. Geol. Soc. Amer., 97, 603-617.

Ma, X.Y., Liu, H.P., Wang, W.X. and Wang, Y.P, 1983, Mesozoic and Cenozoic rifting and extension tectonics in eastern China, Acta Geologica Sinica (in Chinese), 59, 22-32.

Meissner, R. and Wever, T., 1992, The possible role of fluids for the structuring of the continental crust, Earth-Science Review, 32, 19-32.

Hellinger, S.J., Sherlock, K.M., Sclater, J.G. and Ye, H., 1985, Cenozoic cvolution of the North China basin, Tectonics, 4, 343-358.

Ma, B.L., Liu, RX. and Liu, G.D., 1996, Analysis on intracrustal detachment and shallow-deep active tectonic system in Xingtai earthquake area, Seismology' and Geology (in Chinese),18, (submitted).

Mooney, W.D. and Brocher, T.M., 1987, Coincident seismic reflection/refraction studies of the continental lithosphere: A global review, Rev. Geophys., 13, 107-120.

Scismological Bureau of Hebei Province, 1986, Xinglai Earthquakes in 1966 (in Chinese), Scismological Press, Beijing.

Sibson, R.H., 1982, Fault zone models, heat flow, and depth distribution of earthquakes in the continental crust of the United States, Bull. Seism. Soc. Am., 72, 151-163.

Song, H.Z., Liu, J. and Lan, Y.G., 1993, Finite difference formula for dislocation model, Northwestern Seismological Bulletin of China (in Chinese), 15, 6-12

Smith, R.B. and Bruhn, R.L., 1984, Intraplate tectonics of the eastern Basin-Range: inference on structure style from seismic reflection data, regional tectonics, and thermal-mechanical model of brittleductile deformation, J. Geophys. Res., 89, 5733-5762. 
Sun, W.C., Zhu, Z.P., Zhang, L. et al., 1988, Exploration and study on the crust and upper mantle in North China, in: Development s on the Research of Deep Structure of Chinese Continent, Department of Scientific Programming and Earthquake Monitoring (ed.), SSB (in Chinese), 1937, Geological Press, Beijing.

Teng, J.W., Feng, Z.F., Li, J.S. et al., 1974, The relationship between the deep structure background of the central region in North China plain and Xingtai earthquakes (1) (in Chinese), Acta Geophysica Sinica, 17, 255-271.

Xu, J., Hong, H.J. and Zhao, G.Z., 1985, The evolution and kinematics characteristics of the Cenozoic rift basin in the North China plain, in: Continental Rifts and Deep Internal Processes, Institute of Geology (ed.), SSB, 26-40 (in Chinese), Geological Press, Beijing.

Xu, Z., Wang, S., Huang, Y., and Gao, A., 1992, Tectonic stress field of China inferred from a large number of small earthquakes, J. Geophys. Res., 97(B8), 11867-11878.

Ye, H., Shedlock, K.M., Hellinger, S.J. and Sclater, J.G., 1985, The North China basin: an example of a Cenozoic rifted intraplate basin, Tectonics, 4, 153-169.

Zhu, Z.P., Zhang, X.K., Gai, Y.J. et al., 1995, Study of crustal and upper mantle's velocity structure in Xingtai earthquakcs arca and its surrounding (in Chinese), Acta Seismologica Sinica, 17, 328334.

Figure captions:

Fig. 1 Regional geologic setting and location of seismic profiles. 1) coastline; 2) boundary of North China basin; 3) buried uplifted blocks; 4) Quaternary subsidence zone; 5) decp reflection profile (solid line) and wide-angle reflection/refraction profile (dashed line), where "a" is the Yuanshi-Jinan profile (Teng et al. 1974), "b" is the Tai'an-Longyao-Xinzhou profile (Zhu et al., 1995), and "c" is the Renxian-HejianWuqing profile (Sun et al., 1986).

Fig. 2 Geologic setting of the Xingtai carthquakes area and location of three deep reflection profiles. "A" is the Ningiin-Xinhe profile; " $\mathrm{B}$ " is the Lincheng-Julu profilc; " $\mathrm{C}$ " is the Renxian-Ningiin profile. The focal mechanism of the first shock $(M s=6.8)$ and the main shock $(M s=7.2)$ are also shown.

Fig. 3 Epicentcr location of Xingtai earthquakes with $M>2.8$, where the data of epicenter location are referred from the Seismological Bureau of Hebei Province (1986).

Fig. 4 Data processing section of profile A with line drawing. (a) CDP stacking section; (b) line drawing. The dashed line is the inferred high-angle fault, two circles denote the foci of main shock $(\mathrm{Ms}=7.2)$ and another strong shock $(\mathrm{Ms}=6.7)$. 
Fig. 5 Data processing section of profile B with line drawing. (a) CDP stacking section; (b) line drawing. " $A$ " is detachment; dashed line is the inferred high-angle fault; and circle is the focus of first shock (Ms=6.8).

Fig. 6 Data processing section of profile $C$ with line drawing. (a) CDP stacking section; (b) line drawing. Two circles denote the foci of first shock $(M s=6.8)$ and main shock $(M s=7.2)$; " $A$ " is arcuate event, " $\mathrm{B}^{\text {" is }}$ crocodile event.

Fig. 7(a) Hypocentral location of the Xingtai earthquakes with $M>2.8$ along profile A. Locations of Ninjin and Dongwang are shown in Fig.2.

Fig. 7(b) Hypocentral location of the Xingtai earthquakes with $M>2.8$ along profile C. Locations of Dongwang and Niujiaqiao are shown in Fig.2.

Fig. 8 Three-dimensional sketch of the crustal structure in the Xingtai earthquake arca, wherc " $A$ " is the detachment, "M" is the Moho discontinuity, and 1: reflection events, 2: low velocity zone, 3: Magma intrusion area, 4 : inferred fault. 


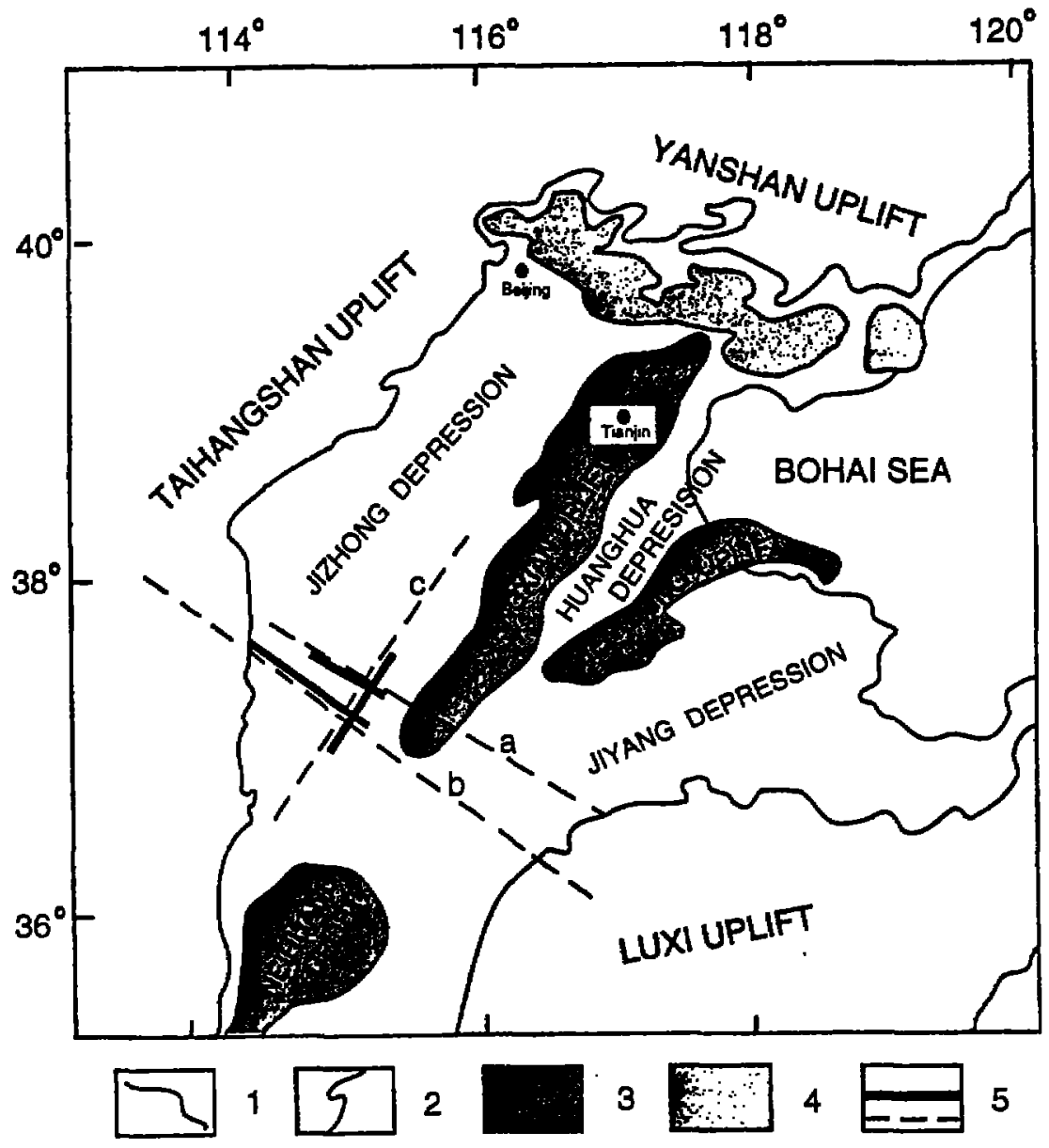

Fig. 1 Regional geologic setting and location of seismic profiles. 1) coastline; 2) boundary of North China basin: 3) buried uplifted blocks; 4) Quaternary subsidence zone; 5) deep reflection profile (solid line) and wide-angle reflection/refraction profile (dashed line), where "a" is the Yuanshi-Jinan profile (Teng et al. 1974), "b" is the Tai'an-Longyao-Xinzhou profile (Zhu et al., 1995), and "c" is the Renxian-HejianWuqing profilc (Sun et al., 1986). 


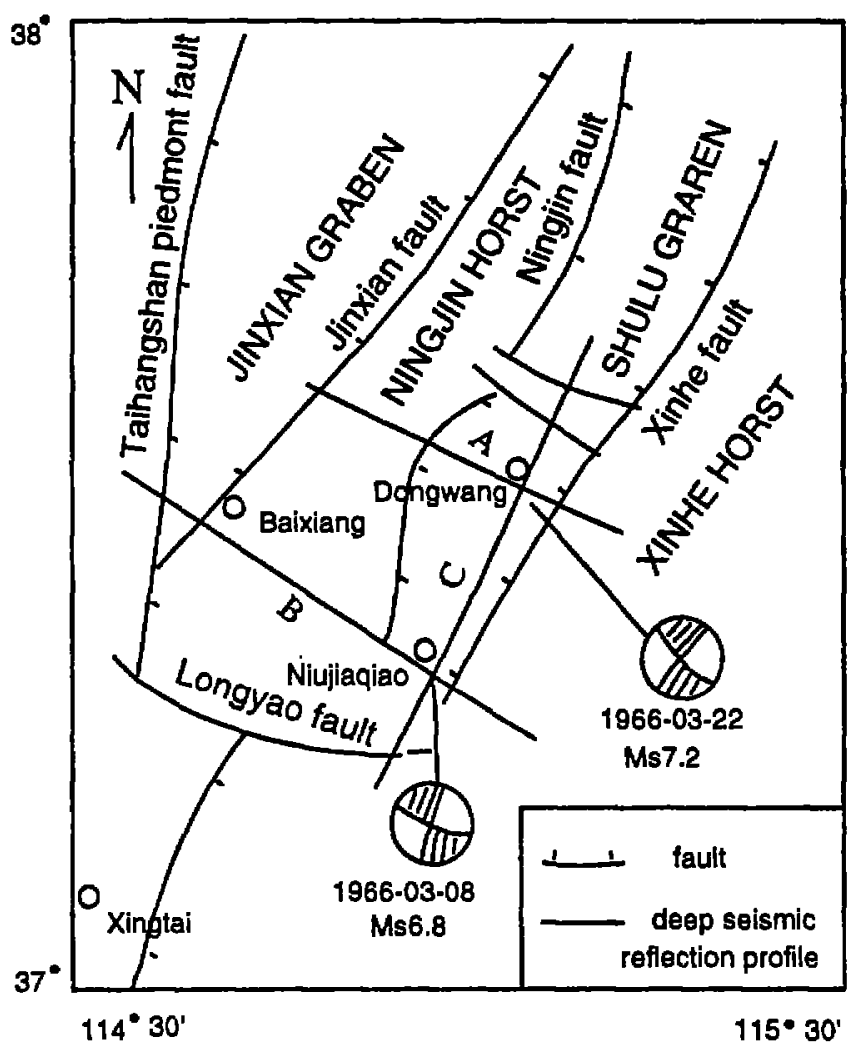

Fig. 2 Geologic setting of the Xingtai earhquakes area and location of three deep reflection profiles. "A" is the Ningiin-Xinhe profile: " $\mathrm{B}$ " is the Lincheng-Julu profile; " $\mathrm{C}$ " is the Renxian-Ningjin profile. The focal mechanism of the first shock $(M s=6.8)$ and the main shock $(M s=7.2)$ are also shown. 


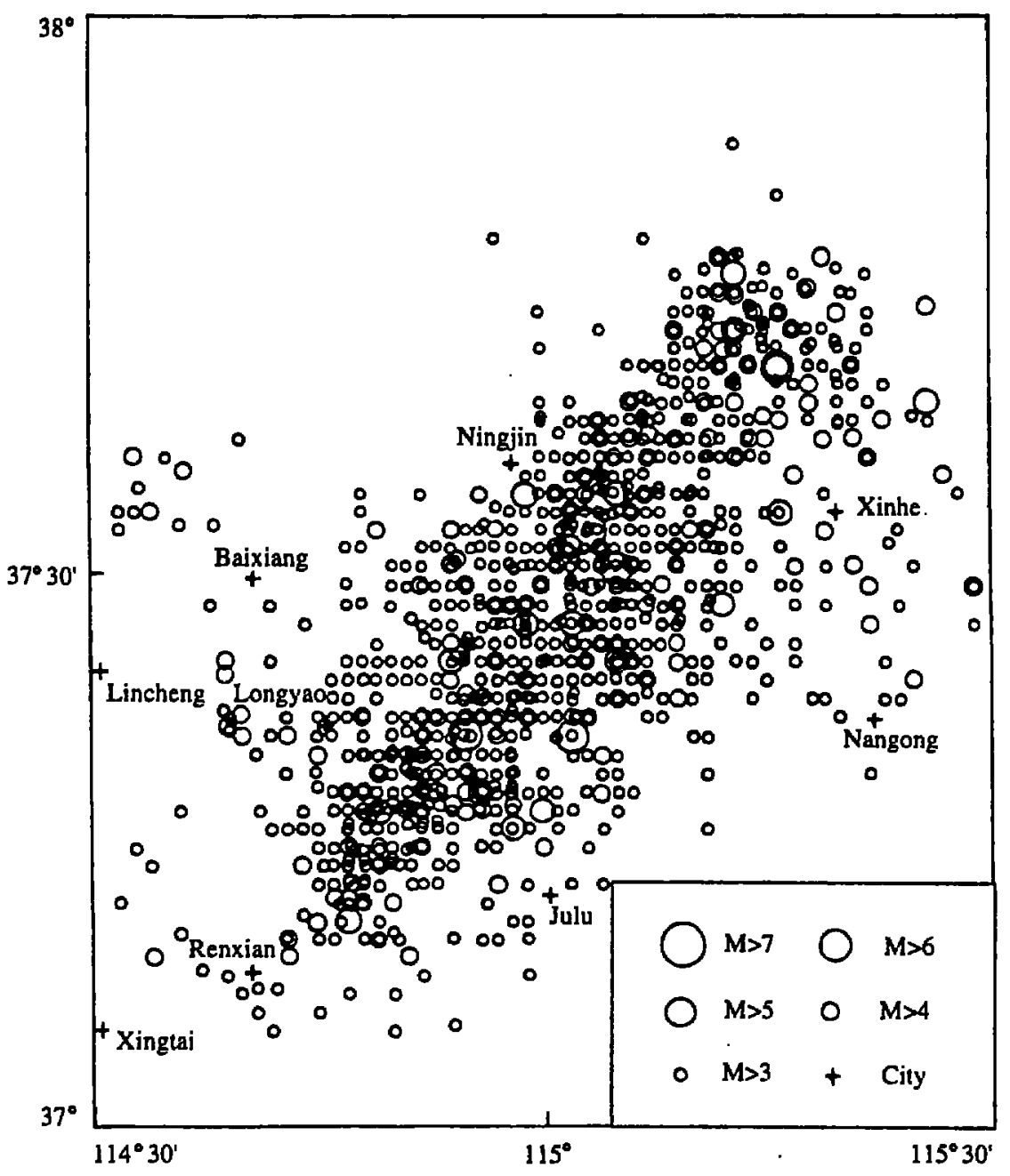

Fig. 3 Epicenter location of Xingtai earthquakes with $M>2.8$, where the data of epicenter location are referred from the Seismological Burcau of Hebei Province (1986). 
(a)

CDP number

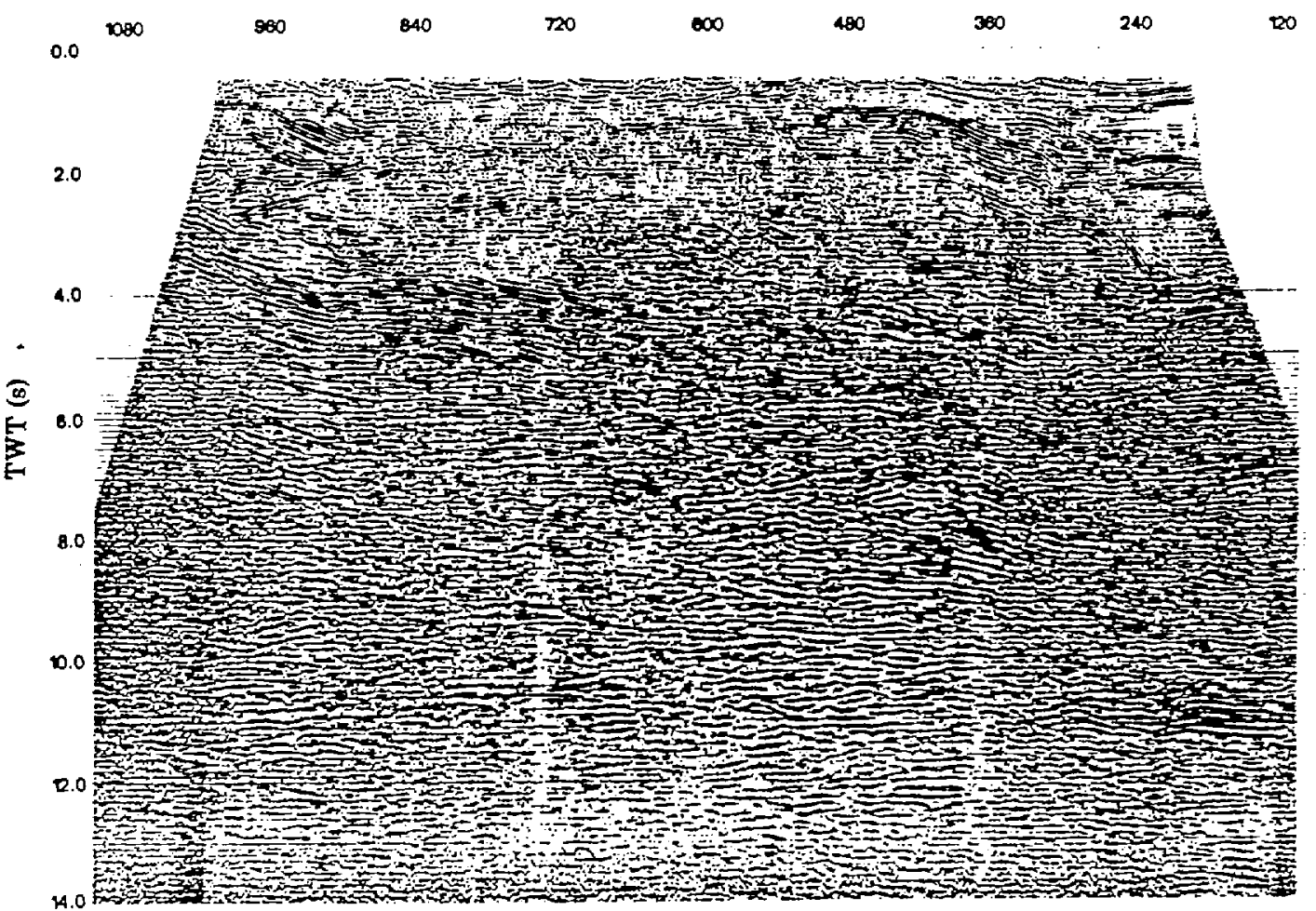

(b)

Bairiang

CDP number

Niujiaqiao

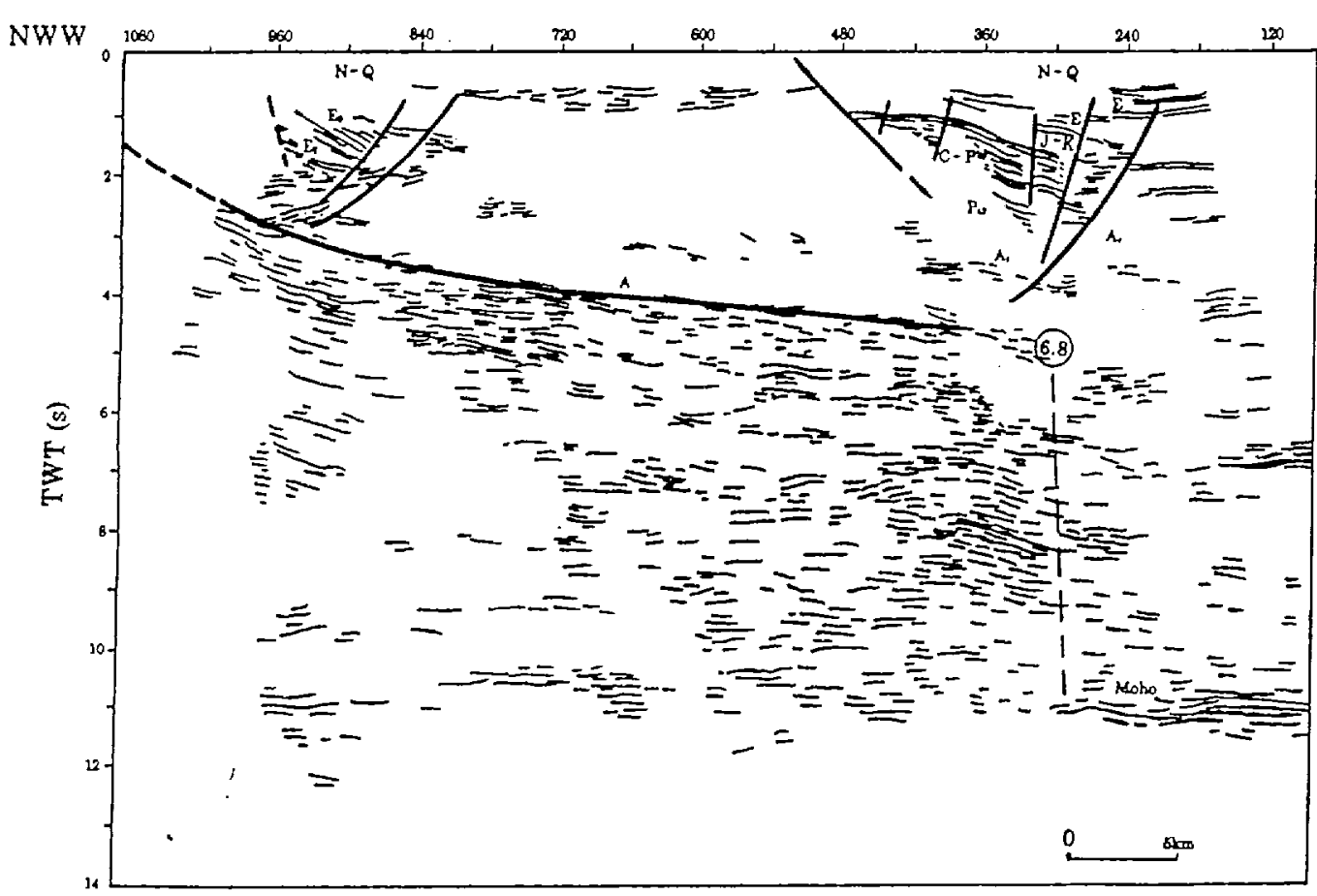

Fig. 5 Data processing section of profile B with line drawing. (a) CDP stacking section; (b) line drawing. " $A$ " is detachment; dashed line is the inferred high-angle fault; and circle is the focus of first shock $(M s=6.8)$. 
(a)

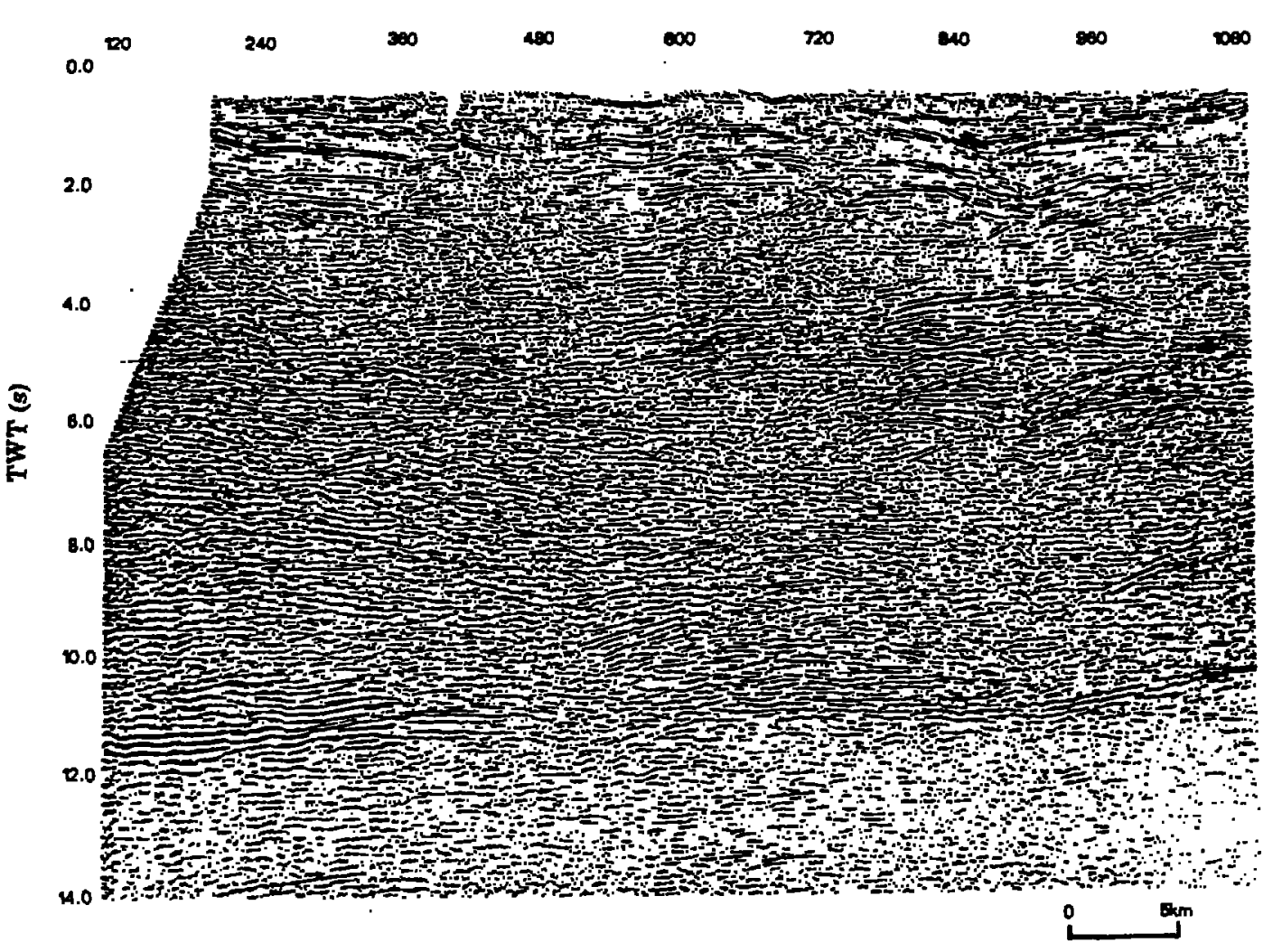

(b)

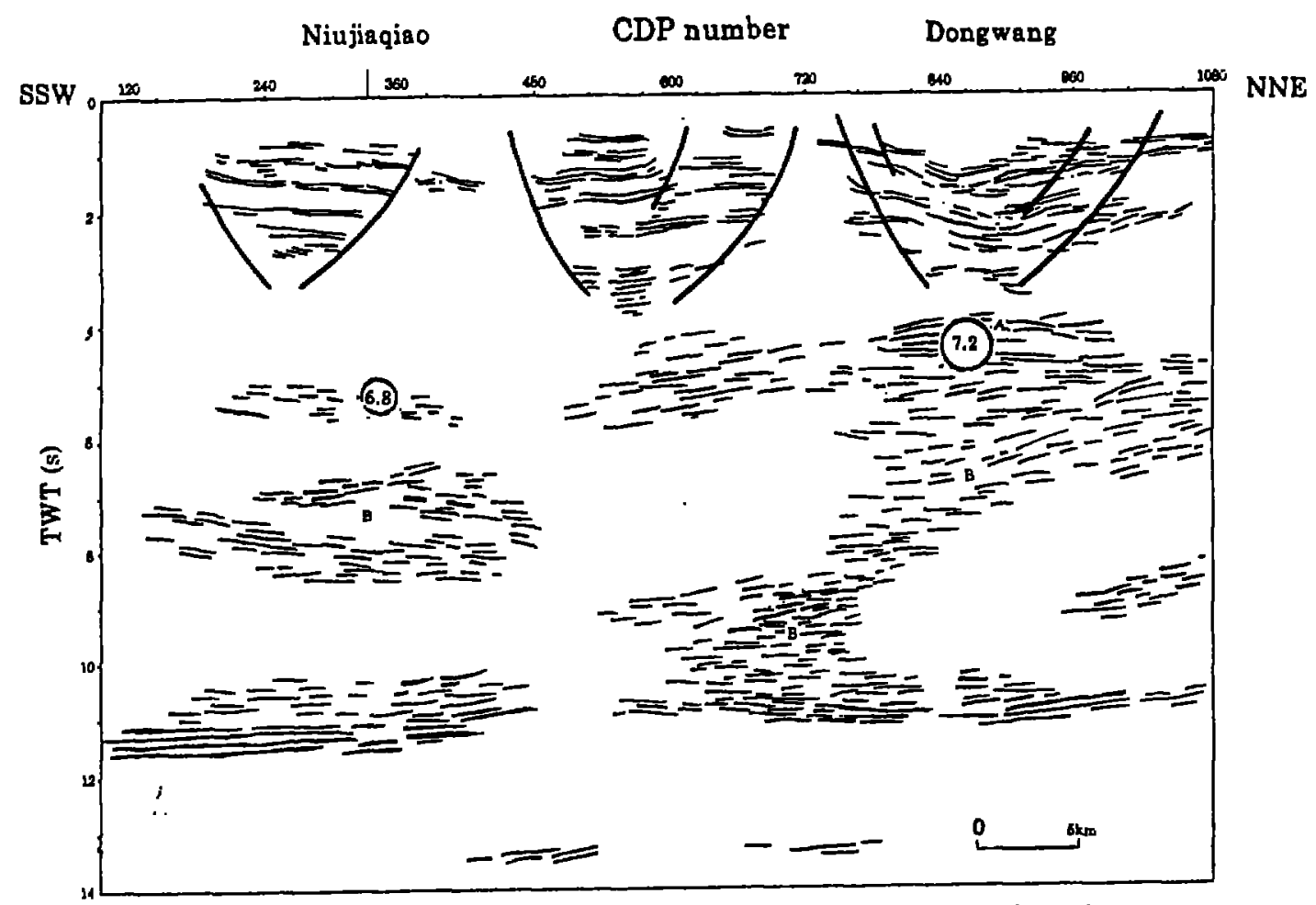

Fig. 6 Data processing section of profile $C$ with line drawing. (a) CDP stacking section; (b) line drawing. Two circles denote the foci of first shock (Ms=6.8) and main shock (Ms=7.2); "A" is arcuate event, "B" is crocodile event. 


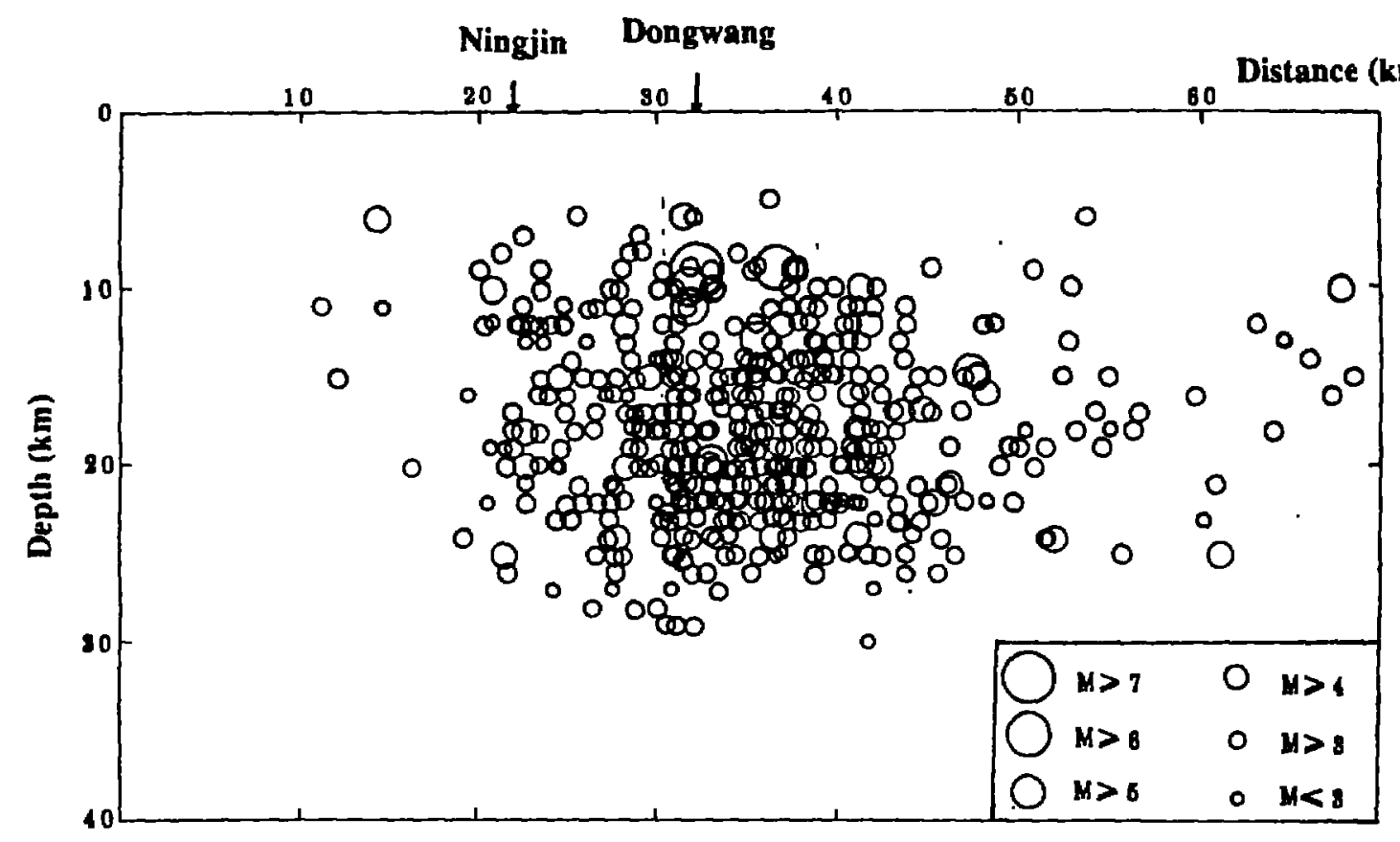

Fig. 7(a) Hypocentral location of the Xingtai earthquakes with $M>2.8$ along profile A. Locations of Ninjin and Dongwang are shown in Fig.2.

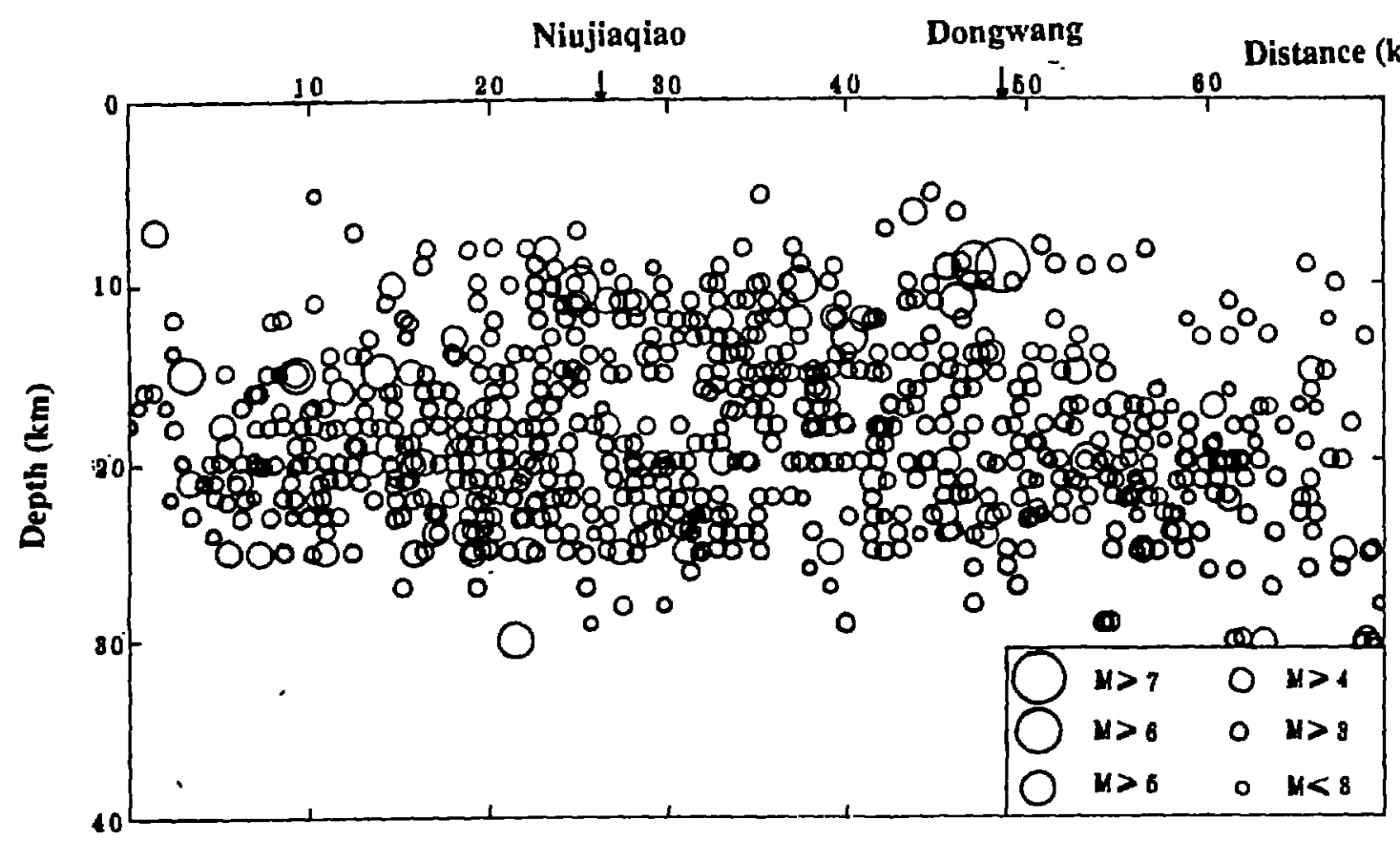

Fig. $7(\mathrm{~b})$ Hypocentral location of the Xingtai earthquakes with $M>2.8$ along profile $C$. Locations of Dongwang and Niujiaqiao are shown in Fig.2. 


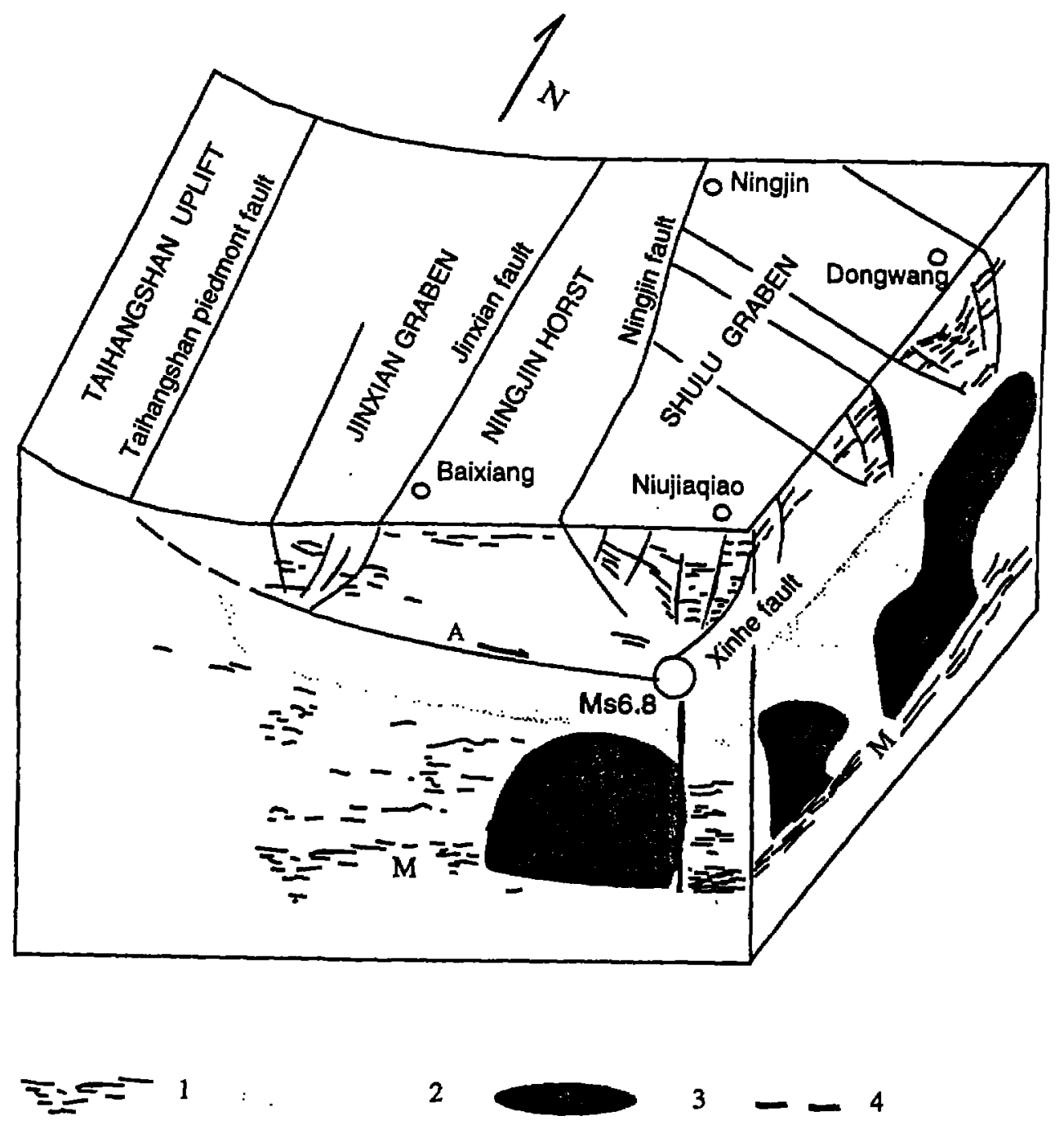

Fig. 8 Three-dimensional sketch of the crustal structure in the Xingtai earthquake area, where " $A$ " is the detachment, "M" is the Moho discontinuity, and 1: reflection events. 2: low velocity zone, 3: Magma intrusion area, 4 : inferred fault. 


\section{Explanatory Notes}

\section{for \\ Global Geoscience Transect \\ Golmud - Ejin Transect, China}

Responsible Institutions: Lithosphere Research Center

and Institute of Geology,

Chinese Academy of Geological Sciences

Project Leaders: Wang Zejiu, Wu Gongjian and Xiao Xuchang

Chief compilers: Wu Gongiian, Liu xun, Gao Rui, Deng Jingfu, and Yao Peiyi

participating Institutions:

562 Comprehensive Research Team, CAGS

China University of Geosciences, Beijing

Changchun College of Geology

Chengdu College of Geology

Institute of Geology, Academia Sinica

Geological Publishing House Beijing

1997 


\section{Chapter 1 Introduction}

The Golmud-Ejin geoscience transect interdisciplinary research is a key project supported jointly by the Ministry of Gcology' and Mineral Resources (MGMR) of China and the National Natural Science Foundation of China (NN.SFC). It is the second geoscience transect compiled "ith financial support of the MGMR and NNSFC following the completion of the YadongGolmud geoscience transect. The main purpose of the transect is to study the structure and formation mechanism of the crust and lithosphere of the transect corridor and its neighboring areas. to study the kinematic process and dynamic mechanism of the formation and deformation of the continental lithosphere, to probe into the formation of the northern boundary of the Qinghai-Tibet plateau and its dynamic relation with the collision of the Indian and Furasian platcs. and to ascertain the deep-scated tectonic background of the distribution of mincral risources and the occurrence of natural hazards in the study region.

Upon completion this transect will be linked with the early-completed Yadong-Golmud transect to form a long geoscience transect running from south to north across the western continent of China. which will successively displays the entire structure of the continental lithosphere from the Qinghai-Tibet plateau to the Beishan Mountains in a completely new form and make it possible to study the uplift mechanism of the Qinghai-Tibet plateau and the decpseated geological background influencing the distribution of mineral resources and natural hizzards from an analysis of the formation of the continental lithosphere and the kinematic and dynamic process of deformation. Therefore this long geoscience transcet is bound to become a Iypical transect of the continental lithosphere in western China or Asia and even the world.

There are four items under the Project: geology. geophysics. geochemistry and comprehensive research. In 1992 the Project was approved by the Department of Science and Tichnology (DST) of the MGMR and then the research began. The responsible orgalizations are the Lithosphere Research Centre (LRC) of the Chinese Acadeıny of Geological Sciences (CAGS) and the Institute of Geology (IG) of the MGMR. The main participating organizations (which refer to the organizations responsible for various special subjects under the Project) include the 562 Comprehensive Rescarch Team of the CAGS. China University of Geosciences (lseijing). Changihun College of Geology. Institute of Geology: Acadimia Sinica and Chengdu College of Geology. In addition, the Institute of Geology, Bureau of Geology and Mineral Resources of Gansu province took part in the work of the Tectonics Group, the Second Geophysical Prospecting Party of the MGMR took part in the field work of deep seismic sounding and the Institute of Geophysics of the Academia Sinica took part in the indoor processing of deep scismic data. The main participants totaled about 40. most of whom were professor researchers and associate professor rescarchers.

Through four years of coordinated efforts. we completed the field surveys and laboratory work. On the basis of the first items of work and the comprehensive research of the last item, we accomplished the compilation of the transect and its explanatery notes, studied the terrane 
division, features of major faults and tectonic evolution in the transect corridor, made geophysical interpretations and geodynamic analysis and studied the existing problems.

The maps of the transect were compiled by the following relevant special subject groups.

Index Maps: Yao Peiyi

Geological Strip Map: Chen Bingwei and Wang Yanbin

Gravity Strip Map: Meng Lingshun, Gao Rui and Guan Ye

Magnetic Strip Map: Yu Qinfan and Lou Hai

5-10 km Factual Cross Section: Liu Xun and Chen Bingivei

Geophysical Interpretations: Gao Ruj et al.

Interpretative Cross Section: Liu Xun, Gao Rui and Deng Jinfu

Time-Space Flow Chart: Liu Xun and Wej Guangming

Map of Block Migration: Dong Xucbing

Dynamic Model: Gao Rui and Wu Gongjian

Legends: Liu Xun and Yao Peiyi

The explanatory notes were written by Liu Xun and Gao Rui, the explanations of relevant maps were provided by the related groups of special subjects and the preface and concluding remarks were written by Wu Gongjian and Wang Naiwen.

We are grateful to the leaders and persons in charge of the MGMR Department of Science and Technology and the NNSFC Geoscience Division for their direction during the research.. 


\subsection{Gcophysical Interpretations}

This map represents parameters of major physical properties in detail, to give a comprehensive interpretation of lithospheric structures in the Golmud-Ejin geoscience transect and describes the downward extension, assemblage and system of the major tectonic elements such as faults on terrane boundaries. The detailed description will be found in Chapter 4.

The Woho deph along the whole transeet was determined by deep seismic sounding and checked by inverse interpretation of gravity profiles. To make the map seen distinctly, data arrays are used to represent interfaces and velocity structures of the crust and 2-D rariation curves of the velosity are illustrated as an insert map in Chapter 4.

The electrical structure of the transect was clarified based on the inverse results of MT and shown by a columnar diagram of electrical resistivity is. depth with the resistivity values (unit: (2.m) printed nearby. The two-dimensional method was used to interprei lateral variation of the clectrical stucture and the result is shown in this booklet.

Characteristics of the lithospheric geotemperature field of the major toranes were inferred in terms of measured geotemperature curves and expressed by temperature.'depth curves. Twodimensional variation of the geotemperature field determined by one-dimensional results is shown 
in Fig.4-2.

To reduce the map's burden, the density structure is not shown in the map but discussed in Chapter 4 instead.

\subsection{Interpretative Cross Section}

This map represents the ultimate result of this research project on the basis of integrated analyses combining geological, geophysical and geochemical data acquired in the course of the research work. The compiled section map summarizes the knowledge of the material composition. structure and evolution of the crust in this transect. The materials and data used for the map compilation were mainly taken from the following work.

(1) Surfacc geological investigation

This investigation presented ideas concerning surficial structures of the crust by means of the $5-10 \mathrm{~km}$ geological section. It was conducted through comprehensive analyses on stratigraphy, biotas, sedimentary formations, magmatism, metamorphism and tectonic deformation of different tectonic units and terranes at surface. This work describes the components. vertical and horizontal variations of the deep or shallow structures shown in the map.

(2) Geophy'sical investigation

Integrated analyses of gravity, magnetic, electrical, seismic: geothermal data and surface waves were done and the map of geophysical interpretations was compiled, which provides a basic frame for interpreting the structure of the deep crust by using this transect. In consideration of the ambiguity of geophysical data interpretations, more geological data should be taken advantage of in order to give more realistic results.

(3) Geochemical investigation

Analyses werc carried out for the composition and metamorphic state of the deep crust (primarily the middle and lower crust) based on typhonic rocks and deep inclusions observed on surface and experimental results of temperatures and pressures for the formation of deep materials along with such data as density, velocity and temperature provided by above geophysical fields. This map mainly shows matcrial compositions, while various symbols denoting metamorphic processes are overprinted to illustrate their spatial distributions and variations and the relationship with tectonic evolution.

$\Lambda$ distinctive feature presented in the map is the apparent vertical and horizontal inhomogencity of the crustal composition and structure in all zones traversed by the transect. Vertically, layering of the crust is exhibited; horizontally, different crustal structures are seen from segment to segment of this transect not only in layering and thickness. but also in material composition.

It can be seen in the upper crustal structure that the five ascertained terranes are markedly: distinctive in their structures, indicating that these terranes have different evolution histories. This will be discussed in detail later. The map also shows that the tectonic events occurred in the upper crust have an cvident orientational nature. On the whole, the Beishan area north of the Hexi 
Corridor basin is characterized chiefly by large-scale napping and detachment from north to south; while the Kunlun area south of Qaidam mainly by detachment and napping from south to north. The Qilian Mountains are located between them and thus characterized by southward and northward napping with the south-central Qilian area as the core (the front of the northward napping even reaches the Kuantanshan fault). As a result, a set of nappe systems were formed in the upper crust along the whole transect with Qaidam and the Dunhuang block in the north Hexi Corridor as the core and there also occurred a series of related strike-slip faults. It should be pointed out, of course. that all these phenomena resulted mainly from the crustal stress ever since Cenozoic and are closely related 10 the uplift of the Qinghai-Tibet platcau and the Qilian Muuntains.

Currently available data show that the middle and lower crust within the transect also varies laterally. Geophysical and geochemical studies of this rescarch revealed that the middle and lower crust here can be horizontally separated into three segments.

(I) Thi' Bivian area

The thickness of the crust is gencrally $40 \mathrm{~km} \pm$ and the sverage velocity is $6.29 \mathrm{~km} / \mathrm{s}$. There is no clear mountian root. The upper crust is $14-17 \mathrm{~km}$ thick and the interval velocity increases trom $5.85-5.93 \mathrm{~km}$ to $6.10-6.17 \mathrm{~km}$. Underlying is a low-velocity layer. $7-9 \mathrm{~km}$ thick. with a beloci!n of $6.0 \mathrm{~km}$ 's. However. the velocity contrast of the low-lelocity layer in this area is not very large. Correspondingly, magnetotelluric sounding discovered a clear lou-risistivity layer. where lies the major detachment surface resulted from a series of aforesaid northward napping vents. The interval velocity of the midcrust is $6.5 \mathrm{~km} / \mathrm{s}$ and the thickness is $i-10 \mathrm{~km}$. It consists primarily of grano-dioritic rocks (shown in the map as granitic composition plus dioritic lenses) and exhibits amphibolite facies metamorphism. The interval velocity of the lower crust is 6.9 $(6.75-7.2) \mathrm{km}$ 's and the thickness is $6-10 \mathrm{~km}$. The interval velocity of the top layer of the upper

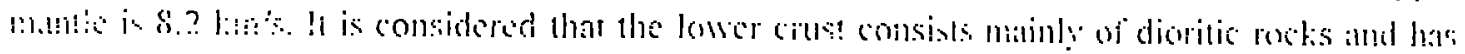
granulite facies metamorphism. In general, the Beishan area has relatively thin crust and no clear low-velocity layer. The lower crust is thinner while the middle and upper crust are thicker in this area. featuring a crustal structure of a stable Meso-Cenozoic continental crust region. In the area south to Yemajing. the Moho begins to dip gently towards the south and the crust thackens graidually:

The cemperature of the top mantle, calculated based on geoihermal data. is $600^{\circ}-700^{\circ} \mathrm{C}$, which is obviously lower than that in the Qilian area of south.

2) 7h: Qilian area

The tota! crustal thickness is $55-70 \mathrm{~km}$ and the average velocity of the crust is $6.35 \mathrm{~km} / \mathrm{s}$. The upper crust is $23-26 \mathrm{~km}$ thick and the interval velocity increases downwards and is up to $6.2-6.3$ $\mathrm{km}$ 's. A clear low-velocity layer rests underneath it with an average velocity between $5.8 \mathrm{~km} / \mathrm{s}$ and $5.9 \mathrm{~km}$ 's. Its thickness varies between $9 \mathrm{~km}$ and $10 \mathrm{~km}$. The available information shows that a series of nappe structures in this area converge downwards near the base of this low-velocity layer and it is naturally a stress-concentrated position responsible for the northward and southward 
napping and detachment of the Qilian Mountains. It is shown by MT that this layer is composed of a set of low-resistivity zones and epicenters of modern carthquakes are also concentrated near the top of this layer. This probably results from intensive mylonitization caused by structural gliding along this layer. The average interval velocity of the midcrust in this arca is $6.35-6.5 \mathrm{~km} / \mathrm{s}$ and the thickness ranges from $8 \mathrm{~km}$ to $11 \mathrm{~km}$. This part of the crust is inferred to be granitic with granulite facies metamorphism. The average interval velocity of the lower crust is $6.8 \mathrm{~km} / \mathrm{s}$ and the thickness is $20 \mathrm{~km} \pm$. It can be inferred that this crustal layer consists mainly of grano-dioritic rocks and has high-pressure granulite facies metamorphism. Some eclogites and high-pressure metamorphic rocks occurring in the southern and northem Qilian areas are likely related to this layer. These rocks were outcropped when this crustal layer was pushed upwards.

Unlike other areas, the crust in the Qilian area is very thick, which is believ'ed to be caused by a special mountain root belt. This root belt is predominantly dioritic and probably contain a large amoun of eclogites and lenses of pyrolites. It is characterized by eclogite facies metamorphism. The bell bas its thickest part around the area from Har Lake to Juhongtu, up to $18-20 \mathrm{~km}$, and it gets thinner remarkably towards the southern and northern sides until it is absent at last. Because of this mountain root belt the southern Qilian area becomes strikingly distinctive from other areas for its great crustal thickness.

In the meanwhile, the temperature at the top of the upper mantle is much higher than that of the both sides of this area, which is evaluated to be as high as $850^{\circ}-950^{\circ} \mathrm{C}$. This indicates that there exists a hot mantle around here. The crustal structure of the whole Qilian area is characterized by a tectonically active belt.

(3) The Qaidam area

The crust in this area is $50-53 \mathrm{~km}$ thick in total and thickens both southwards and not thwards. The average velocity of the crust is $6.15-6.17 \mathrm{~km} / \mathrm{s}$. Based on the velocity structure it can be divided into the upper and lower parts with no middle one, which corresponds to interval velocities of $6.4-6.5 \mathrm{~km} / \mathrm{s}$. The upper crust is $30-35 \mathrm{~km}$ thick and its velocity changes from 5.7 $\mathrm{km} / \mathrm{s}$ to $6.3 \mathrm{~km} / \mathrm{s}$. This part can be further divided into two layers. The upper one is a sedimentary cover and crystalline basement, while the lower is a granitic-grano-dioritic layer with greenschist to low-grade amphibolite facies metamorphism. In the middle of the upper crust, there exist a set of low-resistivity zones detected by MT, which probably indicates a detachment-nappe belt under the Qaidam basin. The lower crust is about $15-20 \mathrm{~km}$ thick and its interval velocity ranges from $6.6 \mathrm{~km} / \mathrm{s}$ to $6.8 \mathrm{~km} / \mathrm{s}$. It consists chiefly of intermediate rock series and thickens evidently towards the mountain chains on both sides of the basin. The temperature of the top mantle is also rather low. calculated to be $500^{\circ}-600^{\circ} \mathrm{C}$. which represents a cool mantle in this area. The facts described above actually represent the features of the crustal structure in an old stable region and these features differ greatly from those of the mountain chains on both sides of this area.

The diversity of the crustal structure within the transect is a composite product of various; geological effects during a long geological history. However, it especially reflects the present geolngical state. Some historical events, such as the opening. subduction and collision of plates. 
could find their marks merely at several depths or in varying degrees. Especially the Paleozoic subduction zones and variation of the crustal structure of the plate on both sides of the Paleozoic collision zone can even hardly be identified at present due to the reworking in the period of 200 Ma ever since the Paleozoic.

The faults in this transect, including those on the terrane boundaries, ductile shear zones formed later, large nappe structures, strike-slip faults and some deep-seated faults recognized in terms of geoplyysical data, are all illustrated in the cross section in a suitable form.

Those fa:!lts possess the following characteristics, which have been learnt on the basis of the information currently available.

(1) Most of the faults have their long active periods, especially the faults on the boundaries of some terranes. Some of them were crustal convergence zones in the Caledonian and Variscan ages and became active again in the Mesozoic due to subsequent new tectonic stresses.

(2) Except some old crustal convergence zones identified in the middle and lower crust, most of the faults, especially the Mesozoic and Cenozoic ductile shear zones and large detachment and nappe structures, do not reach or cut to Moho surface, but are terminated somewherc around the top or hase of the midcrust, or disappear in the low-velocity layers of the miderust.

(3) It is indicated by existing data that these faulting events, especially those of the Cenozoic. are obviously characterized by shearing and strike-slipping. Induced by these events, eruptions of basic magmas originating from the upper mantle have taken place (the northern Qilian area is typical of this case) and there are also a series of modern earthquake activitics.

(4) What should be emphasized is the Kuantanshan fault. The reflection survey revealed that this is a listric fault with the upper part stecper than its lower part and absent at the top of the lower crust, clearly exhibiting a nature of northward napping. Regionally, this fault is regarded as the east extension of the giant Altun strike-slip fault. We, therefore, proposed that it is a part of Whe Altun faul: and a crustal convergence belt closed in the Late Palcozoic, along which strong overthrusting and napping occurred again in the Mesozoic and Cenozoic eras. Especially since the Cenozoic this area is characterized by large-scale sinistral strike-slip movement and becomes a major belt of seismic activity in the present day.

Details will be given in Chapter 3 to describe the specific features of all above-mentioned faults. 


\section{Chapter 5 Concluding Remarks and Unsolved Problems}

Valuable information and data have been gained by combining geological, geophysical and geochemical techniques in the research of the Golmud-Ejin geoscience transect and a map was compiled in light of the unified requirements stipulated by the ICL. The research hows the amalgamation. accretion and formation of the lithospheric blocks in the Qinghai-Tibet plateau and the Beishan orogenic belt. It also shows the structure and composition of the lithosphere and the kinematic process and deep dynamic mechanism of its tectonic evolution and deformation. The research has provided a deep geological basis for hunting more mineral resources. reducing gcological hazards and protecting environment. This transect. when con, zcted with the YadongGolmud geoscience transect. is of particular significance to under.tand the uplift of the whole Qinghai-Tibet plateau. Compared with the Yadong-Golmud transect. this research project involves more tasks and has employed some new methods, including: (1) a subvertical reflection seismic profile (COCORP), which is about 100km long: (2) an intensive geochemical research: (3) iumograply and remote-sensing technique; (4) digitization of geological information and computer-aided map plotting; (5) integrate researches combining geochemical and geophysical investigations along with studies on tectonics. and compilation of a vertical geological interpretive section: and (6) animation of terrane movement.

Major achievements of the research are as follows.

(1) For a long time, the frontal fault of the Qilian Mountains was regarded as the northerm boundary of the Qinghai-Tibet plateau. However. an inclined reflection seismic phase was found on the reflection profile in the time interval from $5 \mathrm{sec}$. to $9.5 \mathrm{sec}$. and continues downwards to the lower crust or even to the Moho. which has also been confirmed by other geoplyysical methods: whereas the frontal fault of the Qilian Mountains has relatively short extension. terminating in the low-velocity layer at the base of the upper crust. We. therefore. concluded that the newly discovered fault - the Kuantanshan fault should be the northern boundary of the plateau.

(2) Eclogites have been found on the northern margin of the Qaidam basin. indicating that this area is a high pressure-ultrahigh pressure metamorphic belt and probably the west extension of the Sulu (Jiangsu-Shandong)-Dabje high pressure metamorphic belt. Moreover, this research ascertained that the northern margin of the basin is also a giant ductile shcar zone.

(3) The Qilian mountains had their orogenic stage in the Middle-Late Jurassic and were involved in the cxtensive uplift of the Qinghai-Tibet plateau following denudation and planation in the Paleozoic, superimposed deformation in the Mesozoic and rejuvenated orogeny in the Pleistocene. Reflection seismic survey shows that the Tertiary is covered by older strata. which again indicates that the thrusting and overlapping were active in the Cenozoic.

(4) The uplifi of the Qilian mountains can be represented by a multifacior model of a botllemouth sye: thrusting and overlapping were caused at first by two-directional compression to force the crust to be folded and then deep matcrials wcre added to the lower crust to make this part of crust thickened. 
(5) The above model was tested by tectonic stress field simulation and it is found that the present Qilian Mountains can be successfully modeled only in the case that the applied force on the north side is greater than that on the south. This suggests that the effect of the India plate has hicon remarkably lessened here.

(6) The Beishan structural belt is characterized by apparent thrusting and napping from north towards south and composed of a set of rootless sheets.

Obviously these ideas have yet to be further proved. Besides, owing to the time limitation. particular location of the study area and limited funds of this research work, there are still some problems to be studied.

(1) Reflection seismic survey proved that the Kuantanshan fault, which traverses the Hexi Corridor basin, is a thrusting fault extending downwards to the middle and lower crust. It is possibly the principal boundary fault of the northern margin of the Qinghai-Tibet plateau. Correspondingly, the basic features of the Qilian Mountains in the orogenic process are very similar to those of the Himalayas on the southern margin of the Qinghai-Tibet plateau and. fillhermore, both of them have almost the same time limits in their development after the Oligocene. The Kuantanshan and Altun faults probably belong to the same structural sy'stem and "le deduce that the former is the east extension of the latter. This idea, however, has not been confirmed by the deep reflection profile across the east of the Altun and Qilian Mountains yet, so we are not able to make a final conclusion in this respect from the viewpoint of regional tectonics. L.ikewise. we have used only refraction data at present to infer the northern margin of the Qaidam basin as a steep north-dipping thrust fault and made only a tentative discussion regarding the downward extension of the faul in the Kunlun area because no reflection seismic data are avialable. In one word. characteristics of the deep structures in the major areas or segments of the transect corridor cannot be further clarified until more deep reflection data are acquired.

12) The preseni layer model of crustal materials was butilt primarily based on velncities and densities obtained in geophysical investigations and general experimental petrological data. but lithochemical features and other geophysical information of the transect corridor and neighboring regions were not effectively utilized. This is also because special and detailed geochemical studies could not be conducted in this research. There are still more problems with the model. such as how the layering of the crustal materials was figured out and what influence the matcrial layering will exert on the preseit crustal uplift and tectonic events now that the model represents the present state of the materials. It is noticed that Cenozoic pyrolites were found in the Kunlun and Qilian : Nountains and that ultrahigh pressure metamorphic rocks (eclogites) found on the nortinern margin of the Qaidam basin. so a special comprehensive geochemical and geological research project seems necessary for the study of their deep occurrence and the mechanism of their emplacement up to the surface.

(3) Some assessment reports have reckoned that the uplifting and orogeny of the nerthern margin of the Qinghai-Tibet plateau were the events mainly in the period from the Pliocene ilrough to the Cenozoic. but the assessment could not be done stage by stage as in the case of the 
Hlimalayas due to lack of systematic dating and quantitative analytical data. For this reason. we need to conduct quantitative analyses and sy'stematic dating for uplifting terranes (e.g. the Qilian and Altun Mountains) and frontal basins of mountains (e.g. the Hexi Corridor basin and the frontal basin of the Altun Mountains). We have proposed an orogenic model of the Qilian Mountains by simulating the structural stress field, i.e. bi-directional compression (the 10ithern component larger than the southern one) plus southward and northward thrusting and napping along the intracrustal detachment layer (the low-velocity and high-conductivity layer). We think this model was buili on good grounds. Then the orogenic process of the Kunlun Mountains tends to be an important problem concerning the orogenic mechanism of the Qinghai-Tibet plateau.

(4) As for the analysis of historical tectonics we hold that the transect corridor and adjacen regions are separated into different parts belonging to different plates or terrane groups by some small Precambrian-Early Paleozoic ocean basins (e.g. the northern central Qilian fault and the Shiban:ing-Xiaohuangshan fault). A further question would be how these small ocean basins are related to the large global ocean basins and how these plates or terrane groups are related to the lirge global plates both in time and in space.

(5) It is commonly considered that the transect corridor and adjacent regions wimessed wo subduction-collision events in the Late Paleozoic besides the Early Paleozoic. Calc-alkaline magmatic activity can be the convincing evidence of the collision. Nevertheless. this understanding is short of such evidence as syntectonic ocean crust rocks (typical ophiolite) and s:lbuliction complexes (accretionary wedges). The Permian alkaline granite belt in the northern Beishan area is part of the gigantic magmatic belt stretching from Inner Mongolia to Junggar. which is generally regarded to be related with rifting. but an interesting question is what is the relationship between this belt and the subduction-collision. All these problems remain to be solved in our future researches. 


\section{REFERENCES CITED}

An Changqiang. Song Zhonghe,Chen Guoying et al., 1993, 3-D shear velocity structure in north-west China. Acta Geophysica Sinica. V. 36, p. 27-36 (in Chinese, with English abstract).

Arnaud N.O.. Ph, Vidol.. Tapponnier, P..Ph, Matte.,and Deng, $\mathrm{W}$.M..1992. The high $\mathrm{K}_{2} \mathrm{O}$ volcanism of northwestern Tibet: Geochemistry and tectonic implications. Earth and Planetary Science Letters, V.111,p. 351-367.

Arvuac J. P.. and Tapponnier P.. 1993, Kinematic model of active deformation in Central Asia. Geophy's. Res. L.etl. V.20. p.895-898.

Bourjot L. \& Romanowicz B._ 1992, Crust and upper mantle tomography in Iibet using surface waves. Geophys. Res. Lett. V.19, No.9. 881-889.

Burchfiel B. C.. Chen Z., Hodges K. V. et al., 1992, The south Tibetan detachment system, Himalayan orogen: Extension contemporancous with and parallel to shortening in a collision mountain belt. Spec. Pap. Geol. Snc. An.. 269, 1-41.

13urciu of Geology and Mineral resources of Gansu Province, 1989, Regional Geology of Gansu Province. Geological Publishing Housc, Beijing. China (in Chinese, with English abstract).

Bureau of Geology and Mineral Resources of Nei Mongol Autonomous Region, 1991, Regional Geology of Nei Mungol (Inner Mongolia) Aautonomous Region. Geological Publishing House, Beijing, China (in Chinesc, with English abstract).

I3ureau of Geology' and Mineral Resources of Qinghai Province, 1991, Regional Geology of Qinghai Province. (icological Publishing House. Beijing, China (in Chinese, with English absiract).

(her Bingwei. Yao Peosi. Guo Xianpu, Liu Xun and Dong Xucbing, 1996. The tectonics and evolution of tarranes in the north part of the Qinghai-Xizang (Tibet) plateau. Geological Publishing House. Beijing.

Chen Zhiliang and 5 others, The south Tibetan detachment system. Tethyan geology; 1995, No. 20, (in Chinese with English Abstract).

Chern Yuntai. Xu L.. S.. LJ X.. Zhao M., 1996, Source Process of the 1990 Gonghe, China, earthquake and tectonic stress field in the northeastern Qinghai-Xizang (Tibet) Plateau. PAGEOPH, V.146, No.3/4, 697-715.

Coleman R. G.. 1989. Continental growth of Norhwest China. Tectonics, V.8, No.3, pp.621-635.

Cui Zunzhou. L.i Qiusheng. W'u Chaodong. Yin Zhouxun and Liu Hongbing. 1995, The crustal and deep struclures in Golmud-Ejin Qi GGT. Acta Geophysica Sinica, V. 38. Supplement II, p. 15-28

Dickinson W. R.. 1974. Plate tectonics and sedimentation. in "Tectonics and Sedimentation", edited by IV.R.IJickinson. Spec. Publ. Soc. Econ. Paleon. Miner. 22. Tulsa. pp.1-27.

1)in:- Zhongsi and Shen Yunqing. 1992, An inversion of physical parameters of the carth's interior in the Chaidamu basin. Acta Goophysica Sinica. V. 35, p. 613-620.

Fu Rongshan. Huang Jianhua.Liu Wenzhong, et al., 1994, Correlation cquation between regional gravity isostatic anomalies and small scale convection in the upper mantle. Acta Geophysica Sinica, v. 37. p. 638-646 (in Chinesc. with English abstract).

(jiv) Rui, 1990. The deformation of lithosphere and continental crust movement in the Qinghai-Tibet Plateau. Annual of the (hinese Geophysical Society: Seismological Press. Beijing. (in Chinese). p.121.

(iik) Rui. Wu Gongiian.1995. Geophysical model and geodynamic process of Yadong-Golmud geoscience tansect in Qinghai-Tibet plateat. J. of Changchun Univ .of Yarth Scinces. V.25. p.2+1-250.

(ja) Rui. 1995á. Recent progress in the geophysical investigation of the upper mantle-crust of the Qinghai-Tibet plateau. Chinese Gcolog: No.215, p.26-28. (in Chinese).

(iao Rui. 1995b. Recent progress in the geophysical investigation of the upper mante-crust of the Qinghai-Tibet plateau. (hinese Geology. No.216, p.20-22. (in Chinese)

(iai Rui. Chen Xiangzhou and Ding Qian. 1995. Prreliminary geodynamic moilel of Golmud-Ejin Qi Geiscience Fransect. Acta Cieophysica Sinica, V. 38. Supplement II, p.3-14 (in Chinese. with English abstract).

Ciatudemer Y'.. Tapponnier P. et al.. 1994. Partitioning of crustal sliphetteen linked. active fatults in the eastern Qilian Shan and evidence for major seismic gap. the "lianzhu gap". on the western Haiyluan Fault. (iansu (China). J. Geoplys. Res. (in press). 
Gung 13aojun, 1987. The Prolerozoic in Gansu province. in "Precambrian Geology: No: 3. Inlemationa! symposium on Late Precambrian Geolog:" Geological Publishing House. Bejijing. p.205-218.

Harrison. T. M.. Copeand. P. Kidd. W. S. F. and Y'in A., 1992. Raising Tibet. Science. 255. 1663-1670.

Hirn A.. 1994. Results of the French resarch in Hinalaya-Tibet-Karakorum inthe ficld of seismology applied to deep structure: present day decp scismological structure and the evolution of Himalaya -Tibet. Frelkh Earth Sciences in Himalaya regions. P'ublished by Alliance Francaise. 81-90.

Iluatl wenlin. Shi Zhenliang. Yan jiaquan. Wang Suy un, 1979. Characteristics of the recent lectonic defiormations. of China and its vicinity: Acta Seismologica Sinica. V.I. p.121-132 (in Chinese. with linglish abiliatl).

Howell. D.G. et al, 1985. Tectonostratigrephic terrannes of the Circum- Pacific region. Pub. by (he (ircum-Pacific council for Energy and Mineral resources. Huston. lixas.

Jiang Chunfa et al.. 1992, Openning-closing tectonics of Kunlun Mountains. Giological Puhlishing Housc. Beijing.

L. Chunyu. Wang Quan. Liu Xiueya aand Tang Yaoqing. 1982. Fxplanatory notes to the Tectonic Map of Asia Carlagraphic Publishing Housc. Beijing. China.

Liu Xun. Fu Berong. Yao Peiyi. Liu Guifang and Wing Naiwen. 1992. The stratigraphy. paleogeography and sedimentary-lectonic development of Qinghai-Xizang (Tibet) plateau in ligglu of Terrime anslysis. Gicolngical Publishing House. Beijing.

Liu Xun. Hei Guangming. Fu Derong and W'ang Yong. 1995. Tectonic evolution of terranes in the corridor of Golmud -lijin Qi Geotransect by study. on the sedimentary features. Acta Geophysica Sinicil. 1:. 3.S. Supplement 1l. p.114-129.

Meng l.ingshum. Guan Ye, Qi Li and Gao Rui. 1995. Ciravily field and decp crustal structure in Cislmud-lijin Qicieoscience Transect and Nearby aren. Acla (jeoplyssica Sinica. V'. 38. Supplement II. p. 30-45

Ifulnar P.. 1989. The geologic evolution of the Tibelan Plateau. American Scicmist. V.7. p.35(1-360).

Molnar P. and He'le'ne lyon-Caen. 1989. Fault plane Solutions of carthquakes and active tectonies of the 'libetan platcau and its margins. Gcophysics .I. Int. V'.99. p.123-15.3.

Molnar P.. England P.. and Martinod J.. 1993. Mantle dynamics. uplifi of the Tibetan platealu. and the Indian monsoon. Review of Geophysics. v.31. no.4. p.357-396.

Mlonger I. W. H.. Clowes R. M.. P'rice. R. A.. Simon!. P. S.. Rididihough. P.. Woodsworth. G. I..1985. B3-2 Centennial continentaliocean transect. Juan de fuca plate to Alberta plains. Geol. Soci. Amer.

Nelson K.I).. 1991.Deep seismic profiling and continental evolution in continental 1.ithosphere:Destp Scismic Reflections. Geodynamics. V.22. p.377-382.

[:Jited by Reading H.G. 1986, Sedimentary environments and facies (second). Blackwell Scientific Publication.

Shen Xianjic. Yang Shuzhen and Shen Jịing. 1995. Heat how study and analysis along lhe (iolmud-fijin oji (jotransect. Acta Geophysica Sinica, V. 38. Supplement 11. p. 86-97. (in Chinese. with English abstract).

Song 7honghe. An Changqiang. Chen (juoying of al.. 1991. Study on 31) velocity structure and anisotsop! heneath the west China from the love wave dispersion. Acta Geophysical sinica. V.3.1. p.694-707. (in (hinese. with English abstract).

sun Guising. Thang Dequan and Xu IIonglin. 1995. Chemical characteristics and fectonic emvironments af granitoids in the corridor from Golmud to Ejin Qi. Acta Geoplỵsica Sinica. V. 38. Supplement II. p.145.158.

Wang Hongzhen. chief compiler. Institute of Geology. Chinese Academy of Geolngical Sciences and II'ulham Coilege of Geolng!' 1985. Atlas of the Palacogeography of China. Carlographic Publishing I louse. Beijing.

Wiang Hongzhen. Liu Benpei and Li Sitian. 1990. Geotectonic units and tectonic development of China and adjacent regions. in "Tectonopaleogeography. palcobiogeography of China and adjacent regions". ediled by IVang Hongzhen. Yang Sennan. Liu Benpei et al. Chinese Lniversity of Geosciences Press. Wuhan. p.3-34.

11 ing Xuvun, Xu zhonghuai. and Gao Ajia. 1991. Earthquake mechanisms map in China and its adjacem areas Seismological Press, Beijing. I sheet.

Niu Francis 1 .. Anatoli L. Jes'shin. 1994, Surface-Wave group velocity tomography of Fast Asian. Phy sics of the Farth and Planetañ Interiors. V.84. p.59-77.

Wu Francis T. Anatuli L. Levshin. and Vladmir M. Kozhevnikos. 1995. Rasleigh wave group velocily 
tomography of Siberia. China and the vicinits. summission to (ieophysical Journal Internatonai.

Nu Gungiian. Xiao Xuchang. Li Tingdong. et al.. 1991. Y'adong to Golmud Transect. Qinghai-Tibet Plakcau.

Chinu. Publication No. 189 of the Internationa! Lithospherc Program, AGU,

II u Ciongiian. Gan Rui. Yu Qinfan, et al.. 1991, Integrated investigations of the Qinghai-Tibet Plateau alung the Yadong-Golnud Geoscience Transect. Acta Gcophysica Sinica. V'. 34. p. 552-562 (in Chinesc with linglish abstract).

IIu (ismgjian. Xiau Xuchang. Li Tingdong, Cheng Qingyun. Cui Junwen. Cui Zuozhou.Dong Xuebin. Gao Kui. ct a!. 1993. Lithosphere structure and evolution of the Jibetan PJateau: the Yadong-Golmud geoscience Irimsect. Tectoniphysics. V.219. p.213-221.

Nu Xustrhi. Wu Chunling. Lu Jie aand Wu Jie, 1995, Research on the Fine crustal structure of northern QilianIlexi Corridor by Deep Seismic Reflection. Acta Geophy sica Sinica. V. 38, Supplenient Il. p. 29-35. (in (Chinese. with English abstract).

Siang Ciuangzhong. Lu Dehui. 1990, Formation, cvolution and geodynamic of Hexi corridor basin Annual of the Chincse (ienphysical Socicty. Seismological Press. Beijing. p.128 (in Chinese).

Xim Xushang. Tang Yag̣ing. Feng Yimin. Zhu Baoging. L.i Jingi and Zhao Min. 1992. Testonic cvolution of rorthern Xingiang and its adjacent regions. Goologicul Publushing Housc. Beijing (ia Chinese with Fnglish (thitalit)

Xis Mlinswian. Di Shiqi and Sun 7.iaoyuan. 1992. The tectonic developmemt of the Qaidam basin and distribution wivil-gas accumulation zones. In "Structure of continental lithosphere and mineral resources". edited by Xu (iuizhong and Chang Chengfa. p.224-240

Vu \%honghuai. II ang Suyun. Gao Ajia. Gto J'ing. 199-4.Redetermination examination and compilation of focal mechanism of (hincse earthquakes. Annual of the Chinesc Ceophysical Socicly. Scismological Press. l3cijing. p.133 (in Chinese).

Yai J.deluan. Shi zhenliang. Wang Suy un. Huan Wenlin. 1979. Some features of the recent tectonic stress field of (hina and ens irons, dcta Seismulogica Sinica. V.1, 9-24. (in Chinese with English abstract).

Yau Peis. 1997. Jaleobiogwography of norihern Qinghai-[ibet plateau and adjacebt areas. Geological lublishing Housc. Becijing.

Y: Zliengren. \%hu Rixiang. 1996. Couping detween mantle circulation and lithospheric plates: (II) the manlle's contstion model and its application to explanation of plate velocity field. Acta Cicophysica Sinica. V. 39. p. $15-57$ in (hinest with English ahstract).

Ii (Y:atia!s. Lou Hai and Hu Zhongdong. 1995. Magnetic da:a interpretation of the crustal struciure of the

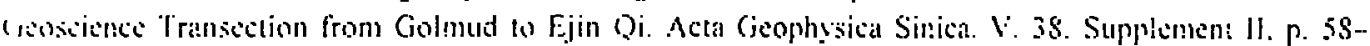

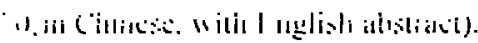

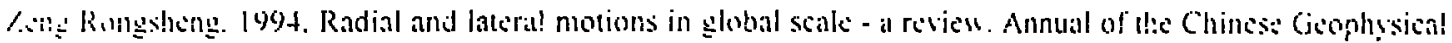

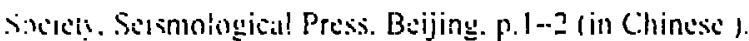

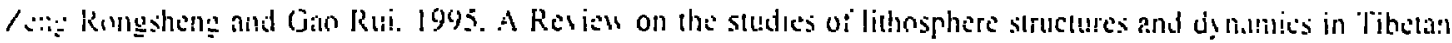

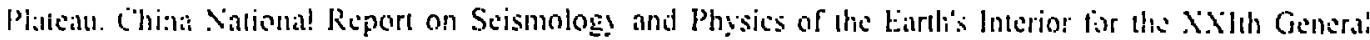
Assemh! of ll:GG. China Meteorological Press. Beijing. p.41-53.

/li.n! Dongning. X!! Zlionghuai. 1994. The simulaton of normal faul! stress state in upper crust southern Ginghai-Tibet Platcau. Annual of the Chinese Cieophysical Socict: Sci:mological Press. Beijing. p.134 (ii) (hiliesse).

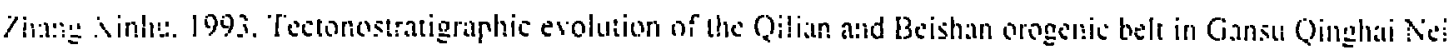

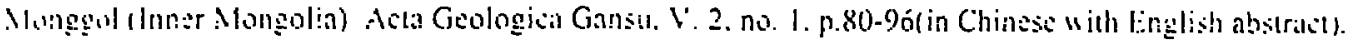

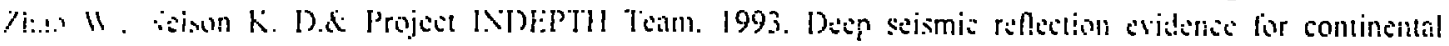

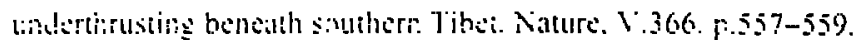

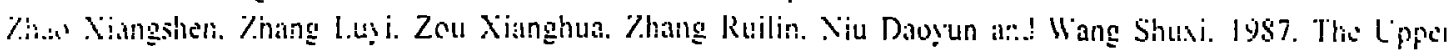

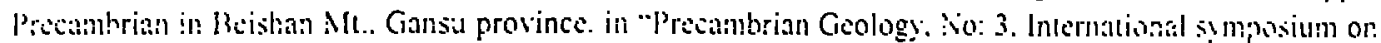
1.Ale Precinmbrian Gcology". Geolngical Publisting Housc. Baijing. p.219-22\$.

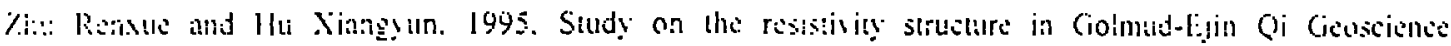

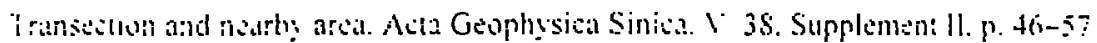


Zhuang Zhen, Fu Zhuwu, Lu Ziling. Song Zhonghe. Chen Guoying, An Changqiang and Chen Lihua. 1992. 3-D shear velocity model of crust aand upper mantle bencath the Tibetan plateau and its adjaccit regions. Acta Geophysica Sinica. V.35, p.694-709.

Zuo Guochao and Liu Jichen, 1987. The evolution of tectonic of Early Paleozoic in north Qilian range. Chinis. Scientia Geologica Sinica, No: 1, p.14-24.

Zuo Guochao and He Guoqi, 1990, Plate tectonics and metallogenic regularities in Beishan regior: Peking L'niversity Press, Beijing, p.194 (in Chinese with English abstract). 
INDEX MAP SHOWING THE DISTRIBUTION OF CHINESE GEOSCIENCE TRANSECTS

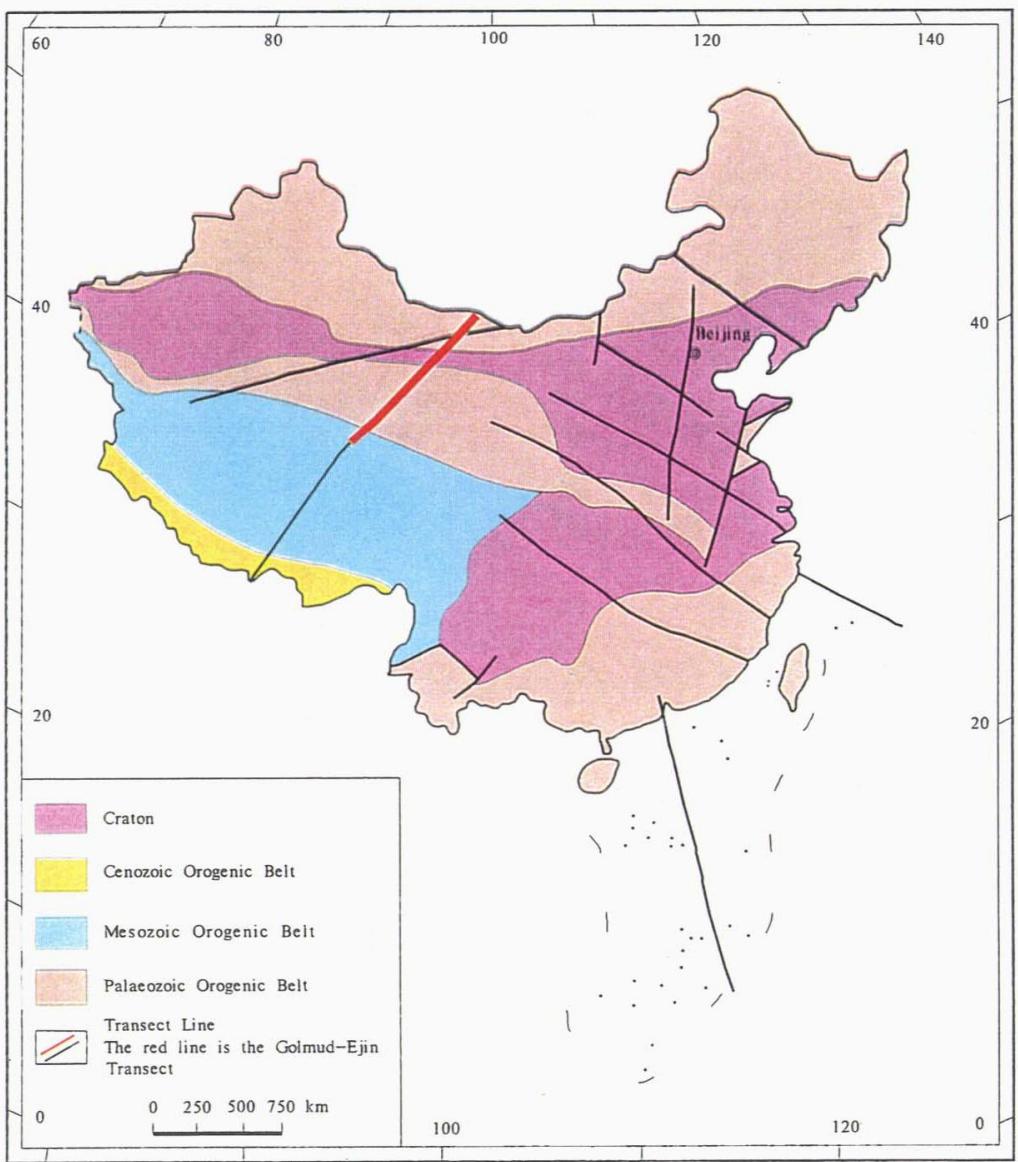

INDEX MAP

SHOWING LOCATION OF GOLMUD-EJIN TRANSECT AND RELATIVE TO TERRANES

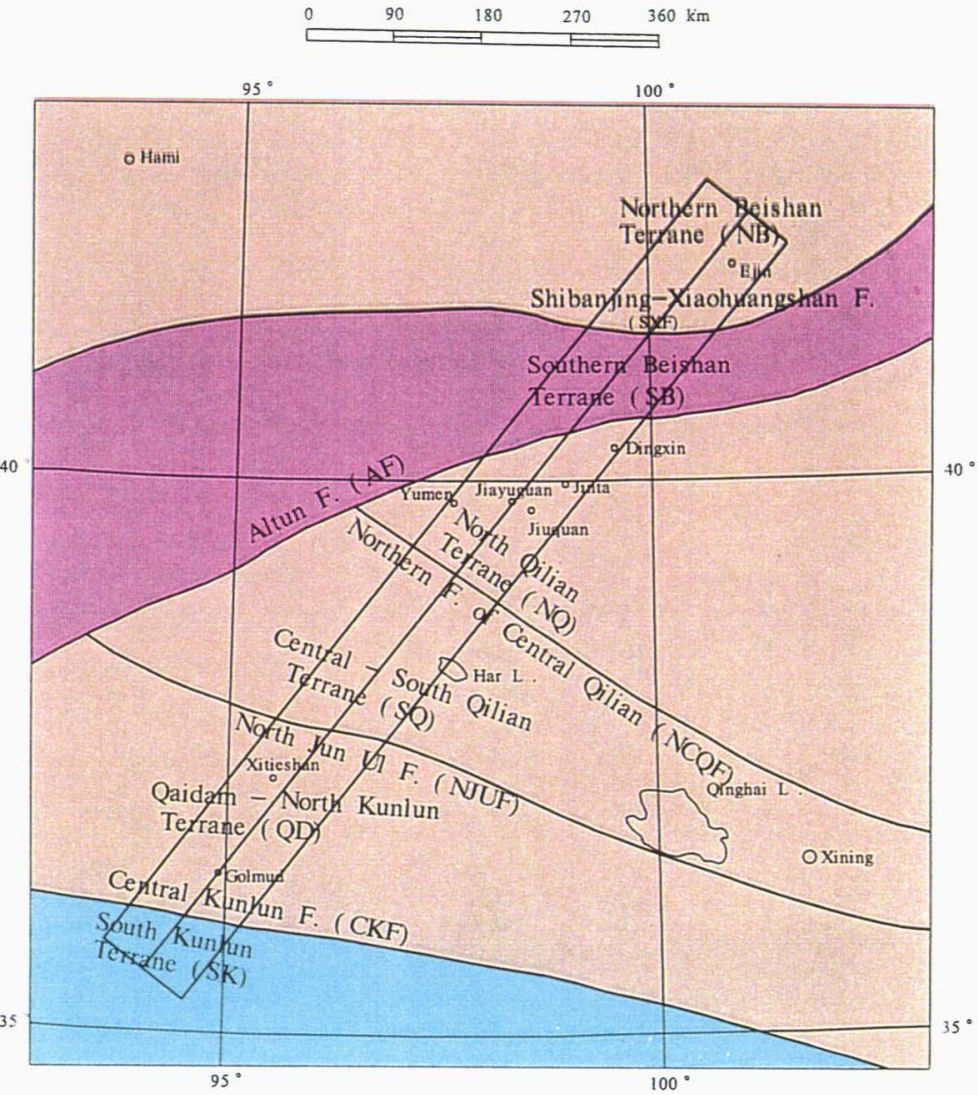




\section{Large \\ Diagram \\ Maps included with Original Report}

For complete Original Report

Call

Reports Library

X37097 
GEOPHYSICAI INTERPRETATIONS

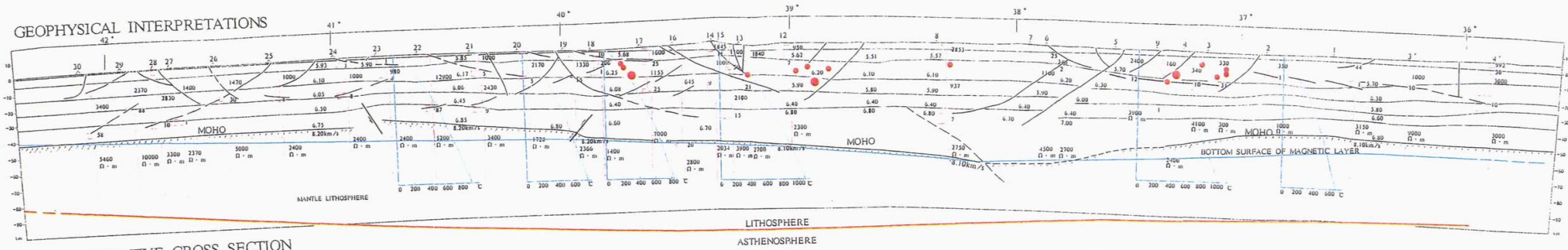

INTERPRETATTVE CROSS SECTION

CORRIDOR BASINQILIAN BELT

- QAidam basin_ 1 Kunlun belt

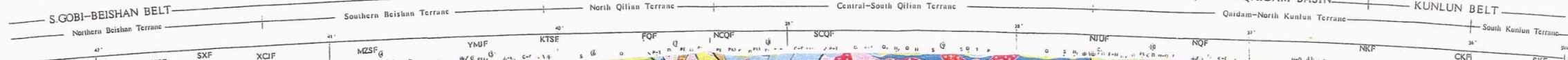

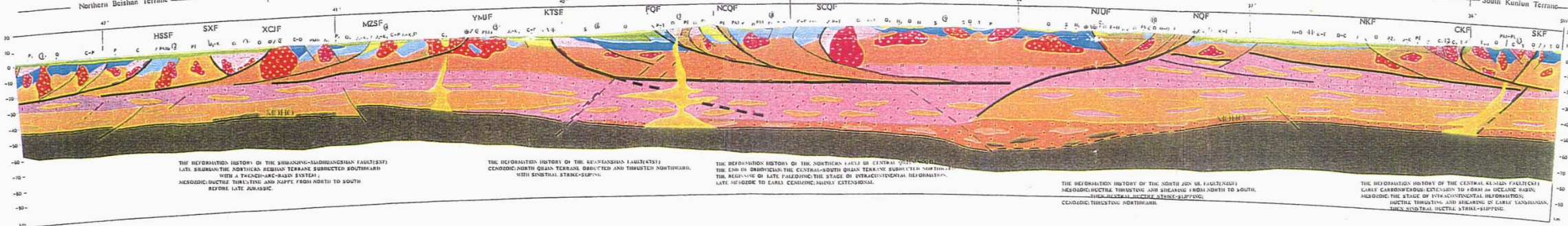


SYMBOLS, COLOURS OF THE TECTONIC KINDREDS (TK)

(FOR THE FLOW CHART AND INTERPRETATIVE CROSS-SECTION)






\title{
A preliminary study on 3-D Velocity structure Beneath Western Yunnan in Southwest China, from Local Earthquake and Deep Seismic Sounding Data
}

\author{
Chun-Yong Wang", Rong-Sheng Zeng", W.D. Mooney", and T.V. McEvilly" \\ 1) Instutte of Geophysics, State Seismological Bureau, Beijing 100081, China \\ 2) US Geological Survey, Menlo Park, CA94025, USA \\ 3) Department of Geology and Geophysics, University of California, Berkeley, CA94720, USA
}

\begin{abstract}
First $P$ arrival time data from 266 local events and 14 borehole shots were used to determine the 3-D crustal structure beneath the seismically active Western Yunnan region in southwest China. An inversion algorithm of the grided model is used to model the entire crust. Although the 3-D model from the inversion is coarse due to the large station spacing in the area, some significant insights are obtaincd from the result. The final model is quite complicated, which may indicate the cvolutionary history of different tectonic units in the study area. At a depth of $41 \mathrm{~km}$ velocity differs on either side of the Red River fault. The lower mean velocity (about $6.2-6.3 \mathrm{~km} / \mathrm{s}$ ) of the crust, and the negative velocity anomaly of the mid-crust in the area are consistent with the tectonically active area. The seismically active zones in the area are generally related to a negative anomaly in the mid-crust, and to a positive anomaly in the upper crust. This may imply that earthquakes occur in area of the upper-middle crust having positive anomaly, and above the negative velocity anomaly zone which may play a rolc in earthquake-generation. In the region between Baoshan and Dali, the negative velocity anomaly in the lower crust is consistent with the weak energy reflection from the Moho at Baoshan shot-NE and the high heat flow values may be related to the magmatism in the region of the Tibet-Yunnan Fold System.
\end{abstract}

\section{Introduction}

Yunnan province in southwest China is close to the China-Burma boundary, and at the northern end of the Red River fault, where there are numerous faults with a northerly and northwesterly trend. These faults are accommodating regional east-west crustal extension and north-south shortening. The Red River fault is considered a deep structural discontinuity associated with the collision between the Indian and Eurasian plates (Molnar and Tapponnier, 1975; Allen et al., 1984). The Western Yunnan is a seismically active region. Since $886 \mathrm{AD}$, more than 200 earthquakes with magnitude $\mathrm{M}>4.0$ have occurred, among them 22 events with magnitude 6-6.9, and 4 earthquakes with magnitude $M \geq 7.0$. The largest event is the Yongsheng carthquake of M7.5 in 1511. The latest is the Lijiang earthquake with $M=7.0$ in 1996. The State Seismological Burcau (SSB) of Clina has conducted a number of investigations on seismology, tectonics and crustal structure for over ten 
years in the Western Yunnan Seismic Experiment Site (WYSES), which is located at the geographical coordinates of $24.5-27^{\circ} \mathrm{N}$ and $99-101^{\circ} \mathrm{E}$. A broad field of earthquake study has been started with China-U.S. seismological cooperation, and the project of crustal seismology in China has had produced fruitful results (e.g., Kan et al., 1986).

The Kunming Telemetry Seismic Network (KTSN) established in early 1980 is monitored with automatic detection and real-time processing of the incoming signals. The establishment of the network is aimed towards the fast response to the earthquake hazard and the study of scismology. There are 18 seismographic stations in the Westem Yunnan. Since 1982, a considerable amount of seismic records have been obtained in the Kunming processing center. In addition, two projects to collect the decp seismic sounding (DSS) profiles were conducted successively in the Western Yunnan area and its vicinity in 1982 and 1987. The data from the DSS profiling were interpreted and 2-D crustal structure models along each profile were presented (Hu et al., 1986; Lin et al., 1993). Six fan profiles in the projects give the ray path coverage of the Western Yunnan area to a degree (Fig. 5), the data have not been exploited until recenuly. An attempt is madc in this paper to obtain a 3-D model in the Western Yunnan based on the first arrival time data from the local earthquakes recorded in KTSN and the DSS profiles (in-line and off-line). We noted that the depth extent of local earthquake tomography models is generally limited by the maximum earthquake focal depths in the arca. Therefore, the 3-D model determined in this study will be coarse due to the large station spacing.

The method of determination of threc dimensional velocity anomalies under a seismic array using $P$ arrival times from local earthquakes is first presented by Aki and Lee (1976). Kissling (1988) has been described the ACH-inversion ( Aki and Lee, 1976) in detail, which is based on the block model. The travel time inversion of local $\mathrm{P}$ arrival is a coupled hypocenter-velocity inversion, and must calculate simultaneously the hypocenter corrections and the velocity corrections by minimizing the global travel timc residual of a largc number of the events (Pavlis and Booker, 1980). After the approach of Aki and Lee (1976), some developments in the representation of structure and the ray path and travel time calculation have been presented, such as the grid model of 'Thurber (1983), and the 'no-block' approach of Tarantola and Nercessian (1984), The model, including the Conrad and Moho discontinuities (Zhao, 1991), the approximate ray-tracing scheme (Thurber and Ellsworth, 1980), the nonlinear inversion (Koch, 1985), and the combination of $P$ and $S$ velocity structure (Ebertart-Phillips, 1990), has been developed. Walck and Clayton (1987) have inverted 'pure noise' synthetic data to assess the level of uncertainty in the model. The recent alternative approach to the ray tracing problem is the finite-difference method of Vidale (1990).

\section{Geologic Setting and Previous Geophysical Results of the Study Area}

The study area is a triple junction zone of the tectonic units separated by the Jinslajiang fault, the Red River fault and the Xiaojinhe-Lijian fault, and bounded by the Yangize Platform to the eash, the Songpan-Ganzi Fold System to the north, and the Tibet-Yunnan Fold System (i.c. the Sanjiang Fold System) to the west and 
southwest. The Songpan-Ganzi Fold System and the Tibet-Yunnan Fold System belong in the Qinghai-Tibet Fold System (Fig. 1). These blocks are different in the history of their development, and caused the region to form a complicated tectonic zone with a variety of structures having different evolution and a high seismicity (Chen et al., 1987). The study area has been subjected to extension and pulling-apart which resulted in the formation of a relatively depressed taphrogenic zone over a background of overall block uplifting and upper mantle upwelling. Many active faults are distributed between the taphrogenic zone and the high mountains. The relief is higher to the northwest and lower to the southeast, with valleys down to $1500 \mathrm{~m}$ in some places and mountains up to $5500 \mathrm{~m}$, cut by a series of rivers originating on the Tibet Plateau.

In the study area, the boundaries between the main tectonic units are generally the major faults which are as follows (Fig. 2): the Red River Fault, the Chenhai fault, the Xiaojinhe-Lijiang fault, the Jianchuan fault (i.c. the Jinshajiang fault), the Qiaohou fault, the Lancanjiang fault, the Nujiang fault and the Longling fault. Based on the dislocated drainage system, Allen et al. (1984) assigned a possible right-lateral dislocation of $5.5 \mathrm{~km}$ to the Red River fault during the Quatemary. Most boundaries are the seismically active belts, where strong earthquakes occurred. However, the Quaternary activity of the Lancangjiang fault, a large fault close to the Red River faulh, appears to be less seismically active than in earlier geological times. The modem seismotectonics is controlled by the regional stress field with near NS direction and local stress field with near EW direction (Fig. 3).

The DSS profiles provided seismic data having high quality due to the high signal-to-noise ratio and large amount of explosive charge ( $>2000 \mathrm{~kg}$ ) in each shot. The interpretation of the DSS profiles show that the crustal structure in Westem Yunnan is a 3-layer model (Hu et al., 1986; Kan and Lin, 1986; Lin et al., 1993), where, in general, the upper crust is a homogeneous or weak gradicnt layer, the middle crust is a homogeneous layer, and the lower crust is generally a gradient layer, while the gradient varies considcrably over the area. The lateral variation of the velocity structure indicates that the distinct difference in the velocity structure exists among the main tectonic units, and the boundary between the tectonic units is consistent with the major fault on the surface. The mean velocity of the crust is lower $(6.20-6.30 \mathrm{~km} / \mathrm{s})$. The general trend of the Moho variation is that the interface deepens from southeast to northwest. The depth of the Moho increases from $38.5 \mathrm{~km}$ in the south of the study area to $52 \mathrm{~km}$ in the north.

The Bouguer gravity anomaly in the Westem Yunnan decreases from $-220 \mathrm{mgal}$ in the southeast to $365 \mathrm{mgal}$ in the northwest. The NNW-trending gravity anomaly belt with a gradient of $1.1 \mathrm{mgal} / \mathrm{km}$ exists to the north of Dali. The remnant gravity anomaly shows that the Red River fault is located at the boundary between the positive and negative anomalies. The high conductivity layer in the upper mantle spreads with variable depth from 60 to $120 \mathrm{~km}$ (Institute of Geology, SSB and Seismological Bureau of Yunnan Province, China, 1990).

The terrestrial heat flow is quite high in Westem Yunnan (Fig.4). Fourteen heat flow values were obtained in the Western Yunnan and its surrounding region, where the highest is 2.82HFU in the Tengchong, to the west of Baosluan. Dali and Jianchuan, situated in the north segment of the Red River fault area, also have 
higher values 2.28HFU and 2.32HFU, respectively. The region to the east of the Western Yunnan has lower heat flow values. The high heat flow region is generally related to the tectonic activity (Institute of Geology, SSB and Seismological Bureau of Yunnan Province, China, 1990)..

\section{Inversion of 3-D model}

\section{1. method}

The simultancous inversion approach is generally used to determine the velocity structure of the area beneath a network and a set of hypocentral parameters of local earthquakes. The problem can be expressed as solving the following linear equations:

$r=A d x$

where $A$ is the matrix of hypocentral and medium partial derivatives, $d x$ is the column vector of hypocentral and medium parameter perturbations, and $r$ is the column vector of travel time residuals. The matrix $A$ can be written in the following partitioned form:

$$
A=\left[\begin{array}{ccccc}
H_{1} & 0 & \ldots & 0 & \\
0 & H_{2} & \ldots & 0 & \\
: & : & : & : & M \\
0 & 0 & \ldots & H_{n} &
\end{array}\right]
$$

where $H_{i}$ is the partial derivative matrix of the hypocentral parameter of the i'th eventh i.c. $\left(H_{j k}\right)_{i}=\left(\partial T / \partial x_{k}\right) \mid\left(x_{j}, x_{i}^{\prime}\right), i=1,2, \ldots, n$. and $x_{j}$ is the station position, $x_{i}^{\prime}$ is the hypocentral location, $M$ is the partial derivative matrix of the medium. The residuals of an event are coupled to the residuals of another event by means of the medium matrix $M$ only. For a single event, the corresponding equation is:

$r_{i}=A_{i} d x_{i}$

where $r_{i}$ is the $(\mathrm{m} \times 1)$ column vector, $\mathrm{m}$ is the observation number of the i'th event, $A_{i}=\left[H_{i}, M_{i}\right]$. Pavlis and Booker (1980) showed that, when $m>4$, equation (3) can be operated on to form a matrix equation which only contains the medium parameters. This processing is called parameter separation. It makcs the calculation easy when the matrix contains a great number of arrival data. 
Thurber's simultaneous inversion algorithm (Thurber, 1983) has been used to model the crust in this paper. In his algorithm, a 3-D grid approach is used, in which velocity varies continuously in all directions, with linear B-spline interpolation among the nodes. As for the ray path and travel time calculation, we use the pseudo-bending method of Um and Thurber (1987), which is basically an approximate but fairly accuratc treatment of the exact bending method. Although there are some sophisticated improvements to the ray-tracing method recently developed, we did not use them due to the coarse resolution of the large station interval.

\section{Data}

The local first $P$ arrival data were compiled from 26 permanent seismographic stations of KTSN, with 18 stations located inside the study area (Fig. 2) and 8 stations near the area. The basic data set contains the arrival data of 340 earthquakes collected by KTSN and 14 borehole shots from the DSS profiles, recorded by 160 temporary stations. The location error of the earthquakes in the data set is mostly less than $10 \mathrm{~km}$. Arrivals with distinct onsets recorded from shots were collected. In order to converge normally to the earthquake location, we set the following criteria for the data set: (1) the maximum gap of station orientation for an earthquake is less than $160^{\circ}$; (2) the minimum number of $P$ travel time observations is 7; (3) the maximum residual of the travel time is $2.0 \mathrm{~s}$. The arrival times were mostly taken from the Observatory Report of KTSN, and larger residuals from some stations were checked on the seismograms. After the data selection, the number of earthquakes used for the inversion was 266 (Fig. 5). The total number of observations was 2681, where 2331 were for earthquakes, and 350 from the DSS blasts (Fig. 6).

\section{Initial model}

A grid model of Thurber (1983) is used in this study. The initial 3-D model is a laterally Lomogeneous 1-D model. The horizontal division into a 3-D grid model is shown in Fig. 2, where the grid extent is from $24.5^{\circ}$ to $27^{\circ} \mathrm{N}$ in latitude and from $99^{\circ}$ to $100^{\circ} \mathrm{E}$ in longitude, with intervals of $0.5^{\circ}$, respectively. The vertical grid is listed in Table I where the layer below $41 \mathrm{~km}$ has a weak velocity gradient of $0.01 \mathrm{~km} / \mathrm{s}$. The Moho discontinuity is simulated as a transition layer from depth $38 \mathrm{~km}$ to $41 \mathrm{~km}$ with a strong gradient. Although the topography of Moho along the profile varies considerably, the depth of the Molso beneath the 3-D grid model is limited to the extent of $41 \pm 2 \mathrm{~km}$. The 1-D initial model in Tab. 1 is an average of the models presented by the DSS profiles.

Ray tracing in the 1-D model shows that first arrivals beyond a distance of about $170 \mathrm{~km}$ are $\mathrm{Pn}$ phase, which is clear on the seismograms of the area. The seismographic stations in this network have relatively large station spacing. In most cases, both $\bar{P}$ and $\mathrm{Pn}$ of an earthquake are recorded as first arrivals at the stations in the network.. In addition, Pn can be simulated as a diving wave below the Mobo on the grid model, which also illuminates the lower crust to a degree. Therefore, we try to obtain a model of the entire crust in the area. About $50 \%$ of the arrival time data in the data set are $\mathrm{Pn}$ phase. In general, the travel time of $\mathrm{Pn}$ phase is insufficient for earthquake location, the accuracy of the earthquake location is limited. 
Table 1 1-D initial model

\begin{tabular}{l|l}
\hline Depth $(\mathrm{km})$ & P-velocity $(\mathrm{km} / \mathrm{s})$ \\
\hline-1.0 & 4.50 \\
0.0 & 5.25 \\
5.0 & 5.90 \\
18.0 & 6.20 \\
38.0 & 6.70 \\
41.0 & 7.95 \\
\hline
\end{tabular}

The arrival time data from DSS profiles have higher reliability than the data from earthquakes. Therefore, we set the weight (3.0) to the DSS data in the inversion. According to the resolution and standard error assessment in the result of inversion, the final model is basically reliable, although the resolution of the lower crust is lower than that of the upper-mid crust in the model. The resolution of the uppermost mantle is fair.

\section{Final 3-D model}

The number of rays that passed through the vicinity of a node is generally sufficient for the inversion. The number of rays for all of the 180 nodes is greater than 30 . The final 3-D model after 10 iterations is shown in Fig. 7. The relevant resolution and standard error at each node are shown in Fig. 8 and 9 respectively. The first layer at depth $-1 \mathrm{~km}$ generally has very poor resolution. The resolution and standard crror of the solution of nodes at a depth of $5 \mathrm{~km}$ and $18 \mathrm{~km}$ are higher and lower than those at a depth of $38 \mathrm{~km}$ and $41 \mathrm{~km}$, respectively. In general, the reliability of the solution at the nodes on the boundary of the study is less then the central nodes. Although the lower crust is illuminated by the Pn ray, the ray segment with a ligher angle and a shorter path penetrates lower crust. The standard error at the depth of $41 \mathrm{~km}$ varies from 0.10 to 0.15 .

The velocity structure in the area is complicated. The velocity anomaly distributions at different depths are quite different (Fig. 7). The anomaly at a depth of $5 \mathrm{~km}$ are similar to the remanent Bouguer gravity anomaly. However, it is different from that at a depth of $18 \mathrm{~km}$. The seismically active zones in westen Yunnan (DL, JC and YS areas in Fig.7d) are generally related to a negative anomaly at a depth of $18 \mathrm{~km}$, while they are related to a positive anomaly at a depth of $5 \mathrm{~km}$. This demonstrates that the earthquakes occur in the upper-middle crust which has a positive velocity anomaly and a negative velocity anomaly zone undeneath.

The velocity anomaly at a depth of $41 \mathrm{~km}$ is obviously divided by some of the main faults in this area. The Red River fault is the boundary between the positive and negative velocity anomaly. The Lancanjiang fault is also an dictinct boundary. However, another positive anomaly region to the northwest of DL in Fig. 8c is difficult to explain. 
Based on the velocity anomalies at the nodes, Fig. 10 shows a cross section with relative velocity anomaly of the entire crust. The cross section is from the node of $\left(25^{\circ} \mathrm{N}, 99^{\circ} \mathrm{E}\right)$ near BS to the node of $\left(27^{\circ} \mathrm{N}\right.$, $101^{\circ} \mathrm{E}$ ) near YS (Fig. 5) with a middle point at DL and trending NW. The image shows that there are negative anomaly zones in the mid-crust in the northwest and in the lower crust in the southwest, which are consistent with the DSS results. The Red River fault passes through the neighbothood of DL and is clearly seen as the boundary between two tectonic units, the Yangtze Platform and the Sanjiang Fold System. The reflection from the Moho is unusually energetic in the Westem Yunnan area. However, on the record section of the BS shotpoint-NE on the DSS in-line profile, the reflection from the Moho is too weak to be recognized (Kan et al., 1986). Both the anomalous low velocity zone existing in lower crust and the obscure Molo discontinuity may be generated by the magma underplating.

\section{Discussion}

The 3-D velocity model of the crust beneath the Western Yunnan, China was obtained from the inversion. However, it is coarse due to the large station spacing , although the seismic activity is high level in this area. In order to improve the accuracy of location and rise the reliability of the final model, the unique way is to increase the number of stations and decrease the station interval in the study area.

Nevertheless, some significant insights are still obtained from the final model. The complicated velocity model may be related to the evolutionary history of the study area. This area is located at the junction of threc major tectonic units, each having a different geological history. Based on the study of the rocks and their different geological histories on either side of the Red River fault, the fault is considered a main boundary of the tectonic units (Allen et al., 1984). However there is no clear evidence for a change in the vclocity distribution across the fault on the DSS profiles (Kan et al., 1986). Images at a depth of $41 \mathrm{~km}$ in this study show different velocity anomalies on either side of the fault. The reason for the inconsistent results may be due to sparse data from the Moho in the DSS profiles.

The lower mean velocity $(6.2-6.3 \mathrm{~km} / \mathrm{s})$ of the entire crust, and the negative velocity anomaly of the nid-crust in the area are consistent with the tectonically active area (Mooney and Brocher, 1987). This feature is similar to the North China Basin, another seismically active zone in China.

The focal depth of most earthquakes lies between 5 and $20 \mathrm{~km}$. The velocity anomaly distribution shows that the cluster of earthquakes is located above a negative anomaly zone and/or close to a large fault. The seismically active zones in the area are generally related to a negative anomaly at a depth of $18 \mathrm{~km}$ in the model, and to a positive anomaly at a depth of $5 \mathrm{~km}$. This may imply that earthquakes occur in the upper-middle crust which has a positive velocity anomaly, and above a negative velocity anomaly zone which may play a mole in the carthquake-generation. 
In the region between BS and DL, the negative velocity anomaly in the lower crust is consistent with the weak energy reflection from the Moho at the BS shotpoint-NE and the high heat flow values may be related to the magmatism in the region of the Tibet-Yunnan Fold System.

\section{Acknowledgments}

This study is a part of the project of the China-U.S. Seismological Cooperation. The earthquake data and the DSS data in this study were collected respectively in the Kunming Telemetry Seismic Center, Seismological Bureau of Yunnan Province, and in the Institute of Geophysics, SSB of China, with assistance of W.L. Tong, Q.Z. Yan , Z.Y. Lin and R.J. Kan. The calculation in this study used the inversion program written by C.H. Thurber. The authors wish to express the sincere thanks to them.

\section{References}

Aki, K. and Lee, W.H.K., 1976, Determination of three-dimensional velocity anomalies under a seismic array using first P-arrival times from local earthquakes, 1, A homogeneous initial model, J. Geophys. Res., $81,4381-4399$.

Allen, C.R., Gillespie, A.R., Han, Y., Sieh, K.E., Zhang, B. and Zhu, C., 1984, Red River and associated faults, Yunnan Province, China: Quatemary geology, slip rates, and seismic hazard. Geol. Soc. Amer. Bull., $95,686-700$.

Chen, B.W., Wang, K.W., Liu, W.X., Cai, Z.J., Zhang, Q.W., Peng, G.J., Qiu, Y.Z. and Zheng, Y.Z., 1987, Geotectonics in Nujiang-Lancangjiang-Jinshajiang Region (in Chinese), Geological Publishing House, Beijing.

Eberhart-Phillips, D., 1990, Three-dimensional P- and S-vclocity in the Coalinga region, California, J. Geophys. Res., 95, 15343-15363.

Hu, H., Lu, H., Wang, C., He, Z., Zhu, L., Yan, Q., Fan, Y., Zhang, G., and Deng, Y., 1986, Explosion investigation of the crustal structure in Westem Yunnan Province (in Chincse)., Acta Geopliysica Sinica, 29, 144-154.

Institute of Geology, SSB and Seismological Bureau of Yunnan Province, China, 1990, Active Faults in the Northwestem Yunnan (in Chinese)., pp.321, Seismological Press, Beijing .

Kan, R., Hu, H., Zeng, R., Mooney, W.D. and McEvilly, T.V., 1986, Crustal structure of Yunnan Province, Pcople's Republic of China, from seismic refraction profiles, Science, 234, 433-437.

Kan, R.J., and Lin, Z.Y., 1986, Preliminary results of the crust and upper mantle structure in Yunnan area (in Chinese)., Earthquake Research in China, 2, 50-61.

Kissling, E., 1988, Geotomography with local earthquake data, Rev. Geophys., 26, 659-698. 
Koch, M., 1985, Nonlinear inversion of local seismic travel tim ${ }^{*}$ :or the simultaneous determination of the 3D- velocity structure and hypocenters - application to we seismic zone Vrancea, J. Gcophys., 56, 160-173.

Lin, Z., Hu, H., Zhang, W., Zhang, H., He, Z., Lin, Z. and Qiu, T., 1993, The Preliminary interpretation of decp seismic sounding in Westem Yunnan, Acta Seismologica Sinica, 6, 282-295.

Mooney, W.D., and Brocher, T.M., 1987, Coincident seismic reflection/refraction studies of the continental lithosphere; A global review, Review of Geophysics, 25, 723-742.

Molnar, P. and Tapponnier, P., 1975, Cenozoic tectonics of Asia, effect of a continental collision, Science, 189,

Pavlis, G.L. and Booker, J.R., 1980, the mixed discrete-continuous inverse problem: Application to the simultaneous determination of earthquake hypocenters and velocity structure, J. Geophys. Res., 85 , 4801-4810.

Tarantola, A. and Nercession, A., 1984, Three-dimensional inversion without blocks, Gcoplys. J. R. Astron. Soc., 76, 299-306.

Thu ber, C.H., 1983, Earthquake locations and three-dimensional crustal structure in the Coyote Lake area, central California, J. Geophys. Res., 88, 8226-8236.

Thurber, C.H. and Ellsworth, W.L., 1980, Rapid solution of ray tracing problem in heterogeneous media, Bull. Seism. Soc. Am., 70, 1137-1148.

Um, J. and Thurber, C.H., 1987, A fast algorithm for two-point seismic ray tracing , Bull. Scism. Soc. Am., 77, 772-786.

Vidal, J.E., 1990, Finite difference calculation of travel times in three dimensions, Geophysics, 55, 521-526.

Walck, M.C. and Clayton, R.W., 1987, P wave velocity variations in the Coso Region, California, derived from local earthquake travel times, J. Geophys. Res., 92, 393-405.

Yang, S.N., and Yang, W.R., 1981, Regional Tectonics in Chinese Continent (in Chinese), pp.210, Geological Publishing House, Beijing.

Zhao, D.,1991, A Tomographic Study of Seismic Velocity Structure in the Japan Islands, Ph.D. Thesis, Tohoku University. 


\section{Figure captions}

Fig. 1 Tectonic pattern of Chinese Cotinent and location of the Westem Yunnan Seismic Experimental Sitc (after Yang and Yang, 1981). 1, the Songpang-Ganzi Fold System; 2, the Sanjiang Fold System (i.e. the TibetYunnan Fold System); 3, the Indian Platform. The frame indicates the study area.

Fig. 2 Location of major faults of the study area with seismic stations and nodes of the grid. Triangle denotes the station position, and cross is the node position of the horizontal grid in the model. Fault names are given by single-letters: a, the Red River; b, the Chenhai; c, the Lijiang; d, the Jianchuan; e, the Qiaohou; f, the Lancanjiang; $g$, the Nujiang; $h$, the Longling. Seismic station names are given by two-letter codes.

Fig. 3 Pattern of the modem seismotectonics in Western Yunnan area (after the Institute of Geology, SSB and Seismological Bureau of Yunnan Province, China, 1990).. 1, active fault zone; 2, pull-apart taphrogenic zone; 3, direction of the fault movement; 4 , shear direction; 5 , direction of the local stress field; 6 , direction of the major compression stress; 7, pull-apart direction; 8, earthquake with magnitude between 6.0 and $6.9 ; 9$, earthquake with magnitude $\mathrm{M}>7.0$.

Fig. 4 Distribution of terrestrial heat flow values in the Western Yunnan and its surroundings region (after the Institute of Geology, SSB and Seismological Bureau of Yunnan Province, China, 1990).. The cities are given by two-letter codes: TC (T'engchong), BS (Baoshan), ZD (Zhongdia), JC (Jianchuan), DL (Dali), XY (xiangyun), CX (Chuxiong), KM (Kunming), ES (Ershan), SZ (Shizhong).

Fig. 5 Epicenter location of the earthquakes used for inversion, and location of the cross sections in the 3-D model indicated by dashed line.

Fig. 6 Location of shotpoints and temporary stations, and ray path coverage for the DSS profiles used in the vclocity and bypocenter inversion.

Fig. 7 Final model with velocity perturbations shown in km/s: (a) depth: $-1 \mathrm{~km}$ (b) depth: $0 \mathrm{~km}$ (c) depth: $5 \mathrm{~km}$ (d) depth: $18 \mathrm{~km}$ (e) depth: $38 \mathrm{~km}$ (f) depth: $41 \mathrm{~km}$. Four cities are given by two-letter codes: DL(Dali), BS(Baoshan), JC(Jianchuan), YS(Yongsheng).

Fig. 8 Resulotion of velocity anomaly at nodes, (a) ... (f) are correspondent to Fig. 7.

Fig. 9, Standard error of the velocity anomaly at nodes, (a) ... (I) are correspondent to Fig. 7.

Fig. 10 Cross sections of the final model, per cent velocity perturbation are with respect to the initial 1-D model. Location of the cross section from $\left(25^{\circ} \mathrm{N}, 99^{\circ} \mathrm{E}\right)$ to $\left(27^{\circ} \mathrm{N}, 101^{\circ} \mathrm{E}\right)$. is shown in Figure 5. 


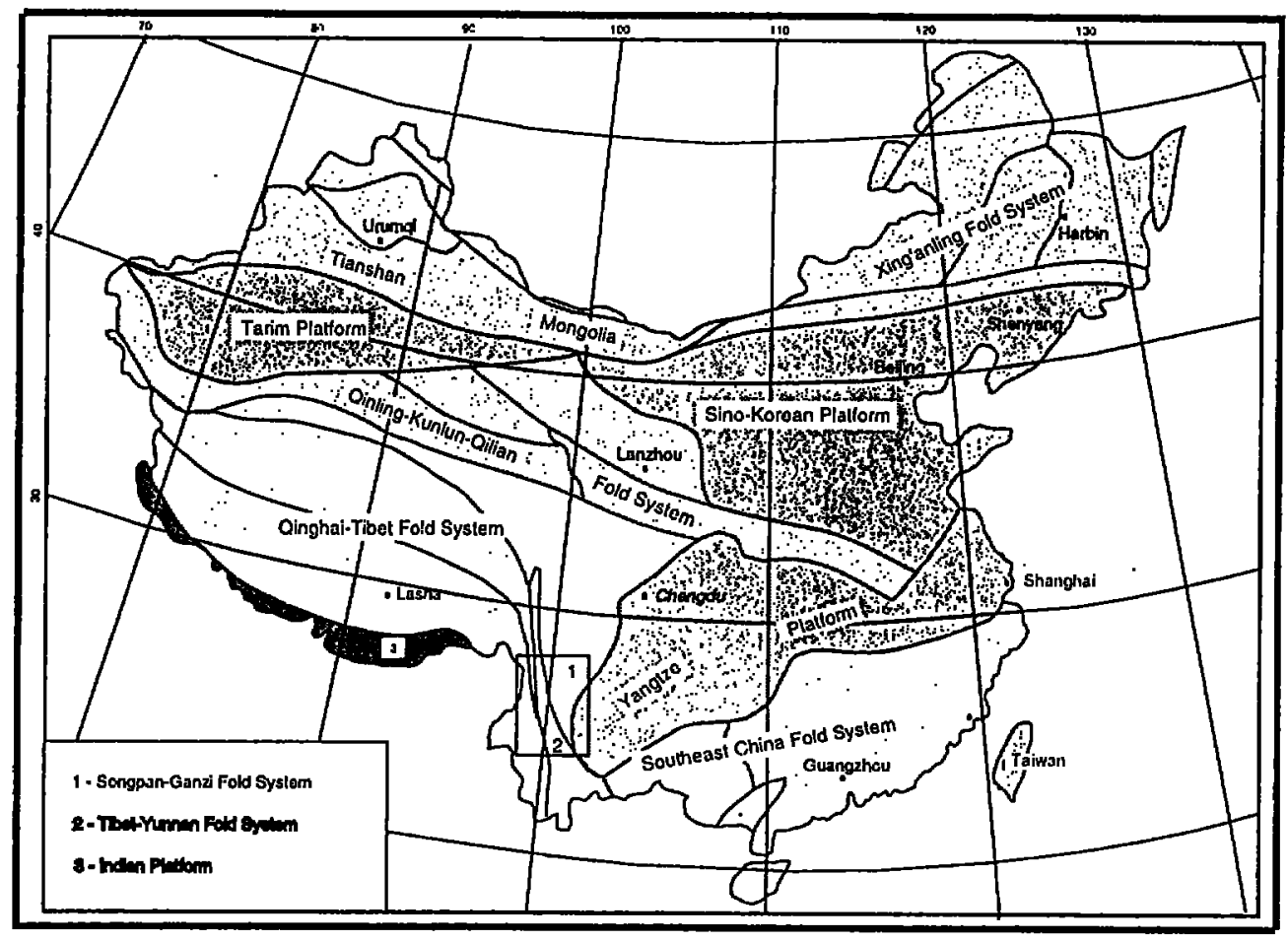




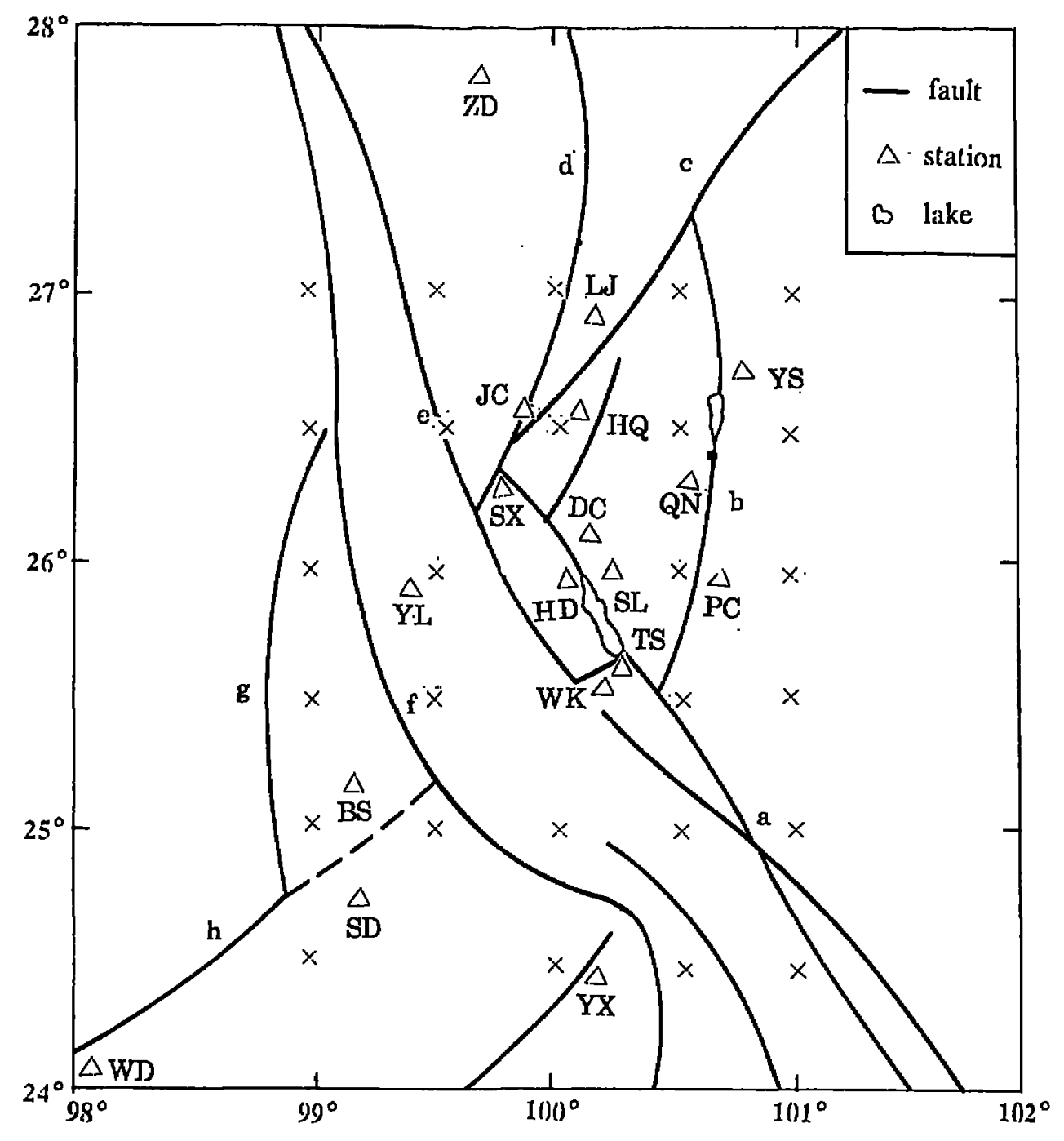

Fig. 2 Location of major faults of the study area with seismic stations and nodes of the grid. Triangle denotes the station position, and cross is the node position of the horizontal grid in the model. Fault names are given by single-letlers: $a$, the Red River; b, the Chenhai; c, the Lijiang; d. the Jianchuan; c. the Qiaolıou: f, the I ancanjiang; $g$, the Nujiang; $h$, the Longling. Seismic station names are given by two-letter codes. 


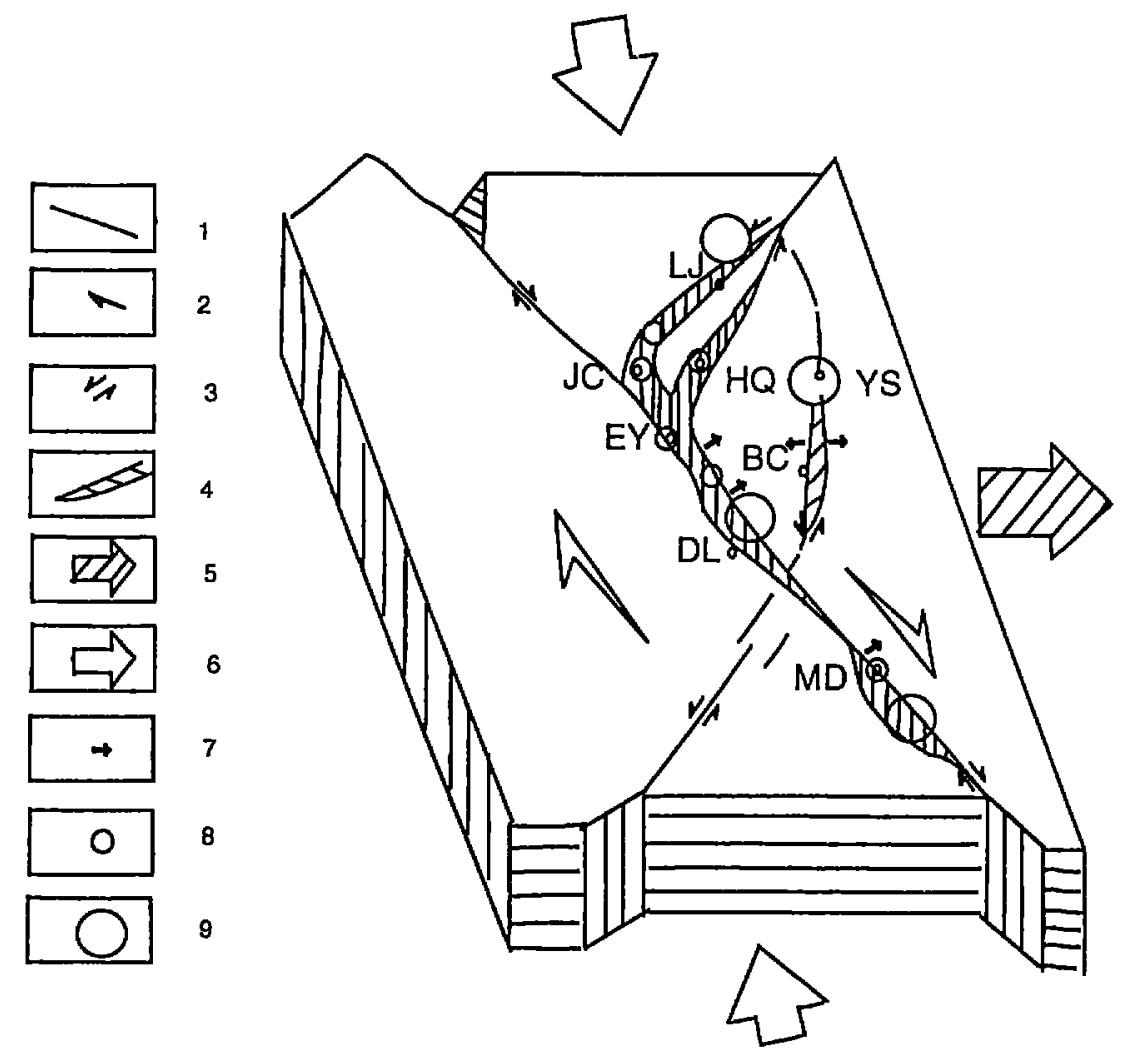

Fig. 3 Patten of the moxiern scismotectonics in Westem Yunnan area (after the Institute of Geolngy, SSB and Seismological Burcau of Yunnan Province, China 1990).. 1, active fiult zonc: 2, pull-apart taphrogenic zone; 3. direction of the fault movement; 4, shear direction; 5, direction of the local stress tield; 6 , direction of the major compression stress; 7, pull-apart direction; 8, earthquake with magnitude between 6.0 and 6.9 ; 9 , earthquake with magnitude $M>7.0$. 

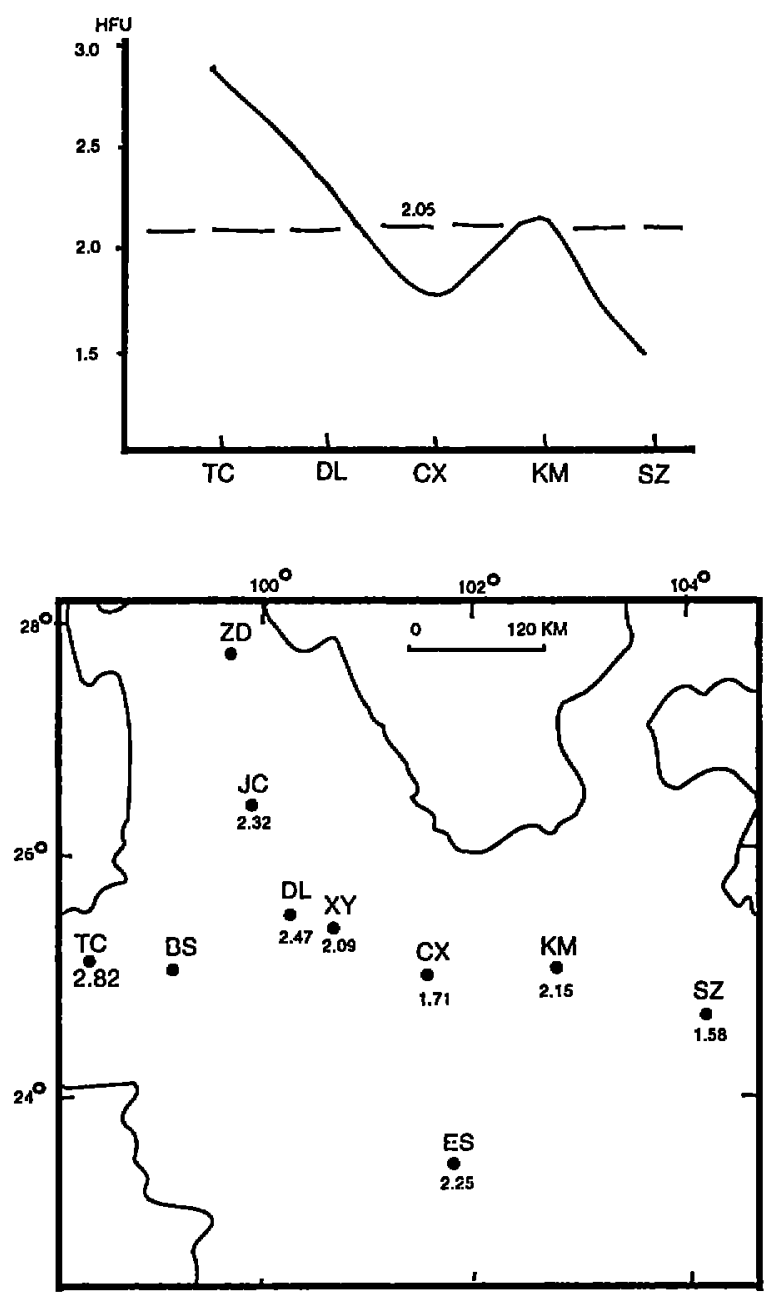

Fig. 4 Distribution of terrestrial heit flow values in the Westem Yunnan and its surroundings region (after the Institute of Geology, SSB and Seismological Burcau of Yunnan Province, China, 1990).. The cities are given by twio-letter codes: TC (Tengchong), BS (Baoshan), ZD (Zluongdia), JC (Jianchuan), DI, (Dali), XY (xiangyun), CX (Chuxiong), KM (Kunming), ES (Ershan), S\% (Shizhong). 


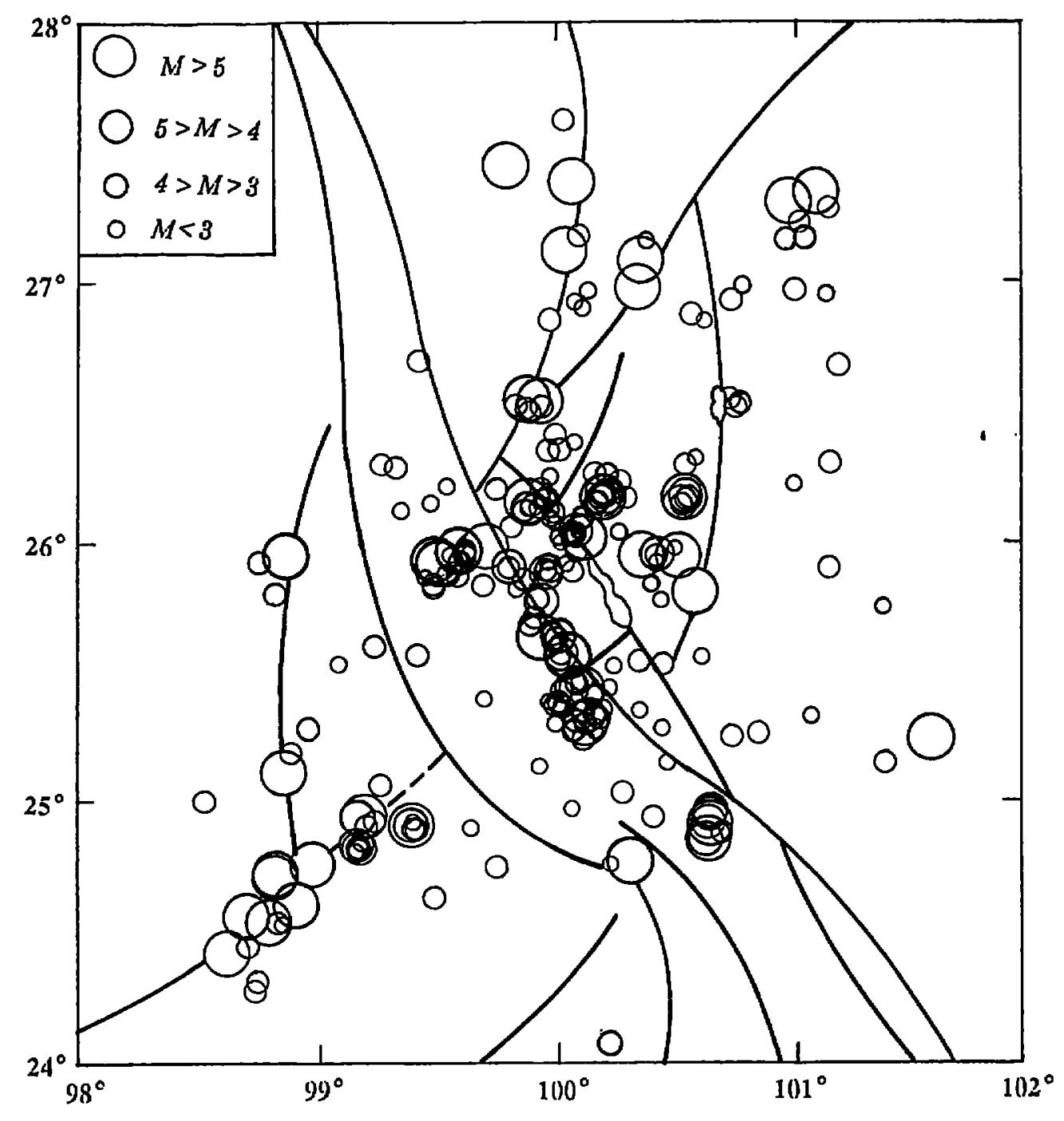

Fig. 5 Epicenter location of the earthquakes used for inversion. and location of the cross sections in the 3-D model indicated by dashed line. 


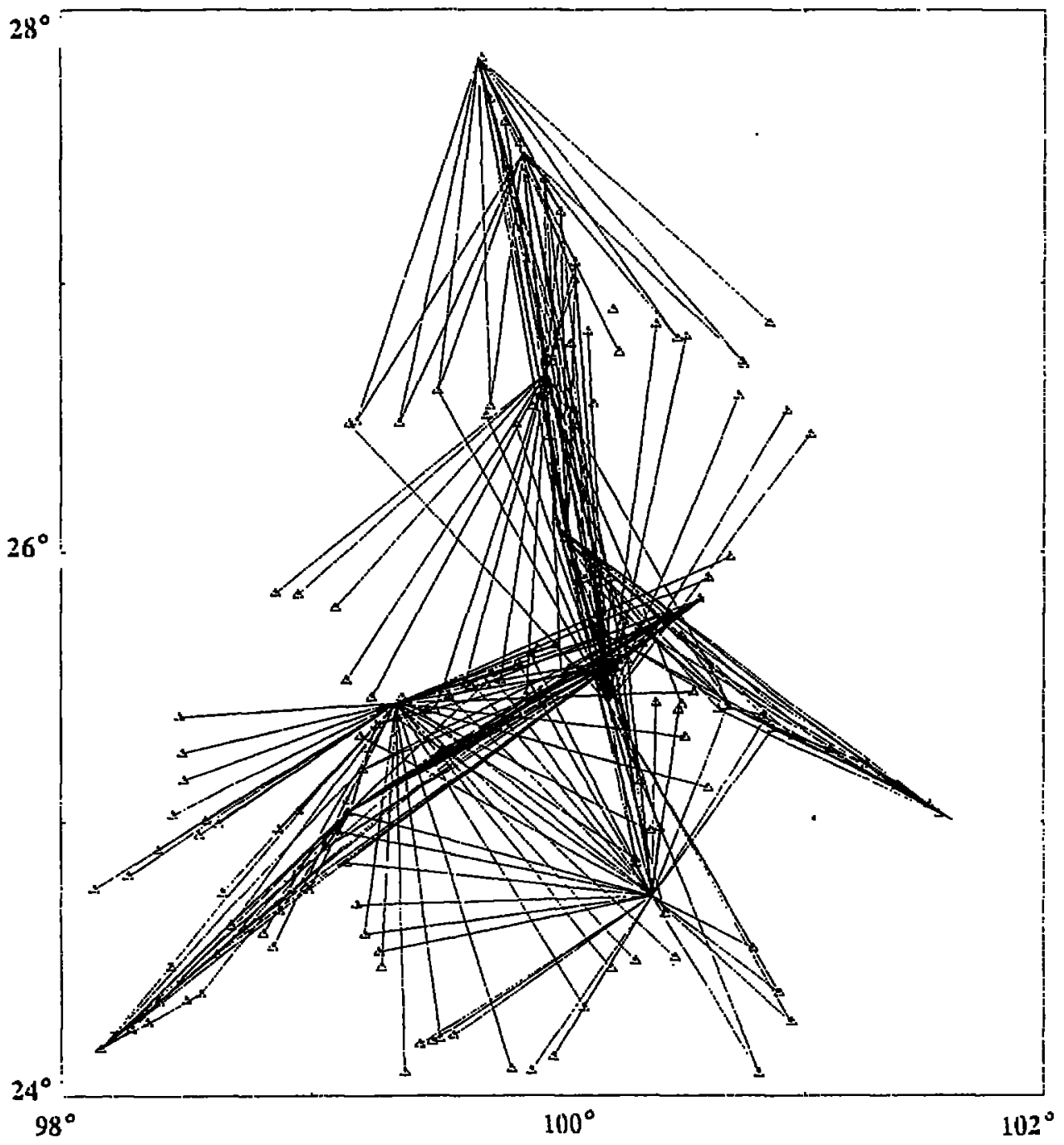

Fig. 6 Location of shotpoints and temporary stations, and ray pad coverage tor the DSS protiles used in the velocity and hypocenter inversion. 

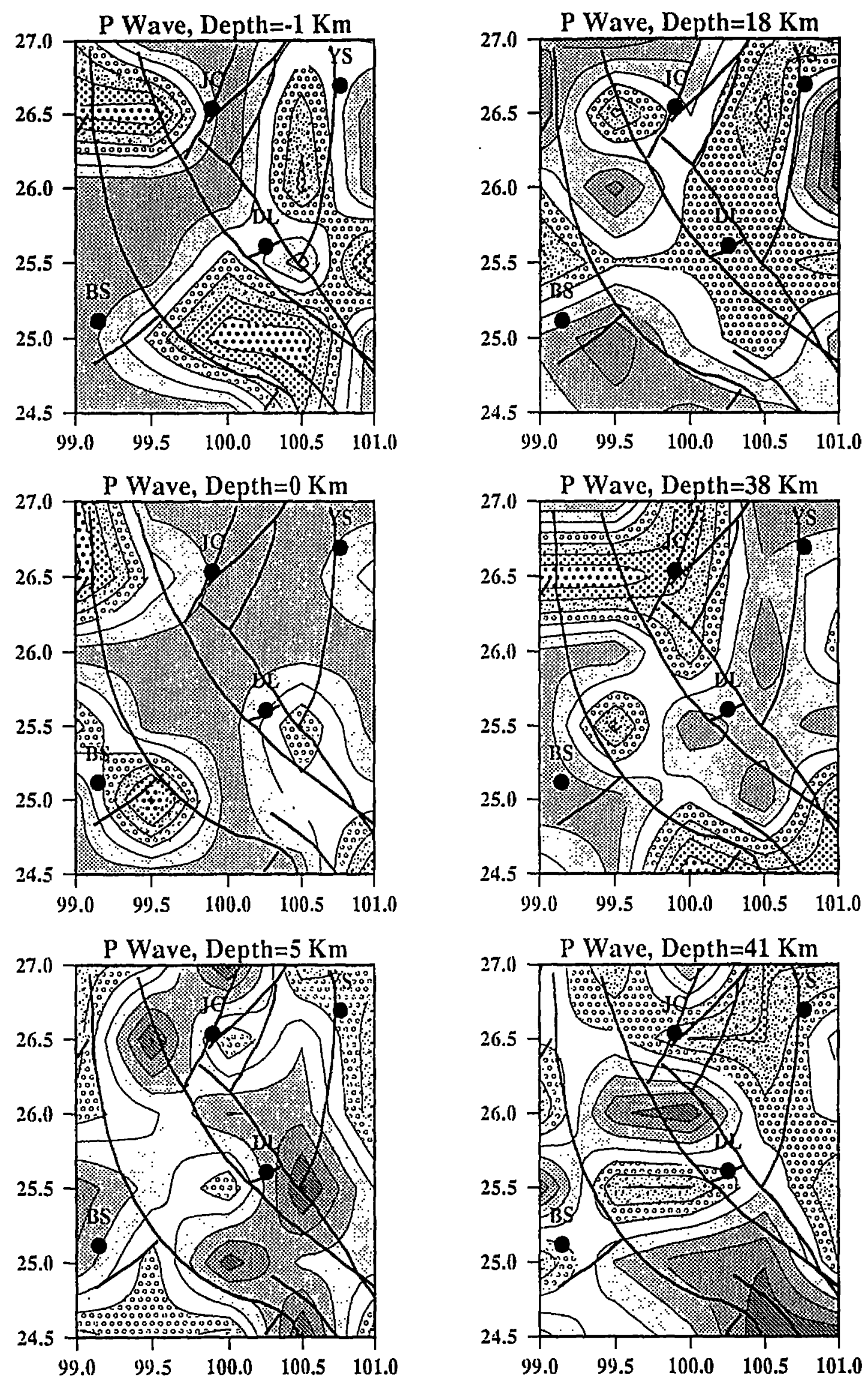

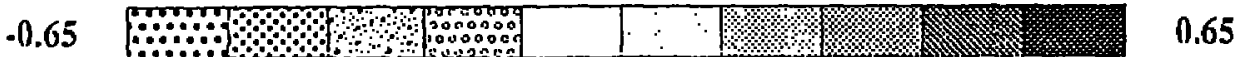

Fig. 7 Final model with velocity perturbations shown in km/s: (a) depth: $-1 \mathrm{~km}$ (b) depth: $0 \mathrm{~km}$ (c) deptl: $5 \mathrm{~km}$ (d) deph: $18 \mathrm{~km}$ (e) deptb: $38 \mathrm{~km}$ (f) depth: $41 \mathrm{~km}$. Four citics are given by two-letter codes: DL(Dali), BS(Baoshan), JC(Jianchuan), YS(Yongsheng). 

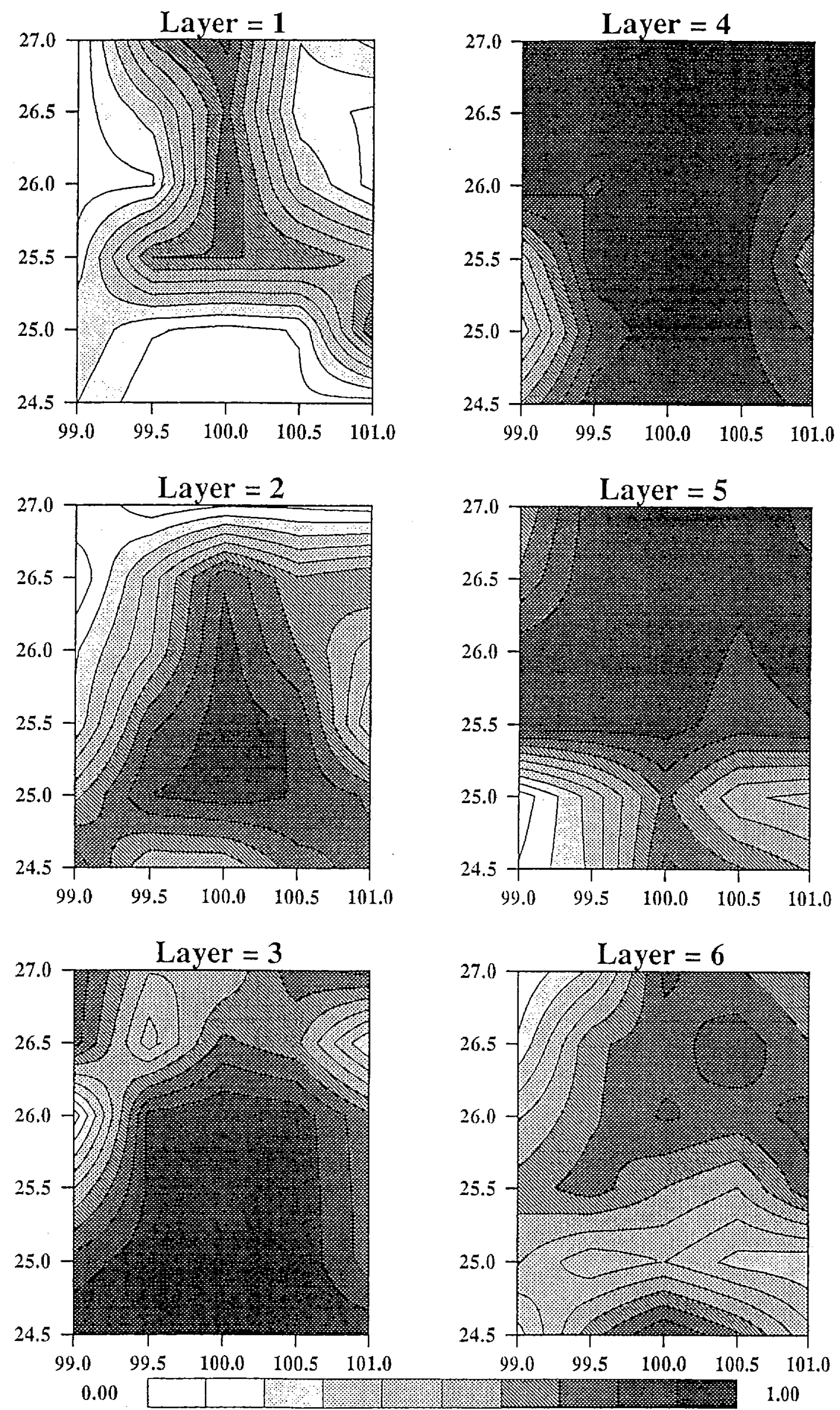

Fig. 8 Resulotion of velocity anomaly at nodes, (a) ... (f) are correspondent to Fig. 7. 

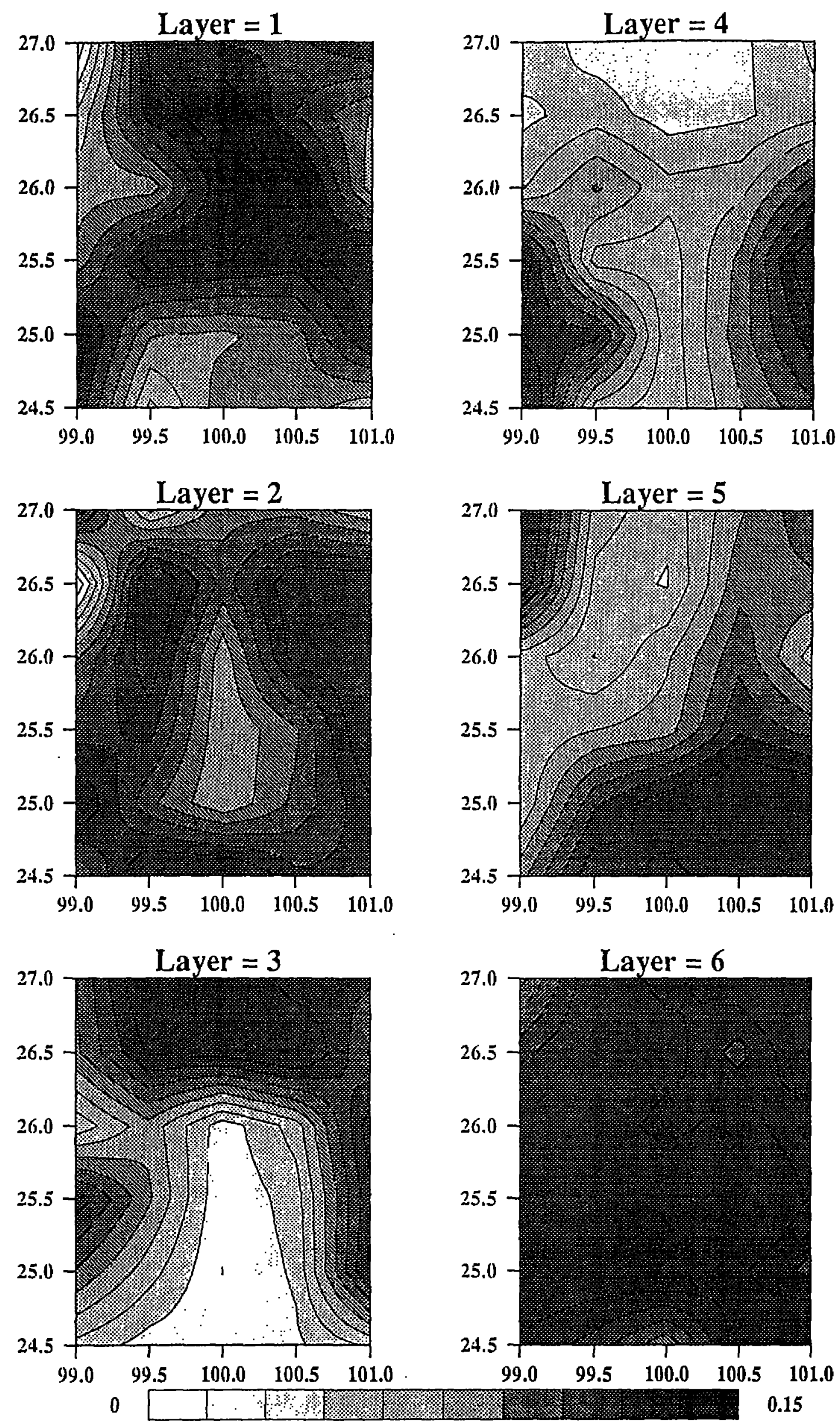

Fig. 9, Standard error of the velocity anomaly at nodes, (a) ... (f) are correspondent to Fig. 7. 


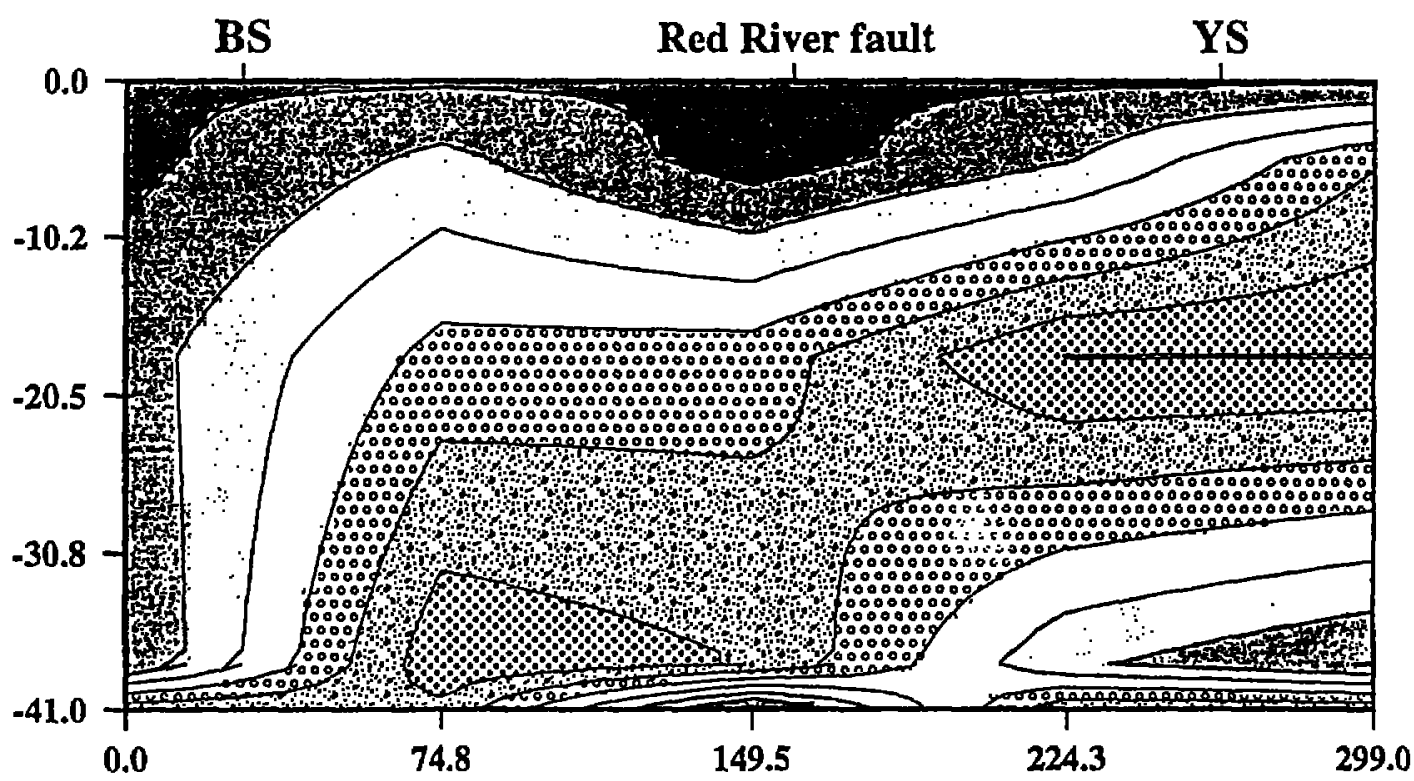

Fig. 10 Cross sections of the final model, per cent velocity perturbation are with respect to the initial 1-D model. I.ocation of the cross section from $\left(25^{\circ} \mathrm{N}, 99^{\circ} \mathrm{E}\right)$ to $\left(27^{\circ} \mathrm{N}, 101^{\circ} \mathrm{E}\right)$. is shown in Figure 5. 

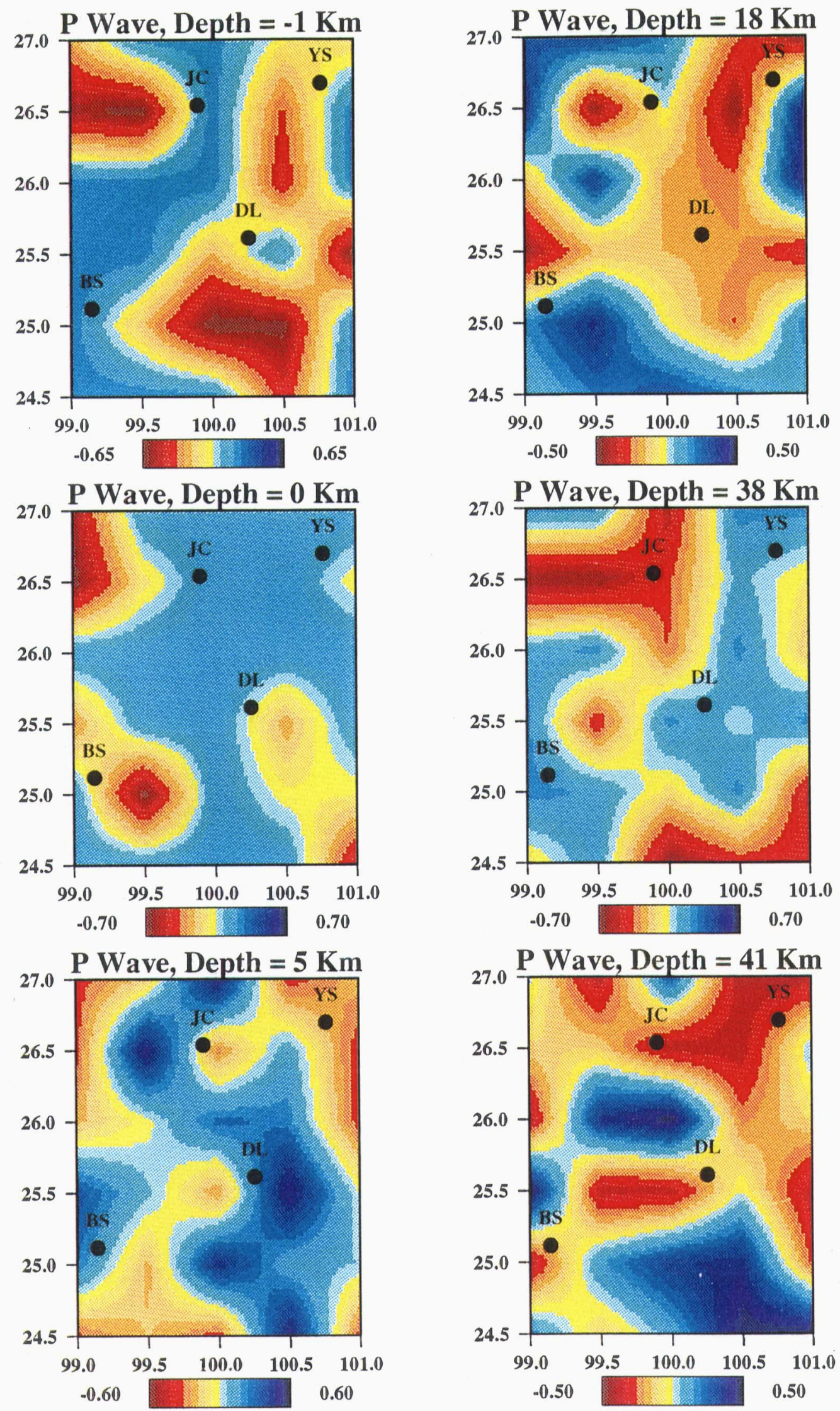


\title{
CRUSTAL STRUCTURE OF CHINA FROM DEEP SEISMIC SOUNDING PROFILES
}

\author{
Songlin $\mathrm{Li}^{(1,2)}$ and Walter D. Mooney ${ }^{(1)}$ \\ (1) U.S. Geological Survey; 345 Middlefield Road, MS 977; Menlo Park, CA 94025 \\ mooney@andreas.wr.usgs.gov \\ (2) Geophysical Prospecting Brigade; Research Center of Exploration Geophysics; State \\ Seismological Bureau; 104 Wenhua Road, ZhengZhou 450003, China
}

\begin{abstract}
More than 36,000 km of Deep Seismic Sounding (DSS) profiles have been collected in China since 1958. However, the results of these profiles are not well known in the West due to the language barrier. In this paper, we summarize the crustal structure of China with a new contour map of crustal thickness, nine representative crustal columns, and maps showing profile locations, average crustal velocity, and $P_{n}$ velocity. The most remarkable aspect of the crustal structure of China is the well known $70+\mathrm{km}$ thickness of the crust of the Tibetan Plateau. The thick (45-70 $\mathrm{km}$ ) crust of western China is separated from the thinner $(30-45 \mathrm{~km})$ crust of eastern China by the north-south trending seismic belt $\left(105^{\circ} \mathrm{E}\right)$. The average crustal velocity of China ranges from 6.15 to $6.45 \mathrm{~km} / \mathrm{s}$, indicating a felsic-to-intermediate bulk crustal composition. Upper mantle $\left(P_{n}\right)$ velocities are $8.0+/-0.2 \mathrm{~km} / \mathrm{s}$, equal to the global continental average. We interpret these results in terms of the most recent thermo-tectonic events that have modified the crust. In much of eastern China, Cenozoic crustal extension has produced a thin crust with a low average crustal velocity, similar to Western Europe and the Basin and Range Province, Western USA. In western China, Mesozoic and Cenozoic arc-continent and continent-continent collisions have led to crustal growth and thickening. Inferences on the process of crustal thickening are provided by the deep crustal velocity structure as determined by DSS profiles and other seismological studies. A high velocity $(7.0-7.4 \mathrm{~km} / \mathrm{s})$ lower crustal layer has been reported in western China only beneath the southernmost Tibetan Plateau. We identify this high velocity layer as the cold lower crust of the subducting Indian plate. As the Indian crust is injected northward into the Tibetan lower crust, it heats and assimilates by partial melting, a process that results in a reduction in the seismic velocity of the lower crust in the central and northern Tibetan Plateau.
\end{abstract}

\section{Introduction}

The geology of China is highly diverse and records a history of crustal evolution from the Archcan core of the Sino-Korean platform to active continent-continent collision in Tibet (Fig. 1). In addition, China is a country with a large population and high levels of seismic activity. Knowledge of the regional crustal structure is therefore important for the determination of epicentral locations, and for relating seismicity patterns to lateral variations in crustal properties.

Approximately $36,000 \mathrm{~km}$ of decp seismic sounding (DSS) profiles have been recorded by several institutions in continental China since 1958, primarily by the State Seismological Bureau (SSB) of China, the country's main DSS research group. In this paper, we begin with a brief description of the geologic and seismotectonic setting of China, and then summarize the main results of DSS investigations. While some of the results from these DSS profiles are known in the West, much information has not left China due to the language barrier. We provide a broad overview of the crustal structure of China rather than a detailed discussion of each profile.

\section{Geology and Tectonics of China}

Like many other continental regions, the geology of China consists of Precambrian platforms surrounded by accreted terranes and fold belts of various ages. These tectonic elements first assembled 
in the Paleozoic era, but have been further deformed and rearranged in multiple episodes throughout the Mesozoic and Cenozoic. The following geologic summary is based on reviews by Zhang et al. (1984), Dewey et al. (1988), Windley (1995), Carroll et al. (1995), and Goodwin (1996).

There are three Precambrian platforms in China: the Sino-Korean platform, the Yangtze platform, and the Tarim basin (which, despite its common name in Western literature, is refered to as a platform in Chinese literature; Fig. 1). The Sino-Korean platform coalesced in the early Archean through Early Proterozoic; it was largely consolidated by $2.0 \mathrm{Ga}$. The Yangtze platform contains igneous and metamorphic rocks that range in age from late Archean through Late Proterozoic. This platform was consolidated and stabilized after the Yangtze orogeny (ca. $825 \mathrm{Ma}$.). The Tarim basin of NW China consists of a nucleus of Archean through Proterozoic age covered by thick Cenozoic sediments. The Tarim basin and Sino-Korean platform collided with the Siberian craton in the Early Paleozoic, creating an east-west arc of fold belts across northern China (Fig. 1) and forming the PaleoAsian supercontinent. The Yangtze and Sino-Korean platforms, which had been separated by the PaleoTethys Ocean, collided in the early Mesozoic to form the Qinling fold system.

The South China fold system of SE China (Fig. 1) is a composite of late Proterozoic through Mesozoic orogens developed from three continental fragments now joined at two well-defined suture zones. The region was stabilized by the beginning of the Jurassic (Hsu et al., 1990).

South of the Tarim basin, the Kunlun fold system and the Tibetan Plateau (which may be subdivided into five fold systems that become younger to the south; Fig. 1) consist of a series of microcontinental fragments, collapsed ocean basins, accretionary metasedimentary rocks, and volcanoplutonic arcs that assembled at the southern margin of Eurasia after the breakup of Gondwana. The most recent major orogeny in southern Eurasia is the Himalayan collision (commencing ca. $45 \mathrm{Ma}$.), and has been marked by $2,000 \mathrm{~km}$ of convergence between India and Eurasia.

\section{Crustal Structure of China}

\section{Profile Locations, Data Acquisition and Interpretation}

The crustal structure of China has been well investigated with DSS profiles concentrated in regions of high population density and/or high levels of seismicity (Fig. 2). Table 1 provides a summary of 22 published profiles; in addition, we have used the results from 19 profiles that are not yet published (dotted lines on Fig. 2). Data quality, in terms of signal-to-noise ratio, is generally very good.

A variety of methods have been used to interpret the DSS data reported here. By far the most common method is the interpretation of seismic travel times and amplitudes using either oneor two-dimensional (1D and 2D) modeling methods (c.f. Mooney, 1989). In reversed DSS profiles, seismic velocities are directly measured, while depths of refraction (or reflection) horizons are successively calculated from the uppermost layer to the deepest measured horizon (usually the Moho). Thus, seismic velocity determinations generally have lower errors than depth determinations. For the seismic profile data compiled here, seismic velocities are accurate to within $3 \%$, or about $+/-0.2 \mathrm{~km} / \mathrm{s}$. All boundary depths (including the Moho) are accurate to within $10 \%$ of the depth.

\section{Maps of Crustal Parameters}

Crustal thickness is a parameter that is well determined by DSS profiles, since both refracted and reflected arrivals are usually observed from the Moho. However, the map of crustal thickness we present (Fig. 3) is the first complete contour map of the crustal thickness of China based primarily on DSS data. Previous maps have been largely based on surface wave, gravity, topography, and geoelectrical data (Compiling Group, 1986). The contour map clearly divides China into an eastern portion with a crustal thickness of $30-45 \mathrm{~km}$, and a western portion with a thickness of $45-70 \mathrm{~km}$. In western China, crustal thickness is positively correlated with 
topogri-iny. The 70-km-thick crust beneath the Tibetan Plateau constitutes some of the thickest crust ir : the world (Allegre et al., 1984; Hirn et al., 1984 a, b; Teng, 1987; Teng et al., 1974, 1983), aiong with the central Andes of South America. The strong gradient in crustal thickness in central China (visible in gravity as well as seismic data) is coincident with the north-south trending seismic belt $\left(105^{\circ} \mathrm{E}\right)$. In addition, the east-west trending fold belts of western China either end at or abruptly change direction when crossing this seismic belt (Fig. 1).

Worldwide, $P_{n}$ velocities for continental mantle range from $7.6 \mathrm{~km} / \mathrm{s}$ to about $8.4 \mathrm{~km} / \mathrm{s}$ (higher values are occasionally reported; Christensen and Mooney, 1995). Low $P_{n}$ velocities (7.6$7.8 \mathrm{~km} / \mathrm{s})$ are usually restricted to regions of thin $(<35 \mathrm{~km})$ crust with moderate to high heat flow, and high $\mathrm{P}_{\mathrm{n}}$ velocities correlate with thicker crust $(>40 \mathrm{~km})$ with low heat flow (i.e., stable continental interiors).

Figure 4 shows $P_{n}$ velocities determined from refraction profiles in China. There is a weak tendency for northeast-southwest refraction profiles to show higher P-wave velocity values (8.1-8.2 $\mathrm{km} / \mathrm{s})$, and for northwest-southeast profiles to show lower values $(7.7-8.0 \mathrm{~km} / \mathrm{s})$. This indicates possible seismic anisotropy in the uppermost mantle of about $4 \%$.

Average crustal velocity, a parameter well determined from DSS data, is of interest because it is directly related to bulk crustal composition, assuming that the measured velocity has not been strongly reduced by anomalously high crustal temperatures or high pore pressure. A low average crustal velocity $(6.0-6.3 \mathrm{~km} / \mathrm{s})$ is indicative of a dominantly felsic composition, and a higher average velocity $(6.5-6.8 \mathrm{~km} / \mathrm{s})$ indicates a significantly more mafic crustal composition (Christensen and Mooney, 1995; Rudnick and Fountain, 1995). Figure 4 summarizes the average crustal velocity for the profiles in China from which we were able to make reliable calculations. Significantly, most values are less than or equal to the global average of $6.44 \mathrm{~km} / \mathrm{s}$ (Christensen and Mooney, 1995). We interpret this to indicate a dominantly felsic to intermediate bulk crustal composition, whereas "typical" (i.e., platform and shield) crust has a significantly more mafic composition. This raises the question of why much of the crust of China is "atypical" in terms of its composition.

\section{Crustal Evolution}

Crustal velocity columns (Fig. 5) provide insights into the evolution of the crust of China. The five crustal columns for eastern China all indicate relatively thin $(29-33 \mathrm{~km})$ crust, close to the continental global average for extended crust $(30.5 \mathrm{~km})$, but significantly thinner than the global average of $39 \mathrm{~km}$ (Christensen and Mooney, 1995). This observation, along with geologic evidence, is consistent with Cenozoic crustal extension in eastern China (Hsu et al., 1990; Zhao and Windlcy, 1990). The low average crustal velocity (Fig. 4) and uppermost mantle velocity (7.8-8.2) are consistent with this inference, as are global tomographic models that indicate low shear-wave velocities in the upper mantle (i.e., thin lithosphere) of eastern China south of $42^{\circ} \mathrm{N}$ (Su et al., 1994; Zhang, 1996). Northeastern China (above $42^{\circ} \mathrm{N}$ ) has no crustal refraction data, but global tomographic models (Ekström et al., 1997) provide evidence for a thick lithospheric root, and geologic cvidence does not indicate significant Cenozoic crustal extension.

The crustal columns for western China (Fig. 5) show thick crust that is characteristic of young orogenic belts. Three of the four columns differ from the thick crust of shields in that they lack a highvelocity (7.0-7.6 km/s) lower crustal layer (Christensen and Mooney, 1995). These three crustal columns are best considered in light of recent seismological studies in western China that define crustal and upper mantle properties on both a regional scale (McNamara et al., 1994, 1995, 1996; Beckers et al., 1994; Zhu ct al., 1995) and locally for the southern Tibetan Plateau (Fig. 1; Allegre et al., 1984; Hirn et al., 1984a,b; Zhao et al., 1993; Nelson et al., 1996; Makovsky et al., 1996a,b). These data are consistent with a model for the evolution of western China that is based on the concepts proposed by 
Zhao and Morgan (1987) and Nelson et al. (1996). The key concept of this model is that the middle and lower crust of the Tibetan Plateau is a fluid-like layer, and the crust of India is injected into the Tibetan crust as an initially cold slab, but is heated and partially melted after moving $200-300 \mathrm{~km}$ northward. Thus, the crust of India is assimilated into the crust of Tibet, and the surface of the Plateau is raised by the increasing crustal volume. We interpret Column (a) (Fig. 5) to show the high-velocity (7.1 km/s) lower crust of the Indian shield prior to its heating and assimilation into the lower crust of Tibet. Such a high velocity lower crustal layer appears to be missing beneath the central and northern Plateau. Bordering the Plateau, the thick crust of Sichuan Province (column c) and Western Yunnan Province (column d) appears to reflect the eastward extrusion ("escape") of this crust from the Tibetan Plateau (Tapponnier et al., 1982).

In summary, the crustal structure of China closely reflects the most recent thermo-tectonic event that has modified the crust. The most recent processes that have dominated crustal evolution are continent-continent collision (western China) and crustal extension (eastern China). Despite the long history of crustal evolution, very little stable continental crust with "typical" seismic properties has been formed to date in China.

\section{Acknowledgments}

We are grateful to many people for sharing the information that is summarized in this paper. Zhang Xian-Kang, Zeng Rong-Sheng, Wang Chun-Yung, Wang You-Xue, and Yuan Xue-Chung provided data from China, and Katharine Favret and Regina Patzwahl provided helpful comments. Support from the USGS Earthquake Hazards Reduction Program and the Deep Continental Studies Program are gratefully acknowledged. 


\section{References}

8301 Program Cooperation Group, 1988. Velocity structure of crust and upper mantle at the east margin of the Tarim Basin and the east part of Qinghai-Tibet Plateau: Developments in the Research of Deep Structures of China's Continent. Geological Publishing House, Beijing, 89-96.

Allegrc, C.J., et al., 1984. Structure and evolution of the Himalaya-Tibet orogenic belt. Nature, 307: 17-31.

Beckers, J., Schwartz, S.Y., and Lay, T., 1994. The velocity of the crust and upper mantle under China from broadband $P$ and PP waveform analysis. Geophys. J. Int., 119: 574-594.

Carroll, A.R., S.A. Graham, M.S. Hendrix, D. Ying, D. Zhou, 1995. Late Paleozoic tectonic amalgamation of northwestern China: Sedimentary record of the northern Tarim, northwestern Turpan, and southern Junggar basins. Geol. Soc. Am. Bull., 107: 571-594.

Chen, B. and W. Gao, 1988. Crustal structure along the Tiajiwen-Shayuan DSS profile: Developments in the Research of Deep Structures of China's Continent. Geological Publishing House, Beijing, 152-168.

Chen, X., Y. Wu, P. Du, J. Li, Y. Wu, G. Jiang and J. Zhao, 1988. Crustal velocity structure at the two sides of Longmenshan Tectonic Belt: Developments in the Research of Deep Structures of China's Continent. Geological Publishing House, Beijing, 97-113.

Christensen, N. I. and W. D. Mooney, 1995. Seismic velocity structure and composition of the continental crust: A global view. J. Geophys. Res., 100(B7): 9761-9788.

Compiling Group of Results of Deep Exploration, State Seismological Bureau, 1986. Results from Geophysical Exploration of the Crust and Upper Mantle in China. Seismological Press, Beijing, 11-13.

Dewey, J.F., R.M. Shackleton, C. Chang, Y. Sun, 1988. The tectonic evolution of the Tibetan Plateau. Phil. Trans. R. Soc. Lond., 327: 379-413.

Ding, W., C. Huang, J. Cao and G. Jiang, 1988. Crustal structures along Suixian-Xian DSS profile: Developments in the Research of Deep Structures of China's Continent. Geological Publishing House, Beijing, 38-47.

Ekström, G., J. Tromp, and E.W.F. Larson, 1997. Measurements and global models of surface wave propagation. J. Geophys. Res., 102:8137-8157.

Feng, Y., R.G. Coleman, G. Tilton and X. Xiao, 1989. Tectonic evolution of the West Junggar Region, Xinjiang, China. Tectonics, 8: 729-752.

Goodwin, A.M., 1996. Principles of Precambrian Geology, Academic Press, San Diego, Calif., $327 \mathrm{pp}$.

Hirn, A., Lepine, J.-C., Jobert, G., Sapin, M., Wittlinger, G., Xin, X.Z., Yuan, G.E., Jing, W.X., Wen, T.J., Bai, X.S., Pandcy, M.R., and Tater, J.M., 1984a. Crustal structure and variability of the Himalayan border of Tibet. Nature, 307: 23-25.

Hirn, A., Nercessian, A., Sapin, M., Jobert, G., Xin, X.Z., Yuan, G. E., Yuan, L.D. and Wen, T.J., 1984b. Lhasa block and bordering sutures - a continuation of a $500-\mathrm{km}$ Moho traverse through Tibet. Nature, 307: 25-27.

Hsu, K.J., Li J.L., Chen H.H., Wang Q.C., Sun, S., and Sengor, A.M.C., 1990. Tectonics of South China: key to understanding West Pacific geology. Tectonophysics, 183: 9-39.

Hu, H., X. Chen, B. Zhang, W. Song, Z. Xiao and Z. He, 1988. Crustal structures along SuixianAnyang DSS profile, Developments in the Research of Deep Structures of China's Continent. Geological Publishing House, Beijing, 48-60.

Huang, T.K., C. Jen, C. Jiang, Z. Chang and D. Chin, 1980. The Geotectonic Evolution of China. Publishing House of Academic, Beijing, China, 124 pp. 
Institute of Geophysics, Acad. Sci., 1981. Explosion seismic study for velocity distribution and structure of the crust and upper mantle, from Danxung to Yadong of the Xizang Plateau. ACTA Geophysica Sinica, 24: 155-170.

Kan, R., H. Hu, R. Zeng, W.D. Mooney and T.V. McEvilly, 1988. Crustal structure and evolution of the Yunnan prov., China from seismic refraction profile: Developments in the Research of Deep Structures of China's Continent. Geological Publishing House, Beijing, 267-276.

$\mathrm{Li}, \mathrm{Y}$. and Z. Xu, 1988. Seismological observation of Qiziqiao Explosion: Developments in the Research of Deep Structures of China's Continent. Geological Publishing House, Beijing, 180-191.

Liao, Q., Z. Wang, Z. Zhu and X. Wu , 1988. Crust and upper-mantle structure in the QuanzhouShantou region of China: Developments in the Research of Deep Structures of China's Continent. Geological Publishing House, Beijing, 227-235.

Liuzhou Explosion Research Group, 1988. Observation of Liuzhou explosion and the crustal structure in eastern Guangxi: Developments in the Rescarch of Decp Structures of China's Continent. Geological Publishing House, Beijing, 246-252.

Lu, Z., G. Zhang, J. Li, L. Wang and J. Zhao, 1988. An explosion-seismology study on the structure of crust and upper mantle in South Liaoning Prov., Developments in the Research of Deep Structures of China's Continent. Geological Publishing House, Beijing, 114-128.

Makovsky, Y., Klemperer, S.L., Huang, L.Y., Lu, D.Y., and Project INDEPTH Team, 1996 a. Structural elements of the southern Tethyan Himalaya crust from wide-angle seismic data. Tectonics, 15: 997-1005.

Makovsky, Y., Klemperer, S.L., Ratschbacher, L., Brown, L.D., Li, M., Zhao, W., and Meng, F., 1996b. INDEPTH wide-angle reflection observation of P-wave-to-S-wave conversion from crustal bright spots in Tibet. Science, 274: 1690-1691.

McNamara, D.E., Owens, T.J., and Walter, W.R., 1995. Observations of regional phase propagation across the Tibetan Plateau. J. Geophys. Res., 100: 22,215-22,229.

McNamara, D.E., Owens, T.J., and Walter, W.R., 1996. Propagation characteristics of Lg across the Tibetan Plateau. Bull. Seismol. Soc. Am., 86: 457-469.

McNamara, D.E., Owens, T.J., Silver, P.G., and Wu, F.T., 1994. Shear wave anisotropy beneath the Tibetan Plateau. J. Geophys. Res., 99: 13,655-13,665.

Mooney, W.D., 1989. Seismic methods for determining earthquake source parameters and lithospheric structure, in Pakiser, L.C., and Mooney, W.D., Geophysical framework of the continental United States: Boulder, Colorado. Geological Society of America Memoir 172.

Nelson, K.D., and twenty-seven others, 1996. Partially molten middle crust beneath southern Tibet: synthesis of project INDEPTH results. Science, 274:, 1684-1688.

Rudnik, R.L., and D.M. Fountain, 1995. Nature and composition of the continental crust: a lower crustal perspective. Rev. Geophys., 33: 267-309.

Su, W.-J., Woodward, R.L., and Dziewonski, A.M., 1994. Degree-12 model of shcar velocity heterogencity in the mantle. J. Geophys. Res., 99: 6945-6980.

Sun, W., Z. Zhu, L. Zhang, S. Song, C. Zhang and Y. Zheng, 1988. Exploration of the crust and upper mantle in North China: Developments in the Research of Deep Structures of China's Continent. Geological Publishing House, Bcijing, 19-37.

Tapponnier, P., Peltzer, G., Le Dain, A.Y., Armijo, R., and Cobbold, P., 1982. Propagating extrusion tectonics in Asia: New insights from simple experiments with plasticinc. Geology, 10: 61 1-616.

Teng, J.-W. et al., 1974. The crustal structure of the Eastern Qaidam Basin from deep reflected waves. ACTA Geophysica Sinica, 17: 122-135. 
Teng, J.-W., 1987. Explosion study of the structure and seismic velocity distribution of the crust and upper mantle under the Xizang (Tibet) Plateau. Gcophys. J. R. Astr. Soc., 89: 405414.

Teng, J.-W., 1979. Geophysical investigations of the Earth's crust and upper mantle in China. ACTA Geophysica Sinica, 22: 346-350.

Teng, J.-W., S. Xiong, Z. Yin, Z. Xu, X. Wang and D. Lu, 1983. Structures of the crust and upper mantle pattern and velocity distributional characteristics at the northern region of the Himalayan Mountains. ACTA Geophysica Sinica, 26: 525-540.

United Observing Group of the Yongping Explosion, SSB, 1988. Yongping explosion and deep structure in Southeast China: Developments in the Research of Deep Structures of China's Continent. Geological Publishing House, Beijing, 140-153.

Windley, B.F., 1995. The Evolving Continents, J, Wiley \& Sons, Chichester, 526 pp.

Zhang, S. et al., 1988. Interpretation of the Menyuan-Pingliang-Weinan DSS profile in West China: Developments in the Research of Decp Structures of China's Continent. Geological Publishing Housc, Beijing, 61-88.

Zhang, Y.-S., 1996. Three-dimensional velocity structure beneath East Asia and its tectonic implication. AGU monograph (submitted).

Zhang, Z. M., J. G. Liou and R. G. Coleman, 1984. An outline of the plate tectonics of China. Geol. Soc. Am. Bull., 95: 295-312.

Zhao, W., Nelson, K.D., and the Project INDEPTH Team, 1993. Deep seismic refloction evidence for continental underthrusting beneath southern Tibet. Nature, 366: 557-559.

Zhao, W.L. and Morgan, W.J., 1987. Injection of Indian crust into Tibetan lower crust: A twodimensional finite element model study. Tectonics, 6: 489-504.

Zhu, L.-P., Owens, T.J., and Randall, G.E., 1995. Lateral variation in crustal structure of the northern Tibetan Plateau inferred from telescismic receiver functions. Bull. Seismol. Soc. Am., 85: 1531-1540. 
Table 1. Brief description of the DSS profiles.

\begin{tabular}{|c|c|c|c|c|}
\hline $\begin{array}{l}\text { Profile } \\
\text { Number }\end{array}$ & Region & Reference & $\begin{array}{l}\text { Source } \\
\text { Type* }\end{array}$ & $\begin{array}{l}\text { Crustal } \\
\text { Thickness }\end{array}$ \\
\hline $1 * *$ & North China Plain and adjacent regions & Sun et al., 1988 & A & $30-34$ \\
\hline 2 & Lower Liao River Plain & Lu ct al., 1988 & A & $32-35$ \\
\hline 3 & $\begin{array}{l}\text { North China Plain and Qinling Folded } \\
\text { Region }\end{array}$ & Hu ct al., 1988 & B & $30-34$ \\
\hline 4 & Qinling Folded Region & Ding et al., 1988 & B & 34 \\
\hline 5 & $\begin{array}{l}\text { Qinling Folded Region and Yangtze } \\
\text { Quasi-Platform }\end{array}$ & Chen and Gao, 1988 & B & 34 \\
\hline 6 & $\begin{array}{l}\text { Yangtze Quasi-Platform and South } \\
\text { China Folded Region }\end{array}$ & Unitcd Observing Group, 1988 & B & 33 \\
\hline 7 & South China Folded Region & United Observing Group, 1988 & B & 32 \\
\hline 8 & $\begin{array}{l}\text { Hengyang Basin, Youxian Basin and } \\
\text { Chaling-Yongxing Basin }\end{array}$ & Li et al., 1988 & B & 29 \\
\hline 9 & Southeast Coastal Fold belt & Liao et al, 1988 & A & 29 \\
\hline 10 & Guilin Uplift and Yishan Uplift & $\begin{array}{l}\text { Liuzhou Explosion Research Group, } \\
1988\end{array}$ & B & 33 \\
\hline 11 & South China Folded Region & $\begin{array}{l}\text { Liuzhou Explosion Research Group, } \\
1988\end{array}$ & B & 32 \\
\hline 12 & Ordos Platform & Personal Communication (Zhang) & A & -- \\
\hline 13 & Ordos Platform & Personal Communication (Zhang) & A & -- \\
\hline 14 & Qilian, Liupian and Qinling Mts. & Zhang et al., 1988 & A & $38-60$ \\
\hline 15 & Sichuan Basin and Tibet Platcau & Chen et al., 1988 & A & $40-51$ \\
\hline 16 & Yunnan-Guizhou Platcau & Kan et al., 1988 & A & $41-46$ \\
\hline 17 & Yunnan-Guizhou Plateau & Kan et al., 1988 & A & $39-46$ \\
\hline 18 & Qaidam Basin & Teng, 1979 & A & 51 \\
\hline 19 & Tarim Basin & 8301 Program Cooperation Group, 1988 & B & 51 \\
\hline 20 & Qinghai-Tibet Platcau & Teng, 1987 & $\mathrm{C}$ & 70 \\
\hline 21 & Qinghai-Tibet Plateau & Inst. Geoph. Acad. Sci., 1981 & C & $45-73$ \\
\hline 22 & & Teng et al., 1983 & $A \& C$ & $73-76$ \\
\hline
\end{tabular}

* A. Bore-hole explosion.

B. Industrial blast.

C. Explosion in water.

*:*: Including 31 DSS profiles. 


\section{Fig. 1}

\section{Figure Captions}

Tectonic sketch map of China (after Huang et al., 1980).

Nearly all geologic provinces have been surveyed with seismic refraction profiles (Fig. 2).

\section{Fig. 2}

Location map of the seismic refraction/wide angle reflection profiles in China (1958-1990). The profile numbers correspond to Table 1.

Solid lines: profiles completed from 1958 to 1986

Dotted lines: profiles completed from 1987 to 1990 ; not yet published

Dashed lines: profile with sparse observational points

Fig. 3

Crustal thickness obtained primarily from seismic refraction/ wide angle reflection experiments. Solid isolines represent more reliable results. Dashed lines were obtained by considering gravity data. The $45 \mathrm{~km}$ contour coincides with the western boundary of the SinoKorean platform and the Yangtze platform, as well as with the north-south seismic belt (Fig. 2).

\section{Fig. 4}

Pn (upper mantle; in parenthesis) and average crustal velocities obtained from seismic refraction profiles in China. Pn velocities are well within the global average of $8.0+/-0.2 \mathrm{~km} / \mathrm{s}$. Average crustal velocities range from $6.14-6.45 \mathrm{~km} / \mathrm{s}$, corresponding to a felsic to intermediate bulk crustal composition. Average crustal velocities greater than $6.45 \mathrm{~km} / \mathrm{s}$, which are commonly reported for the Precambrian of Russia, are not measured in China.

\section{Fig. 5}

Representative seismic velocity-depth functions for nine regions of China which can be divided into two parts by the north-south trending seismic belt $\left(105^{\circ}\right)$ : western region (a-d) and eastern region (e-i). In the western region, the crustal thickness is greater than $45 \mathrm{~km}$, while it is less than $35 \mathrm{~km}$ in the eastern region. 


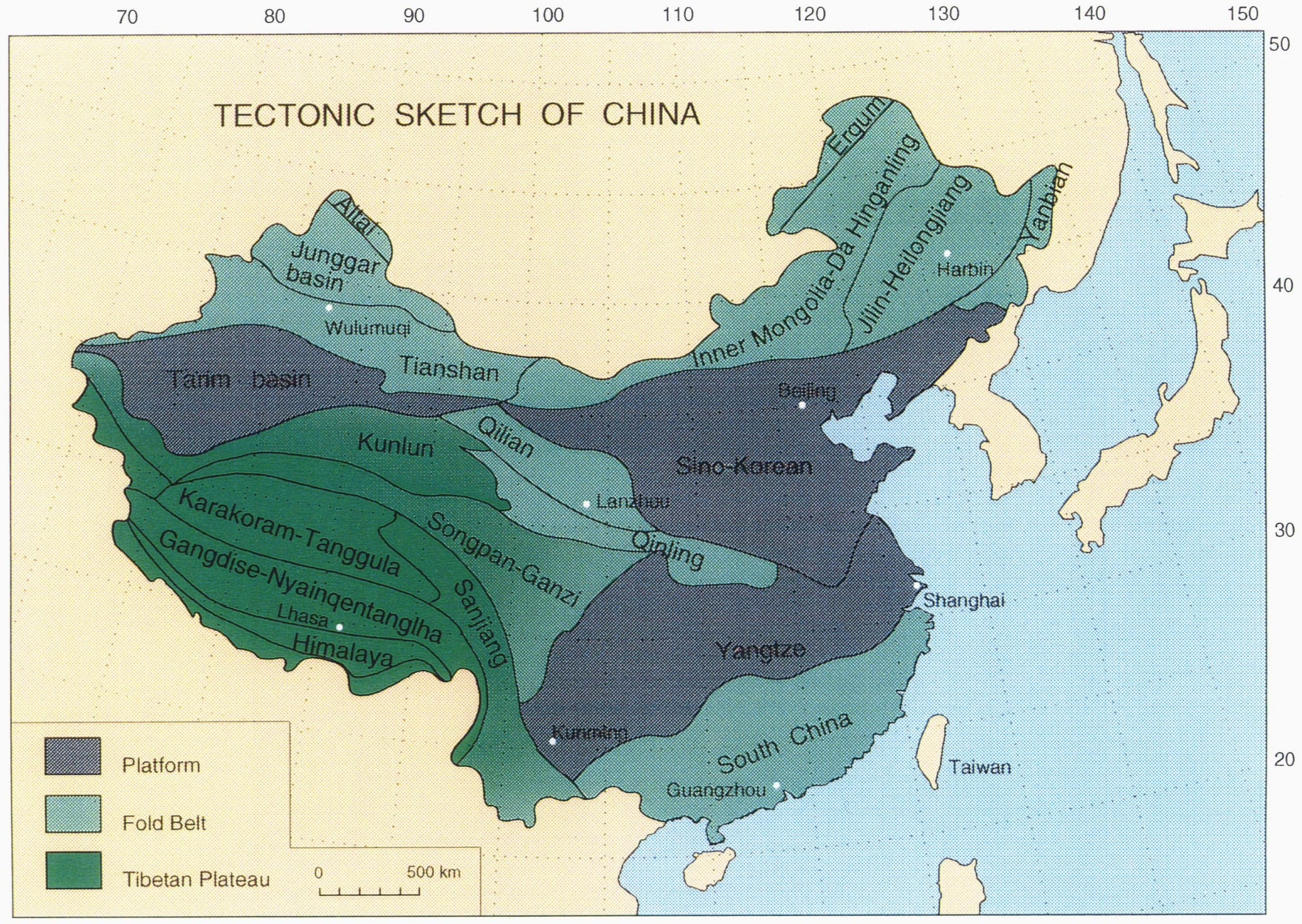




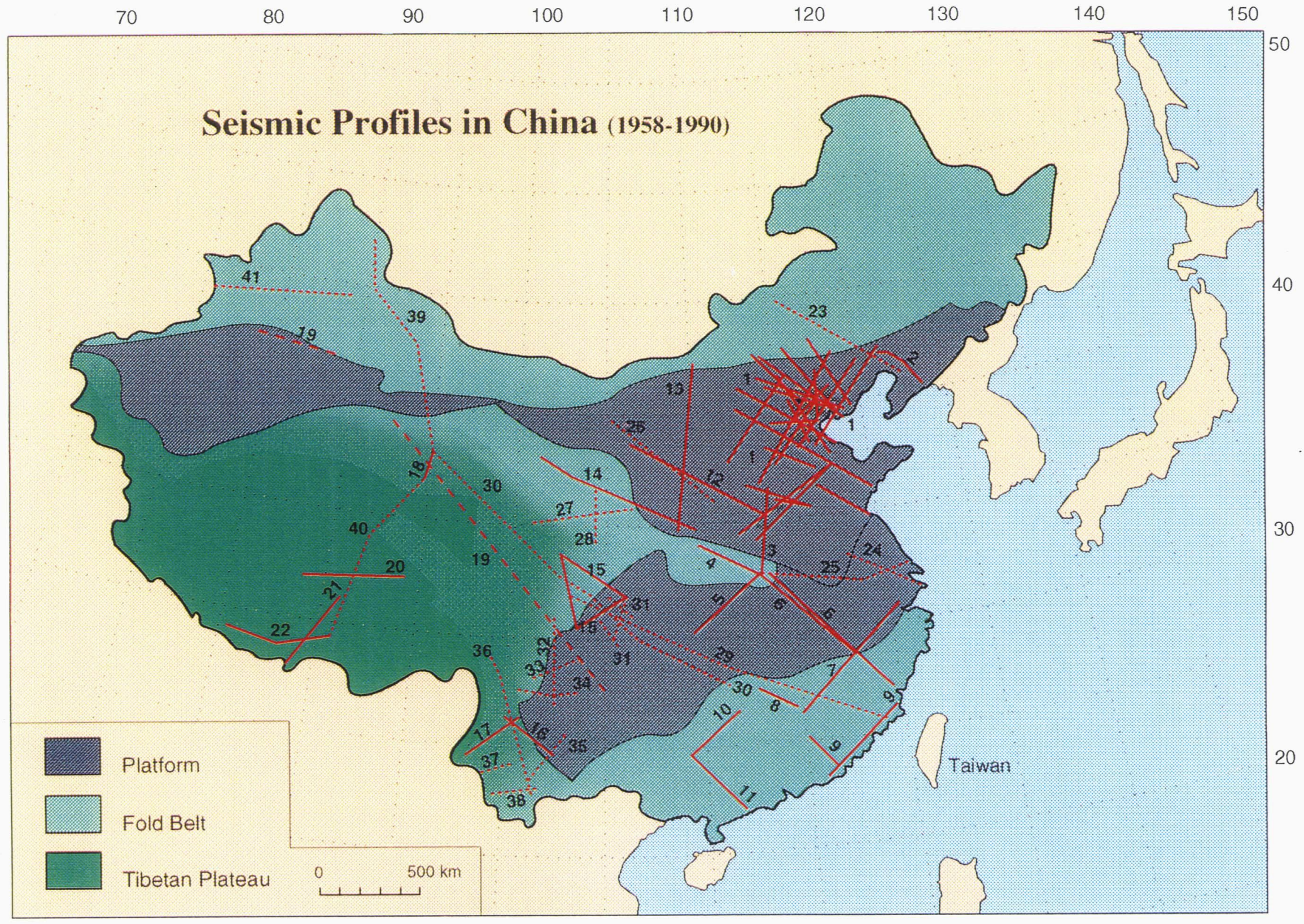




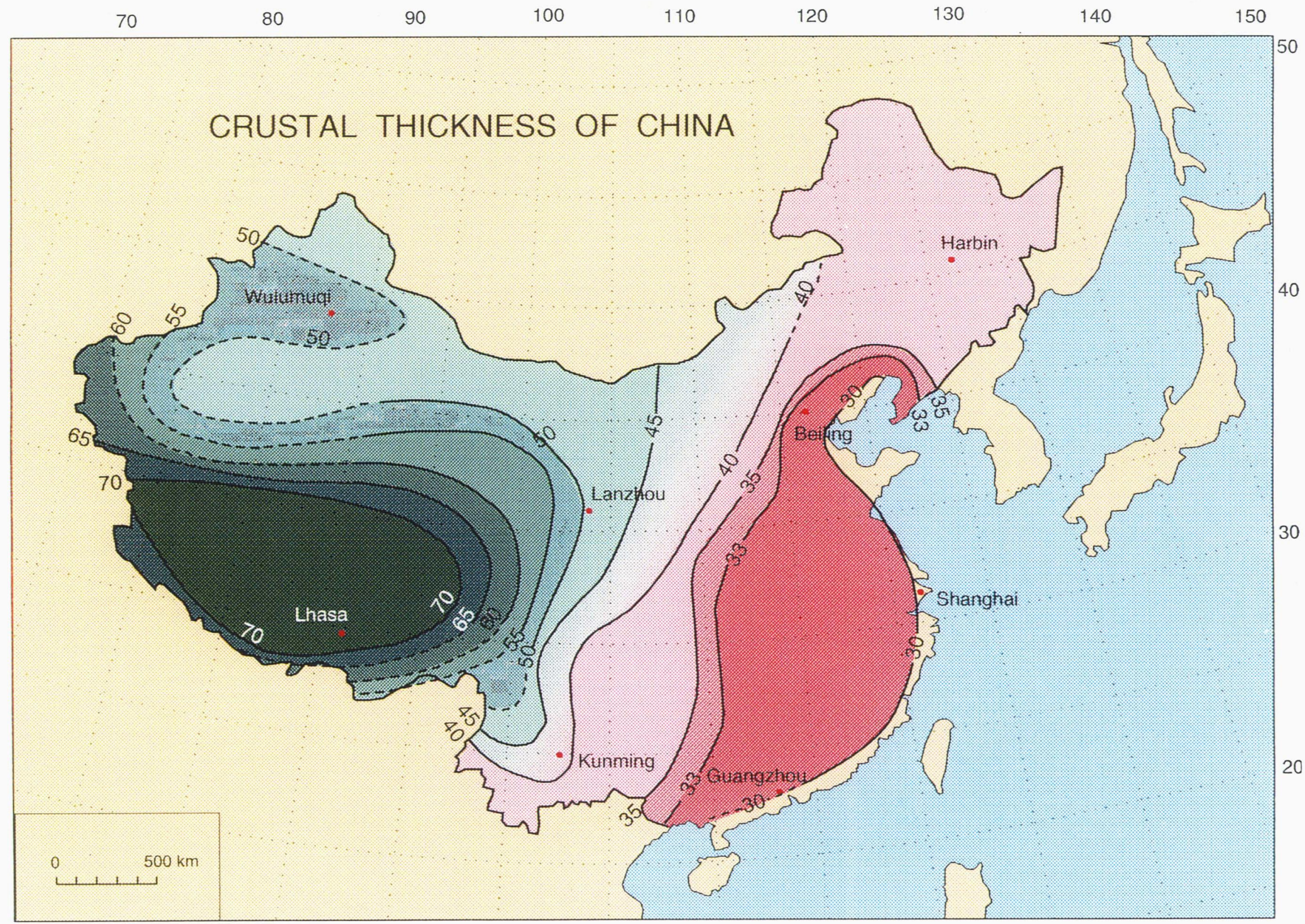




\section{Western Region}

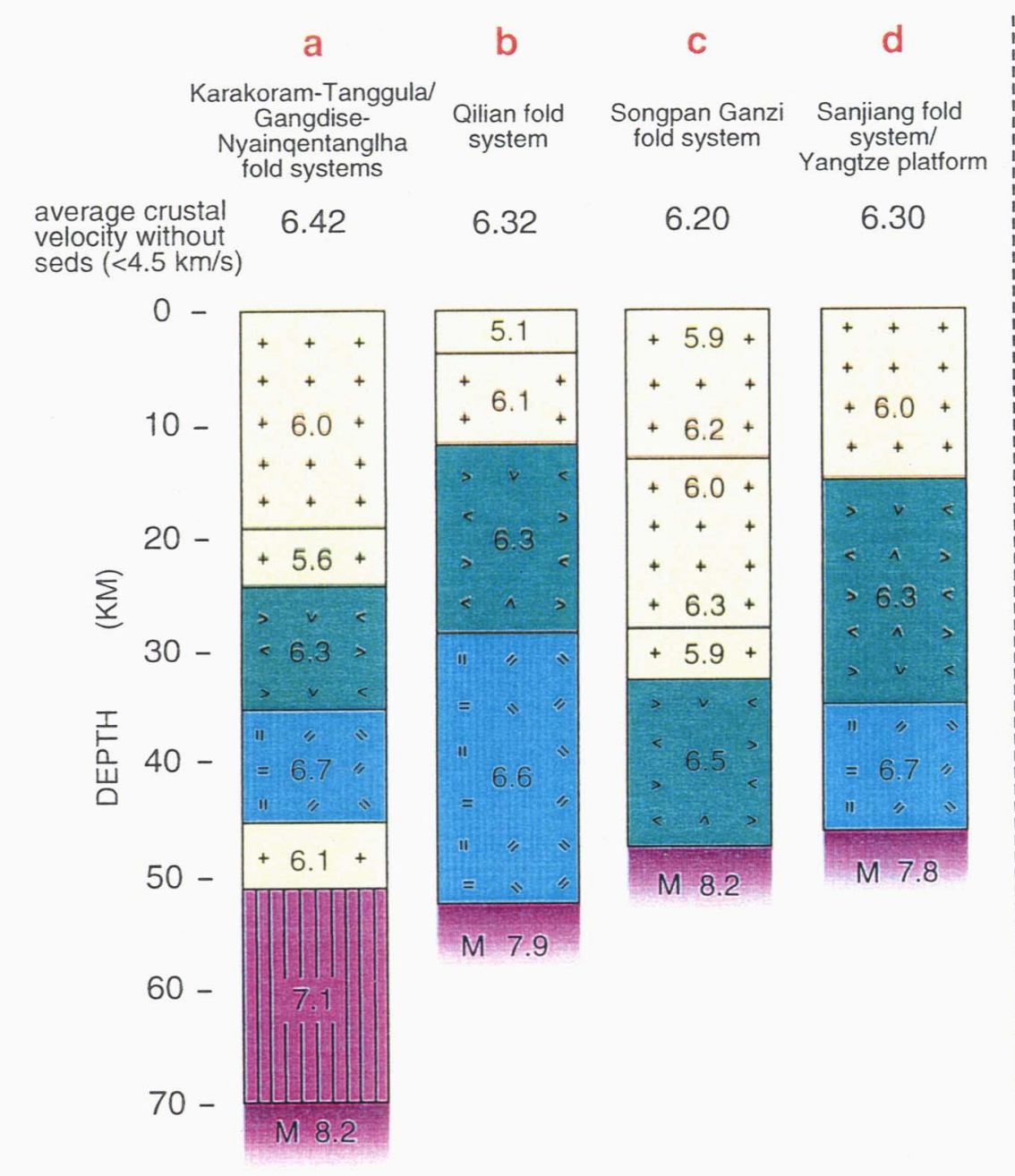

\section{Eastern Region}

e

Sino-Korean
platform

6.44

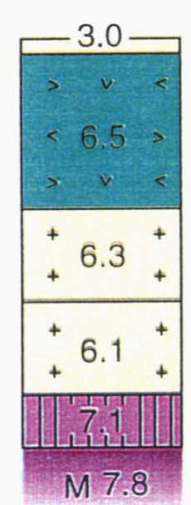

g

Sino-Korean Yantze platform
platform

h

South China fold system

South China fold system

$$
6.32
$$

6.32

6.37

\subsection{6}
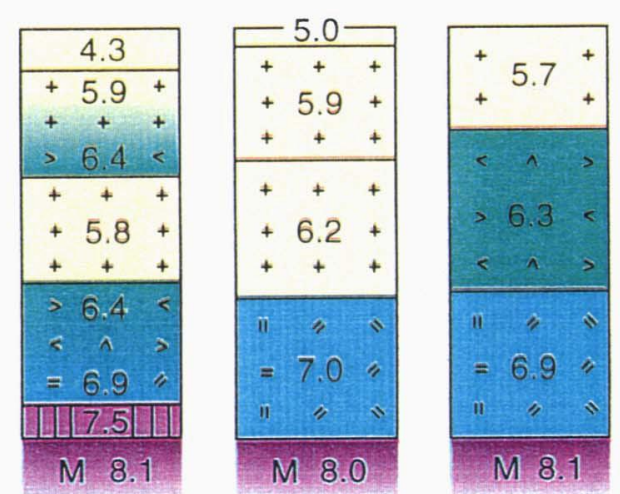

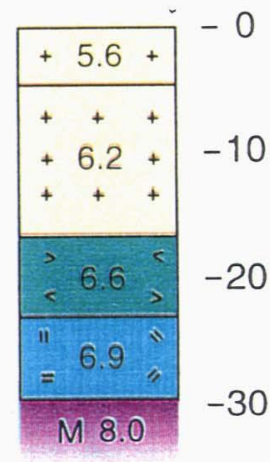

$-40$

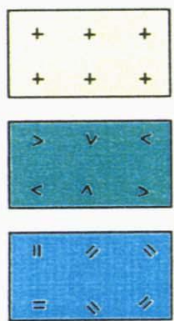

Felsic Crust

$(5.8-6.3 \mathrm{~km} / \mathrm{s})$ $-60$

Felsic / Intermediate Crust $\quad(6.3-6.6 \mathrm{~km} / \mathrm{s})$

Intermediate / Mafic Crust $\quad(6.6-7.0 \mathrm{~km} / \mathrm{s})$

Mafic Crust

$(7.0-7.6 \mathrm{~km} / \mathrm{s})$

M Ultramafic Upper Mantle (> $7.6 \mathrm{~km} / \mathrm{s}$ ) 


\author{
United States Geological Survey \\ Western Earthquake Hazards Team \\ 345 Middlefield Road, Mail Stop 977 \\ Menlo Park, California, USA 94025 \\ Tele: 650-329-4764 \\ Fax: 650-329-5163 \\ Secretary: $650-329-4785$ \\ moonev@andreas.wr.usgs.gov
}

Madame Wang Hongzhen, Director

March 9, 1998

Department of International Cooperation

State Seismological Bureau

No. 63 Fuxing Avenue

Beijing 100036, China

Fax 86-10-68210995

Dear Madame Wang,

Thank you for your fax message with news about the Sino-US Joint Workshop on Geodynamics and Seismic Hazards to be held in Shanghai July 15-18, 1998. I was very pleased to receive your message. I have already discussed your FAX with Prof. Francis Wu.

Your draft plan is excellent. I was pleased to read that Prof. Ma Zongiin of the Institute of Geology had agreed to join Pro. Chen as CoChairman. These two scientists are very distinguished, and are well known in America.

The list of five main topics is very suitable for our workshop. The suggested topics are likely to encourage interesting and stimulating presentations.

Your message included the names of about 15 Chinese participants, and I was pleased to see that many of the most important and creative scientific leaders were included there. We will try to 
organize an American delegation that is well matched to this distinguished group of Chinese Earth Scientists.

Prof. Francis Wu and I have made a preliminary list of possible American participants. Our goal is to include people who are excellent scientists, and who are likely to propose cooperative work through the US National Science Foundation and the USGS. At present we have too many names on our list, and we need to discuss our ideas further in order to reduce the number to about 10-12 leading scientists. I hope that Dr. Leonard Johnson at the NSF will assist us in selecting these final names.

Thank you for your message. We are confident that a very important Workshop will result from our efforts.

Sincerely yours,

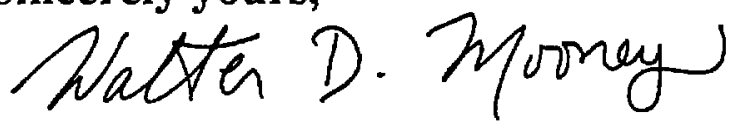

Dr. Walter D. Mooney

USGS Coordinator: PRC-US Cooperative

Program in Earthquake Hazards

Reduction 


\section{国家地展 局 State Seismological Bureau}

\section{No.63 Fuxing Avemuc, Beijing 100036. China Tel: 86-10-68215522. Fax: 86-10-682/0995}

\section{Fax to:}

Dr. Walter D. Mooney

USGS Coordinator

Western Earthquake Hazards Team

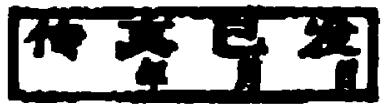

USGS Menlo Park Office

C^ 94025, USA

Fax: 415.329 .5163

c-mail: mooney(ă)andreas.wr.usgs.gov

Re: Joint Workshop on Geodynamics and Seismic Hazard

March 2, 1998

Dear Dr. Walter D. Mooncy:

According to the coordinators' meeting and our discussion in last Nuvember, a joint workshop on gendynamies and scismic hazard will be held in Shanghai this July, just before the Western Pacific Geophysical Mecting. Through the efforts of different departments and scientists of the Chincse side, a preliminary schedule for the neeting has been worked out. Altached, please find the draft plan. We would like to know if the lime and topics are suitable for you and your collcagues. Please feel free to make comments and suggestions. Alst, we'd like to know the name list of participants from the U.S. sidc at your earliest convenience.

I am looking forward to hearing from you scoon.

With my best wishes.

Sincerely yours,

Wang Horigzhen, Director $\frac{7}{5}$ Department of International Co-operation

State Seismological Bureau

ducu:/c:/hu/mooney $1 . d(s e$ 
United States Department of the Interior

$$
\begin{gathered}
\text { GEOLOGICAL SURVEY } \\
\text { Western Earthquake Hazards Team } \\
345 \text { Middlefield Road - MS } 977 \\
\text { Menlo Park, California } 94025 \\
\text { telephone +1-650-329-4764 } \\
\text { fax +1-650-329-5163 } \\
\text { e-mail: mooney@andreas.wr.usgs.gov }
\end{gathered}
$$

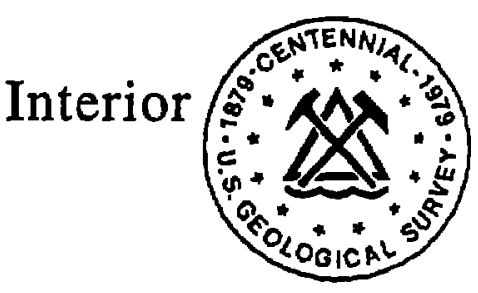

MEMO

October 8, 1997

TO: Mr. He Yongnian

Deputy Director General, SSB

FROM: Walter D. Mooney, USGS Coordinator

US-China Protocol on EQ Hazards Studies

RE: Official Invitation to Visit the United

States

This is an official invitation for an eight person delegation arranged by the State Seismological Bureau (SSB) to visit the United States in the period of around November 12-26, 1997. We understand that the delegates will visit scientific and governmental groups in several cities. The names of the eight delegates are:

1. Li Quianghua, Deputy Director, Office of General Administration, State Seismological Bureau

2. Guo Weiping, Deputy Division Director, Administration Office of the State Council

3. Zhou Chuanrong, Deputy Division Director, Ministry of Publicity 
4. Luo Hongfu, Vice Secretary General, Gansu Provincial People's Government

5. Nur Bakry, Vice Secretary General, Xinjiang Uygur Autonomous Regional Government

6. Zhao Hongqi, Division Director, Administration Office, He Bei Provincial People's Government

7. Tan Xianfeng, Division Director, Office of General Administration, State Seismological Bureau

8. Ms. Li Jing, Deputy Division Director, Center for Analysis and Prediction

Terms of the Invitation: The US Geological Survey will make arrangements for all meetings with Federal, State and private organizations. A professional travel agency will handle all travel arrangements, and all expenses associated with this trip will be paid by the SSB 


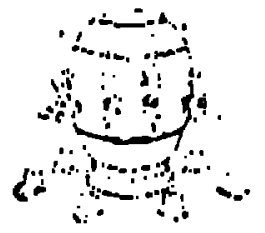
En

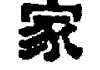

地

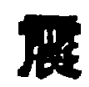

$\sqrt{-1}$

\section{STATE SEISMOLOGICAL BUREAU}

Mr.Walter Mooney

PRC.US Protocol Coordinator

Earthquake Ilazards Team

USGS Menlo Park Office

345 Middleficld Road, Menlo Park

Californis 24025-3591

Fax no: $415.3205143 / 5163 / 5658$

\author{
地 hl: (Add), No.63, Fuxing Avenue \\ Heijing China \\ 电报(Cable)，77777. Reijing C.bina \\ 用) 电报( Telex)，222361 SSB CN \\ 国文传年(Fax)，86-10-8210085
}

September 20, 1997

Dcar Mr.Walter,

You must be back home again afler the long flight from Bcijing to San Francisco I was very pleased to co-work with you in this year's Coordinator's' meeting, and wc had spent very busy but very fruitful days. In addition to the revicw of the ongoing projects, we also added some new projects which will provide more room for the scientists of borh countries to play in the carthquake studies. We really enjoyed the down-lo-canth spirit in the two days' meeting.

As we discussed on the afternoon of September 16, 1997 at Xiyuan Hotel, the Stale Scismological Bureau will send an education delcgation to visit the United States for a perjod of two weeks. The proposed visiting period will be from November 18 to December 1, 1997. The name list of the delegation comes as follows:

1. I.i Qianghua, Deputy Director, Office of General Administration, State Seismological Bureau

2. Guo Weiping, Deputy Division Director, Administration Ollice of the State Council

3. Zhou Chuanrong, Depuly Division Director, Ministry of Publicity

4. Luo llongfu, Vice Secretary General, Gansu Provincial People's Government

5. Nur Bakry, Vice Sccretary General, Xinjiang Uygur Autonomous Region Government

6. Zhao Hongyi, Division Director, Administration Office. He Rei Provincial People's Government

7. Tan Xianfeng. Division Director. Office of General Administration, State Seismological Burcau

8. Ms. L.i Jing, Depuly Division Director, Center for Analysis and Prediction, 


\section{Starc Seismological Bureau}

The purposes of the delegation's visit to the United Stales are to have a general understanding of how earthquake knowledge is reached to the citizens 10 increase their disaster awareness, and how the the resulis of earthquake studies are translated into the governmental concrete action for earthquake disaster mitigation effort. The past experience shows that the public disaster awareness and the government's involvement in disaster reduction will have a great effect on reducing the possible losses from disasters. The delegation, mainly consisting of the responsible officials for the earthquake disaster affair at various levels of governments will further stimulate the government's participation in the disaster reduction effort.

The tentative itinerary comes as follows:

\section{November 18, arrive in San Francisco}

November 19, visit the FEMA's reg onal office, visit Menlo Park Ofice

November 20, visit the governor' Emergency Office

November 21. fly io Los Ange'es

November 22, visit the SC.E., San Fernando where 190/ Northridge earthquake occurred

November 23, visit the Cali Tornia Scismic Safety Committee

November 24, fly y New York

November 25, ynt the Inited Nations Development and Suppon Service

November 26 aly to Buffalo to visit the NC.F.ER, National Center for Earthquake Engineering Research

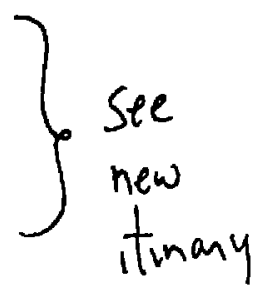
$\ln \operatorname{oct} 5^{2}$
$\operatorname{tax} !$

Novemb, 27, visit in Buffalo

Novgroer 28 , fly to Washington D.C.

Noymber 29, visit the IRIS and USGS

Yovember 30, social activities in D.C., and fly to New York

t)ecember 1, depart for Bcijing via New York

All the expenses will be covered by the State Seismological Bureau.

You are kindly requested to issuc a letter of invitation with all the names of the visitors covering the period of November 18 to December I, 1997.

SSB also would like to seek your assistance for the delegation 's local transportation and hotel reselvation. and coordinate the activities of the dclegation during its stay within the U.S.

I have finished the Minutes of 1997 Coordinators' meeting and it will be distributed 10 other participants for further revisions When all the revisions are madc, I will send Leonard and you the signed copy

Looking forward to your reply snon. 
Please remember me to Mehmet Celebi.

Yours Sincerely.

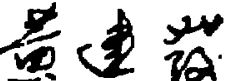

Huang Jianf', Division Director

Department of Intcrnational Couperation

Statc Seismological Bureats 


\section{AGREEMENT ON EXTENSION OF THE PROTOCOL BETWEEN}

THE NATIONAL SCIENCE FOUNDATION

OF THE UNITED STATES OF AMERICA AND

THE GEOLOGICAL SURVEY OF THE DEPARTMENT OF THE INTERIOR

OF THE UNITED STATES OF AMERICA

AND

STATE SEISMOLOGICAL BUREAU OF THE PEOPLE'S REPUBLIC OF CHINA

FOR SCIENTIFIC AND TECHNICAL COOPERATION

IN EARTHQUAKE STUDIES.

In accordance with Article 11 of the Protocol between the National Science Foundation of the United States of America, and the Geological Survey of the Department of the Interior of the United States of America, and the State Seismological Bureau of the People's Republic of China, for Scientific and Technical Cooperation in Earthquake Studies signed in Beijing on January 24, 1980, and extended on July 17, 1984, effective January 24, 1985, the Parties agree to extend the Protocol for a period of five years, effective January 24 , 1990.

Done in quadruplicate in Washington, D.C. on and 1990, and in Beijing Mar \& 1990, in the Chinese and English languages; both texts being equaliy authentic.
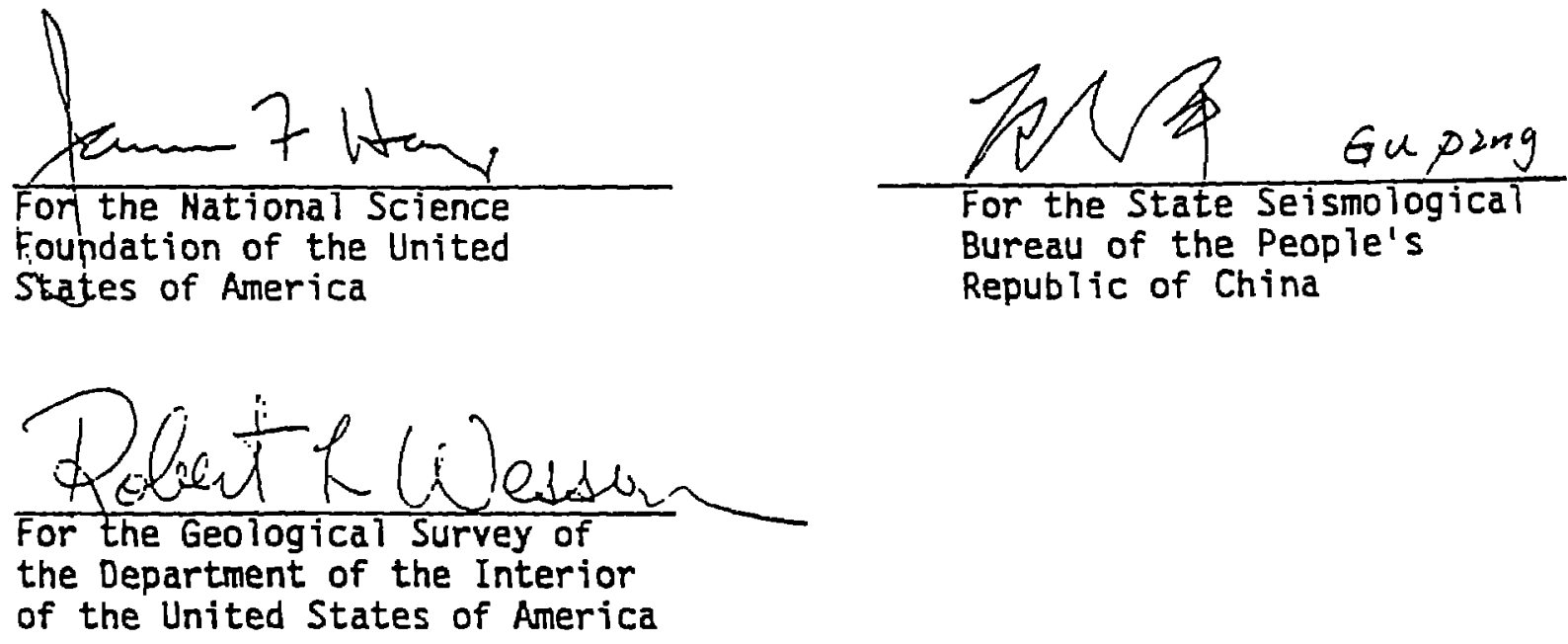


\section{关于中华人民共和国国家地震局和}

\section{美利坚合众国国家科学基金会与}

美利坚合众国内政部地质调查局

地震研究科学技术合作议定书的延长协议

根据一九公0 年一月二十四日在北京签订并于一九八 四年四月十七三具次签署还长的中华人民共和国国家地震 局和美利紧合众国国家科学基金会与美利坚合众国内政部 地质调查局地震研究科学技术合作议定书第 11 条, 双方 代表一致同意中美地震研究科学拉术合作议定书自本协议 签宇后，从一九九０年一月二十四日起继续有效，有效期 五年。

府赤议于一九九 0 年五月 日在华盛顿特区和一 九九 0 年五月 8 日在北京签订, 一式四份, 年份都用 中文和芙文写成，两种文植真有同等效力。

中华人民共社国美利坚合众国美利坚合众国 国家地震局国家科学基金会、内政部地质调查局 代 表 代表
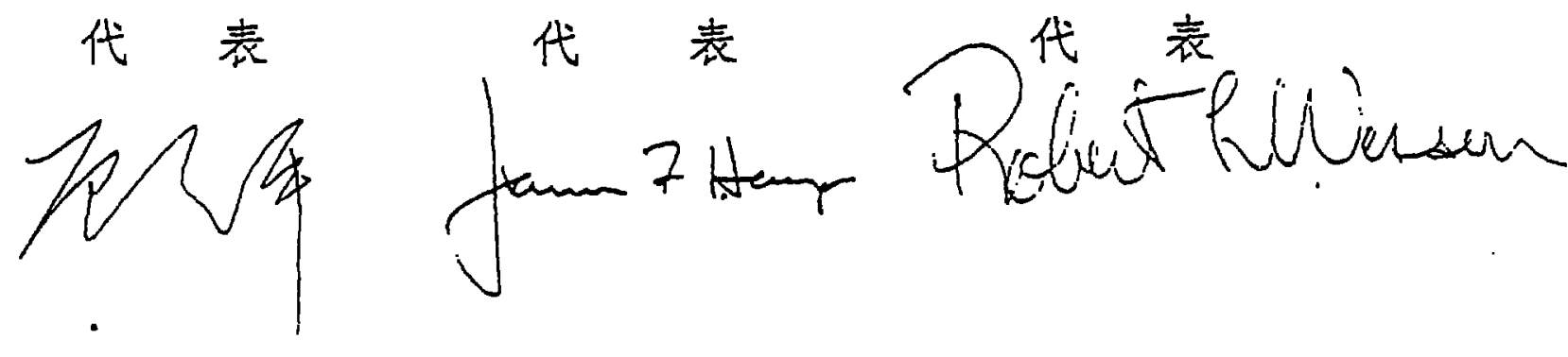


\section{AGREEMENT-IN-PRINCIPLE}

between the

STATE SEISMOLOGICAL BUREAU, PEOPLE'S REPUBLIC OF CHINA

and the

UNITED STATES GEOLOGICAL SURVEY

under Annex I of the Earthquake Studies Protocol

for

UPGRADES TO THE

CHINA DIGITAL SEISMOGRAPH NETWORK

27 March 1990

Signed:

1019 Guphes, pro side

Chief popartment of Internationat Robert 1 . Wesson

Signed:

Copperation, State Seismological Bureau

Chief, Office of Earthquakes, Volcanoes,

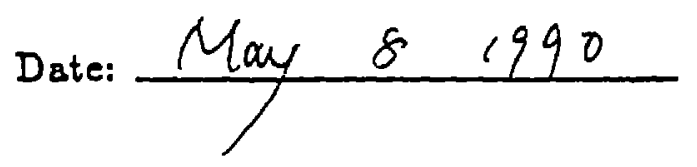
and Engineering, USGS

Date: Marich $\$ 7990$ 


\section{INTRODUCTION}

The CDSN has been in operation since 1886, and has been producing high quality digital data for research seismologists world wide since early 1987. The CDSN daia are made available to the research community through the CDSN Data Management Center (DMC) in Beijing, the USGS Albuquerque Seismological Laboratory (ASL), and the USGS National Earthquake Information Center (NEIC) in Golden, Colorado. These data are distributed by the CDSN DMC in the form of Network Day Tapes, by ASI as global network day tapes or volumes written in SEED (Standard for the Exchange of Earthquake Data) Format, and by NEIC in the form of CD ROM optical disks containing event data. The SEED volumes produced by ASL take the place of the Network Day Tapes produced previously by ASL. SEED volumes (presently tapes) are written in a standard format agreed upon by a significant portion of the international seismological community. Research seismologists are finding the inclusion of the CDSN data in the published data volumes to be a valuable asset in their studies. For example. the recent (Nov. 1988) large earthquake in Yunnan province can be studied in much greater detail because of the availability of CDSN digital data.

However, this particular earthquake pointed to the need for even greater dynamic range than is available in the present CDSN system. There was evidence of clipping on at least some channels at each of the five stations from which ASI receives data on a regular basis. The lowest gain channels are the broadband channels, and these did not show evidence of clipping except at Kunming. Installation of IRIS/GSN (also known as IRIS-2) equipment at the stations would allow the recording of broadband (BB) data at five times lower sensitivity than in the CDSN, so that large earthquakes would be even more likely to be recorded without clipping. Also the BB data would recorded continuously instead of being triggered. The IRIS-2 data loggers may also be equipped with optional very short period (VSP) and low gain (LG) sensors to allow the recording of high frequency (up to $50 \mathrm{~Hz}$ ) and high amplitude (up to $2 \mathrm{~g}$ ) waveforms of local end regional interest.

The desired capabilities for a Global Seismograpbic Network (GSN) of digital seismographic stations were defined as a result of the IRIS initiative. In 1984, the Incorporated Research Institutions for Seismology (IRIS) prepared a Science Plan for a New Global Seismographic Network (GSN). This plan was submitted to the US National Science Foundation (NSF) and resulted in a cooperative program between IRIS, NSF, and the USGS, to develop and install a modern digital broadband seismograph network of 50 to 100 stations distributed evenly around the globe. Based on the Science Plan's requirements, "The Design Goals For A New Global Seismographic Network," dated March 13, 1985, and a "5-Year Siting Plan IRIS Contribution to the Global 
Digital Seismographic Network," dated March 28, 1886, were prepared. These two documents state in detail the technical specifications and the proposed station locarions for the GSN stations.

The Siting Plan depends on the CDSN stations for seismographic coverage of China, as an integral part of the GSN. However, the CDSN stations do not presently meet all of the IRIS technical specifications in the Deaign Goals. In order for the CDSN to become a fully participating partner in the GSN program, it will be necessary to upgrade the CDSN stations and the DMC equipment to meet IRIS standards. These standards include:

1. BANDWIDTH: Sufficient bandwidth to adequately record the entire spectrum of seismic signals that propagate over distances that are large compared with the station separation, on the order of 20 degrees for a 100 station network. Broadband data should be recorded continuously at 20 samples per second, with bigher frequency channels recorded on an event basis.

2. RESOLUTION AND FULL-SCALE: Over the specified bandiridth, the system should be capable of resolving signals at the level of minimum ambient ground noise and of recording signals from the largest expected teleseismic event. Neither the full scale clipping nor the system noise should obscure any signal of interest.

3. IINEARITY: The system output should be a linear time-invariant funetion of the ground motion. Further, the linearity should be such that signals near the ground noise minimum can be resolved in the presence of ground noise at other frequencies near the expected ground noise maximum.

In addition to these design goals, the GSN systems also have the ability to transmit any or all of the acquired data via a serial port to a host computer or central receiving station. There is also a dial-up port that may be connected to a telephone line or modem so that buffered data may be retrieved by calling the station processor from another computer. Up to sir channels of IP or SP anaiog outputs are available for use in producing conventional analog seismograms on drum recorders.

The recording systems proposed for upgrading the CDSN over the next two to three years will meet all of the design goals for the GSN. In addition, the new DMC equipment proposed will be able to read tape cartridges from the upgraded stations and compile SEED network volumes from them and from eristing CDSN tape cartridges.

:In preparation for installation of IRIS-2 seismic data systems in China under this Agreement, the USGS and the SSB agree to cooperate in the early installation of Sun seismic data systems at four CDSN stations, and to telemeter 
seismic data from these stations to the DMC in Beijing and to ASL. ASL will transmit event parameter data to the DMC in Beijing over the reverse link. The Sun seismic daia systems at each station will operate for about one year or until an IRIS-2 data system is installed at that station. At that time, the Sun system may be attached to the IRIS-2 system as a work station, it may be moved as a complete system to another station, or it may be left in place and continue to be used as before.

The USGS wiil let a contract for the installation work and the training. The USGS field engineer in China and the SSB will assist the USGS and its contractor in installation of the Sun seismic data systems and telemetry links. 


\section{PURPOSE}

The purpose of this Agreement-In-Principle is to list the steps necessary for upgrading the present China Digital Seismograph Network (CDSN) to be compatible with IRIS/GSN standards, to install Sun systems at four stations, and to assign the responsibilities and costs for each item to the PRC side or the USA side. This Agreement-In-Principle is understood by both sides to be within the original terms and conditions of Annex I to the Earthquake Studies Protocol, signed in 1980 by the State Seismological Bureau (SSB), the U. S. Geological Survey (USGS), and the U. S. National Science Foundation (NSF). It will result in an upgraded and expanded seismograph network in China, consisting of 10 IRIS/GSN-type stations, four stations with Sun systems and work stations, an upgraded Data Management Center (DMC), and an upgraded Network Maintenance Center or Depot (NMC). It will also result in data being telemetered by satellite from some stations to the DMC and from the DMC to the USA, and in earthquake parameter data being telemetered from ASL to the DMC in Beijing.

As with all cooperative activities under the USGS Protocol on Earthquake Studies, this activity is subject to the availability of funds. 


\section{USA SIDE RESPONSIBIITIES}

A. Install Sun Seismic Data Systems.

1. At four CDSN stations, install a Sun seismic data system, including three short period seismometers, three broad band seismometers, digitiring system, digital recorder, work station, and Uninterruptible Power System (UPS). This equipment will be installed in addition to the current CDSN data system and seismometers.

2. The four stations will be Baijatuan (BJI - near Beijing), Lanqhou (LZH), Hailar (HIA), and Jrumqi (WMQ).

B. Upgrade Stations To IRIS/GSN Standards.

1. Upgrade five CDSN stations by replacing the present CDSN data logger and seismometer system with IRIS-2 data logger, VBB seismometer system, and possibly very short period (VSP) and/or low gain (LG) seismometer systems (optional).

2. The five stations will be:

Kunming (KMI), Mudanjiang (MDJ), Enshi (ENH), Qiongzhong (QIZ), and Sheshan (SSE).

3. Upgrade the remaining four stations of the CDSN network, plus a new site at Lhasa, by replacing the present CDSN data logger and seismometer system with IRIS-2 data logges, VBB seismometer system, and possibly very short period (VSP) and/or low gain (LG) seismometer systems (optional).

4. The four stations in addition to the station at Lhasa will be: BJI, LZE, HIA, and WMQ.

5. This will result in a total of $10 \mathrm{CDSN}$ stations that fully meet IRIS/GSN standards.

C. Telemeter Data To Beijing And ASL.

1. Telemeter Sun System Data To Beijing And ASL:

Telemeter basically continuous VBB, LP, and SP data from the Sun systems at stations BJI, LZH, HLA, and WMQ to the DMC in Beijing and to ASL. The OSGS and its contractor will work through the SSB with the China Brosdcast Satellite Corporation (CBSC) in establishing two-way satellite links from each station to the DMC.

This responsibility includes the purchase and installation of VSAT electronics and antennas, satellite link lease costs, and installation of a land link or other surface link (such as a microwave link) from the CBSC Hub (Central Earth Station) to the DMC. It also includes the responsibility for any necessary land link for connecting the DMC to the out-going satellite link to the USA. 
The land link or other suriace link from the CBSC Hub to the DMC will be installed with a minimum capacity of 112,000 bits per second to allow for future expansion by SSB.

2. Telemeter IRIS-2 System Data To Beijing And ASL:

For stations BJI, LZH, HIA, KMI, WMQ, and Lhasa (after upgraded to IRIS-2), telemeter basically continuous very broad band (VBB) and IP data, very short period (VSP) events, and low gain (LG) events from the IRIS-2 systems to the DMC in Beijing, and from the DMC to the Albuquerque Seismological Laboratory (ASL).

3. Telemeter event parameter data from the National Earthquake Information Center (NEIC) in Golden, Colorado, through ASL to the DMC in Beijing on the reverse satelite link. Telemeter parameters for all events detected in China greater than Richter magnitude 5 and for all other events in the world greater than magnitude 6 , if available. Also telemeter to the DMC event waveforms, if available, upon special request from the DMC.

D. Upgrade Data Management Center.

1. Upgrade the computer equipment of the DMC to Digital Equipment Corporation (DEC) Microvax III computer(s), capable of writing SEED network volumes from IRIS-2 station tape cartridges and from current-type CDSN station tape cartridges.

2. Install in the DMC one or two Sun computers to be used as telecommunications computers to receive data from Sun systems and/or IRIS-2 systems at the stations and transmit data to ASL, to receive event parameter data from ASL, and to function as a work station. Connect the Sun computer(s) to the DEC computer(s) vis DECNET.

3. Provide and install one IBM PC compatible computer in the DMC and connect it to the DEC computer(s) vis DECNET.

4. Insure that the DMC will be capable of producing copies of station tapes, SEED network volumes, and possibly other data sets, on a variety of media that are convenient for data users. These media will include IBM PC floppy disks, station-type cartridges (150 Mbytes), Exebyte cartridges (1.5 Gbytes), and possibly 8-track tapes. If Exebyte cartridge drives are not exportable to China, a substitute highcapacity medium and drive will be provided.

E. Training.

1. Sun System Training For NMC And DMC People:

Sun system training in the USA will be provided for two NMC and two DMC technical English-speaking people who can prove equal to 
this task, for two to three weeks.

2. IRIS-2 System Thaining For NMC And DMC People:

IRIS-2 system training for NMC and DMC people will be provided in a single training period in the USA for a iotal of 25 man-weeks (for example, 5 PRC people for 5 weeks). SSB agrees to send good technical people who can speak and understand English reasonably well. This training will take place just before the first station upgrades begin. Additional training will be provided in Beijing after the upgrades begin.

3. Station Operator Training:

Sun system training for station operators will be provided in China at the time of Sun system installation, either in Beijing or at the station site, at SSB's preference.

IRIS-2 system training for station operators will be provided in China at the time of IRIS-2 system installation, either in Beijing or at the station site, at SSB's preference.

F. Tpgrade The Network Maintenance Center, Provide Spare Parts.

1. NMC Equipment And Parts For The Sun Systems:

Stock the NMC with spare parts and equipment for station systems and DMC telecommunications computer at a level sufficient to keep the Sun systems operating at a high percentage of up-time, and maintain that level of stock for the duration of the Sun system experiment.

2. NMC Equipment And Parts For The IRIS-2 Systems:

Provide one complete IRIS-2 station data acquisition system and install in the NMC, to be used for depot maintenance and check-out of station spare parts.

3. Stock the NMC with spare parts for IRIS-2 station systems at a level sufficient to keep the entire network operating at a high percentage of up-time, and maintain that level of stock for the duration of the cooperative agreement between SSB and USGS for operating the CDSN IRIS-2 network.

4. Jpgrade and augment NMC test equipment as necessary for proper support and maintenance of the IRIS-2 data acquisition systems.

5. Provide one IBM PC compatible computer for the NMC, to be used as a diagnostic tool for the IRIS-2 station systems and for use in inventorying NMC spare parts.

G. Equipment For One Additional CDSN Station. 
1. Ship one current-type CDSN system, including data acquisition system and UPS, to China for installation at Lhasa.

2. Provide technical assistance, as necessary, during installation of this equipment at Lhasa.

B. Network Support.

1. Sun Network Support:

Provide support for the Sun station systems and the Sun telecommunications computer. Provide field assistance in China as necessary to support the installation, operation, and maintenance of the Sun network. Provide operating supplies that are not available in China.

2. IRIS-2 Network And CDSN Support:

Continue to provide support for the current-type CDSN stations and IRIS-2 upgraded CDSN stations at BJI, WMQ, LZH, HIA, KMI, MDJ, ENH, QIZ, and SSE. Provide support for the cti:ent-type CDSN equipment at Lhasa, when installed. Provide support for IRIS-2 equipment at Lhasa, when installed. Continue to provide support for the NMC and the DMC in Beijing. Provide field assistance in China as necessary to support the continuing operation and maintenance of the CDSN. Provide operating supplies that are not available in China.

3. DMC Mair :nance:

Provide I intenance of DMC equipment as much as possible by maintenance contracts.
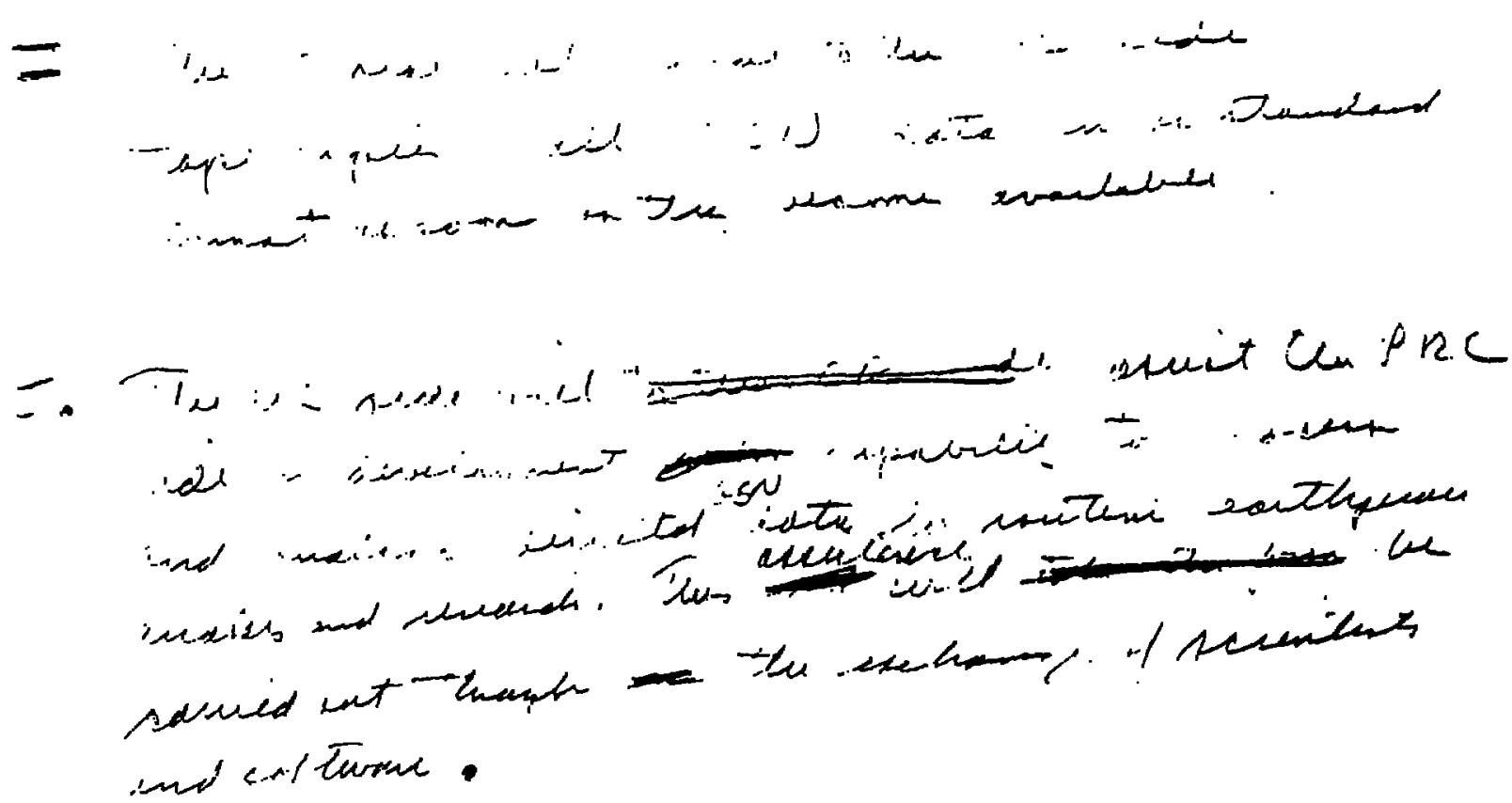


\section{PRC SIDE RESPONSIBILITIES}

A. Site Preparations For Sun Systems.

1. Perform any minor site upgrades and improvements at the four CDSN stations (BJI, LZH, HIA, and WMQ) as may be necessary for installation of the Sun systems. Also perform any necessary improvements of DMC and NMC facilities, such as additional space and better environmental controls, for installation of the Sun telecommurications computer.

2. Perform satelite signal strength tests and RF noise tests at stations BJI, LZE, HIA, and WMQ.

3. Cooperate with US technical personnel in checkout, installation, and acceptance testing of new equipment.

4. Provide all transportation of equipment in China.

5. Continue to provide daily management of the 9 -station network, including the Sun systems at BJI, LZH, HIA, and WMQ. Continue to provide daily management of the DMC and the $\mathrm{NMC}$, including the Sun system at the DMC.

6. Insure that seismic data are telemetered from the Sun systems at the four stations BJI, LZH, HIA, and WMQ to the DMC in Beijing, and from the DMC to ASL. Provide copies of Sun system station tapes for time periods during which telemetered data from these four stations are missing due to technical problems with the telemetry links.

7. Take whatever steps are necessary to insure that power is available to the DMC equipment 24 hours each day.

B. Site Preparations For CDSN System At Lhasa:

Prepare one new CDSN site at Lhasa for installation of current-type CDSN station equipment. This includes capital construction, seismometer vault or tunnel construction, and line power supply improvements, but not UPS.

C. Site Preparations For IRIS-2 Systems.

1. Perform necessary site upgrades and improvements at the nine existing CDSN stations to prepare for installation of IRIS-2 systems, such as improved line power, seismic noise surveys, and construction of improved seismometer vaults or tunnels. Also perform necessary improvements of DMC and NMC facilities, such as additional space and better environemental controls.

2. At stations KMI and Lhasa, perform satellite signal strength tests and RF noise tests in preparation for satellite telemetry of IRIS-2 data from those sites. 
D. Cooperate with US technical personnel in checkout, installation, and acceptance testing of new equipment.

E. Provide all transportation of equipment in China.

F. Provide daily management of the 10-station network, the DMC, and the NMC.

G. Insure that data are telemetered from the IRIS-2 systems at the six stations BJI, LZH, HIA, KMI, WMQ, and Lhasa (after upgrade), to the DMC in Beijing, and from the DMC to ASL. Provide copies of

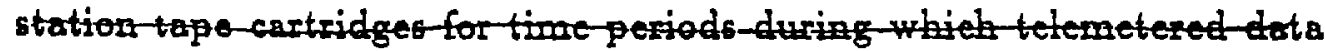
from these six stations are missing due to techrical problem the telemetry links.

H. Install the spare IRIS-2 station UPS in the NMC.

I. Take whatever steps are necessary to insure that power is available to the DMC equipment 24 hours each day.

J. If SSB wishes to telemeter data from the IRIS-2 systems at stations MDJ, ENH, QIZ, and SSE, such telemetry will be at the cost of the SSB. Any excess capacity available in the installed surface link from the CBSCHub to the DMC may be used by SSB at no additional cost.

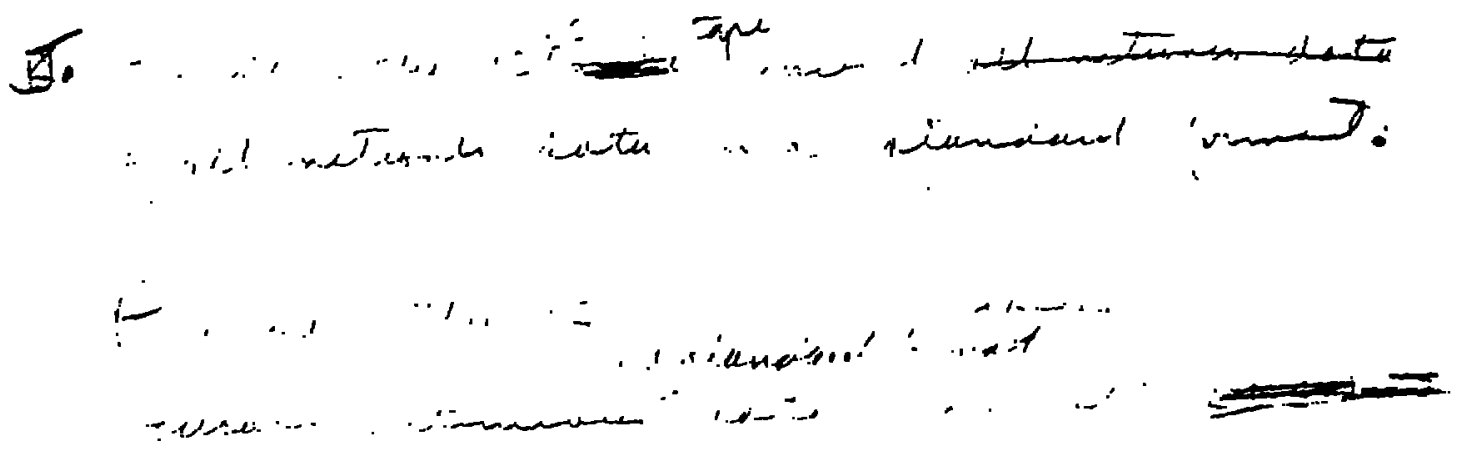

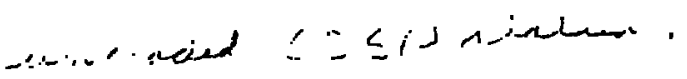




\section{PROPOSED SCHEDULE}

A. In 1890:

Install Sun systems alongside the current CDSN systems at BJI, LZH, HIA, and WMQ. Also install Sun telecommunications computer at the DMC, telemetry links from these four stations to the DMC, and a telemetry link from the DMC to ASI.

B. In 1980 and 1891:

Upgrade stations KMI, MDJ, ENH, QIZ, and SSE with IRIS-2 systems.

C. Beginning in 1990:

Upgrade the NMC to handle Sun systems and IRIS-2 systems. Upgrade the DMC to handle data from Sun systems and IRIS-2 systems, and to produce SEED network volumes.

D. In 1891 anà 1892:

Upgrade stations BJI, IZZH, HIA, WMQ, and Lhasa with IRIS-2 systems.
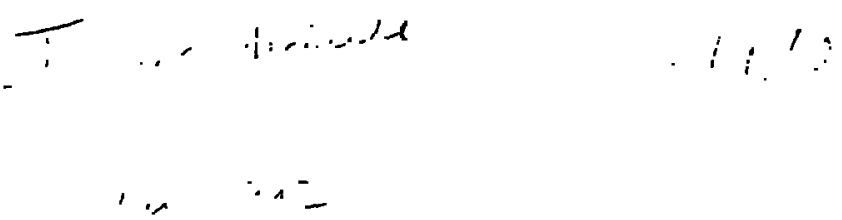


\section{中华人民共和国国家地震局和美利坚 合众国地质调望局就列入地震研究 议定令附仁一中关于改进中国 数字化地震台网的原则协议}

签 宇：篮 字:

国家地震局

美国地质调查局

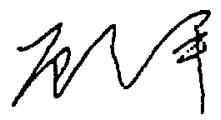

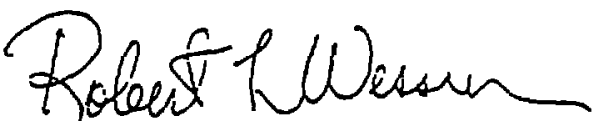

日期 $/ 990.5 .5$.

日期

$7 / 7 / 90$ 
一, 前言

1986 年后, 安国数字化地震台网(CDSN)已投人运行. 以 1987

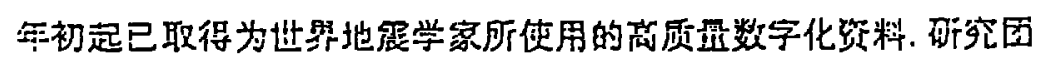
休可近过中国北京 CDSN 的数招管理中心(DMC), 美国地质证括 局的阿尔布开怘地震实验室(ASL)和科罗拉多州戈尔登的美国地 调局层察地军情招中心(NEIC)得到该台网的资料.这些驽料可由 该台网的数据笛理中心以网日带的形式，同尔布开克地震实验室以

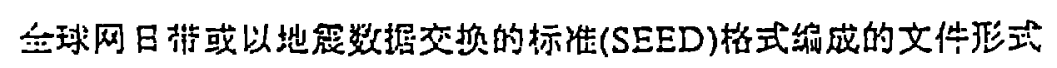

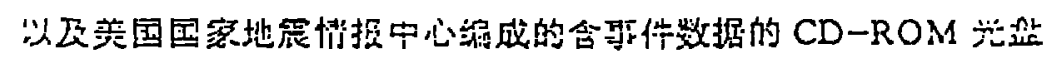

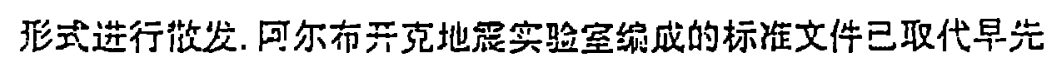

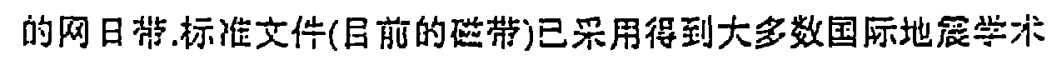
因体认可的标准格式写成，地震学家们正在发现，在已发行的资料 中，该台网数据对他们的研究有很大的帮助. 等如,对最近(1988年 11 月)云南省的大地䟭，狂于该台网数字化数据的可用性，可迸行更 为深人的研究.

然而，这一特有的地震还表明霜要有比目前现有该台网系综更 大的动态范围.在常规的瑟础上,阿尔布开克地要实验室得到 5 个台 的资料，每一个台至少有若干道数据已明显限幅.报低增益信道是宽 步带信道，除昆盟台外，其它台没有明显限幅，如在台站上安装 IRIS / GSN(也称IRIS-2)设备，可记录到比该台网记录灵政应低 五倍的宽频带(BB)数据，而不会限幅。再者，宽频数据由达续记录代 替原来的触发记录.IRIS-2 数据记录器也可配备附加的甚烦周期 (VSP)和低增真(LG)传感器以记录感兴趣的地方震和区域地震的 


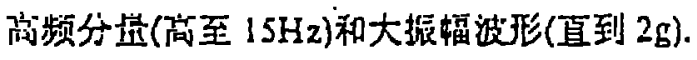

全球地震台网(GSN)的数宇地震台网所期望的性能是迹过 IRIS 的计划而确足的. 1984 年, 地震学联合作究埧团(IRIS)损定了 一份关于前全球地很台网(GSN)的科学计划. 该计划提交给美国科 举基金会(NSF)迸行审议，结果产生了该集团、美国科学基金全、 和美国地质调背局之问一项关于研制和安装一个全球均匀分布、 由 50 至 100 个台站所组成的现代化数宇宽频蒜地震台网的合作计

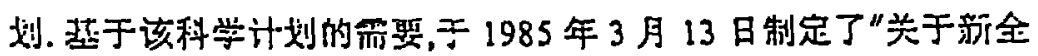
球地震台网的设计目标”，并于1986 年 3 月 28 日矨定了“关于金球

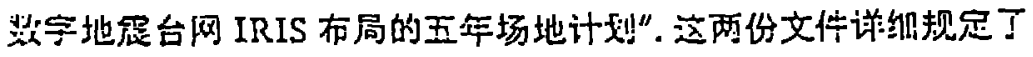
台站的技术指标和建议的场地位悬。

作为全球台网整体的一部分，中国数宇化地震台网台站的场地 计划取决于对中国的地祳覆盖. 但是，现有台网台站节非全部较足 IRIS 设计目标规定的拉标指标. 为了便该台网成为全球台网计划 的合乎规范的參与伙伴，必须对台网台站和数据管理中心设备芒行 改进以适应 IRIS 标准. 这些标准包括:

1.频带宽度: 足的的频带宽度可记录传摇距称比台站问距大的 地震信号的全部频谱，对于 100 个台的台网，台站问距约为 20 店. 资频带数据每秒采样 20 次,连续记录, 而高频信道则以件知发为 基础.

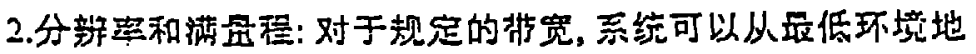

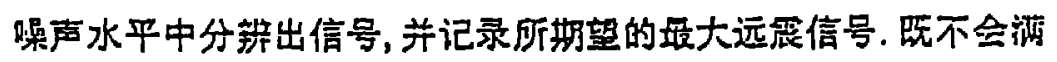
盈程限幅又不会他系统噪声炛盖任何感兴趣的信号.

3. 线性应: 系综输出是线性时不变函数. 此外、其线性度应在有 


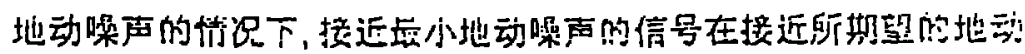

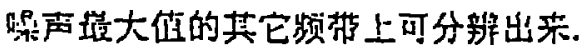

除上述设计目标外，全球台网还有近过一系列转接站问一竞主

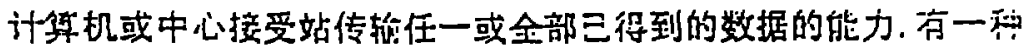
造号接口可连接到电话线或调制解调器上，以便用一台计等机访问 基地信息处理机取回已哏存的数据，可得到多达 6 道长周期或短活

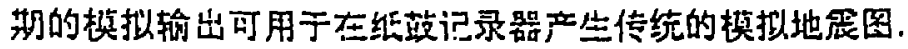

为改进中国媇宇化地震台网，在今后二三年时问内安装的所建 议的记录系统将满足全球台网的全部设计目标。此外，所超议的新

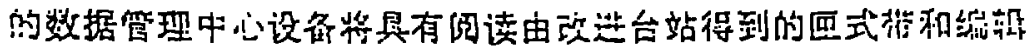

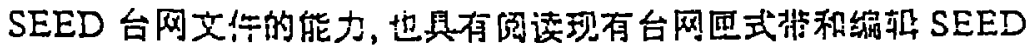
文件的能力。

按此协议、为准备在中国安装 IRIS-2 㤠地震数据系婉、美国地

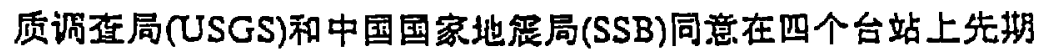
安装 SUN 地縟数据系统，并将数据由这些台站遥测到北京数据管 理中心(DMC),并从该中心传输到美国阿尔布开克地震实验室 (ASI), 该实验室将在反向涟路上把㻗件参数数据传输到北京。每 个台站的 SUN 地震数据系统将运行大约一年或直到该台站安装 一套 IRIS-2 数据柔统时为止.那时,这个 SUN 系统可作为一个I 作站并人 IRIS-2 系统,或者作为一空完整的系统移到另一台站, 或 者能续留在原地体用。

美国地质调运局将篮订一项关于安装和培训的合同.由美国地 调局派往中国的现场工程师和国家地震局将协助美方及其合同人 员安装 SUN 地震数据系统和通测结路.

- 4 - 
二.目的

该原则协议的目的是列出改进现有中国䚺字化地䇥台网以适 应 IRIS / GSN 标准所箱奖采取的步留，在四个台站安装 SUN 系 统，以及规足中方和美方的职恐和费用. 双方一致同意该倞则协议 由中国国家地震局，美国地质调查局，美国科学萑金会于1980年签

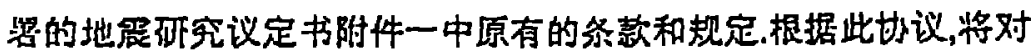
中国地䠆台网进行改进和扩展，即由 10 个 IRIS / GSN 类型的台 站, 四个具有 SUN 系统和工作站的台站, 一个改进的数据管理中 心(DMC)，一个改进的台网维护中心或检修站(NMC)所组成，同时， 一些台站的数据将依此还过卫星传输到数据笛理中心，并从该中心 传输到美国以及把地震参数数据从美国传造的北宗。

缐所有的美国地㶽局执行地震矿究议定书中的合作活动一样， 本项活动也受经势的制约.

三.美方职责

\section{A.安装 SUN 地咙数据系统}

1. 在其中四个台站上,各安装一尝 SUN 地震数据系统. 包括三

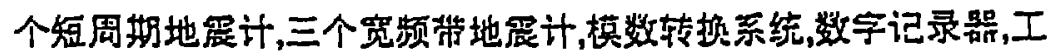
作站和不间断电源.

2.四个台站确定为白家暗(BII北京附迆)，兰州( LZH)，海拉尔 (HIA)和与等木(WMQ).

B.改进台站以达到 IRIS / GSN 标准

1.用 IRIS-2 型数据记录䎏，莣宽频地震计系统，或甚短周期 
(VSP)和(或)低增益(LG)地震计系统(任遂)取代现有其它互个台站 的数据记录器和地震计系统。

2.这五个台站是: 昆明(KMI),告丹冮(MDJ),恩施(ENH)，玢中 (QIZ),和会山(SSE).

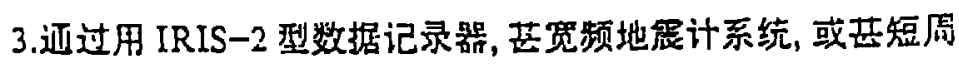
期(VSP)和(或)低增益(LG)地䞥计系统(任选)取代目前台网的数招 记录哭和地震计系统以改进其余四个台站。并新增设一个拉萨台站.

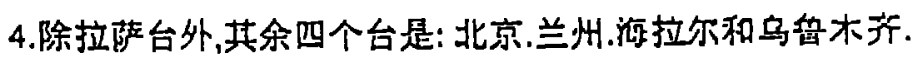

5.完全符合 IRIS / GSN 标脚台站总数为十个.

C.传输数据到北京和美国:

1.遥测传轺，SUN 系统孜据到北京和美国:

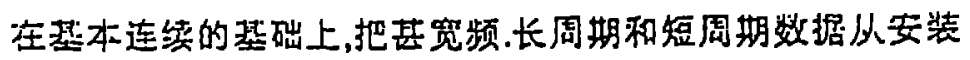
SUN 系绕的四个台站传送到北京的数据管理中心(DMC)和阿尔 布开克地震实验室(ASL). 美国地调局和它的合同人员将近过国家 地震局与中国广搯卫星公司(CBSC) 为每个台站与北京间，北京与

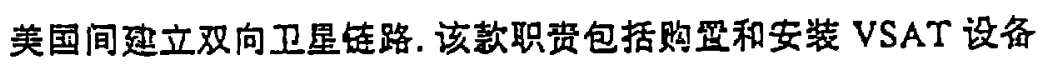
和天线，卫星近道租金和由中心地面站(CES)到中心安装一条地而 链路(例如:微波路).还包括提供由中心到卫星的引接和传输到美 国所需的在何必要的路。从卫星公司插孔包数据中心的地西引接 路或地表知路应不少于 $112 \mathrm{~Kb} / \mathrm{s}$ 的容量, 以位于地笼局的扩䒧 伅用。

2.遈测传输 IRIS-2 系统努据到北京和美国:

在基本造续的基础上，将北京，兰州，海拉尔，昆明，乌㽜木齐和拉 萨(完成改进到 IRIS-2 后)的甚宽频带数据，长周期数据，芒短周期 
等件和低增益 (LG)事件传输到北京, 芹从北京传输到美国.

3.由科罗拉多州戈尔登的美国国家地霞情报中心(NEIC)向中 国北京近过反向卫星经路传输联件参数数招. 关于传输所有检测到 的取件参数，是指已得到的发生在中国的大于里氏震级五级的和发

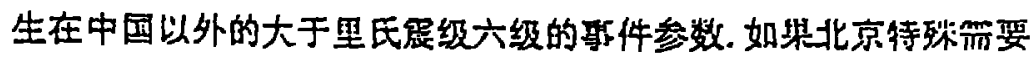
，也将向北京传输已得到的事件波北。

D.改善数据筞理中心

1.用 DEC 公司的 MICRO VAXIII 计算机改管中心的计得机

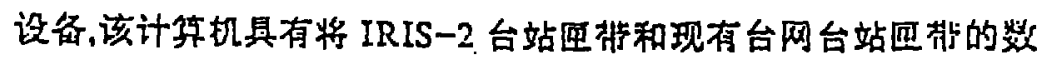
据编写为 SEED 文件的能力。

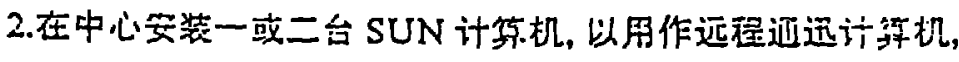
接受台站数据社传输数据到美国. 近过 DECNET 将 SUN 计算机 与 DEC 计算机增机。

3.为中心堤供和安装一台 IBM PC 可苏容的计算机，近过 DECNET 使它与 DEC 计算机联机。

4.为方便数据用户将保证中心拥有多种媒质以生产台站磁嗦 搭贝,SEED 台网文件和可能的其它类数据集. 这些媒质包括: IBM-PC 机㰪盘，台站型回带(150MB)，商容量匣带(1.5GB), 可能 还有 9 轨磁带. 如果高容量医带驱动㽞不准向中国出口，将提供代 用的高容避媒质积驱动器.

E.培训

1.对台网两个中心的人员进行 SUN 系统培训.

每中心有两位能陆任该项工作，会讲获语的技冰人员赴䒿培训 2 到 3 周. 
2.对台网两个中心人员进行 IRIS-2 系统培训。

在莱国将安排一次对 NMC 和 DMC 人员进行 IRIS-2 系统 的培训，总数为 25 人周 (例如,5 个中方人员 5 周), 国家地震局派具 有英语听说能力和有经验的芰水人员起美. 培训特安排在管一个台 站改进开始之前. 在改进开始后，将在北京提供附加培训.

\section{3.台站操作员培训。}

对台站操作员的 SUN 系统培训将在安装 SUN 系统时在中国 这行，具作安排由地震局䂵足.

对台站㙅作员的 IRIS-2 系统唔训将在安菨 IRIS-2 系结时在 中国进行，具休安韮由地震局挽定。

F.改进台网维修中心(NMC)，铝供保件

1.维修中心用于 SUN 系统的设备和部件.

在维修中心存贮的用于台站系统和管理中心远程近信计算规 的备件和设备必须保证 SUN 系统能以高百分率运行及满足试验 期间维修所霜的坚备水平. 2.维修中心用于 IRIS-2 系统的设备和 部件.

为维修中心提供一套完整的 IRIS-2 型台站数据采集设备,以 用于台站备件的捡修和测试.

3.在台网维修中心这备足的的台站系统备件，以保持登个台网 在一个高百份率下正常运落, 并在国家地震局与美国地调局执行台 网合作协议期间保持这一些各水采。

4.改管和增加维修中心的必霜测试设备，以进行常规支持和用 于 IRIS-2 数据采集系统的检修.

5.为维修中心提供一台 IBM-PC 获容式计算㧈, 作为 IRIS-2

$-8-$ 


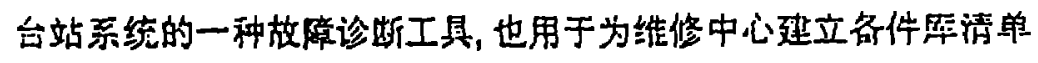

G.关于增设一个台网台站的设备

1.向中国提供一窟包括数据采集系统和不间断电源在内的现 有台网类型的设备，安拱在拉萨台.

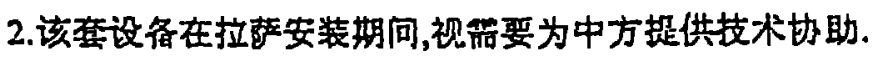

H.关于台网支持

1.SUN 网络支持

为 SUN 台站系统和 SUN 远理近信计算机提供支持.为所篮 的 SUN 网络的安装，运行和维护提供现场帮助.哫供在中国得不到 的常规消耗品.

2.IRIS-2 台网和 CDSN 台网支持

继续对现有类型的 CDSN 台站和用 IRIS-2 型改进的北京,兰 州，海拉尔，昆明，生丹江，恩施，琼中和余山地震台提供支持。为在拉 范安装现有类型的 CDSN 仪器提供支持. 为在拉蓼安装的 IRIS-2 仪器提供支持. 继续为北京的数据管理中心和台网维修中心提供文 持，为所需的为台网的连续运行和维护提供现场帮助.提供在中国得 不到的常规消耗品.

3.数据管理中心维护:

近过签订维修合同尽可能为中心设备提供维护.

四. 中方职责

\section{A.SUN 系统的场地准备}

1.在四个台站上提供安装 SUN 系统所简要的场地改造.改臂 
管理和维修中心的设施条件，诸如增加空间和更好的环境控制，以 佂安装 SUN 还讯计算机.

2.在北京，兰州，海拉尔和鱼各不剂四个台站进行卫星信号强度 测试和 RF 噪声试崄。

3.与萃方技术人员在新设条的检查，安装和接收测证方面遊行 合作.

4.提供在中国境内的所有仪器的运输.

5.侳续提供包括在北京，兰州，海拉尔和鸟燳木齐台的 SUN 系 统在内的九个台站的台网日常管理，继绩提供包括在数据管理中心 的 SUN 系统在闪的数据管理中心和台网维修中心的日常管理.

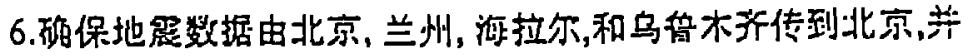
且由北京传到笑国。提供由于掘测链路找术问题引起的从这四个台 传送数据期间所丢失数据的 SUN 系统台带拷贝.

7.采取任何需要的措施以确保数据管理中心设备每天 24 小吋 工作所篮的供电.

\section{B.拉萨台 CDSN 系统的场地准备}

在拉萨台准备一个新的场地以安装现有 CDSN 类型的台站设 备. 包括基本建设，地震计摆房或山洞建设，电力坮容，但不包括捉 供UPS 系统.

\section{C.IRIS-2 系综的场地浩备:}

1.在九个现府 CDSN 台站上进行必要的改造和改管以准备安

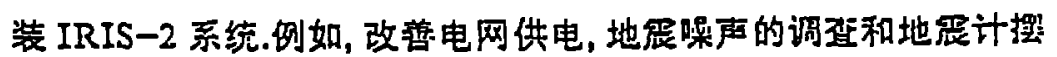
房或山洞条仵的改善. 对数据笛理中心和台网经修中心的设施也进 行改揞，例如增加空间和进行较好的环境控制.

$-10-$ 
2.在昆明台和拉萨台，进行卫星遥测信号的强度测试和在台站 进行 RF 嗓声测话。

D.与美方技术人员合作，共同对新设备进行调诒，安和验收 测迅.

E.承担所有设备在中国国内的运输费用.

F.秉担台网十个台站，数据管理中心和台网维修中心的日常管 理.

G.保证来自北京，兰州，海拉尔，昆明，马增木齐和拉萨(改进后 )六个台站的 IRIS-2 系统数据由台站传输到北京井由北京传至美

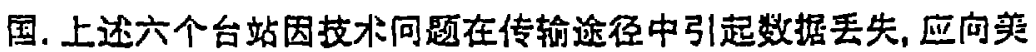
方提供 IRIS-2 系统台站回带的拷贝.

H.在维修中心安装备用的台站 UPS 系统.

I.梁取一切必要步架挽保数据筸理中心的电源供应以使数据管 理中心设备每天 24 小时工作.

J.如果中方希望由其余㣖丹江，䍐施，琼中和余山四个改进后的 CDSN 台站将数据传输到管理中心，中方应乘扭传输费用。中方不

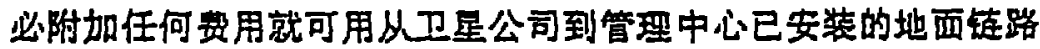
的娳余容量.

五.建议的执行进度

A. 在 1990 年

在现有 CDSN 系统的北京，兰州，海拉尔和乌暨本芹台安装 SUN 系统并行运转。在管理中心安装 SUN 远程近信设备,和安装 从四个台站到管理中心的遇测路及从管理中心到美国的遥测锛 
路.

B.在 1990 年和 1991 年

用 IRIS-2 系浣改进昆明，牡丹江，恩施、琼中和余山台.

C. 在 1990 年初

改进台网维修中心以管理 SUN 系统和 IRIS-2 系统. 改进数 据管理中心以管玨来自 SUN 系统和 IRIS-2 系统的数据和编转 SEED 台网文件.

$D$. 在 1991 年和 1992 年

用 IRIS-2 系统改进北京，兰州，海拉尔，乌㬗木齐和拉萨台. 
United Sitater Department of Energy
Washingtori, D.C. 20585
DOE Interagency
Agreement/Amendment
Part I-General Information

6. Name and Address of DOE Technical Office:

Office of Research and Development, NN-20

U.S. Department of Energy

1000 Independence Ave., SW

Washington, DC 20585-0420
1. DOE IA Identification (ID) No.: DE-A101-97NN20004

2. Servicing Agency IA ID No. (Ifknown):

3. DOE Procurement Request No.: 0197NN20004.000

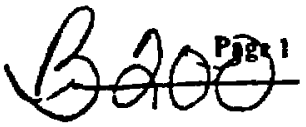

4. TA No::

5. Modification No:

A000
7. Name and Address of Servicing Agency:

United States Geological Survey

Office of Earthquakes, Volcanoes, and Engineering

Branch of Seismology

345 Middlefield Road - MS 977

Menlo Park, California 94025

8. Project Title: CTBT Research in China; Opportunities for Cooperative National Laboratory/USGS Work

9. DOE Project Officer (Name, Address, Phone No.): $\quad$ 10. Servicing Agency Project Orficer (Name, Address,

Leslie Casey

Office of Research and Development, NN-20

U.S. Department of Energy

1000 Independence Ave., $5 W$

Wastington, DC 20585-0420

Phonek 202-586-2151

11. Project Period: 1 July, 1997 to I July, 1998 Phone No.):

13. Scope of Work: See Exhibit 1

14. Deliverables/Reporting Requirements: Technical Report describing primaryinformption to includf: digital sejmis Haterorf data, coordinates of chemical explosjohs, shot sizes, fecorder coordinates, instrument response, and related information. See Exhibit 2

15. (a) This $I A$ is issued pursuant to the Economy Act of 1932, as amended (3I U.S.C. 1535) |X | Yes | No
(b) This IA is issued to provide Financial Assistance support for Project Activities (b) This IA is issued to provide Financial Assistance support for Project Activities If yes, provide Statutory Authority

\begin{tabular}{|l|l|l|l|}
\hline \multicolumn{1}{|c|}{ Funds/C' ligations } & Previous Amount & Amount This & Amended Total \\
\hline 16. DOE Amount & 50.00 & $\$ 81,000.00$ & $\$ 81,000.00$ \\
\hline 17. DOE In-Kind Amount & & & \\
\hline 18. Servicing Agency Amount & & & \\
\hline 19. Servicing Agency In-Kind Amount & & & \\
\hline
\end{tabular}

20. Total Project Cost $\$ 81,000.00$

21. DOE FUNDS COMMITTED

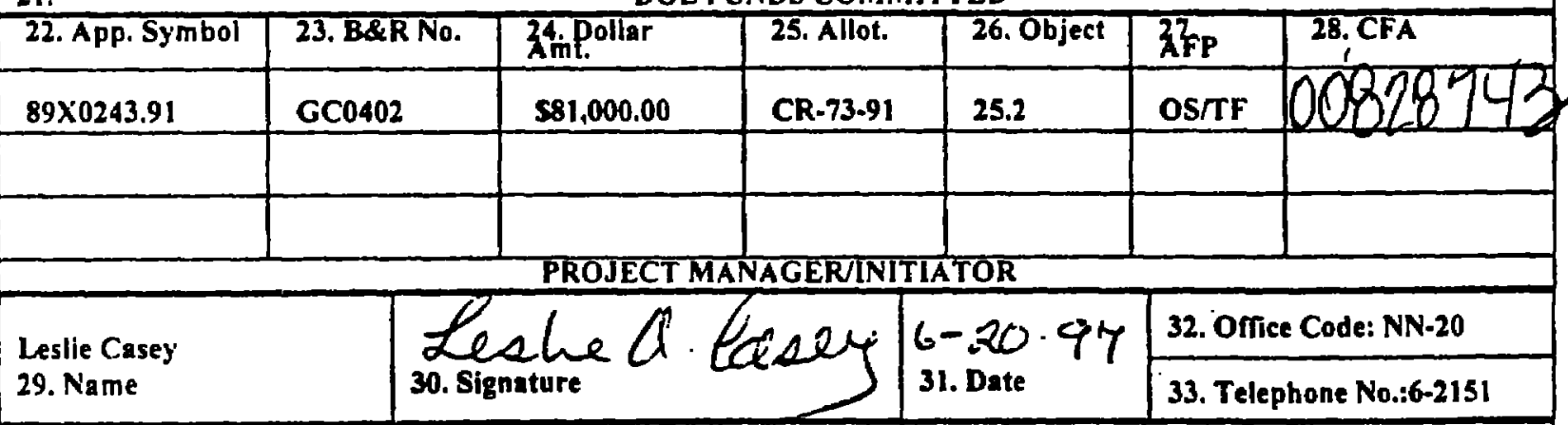

PROGRAMS OFFICIALS, We hereby certify that the funds citgd, in items 22.28 are being appropriately used.

Robert Waldron

34. Reviewing Official's Name

Laurence Lanes

37. Budget Official's Name

40. Type of Procurement Action (TPA) Code

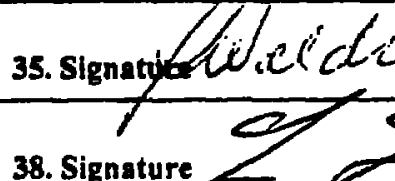

38. Signature $\times 5$
41. Negotiator Code
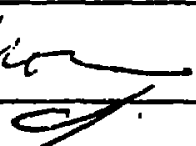

\footnotetext{
42. Security. Will employees require security clearances for performance of this procurement? || Yes $|x|$ No

43. Energy Policy Act. Is this procurement subject to the Energy Policy Act of 1992 (EPACT); i.e., will it digegtly,

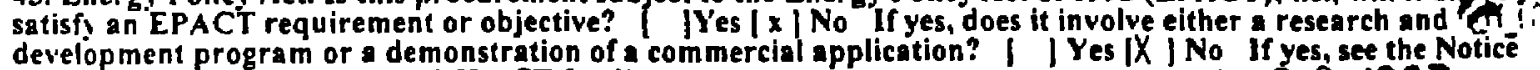
related to this item. Amount of EPACT funding:

U IN 921097 


\begin{tabular}{|c|c|c|c|}
\hline $\begin{array}{l}\text { 44. Nan ORRESTAI FINANCIAT } \\
\text { 47. Initiating Omicial/Local Ofice Use }\end{array}$ & 7 & & 46. Bate \\
\hline $\begin{array}{l}\text { Part II - Approved Budget - DOE Contribution } \\
\text { Plus Servicing Agency Contribution }\end{array}$ & \multicolumn{3}{|c|}{ Ddel'A ID No.: DE-A101-97-NN20004 } \\
\hline 48. Budget Categories & $\begin{array}{l}\text { Itemization of } \\
\text { This Action }\end{array}$ & $\begin{array}{l}\text { Itemization of } \\
\text { Previous Actions }\end{array}$ & $\begin{array}{l}\text { Itemization of All } \\
\text { Actions to Date }\end{array}$ \\
\hline (a) Personnel & $530,000.00$ & & $\$ 30,000.00$ \\
\hline \multicolumn{4}{|l|}{ (b) Fringe Benefits } \\
\hline O Travel & $524,000.00$ & & $\$ 24,000.00$ \\
\hline \multicolumn{4}{|l|}{ (d) Equipment } \\
\hline (e) Supplies & S $4,000.00$ & & $S 4,000.00$ \\
\hline \multicolumn{4}{|l|}{ () Procurement/Assistance } \\
\hline \multicolumn{4}{|l|}{ (g) Construction } \\
\hline \multicolumn{4}{|l|}{ (h) Other: Transportation of Equipment } \\
\hline (1) Total Direct Charges & $558,000.00$ & & $\$ 58,000.00$ \\
\hline (j) Indirect Costs: Rate $\mathbf{4 0} \%$ Base $\$ 58,000$ & $523,000.00$ & & $\$ 23,000.00$ \\
\hline $\begin{array}{l}\text { (k) Total } \\
\text { (DOE Share 100\%) (Servicing Agency Share 0\%) }\end{array}$ & $581,000.00$ & & $\$ 81,000.00$ \\
\hline
\end{tabular}

49. Js equipment authorized to be furnished by DOE or leased, purchased, or rented with DOE funds? $\mid$ | Yes $|x|$ No (Identify all equipment costing $\$ 1,000$ or more)

50. Are any of these funds being used on contracts and/or financial assistance || Yes $|\times|$ No (See item 48గ)

Type of Contract and/or

Financial Assistance

I |Grant | | Cooperative Agreement $\{x \mid$ Procurement (includes small purchase order)

Contractor Name N/A
Total Extramural Amount Under This Project N/A
Percent Funded by DOE (if known) N/A

\section{Part 111 - Funding Methods and Billing Instructions}

51. Funds-Out Agreement/Disbursement Agreement

| | Reimbursement, or

[x | Progress

I Idvance
Request for repayment of actual costs must be itemized on OPAC or other Form previousiy approved by DOE's Contracting Officer and submitted to the U.S. Department of Energy, Accounts Payable Division, P.0. Box 500, Germantown, MD 20875-0500. Quarterly cost reports will be forwarded to the U.S. Department of Energy, Accounts Payable Division, P.O. Box 500, Germantown, MD $20875-0500$.

\section{| I Monthly I X] Quarterly I | Upon Completion of Work}

Only available for use by Federal agencies on working capital funds or with appropriate justification of need for this type of payment method. Unexpended funds at completion of work will be returned to DOE. Quarterly cost reports will be forwarded to the U.S. Department of Energy, Accounts Payable Division, P.O. Box 500, Germantown, MD 20875-0500. See attached Justification 

To take advantage of Chinese willingness to provide critical seismological data in exchange for visits to the US for (1) training, (2) data and software exchange, and (3) cooperative data interpretation.

To lay the groundwork for US/China cooperation in the monitoring of large chemical explosions to be fired in Western China during the next two years. These eventc represent targets of opportunity for the calibration of seismic propagation path effects and of the International Monitoring System in and around Western China.

These activities all relate to the monitoring of large chemical explosions in China. However, they are complimented by the data of the Chinese Digital Seismic Network that is operated by the USCS, which is freely available to all parties. The data from these chemical explosions are presently available through the USGS by virfue of a Protocol Agreement (see attached) between the USGS and China that dates back to 1982. This protocol has been renewed every five years, and is subject to an annual USGS/China technical review.

This request will allow the USGS to support FY97 cooperative activities between LANLLLNL/USGS and the relevant Chinese institutions.

Chinese data (1988/1989 vintage) from large chemical explosions provide critical information regarding seismic wave propagation in China. Newly available are data along $\$ 4,300 \mathrm{~km}$ long profile that crosses the entire country in a NW'-SE direction, passing near the Chinese test site, Lopnor. These data consist of (1) 7,400 three-component recordings with an average spacing of $2 \mathrm{~km}$, (i.e, 2,150 separate recording sites) and (2) 46 shot points with an average spacing of $90 \mathrm{~km}$, and a charge size of 0.8-3.9 tons. These data were obtained at the cost (to the Chinese) of several million Chinese yuan.

Copies of the digital data are available for evaluation by US investigators. In addition, we will obtain the geographical coordinates and shot times for all of the chemical explosions that were detonated. This information is needed for the purposes of seismic verification and calibration.

These data will be used to develop empirical travel time curves and velocity models for the region. They are anticipated to provide the necessary regionalization information leading to improved location capabilities.

The Chinese (State Seismological Bureau) have announced plans to detonate a series of large (2-4 ton) chemical explosions in W'estern China over the next two years. These explosions will be recorded by hundreds of Chinese portable seismographs along seismic profiles. The announcement of these large chemical explosions provides a unique opportunity for the staff at the US National Laboratories (LANL and LLNL) to conduct on-site monitoring of seismic, chemical, and electro-magnetic signals associated with these explosions. Signals from the largest of these controlled sources may provide data for the calibration of existing CTBT seismic stations.

FY97 Work Plan

Prof. Yuan Xuecheng and Mr. Wang Youxue will be invited to visit USGS July-September, 1997, to provide the US side with copies of 1988/89 digital data, source coordinates, and the existing Chinese geophysical interpretation. USCS employee Ms. Katharine Favret will devote full time to data transcription and verification, providing the Chinese with USGS seismic data in exchange, and training the Chinese visitors in the use of USGS seismic data processing software.

The USGS Crustal Studies Project in Menlo Park has developed, over a period of 15 years, an extensive array of software programs for the organization, analysis, and interpretation of data from long seismic profiles. The Chinese recognize this, and this is one of the reasons they are willing to share their data with the USGS.

A technical report describing primary information (coordinates of chemical explosions, shot sizes, recorder coordinates, instrument response, and related information) will be prepared by the Chinese and Ms. Favret. Copies of the data will be made available to DOE scientists.

Prof. Wang Chunyong (Project Chief for the Western China Project) will be invited to the USGS in August, 1997, to plan cooperation in the field (on-site recording) for the planned large chemical explosions. It will also be necessary to provide Chinese scientists with copies of USGS seismic data to establish the basis for future exchange of Chinese data. Pros. Wang will travel to Livermore, California and Los Alamos, New Mexico, to discuss project plans with DOE scientists for the Western China project. There are many logistical details to be agreed on for on-site recording by the American side in China (air transport, field vehicles, import of recording equipment, visas, taking data out of the country, etc.). 


\section{Program/Project Title}

Office of Research and Development, NN-20

CTBT Research in China; Opportunities for Cooperative National Laboratory/USGS Work - Project * ST912
2. Identification number

DE-A! 0 I-97-NN20004

\section{Participant Name and Address}

United States Geological Survey, Ofrice of Earthquakes, Volcanoes, and Engineering, Branch of Seismology 345 Middlefield Road - MS 977, Menlo Park, Californis 94025

4. Planning and Reporting Requirements

A. General Managements

\section{Frequency}

I I Management Plan

I Status Report

I I Summary Report

B. Schedule/Labor/Cost

I I Milestone Schedule/Plan

I I Labor Plan

I I Facilities Capital Cost of Money

Factors Computation

I I Contract Facilities Capital and Cost of Money

I I Cost Plan

I I Milestone Schedule/Status

| | Labor Management Report

I Cost Management Report

C. Exception Reports

I Conference Record

I Hot Line Report

D. Performance Measurement

I | Management Control System Description

I | H'BS Dictionary

1 Index

[ Element Definition

I ] Cost Performance Reports

1) Format 1-WBS

1 | Format 2 - Function

I | Format 3 -Baseline
E. Financial Incentives

I I Statement of Income and Expense

I | Balance Sheet

I Cash Flow Statement

I I Statement of Changes in Financial Position

| | Loan Drawdown Report

1 / Operating Budget

I I Supplementary Information

F. Technical

I | Notice of Energy RD\&D Project (Required with any of the rollowing)

I I Technical Progress Report

I I Draft for Review

| | Final for Approval

I I Topical Report

[x] Final Technical Report

I | Draft for Review

I f Final for Approval

I I Software

| x | Other (Specify):

Technical Report describing primary information to include: digital seismic waveform data, coordinates of chemical explosions, shot sizes, recorder coordinates, instrument response, and related information.

\section{Frequency Codes}

A - As Required

C. Change to Contractual Agreement Changes

$F$ - Final (end of effort)
M - Monthly

O. Once After Award
S - Semi-annually

X - With ProposalBid/Application or

6. Special Instructions (Attachments) [ x | Report Distribution List/Adressees

Leslie Casey

Office of Research and Development, NN-20

U.S. Department of Energy

1000 Independence Ave., SW

W'ashington, DC 20585-0420

Craig Pearson

LANL; MS C335

P.O. Box 1663

Los Alamos, NM 87545

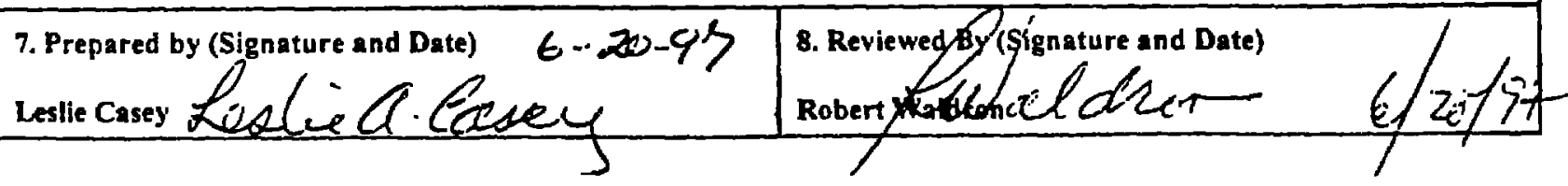




\section{Vitac: Walter D. Mooney}

Office Phonc: 650-329-4764; Fax 650-329-5163; mooney@andreas.wr.usgs.gov

U. S.. Geological Survey, MS 977, 345 Middlefield Road, Menlo Park, CA 94025

\section{Academic Background}

University of Wisconsin, Ph.D. in Geophysics, 1979.

Cornell University, B.S. in Physics, 1973.

\section{Positions}

Geophysicist, USGS 1978- present

Seismology Section Chief, USGS 1994-1997

Consulting Prof. Geophysics, Stanford University, 1984-present

Visiting Prof. Geophysics, University of Kiel, Germany, 1985

Professional Associations; Awards and Recognition

American Geophysical Union (1973), Fellow, 1996

Seismological Society of America and SSA Eastern Section (1973)

Geological Society of America (1973), Fellow, 1987; Gcorge P. Woollard Award, 1995

Sigma Xi (1980)

Selected Committee and Liditorial Service

Co-cditor (with L. Pakiser, Denver) GSA Memoir "Geophysical Framework of the Continental United States," 1986-1988

Associate Editor, Journal of Geophysical Rescarch, 1988-1994, 1997-present

Commission on Controlled Source Seismology (CCSS) (IASPEI), 1977 - present

Secretary, CCSS, 1987 to 1995; Chairman 1995-present

Standing Committee, PASSCAL, 1987-1990; 1997-present

Member, BIRPS Review Panel, Cambridge, United Kingdom, 1987, 1992, 1996

Member, Lithoprobe Review Panel, Canada, (Elected by NERC, Canada), 1989

Member, European Geotraverse Review Panel, Strasbourg, 1991

Board of Directors, Lithoprobe (Canadian Geoscience Program), 1991 - present

\section{Six Selected Publications (100 peer reviewed papers)}

Mooncy, W. D., 1987. Scismology of the continental crust and upper mantle, Revicw of Gcophysics, 25, $1168-1176$.

Mooncy, W. D., 1989. Scismic methods for determining earthquakc sourcc parameters and lithospheric structure, G.S.A. Mcmoir 172, 11034.

Mooney, W. D., and Brailc. L. W.. 1989. The scismic structure of the Continental crust and upper mantle of North America. Vol. A, DNAG, GSA, 39-52.

Moone;, W. D., and Meissner. R.. 1992, Multi-genctic origin of crustal reflectivity: a review of seismic reflection profiling of the continental lower crust and Moho, in The l.ower Continental Crust, cd. D. M. Fountain, Elscviur, 39-52.

Christensen, N.I. and Mooncy: W.D., 1995, Scismic velocity structure and composition of the continental crust: $\Lambda$ global view; Jour. Gcophys. Res., 100, 9,761-9,788.

Mooncy; W.D., Laske, G., and Masters, T.G., 1998, CRUST 5.1: A global crustal model at $5^{\circ} \times 5^{\circ}, J G R, 103,727-747$. 